\author{
U. S. Department of Energy \\ Nuclear Engineering Education Research
}

\begin{abstract}
Experimental and Thermalhydraulic Code Assessment of the Transient Behavior of the Passive Condenser System in an Advanced Boiling Water Reactor
\end{abstract}

Project Carried Out With Support From US DOE Under Award NO: DE-FG07-04ID14605

Final Report

S. T. Revankar, W. Zhou and Gavin Henderson
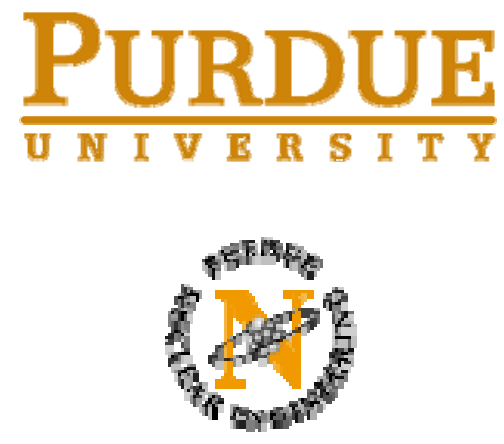

SCHOOL OF NUCLEAR ENGINEERING 
U. S. Department of Energy

Nuclear Engineering Education Research

\title{
EXPERIMENTAL AND THERMALHYDRAULIC CODE ASSESSMENT OF THE TRANSIENT BEHAVIOR OF THE PASSIVE CONDENSER SYSTEM IN AN ADVANCED BOILING WATER REACTOR
}

Final Report

September, 2004 to April 30, 2008

DOE Project: DE-FG07-04ID14605

\author{
PRINCIPAL INVESTIGATOR: \\ SHRIPAD T. REVANKAR \\ PURDUE UNIVERSITY \\ School of Nuclear Engineering \\ West Lafayette, IN 47906-1290 \\ 765-496-1782 \\ shripad@ecn.purdue.edu
}

Contributing Authors:

S. T. Revankar, W. Zhou and Gavin Henderson

PURDUE UNIVERSITY

School of Nuclear Engineering

West Lafayette, IN 47906-1290

June 2008 


\section{TABLE OF CONTENTS}

LIST OF FIGURES iv

LIST OF TABLES $\quad \mathrm{x}$

ACRONYMS $\quad$ xi

NOMENCLATURE Xii

EXECUTIVE SUMMARY Xiv

1 INTRODUCTION $1-1$

1.1 Significance of the Problem 1-1

1.2 PCCS Operation 1-2

1.3 Research Focus $1-4$

1.4 References $1-6$

2 PROJECT OBJECTIVES 2-1

2.1 Goals and Objectives $2-1$

2.2 Project Schedule 2-1

3 SINGLE TUBE EXPERIMENT PROGRAM 3-1

3.1 Experimental Loop 3-1

3.2 Experiment Procedures 3-8

3.3 Data Reduction 3-13

3.4 Test Results 3-17

3.5 Transient Operation 3-51

3.6 References 3-61

4 ANALYSIS PROGRAM 4-1

4.1 Boundary Layer Model 4-1

4.2 Heat and Mass Analogy Model 4-17

Purdue University 
4.3 RELAP5 Condensation Model Assessment 4-38

4.4 References $\quad 4-45$

5 MULTI MULTI-TUBE EXPERIMENT PROGRAM 5-1

5.1 Tube Bundle Experimental Loop 5-1

$\begin{array}{ll}5.2 \text { Experiment procedures } & 5-19\end{array}$

$\begin{array}{lll}5.3 \text { Data Reduction } & 5-27\end{array}$

5.4 Test Results $5-31$

5.5 References $5-43$

6 ACCOMPLISHMENTS 6-1 


\section{LIST OF FIGURES}

Figure 1.1 PCCS Flow Diagram in ESBWR during a Loss of Coolant Accident 1-4

Figure 1.2 Schematic of different operation mode of PCCS 1-4

Figure 3.1 Schematic of PCCS Test Loop 3-2

Figure 3.2 Cross Section of Test Section with T/Cs 3-4

Figure 3.3 Schematic of $52.5 \mathrm{~mm}$ Test Section with Secondary Pool 3-5

Figure 3.4 Mass Balance for the Complete Condensation 3-20

Figure 3.5 Energy balance: Condensation vs. Evaporation + Heat Loss 3-20

Figure 3.6 Comparison of condensation rate between $26.6 \mathrm{~mm}$ and $52.5 \mathrm{~mm} \quad 3-22$

TS

Figure 3.7 Complete Condensation: Condensation Mass Flux vs. $\Delta \mathrm{T} \quad 3-22$

Figure 3.8 Complete Condensation: Heat Transfer Coefficients for $52.5 \mathrm{~mm} \quad 3-23$

TS

Figure 3.9 Complete Condensation: Heat Transfer Coefficients for $26.6 \mathrm{~mm} \quad 3-24$

TS (From Purdue Data, 2004)

Figure 3.10 Comparison of Condensation HTC vs. $\Delta \mathrm{T}$ between $26.6 \mathrm{~mm}$ and $\quad 3-25$

$52.5 \mathrm{~mm}$ TS

Figure 3.11 Venting Frequency and Period for $\mathrm{P}=180 \mathrm{kPa}, \mathrm{Mst}=2.35 \mathrm{~g} / \mathrm{s} \quad 3-27$

Figure 3.12 Cyclic Venting: Condensation Rate for $\mathrm{P}=180 \mathrm{kPa}, \mathrm{Mst}=2.35 \mathrm{~g} / \mathrm{s} \quad$ 3-27

Figure 3.13 Cyclic Venting: Condensation HTC for $\mathrm{P}=180 \mathrm{kPa}, \mathrm{Mst}=2.35 \mathrm{~g} / \mathrm{s} \quad 3-28$

Figure 3.14 Comparison of venting frequency for different pressures 3-29

Figure 3.15 Comparison of venting period for different pressures 3-29

Figure 3.16 Condensation Rate for $\mathrm{P}=235 \mathrm{kPa} \quad 3-31$

Figure 3.17 Condensation HTC for $\mathrm{P}=235 \mathrm{kPa} \quad 3-31$

Figure 3.18 Condensation Rate for $\mathrm{P}=220 \mathrm{kPa} \quad 3-32$

Figure 3.19 Condensation HTC for $\mathrm{P}=220 \mathrm{kPa} \quad 3-32$

Figure 3.20 Condensation Rate for $\mathrm{P}=190 \mathrm{kPa} \quad 3-33$

Figure 3.21 Condensation HTC for $\mathrm{P}=190 \mathrm{kPa}$ 3-33

Figure 3.22 Condensation Rate for $\mathrm{P}=150 \mathrm{kPa} \quad 3-34$

Figure 3.23 Condensation HTC for $\mathrm{P}=150 \mathrm{kPa} \quad 3-34$ 
Figure 3.24 Pure Steam Through Flow: Condensation Rate, Mst=4.0 g/s 3-36

Figure 3.25 Pure Steam Through Flow: Condensation HTC, Mst=4.0 g/s 3-36

Figure 3.26 Through Flow: Condensation Rate at $\mathrm{P}=200 \mathrm{kPa}, \mathrm{Mst}=4.0 \mathrm{~g} / \mathrm{s} \quad 3-37$

Figure 3.27 Through Flow: Condensation HTC at $\mathrm{P}=200 \mathrm{kPa}, \mathrm{Mst}=4.0 \mathrm{~g} / \mathrm{s} \quad 3-38$

Figure 3.28 Through Flow: Condensation Rate at $\mathrm{P}=176 \mathrm{kPa} \quad 3-39$

Figure 3.29 Through Flow: Condensation HTC at $\mathrm{P}=176 \mathrm{kPa} \quad 3-39$

Figure 3.30 Through Flow: Condensation Rate at $\mathrm{P}=200 \mathrm{kPa} \quad 3-40$

Figure 3.31 Through Flow: Condensation HTC at $\mathrm{P}=200 \mathrm{kPa} \quad 3-40$

Figure 3.32 Through Flow: Condensation rate at Mst=3.98 4.12 g/s 3-41

Fig. 3.33 Through Flow: Condensation HTC at Mst=3.98 4.12 g/s 3-42

Figure 3.34 Through Flow: Condensation rate at Mst=3.5 3.65 g/s 3-42

Figure 3.35 Through Flow: Condensation HTC at Mst=3.5 3.65 g/s 3-43

Figure 3.36 Complete Condensation: Condensation Rate for Half and Full 3-44

Height Test

Figure 3.37 Condensation Mass Flux in Half Height and Full Height Test 3-45

Figure 3.38 Venting Frequency and Period at $\mathrm{P}=280 \mathrm{kPa}$ in Half Height Test $\quad 3-46$

Figure 3.39 Cyclic venting: Condensation Rate for Half Height Test, 3-46

$\mathrm{P}=280 \mathrm{kPa}$
Figure 3.40 Cyclic Venting: Condensation HTC for Half Height Test, 3-47

$\mathrm{P}=280 \mathrm{kPa}$

Figure 3.41 Through Flow: Condensation Rate for Half Height Test, Mst=4.0- 3-48 $4.1 \mathrm{~g} / \mathrm{s}$

Figure 3.42 Through Flow: Condensation HTC for Half Height Test, Mst=4.0- 3-48 $4.1 \mathrm{~g} / \mathrm{s}$

Figure 3.43 Through Flow: Condensation Rate for Half Height Test, $\mathrm{P}=160 \mathrm{kPa} \quad 3-49$

Figure 3.44 Through Flow: Condensation HTC for Half Height Test, 3-50 $\mathrm{P}=160 \mathrm{kPa}$

Figure 3.45 Through Flow: Condensation Rate, $\mathrm{Mst}=4.0-4.1 \mathrm{~g} / \mathrm{s}, \mathrm{P}=160 \mathrm{kPa} \quad 3-51$

Figure 3.46 Through Flow: Condensation HTC, Mst=4.0-4.1g/s,P=160kPa 3-51

Figure 3.47 PANTHER PCCS test results for pool water level change and its 3-53

effect on inlet steam pressure. (Figure is reproduced from the NRC web site

[1]:http://www.nrc.gov/reactors/new-licensing/license-

reviews/esbwr.html\#reviews).

Figure 3.48 System Pressure vs. Time : Complete Condensation, Mst=3.34g/s 3-58 
Figure 3.49 Condensation rate vs. Time : Complete Condensation, 3-59 $\mathrm{Mst}=3.34 \mathrm{~g} / \mathrm{s}$

Figure 3.50 Condensation HTC vs. Time : Complete Condensation, 3-59 $\mathrm{Mst}=3.34 \mathrm{~g} / \mathrm{s}$

Figure 3.51 System Pressure vs. Time : Through flow, Mst=3.4g/s 3-60

Figure 3.52 Condensation rate vs. Time : Through flow, Mst $=3.4 \mathrm{~g} / \mathrm{s} \quad 3-60$

Figure 3.53 Condensation HTC vs. Time : Through flow, Mst=3.4g/s 3-61

Figure 4.1 HTC profile along tube length with same noncondensable frac- 4-9 tion $(\mathrm{Min}=5.09 \mathrm{~g} / \mathrm{s}$ for $26.6 \mathrm{~mm}$ ID, Min=10.2 $\mathrm{g} / \mathrm{s}$ for $52.5 \mathrm{~mm} \mathrm{ID})$

Figure 4.2 Film thickness with tube length $(\mathrm{Min}=5.09 \mathrm{~g} / \mathrm{s}$ for 26 ,

$\operatorname{Min}=10.2 \mathrm{~g} / \mathrm{s}$ for $26 \mathrm{a})$

Figure 4.3 HTC comparison with Nusselt solution (Min=5.09g/s for 26,

$\operatorname{Min}=10.2 \mathrm{~g} / \mathrm{s}$ for $26 \mathrm{a}$ )

Figure 4.4 Bulk Gas Concentration Profile with Tube Length (Min=5.09g/s 4-12 for $26, \operatorname{Min}=10.2 \mathrm{~g} / \mathrm{s}$ for $26 \mathrm{a}$ )

Figure 4.5 Interfacial Gas Concentration Profile with Tube Length $(\mathrm{Min}=5.09 \mathrm{~g} / \mathrm{s}$ for $26, \mathrm{Min}=10.2 \mathrm{~g} / \mathrm{s}$ for $26 \mathrm{a})$

Figure 4.6 Interfacial Temperature Profile with Tube Length

$(\mathrm{Min}=5.09 \mathrm{~g} / \mathrm{s}$ for $26, \mathrm{Min}=10.2 \mathrm{~g} / \mathrm{s}$ for $26 \mathrm{a})$

Figure 4.7 Liquid Film Region Reynolds Number

Figure 4.8 Boundary Layer Thickness for Purdue Data's run number=26

$4-15$

Figure 4.9 Dimensionless Axial Velocity for Purdue Data's run num-

4-16

ber $=26$

Figure 4.10 Dimensionless Temperature for Purdue Data's run number $=26$

Fig. 4.11 Dimensionless NC Gas Mass Fraction for Purdue Data's run number $=26$

Figure 4.12 Physical model for film condensation

Figure 4.13 Comparison of average condensation HTC with respect to inlet NC gas mass fraction for $26.6 \mathrm{~mm}$ ID tube

Figure 4.14 Comparison of average condensation HTC with analogy model for 4-28 $26.6 \mathrm{~mm}$ ID tube

Figure 4.15 Analogy model predictions for $52.5 \mathrm{~mm}$ ID tube with system pres- 
sure of $185-187 \mathrm{kPa}$

Figure 4.15 Analogy model predictions for 52.5mm ID tube with system pres- 4-29 sure of $185-187 \mathrm{kPa}$ (Continued)

Figure 4.16 Comparison of average condensation HTC with analogy model for 4-30 $52.5 \mathrm{~mm}$ ID tube

Figure 4.17 Average condensation heat transfer coefficients as a function of 4-32 system pressure, for pure steam cases predicted by the heat and mass transfer analogy model

Figure 4.18 Average condenser heat flux as a function of absolute system pressure, for pure steam cases predicted by the heat and mass transfer analogy model

Figure 4.19 Local condensation heat transfer coefficients as a function of axial length, for 2 " full length pure steam cases predicted by the heat and mass transfer analogy model

Figure 4.20 Local total heat transfer coefficients as a function of axial length from the entrance, for 2 " full length pure steam cases predicted by the heat and mass transfer analogy model

Figure 4.21 Local heat flux as a function of axial length from the entrance, for

2 " full length pure steam cases predicted by the heat and mass transfer analogy model

Figure 4.22 Local bulk Reynolds number as a function of axial length from the

entrance, for 2" full length pure steam cases predicted by the heat and mass transfer analogy model

Figure 4.23 Local film resistance as a function of axial length from the en-

trance, for 2 " full length pure steam cases predicted by the heat and mass transfer analogy model

Figure 4.24 Comparison of local condensation HTC for Kuhn's experiment 4-37

Figure 4.25 Condensation rate with system pressure for 52.5mm ID tube $\quad 4-40$

Figure 4.26 Condensation HTC with system pressure for 52.5mm ID tube 4-41

Figure 4.27 RELAP5 predicted temperature with system pressure for $52.5 \mathrm{~mm} \quad 4-41$

ID tube

Figure 4.28 Condensation mass flux comparison between $26.6 \mathrm{~mm}$ and $52.5 \mathrm{~mm}$

ID tubes 
Figure 4.29 Comparison between 1" tube Relap5 and Experimental Results

Figure 4.30 Comparison between 2" tube Relap5 and Experimental Results

Figure 4.31 Condensation Rate Comparison between 1" and 2" tubes using

Relap5

Figure 4.32 Condensation Heat Transfer Comparison between 1" and 2" tubes

$4-44$

using Relap5

Figure 4.33 HTC Comparison between 1" and 2" tubes using Relap5

Figure 4.34 Temperature Difference Comparison between 1" and 2" tubes using Relap5

Figure 5.1 Schematic of Bundle PCCS Test Loop

Figure 5.2 Steam Generator design for bundle loop

(Diameter: 18 inch, Height: 120 inch)

Figure 5.3 Steam generator tank installed. Inset: $100 \mathrm{~kW}$ immersion heater $\quad 5-6$

Figure $5.4100 \mathrm{~kW}$ power control panel 5-7

Figure 5.5 Condenser schematic design and bundle arrangement (unit: $\mathrm{cm}$ ) 5-9

Figure 5.6 Design of four tube bundle condenser and T/C locations 5-10

Figure 5.7 Picture of the condenser tube bundle with thermocouples mounted 5-11 on the tubes

Figure 5.8 Schematic of $52.5 \mathrm{~mm} 4$ Tube Test Section with Secondary Pool

$5-11$

Figure 5.9 Tube bundle condenser secondary boiling pool tank and assembly

$5-12$

of the tube bundle inside the boiling pool tank

Figure 5.10 Tube bundle condenser secondary pool tank

$5-12$

Figure 5.11 Condensate tank

$5-14$

Figure 5.12 Suppression Pool 5-15

Figure 5.13 Multi-tube PCCS condenser test facility 5-16

Figure 5.14 Instrumentation $\quad 5-27$

Figure 5.15 Condensation rate as a function of system pressure for multi-tube 5-33

full height complete condensation experiments

Figure 5.16 Multi-tube condensation rates compared to single tube results.

All condensation rates were normalized to the condensation flow rate per full length condensing tube

Figure 5.17 Condensation mass flow rates as a function of system pressure from multi-tube tests for four groups of secondary heights: $1 / 4,1 / 2,3 / 4$, and full Figure 5.18 Three complete transient cases at different power supply temperatures $\left(210^{\circ} \mathrm{F}, 215^{\circ} \mathrm{F}\right.$, and $\left.220^{\circ} \mathrm{F}\right)$ for multi-tube complete condensation experiments

Figure 5.19 System pressure responses to decreasing secondary water level over time for multi-tube complete condensation experiments

Figure 5.20 Condensation mass flow rate as a function of time, during decreasing secondary water level, for multi-tube complete condensation experiments 
Figure 5.21 Condensation mass flow rate as a function of increasing pressure, $\quad$ 5-38 during decreasing secondary water level, for multi-tube complete condensation experiments

Figure 5.22 Condensation mass flow rate as a function of secondary water level for multi-tube complete condensation experiments

Figure 5.23Through Flow Normalized Condensate Rate vs. Air Mass Fraction $\quad$ 5-40 (Flow Pressure: 23.091-24.113psi)

Figure 5.24 Flow Pressure Change during a Through Flow Experiment 5-41

Figure 5.25 SG Water Level Change during a Through Flow Experiment 5-41

Figure 5.26 Steam Flow Rate Change during a Through Flow Experiment $\quad$ 5-42

Figure 5.27 CT Water Level Change during a Through Flow Experiment $\quad$ 5-42

Figure 5.28 SEC Water Level Change during a Through Flow Experiment $\quad$ 5-43 


\section{LIST OF TABLES}

Table 3.1 List of Instruments

Table 3.2 Test parameters' range for various operation modes and pool levels

$3-18$

Table 3.1 Test matrix for transient condensation experiment of $52.5 \mathrm{~mm}$ single

$3-56$

tube

Table 4.1 Summary of the inlet condition for the calculation (Tube length: 1.0

m)

Table 4.2 Correlations, transpiration effects and blowing parameters

4-23

Table 5.1 PCCS Parameter comparison of experimental PCCS with proto-

type design

Table 5.2 Multi-tube PCCS condenser design

Table 5.3 Steam generator design

Table 5.4 Information of Heater and Control Panel for Bundle Loop

Table 5.5 List of Instrumentation for PCCS Loop

Table 5.6 Description of Valves

$5-25$

Table 5.7 Summary of multi-tube through flow mode experimental results

$5-39$ 


\section{ACRONYMS}

$\begin{array}{ll}\text { ABWR } & \text { Advanced Boiling Water Reactor } \\ \text { AP600 } & \text { Advanced Passive 600 MWe Pressurized Reactor } \\ \text { DOE } & \text { Department Of Energy } \\ \text { DW } & \text { Dry Well } \\ \text { ESBWR } & \text { Economic Simplified Boiling Water Reactor } \\ \text { GDCS } & \text { Gravity Drain Cooling System } \\ \text { GE } & \text { General Electric } \\ \text { GE-SBWR } & \text { 600 Mwe GE designed Simplified Boiling Water Reactor } \\ \text { ICS } & \text { Isolation Condensation System } \\ \text { LOCA } & \text { Loss Of Coolant Accident } \\ \text { LWR } & \text { Light Water Reactor } \\ \text { MIT } & \text { Massachusetts Institute of Technology } \\ \text { NRC } & \text { Nuclear Regulatory Commission } \\ \text { PCCS } & \text { Passive Containment Cooling System } \\ \text { RELAP5 } & \text { A Reactor Safety Analysis Code } \\ \text { RPV } & \text { Reactor Pressure Vessel } \\ \text { SBWR } & \text { Simplified Boiling Water Reactor } \\ \text { SBWR-600 } & \text { 600 MWe GE Designed Simplified Boiling Water Reactor } \\ \text { SP } & \text { Suppression Pool } \\ \text { TS } & \text { Test Section } \\ \text { T/C } & \text { Thermocouple } \\ \text { UCB } & \text { University of California Berkeley }\end{array}$




\section{NOMENCLATURE}

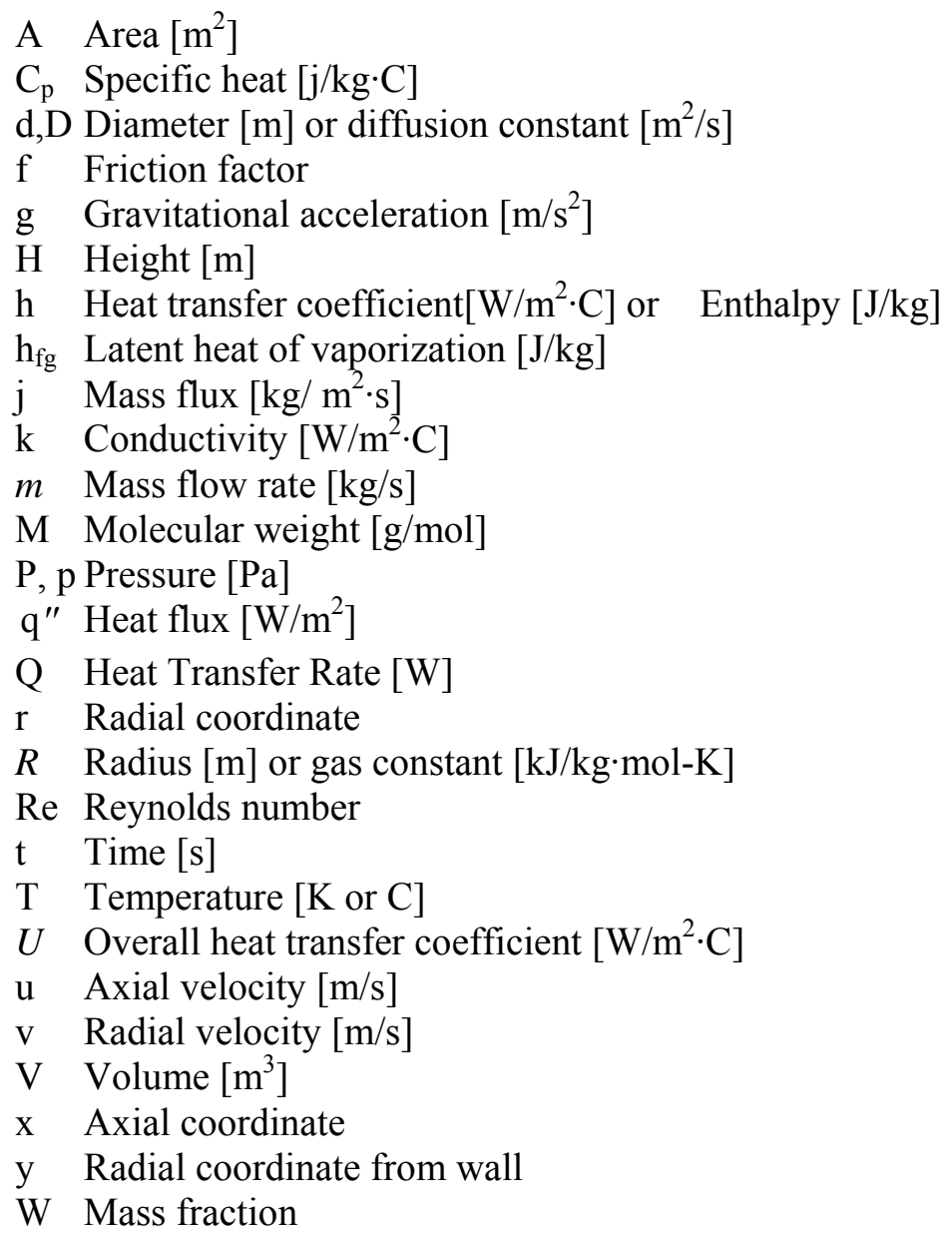

\section{Greek Symbols}

$\alpha_{\mathrm{s}}$ Thermal Diffusion Coefficient

$\delta \quad$ Film thickness [m]

$\varepsilon \quad$ Eddy diffusivity $\left[\mathrm{m}^{2} / \mathrm{s}\right]$

$\mu \quad$ Dynamic viscosity $[\mathrm{kg} / \mathrm{m} \cdot \mathrm{s}]$

$v$ Kinematic viscosity $\left[\mathrm{m}^{2} / \mathrm{s}\right]$

$\rho$ Density $\left[\mathrm{kg} / \mathrm{m}^{3}\right]$

$\sigma$ Surface tension $[\mathrm{N} / \mathrm{m}]$

$\tau$ Shear stress $[\mathrm{Pa}]$

\section{Subscripts}

a Ambient, air 


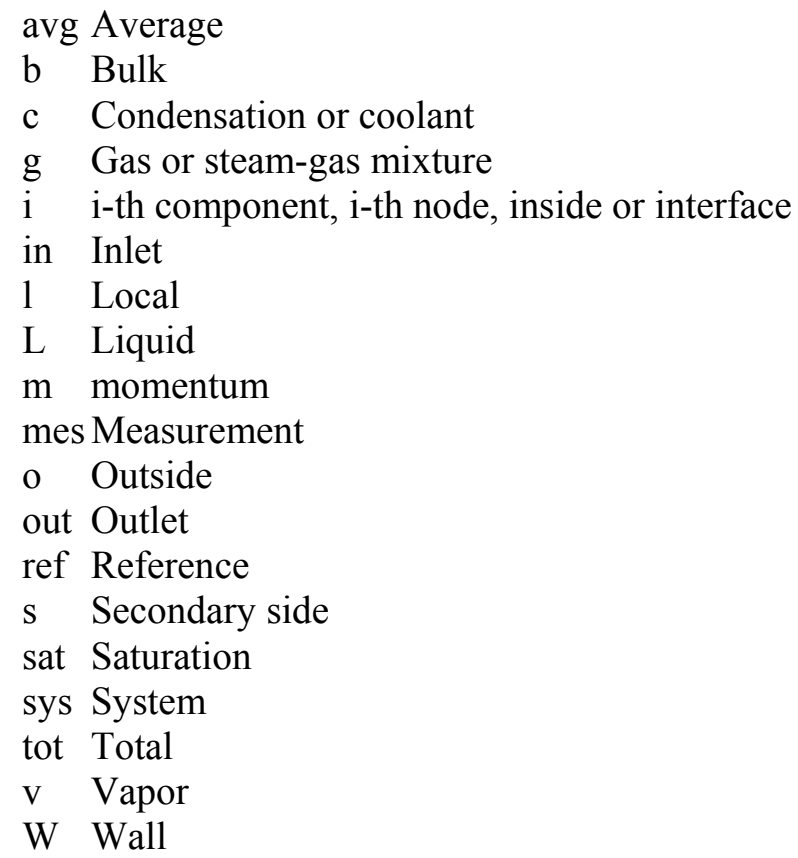




\section{EXECUTIVE SUMMARY}

The main goal of the project was to study analytically and experimentally the condensation heat transfer for the passive condenser system such as GE Economic Simplified Boiling Water Reactor (ESBWR). The effect of noncondensable gas in condenser tube and the reduction of secondary pool water level to the condensation heat transfer coefficient was the main focus in this research. The objectives of this research were to: 1) obtain experimental data on the local and tube averaged condensation heat transfer rates for the PCCS with non-condensable and with change in the secondary pool water, 2) assess the RELAP5 and TRACE computer code against the experimental data, and 3) develop mathematical model and heat transfer correlation for the condensation phenomena for system code application. The project involves experimentation, theoretical model development and verification, and thermal- hydraulic codes assessment.

The research spanned over three phases.

Phase 1 - Phase 1 covered the following tasks: (1) Perform scaling analysis for single and multi-tube PCCS condenser design; (2) Perform single $5.04 \mathrm{~cm}$ tube condenser design, loop design, and construction and testing; (3) Steady state experimental data on heat transfer for $5.04 \mathrm{~cm}$ condenser for three PCCS flow conditions: through flow; complete condensation; and cyclic condensation at different secondary pool water level; (4) Single tube transient tests with continuous secondary water level change in through flow and complete condensation modes.

Phase 2 - Phase 2 covered the following tasks: (1) Construct four tube condenser unit and obtain experimental data for three PCCS flow conditions: through flow; continuous condensation; and cyclic condensation at different secondary water level; (2) Multi-tube transient tests with continuous secondary water level change in through flow and complete condensation modes; (3) Development of analytical model; (4) Comparison of analytical model and experimental data; (5) RELAP5 and TRACE code modeling of PCCS condensation. 
Phase 3 - Phase 3 covered the following tasks: (1) Obtain experimental data with $2.54 \mathrm{~cm}$ single tube and additional data with single $5.04 \mathrm{~cm}$ and multi-tube condenser; (2) RELAP5/MOD3 code model for the PCCS condensation and code assessment; (3) Development of PCCS condensation heat transfer correlation.

\section{Accomplishment for the project}

- A primary scaling analysis for the multi-tube PCCS condenser was performed. The scaling parameters were identified to scale down the prototype condenser design.

- Experimental loops were constructed with $5.04 \mathrm{~cm}$ diameter single tube condenser and $5.04 \mathrm{~cm}$ diameter 4-tube bundle condenser. The design of the condenser tube was based on the scaling analysis. The design and construction for new experiment loops with multi-tube condenser was finished successfully. The experimental facilities work very well such that we can obtain new database for PCCS condenser.

- Condensation experiment was conducted on the test facility with single $(5.04 \mathrm{~cm})$ condenser and 4-tube bundle condenser. Experimental database was obtained for three PCCS flow conditions: through flow; complete condensation; and cyclic venting at different secondary pool water level. Data were obtained with or without the presence of non-condensable gas. Single tube and tube bundle transient tests with continuous secondary water level change in forced flow and complete condensation modes was also conducted and database was acquired.

- A boundary layer model developed by previous researcher was employed to simulate the tests. Calculation results of various parameters from different test sections were compared to each other. The conclusions from model analysis were consistent with and verified by experiment data.

- A heat and mass analogy model was developed to predict the film wise condensation with the noncondensable gas. The analysis results of the model were compared with the experimental average condensation heat transfer coefficient data 
and with the local condensation heat transfer coefficient data from literature. The agreement was satisfactory except for high heat transfer coefficient cases such as very low pressure or small NC gas mass fraction conditions.

- PCCS tube condensation was modeled with RELAP5 thermalhydraulics code. Experimental data were compared with the RELAP5 code predictions for complete condensation mode of operation. Two condensation models in the RELAP5 code were assessed. 


\section{INTRODUCTION}

\subsection{Significance of the Problem}

The condensation phenomenon plays an important role in the heat transfer process in the chemical and power industry, including nuclear power plants. This mode of heat transfer is often used in engineering because high heat transfer coefficients are achieved. Many industrial systems use vertical tube condensers and industrial practice has indicated that, often, much higher coefficients of heat transfer are obtained when vapors are condensed inside tubes rather than outside. However, in practical operations of the condensers, small amounts of non-condensable gas may exist in working vapors due to characteristics of the system or dissolution of working vapors. It is well known that the presence of non-condensable gases in a vapor can greatly reduce the performance of condensers. This is because of the fact that the presence of non-condensable gas lowers the partial pressure of the vapor, thus reducing the saturation temperature at which condensation occurs. In the nuclear reactor industry, condensation heat transfer is very important. The presence of the noncondensable gases in vapors can greatly reduce the condensation process. Since Noncondensable gas is unable to pass into the condensate film it accumulates at the liquid-vapor interface leading to a decrease in vapor partial pressure and thus the interface temperature at which condensation occurs.

In the nuclear reactor industry, condensation heat transfer is very important in many situations. In the case of loss of coolant accident (LOCA), a large portion of the heat is removed by condensation of steam in the steam generators in reflux condensation mode. The presence of the noncondensable hampers the heat removal process. In the advanced light water reactors such as the Westinghouse Electric designed Advanced Passive 600 MWe (AP600) [1], and General Electric (GE) Simplified Boiling Water Reactor (SBWR) [2], and recently introduced WE AP1000 [3] and GE's 4000MWt simplified boiling water reactor referred as ESBWR [4], there is a greater emphasis on replacing the active systems with passive systems in order to improve the reliability of operation and safety. For example, the ESBWR is based on natural circulation cooling. This reactor designs uses the gravity driven cooling system (GDCS) as an emergency core cooling system following an accident in addition to the suppression pool (SP). After the reactor is scrammed the reactor pressure vessel (RPV) is depressurized with a system of valves. When the pressure in the RPV is reduced the water in PCCS Drain Tank drains into the RPV. The containment steam is condensed by a condenser system 
called Passive Containment Cooling System (PCCS). The containment pressurization thus depends on the condensing capability of the PCCS after the blowdown process. Development programs on advanced light water reactor based on passive safety systems are also underway in Europe [5] and Japan [6]. Currently Nuclear Regulatory Commission (NRC) is reviewing Westinghouse Electic's request for final design approval and standard design certification for the AP1000 [3]. Also the NRC is conducting pre-application review of the GE ESBWR [4].

In the ESBWR the PCCS is a passive heat exchanger that allows the transfer of heat via steam condensation to the water pool. The PCCS condenser must be able to remove sufficient energy from the reactor containment to prevent containment from exceeding its design pressure following a design-basis accident. The efficient performance of the PCCS condenser is thus vital to the safety of the ESBWR. The rate of heat transfer in the PCCS condenser is strongly coupled to the hydrodynamic characteristics of the PCCS. The ultimate heat sink for the long term cooling of the reactor is the PCCS water pool. When the pool water level decreases the condenser tubes are exposed and the secondary heat removal rate is drastically reduced. This has large bearing on the containment heat removal. Hence a detailed knowledge of the variation of local heat transfer coefficient is necessary in order to predict the performance of the PCCS for all possible transient and for design optimization.

\subsection{PCCS Operation}

A flow diagram of the PCCS is shown in Figure 1.1. The PCCSs are immersed in a large interconnected pool of water which is located outside and above the containment. Condensed water produced in the PCCS condensers returns to the Reactor Pressure Vessel (RPV) via PCCS Drain Tank. Non-condensable gases and uncondensed steam from the PCCS are vented to the SP. The driving head of the PCCS is provided by the pressure difference between the DW and the SP. There are no valves or pumps in the PCCS and any operational actions or signals are not needed, which makes the PCCS a truly passive system. Three different operational modes are possible in the PCCS depending on the non-condensable gas concentration and the pressure difference between the DW and the SP. These are bypass or through flow mode, complete condensation mode, and cyclic venting mode.

The PCCS will be in through flow mode when the pressure difference between the DW and the SP is relatively high compared with the head due to the submergence of the 
vent line in the SP. This condition is realized during the blowdown process. In this mode, steam and non-condensable gas pass through the PCCS condensers with condensation. This mode of operation corresponds to forced convection flow condensation studied by MIT [7, 8] and UCB [9, 11] groups. When the pressure difference between the DW and the SP is comparable with the head due to the submergence of the vent line in the SP, the PCCS will be in either complete condensation mode or cyclic venting mode depending on the non-condensable gas concentration. The PCCS will be in complete condensation mode when the non-condensable gas concentration is very low. This condition will be obtained in the later stage of an accidental transient after most of noncondensable gas is vented to the SP.

The PCCS will be in cyclic venting mode when the non-condensable gas concentration is relatively high. This condition sets in immediately after the blowdown process. In this mode, steam has enough time to be condensed in the PCCS condensers. In the condensation process, non-condensable gas is accumulated in the PCCS condensers. Hence the DW pressure begins to rise as the condensation decreases. The DW pressure continues to increase after the condensation process greatly deteriorates. When the pressure difference is high enough to overcome the head due to submergence of the vent line in the SP, non-condensable gas is vented to the SP. The condensation process begins again after clearing of non-condensable gas from the PCCS. This cycle repeats. The effectiveness of clearing of the non-condensable gas from the PCCS tubes depends on the type of non-condensable gas. If hydrogen is present then it accumulate in the top side of the condenser tube and may not clear from the tube during the venting process. The schematic of three operation mode is shown in Figure 1.2. 


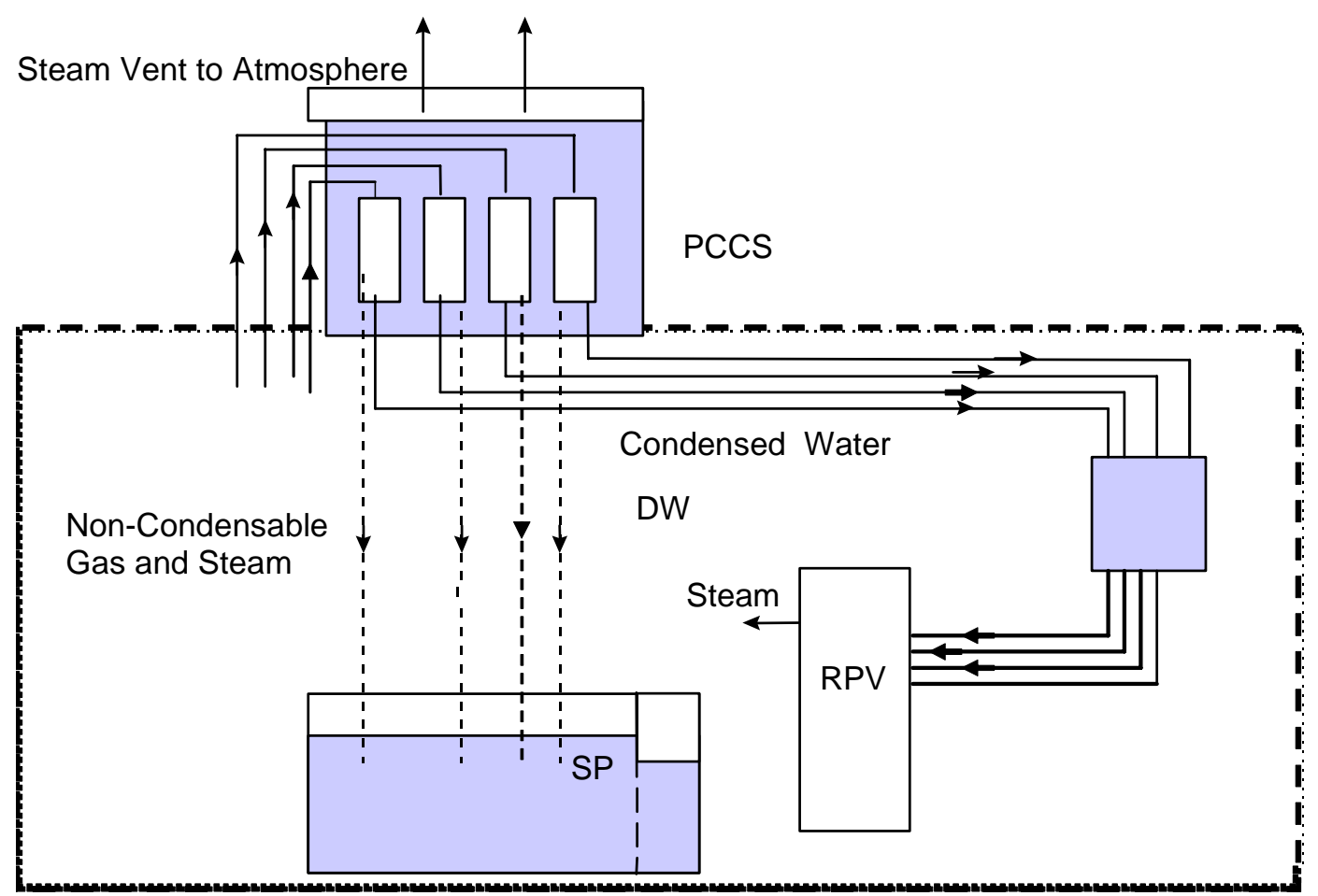

Figure 1.1 PCCS Flow Diagram in ESBWR during a Loss of Coolant Accident

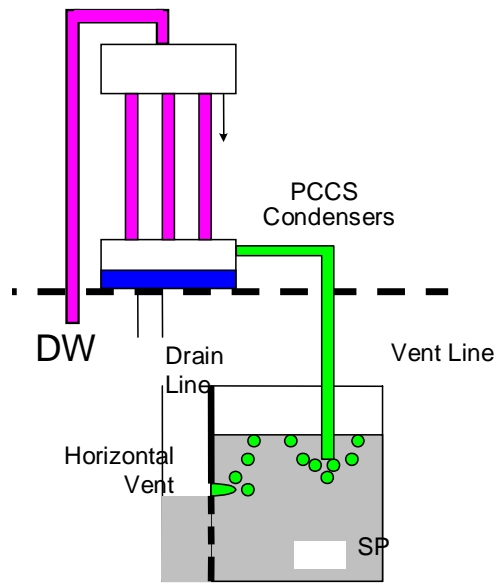

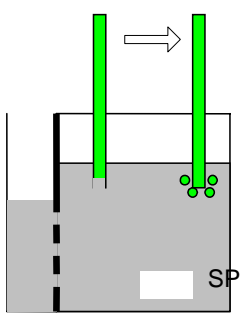

Complete condensation Through flow

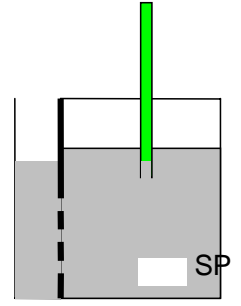

Cyclic venting

Figure 1.2 Schematic of different operation mode of PCCS

\subsection{Research Focus}

Uchida et al's [11] experiments on steam-gas condensation on outside wall of vertical tube provided first practical correlation for the degradation of condensation. Since then several theoretical works on the effects of the non-condensable gas on condensation in vertical pipe have been conducted [12-14]. The relevant separate effects experiments on PCCS condensation under the presence of noncondensable gas were con- 
ducted at Massachusetts Institute of Technology (MIT) [7, 8] and at University of California Berkeley (UCB) [9, 10]. Both MIT and UCB tests provided a new database and correlation for forced convection condensation of steam in a vertical tube in the presence of noncondensable gas. The flow of steam/gas mixture in the PCCS condenser tube is not always forced convection. Hence the UCB and MIT correlations do not apply for all flow conditions in the PCCS. Recent work at Purdue University (PU) [15-21] addressed this particular problem with experiments for the flow conditions expected in the PCCS condenser. The PU tests showed that the PCCS condensation heat transfer rates for the flow conditions other than forced flow are smaller than that for the forced flow conditions. These tests were conducted with SBWR-600 PCCS design [2] with air as non-condensable gas. The ESBWR PCCS has slight changes in the design of the condenser system. Here new research was aimed to perform separate effect experiments on ESBWR PCCS to investigate condensation heat transfer characteristics of PCCS with pool water level changes and the effect of non-condensable gas.

Also, the present experimental work investigated in detail the effect of PCCS pool water level change on the PCCS heat transfer characteristics for all flow conditions. In addition to the experimental work RELAP5 code model was developed for PCCS condensation and the assessment of the code is performed. 


\subsection{References}

1. Bruschi H J., AP600-safety through simplicity. [Conference Paper] Proceedings of the International Topical Meeting on Advanced Reactors Safety. ANS. Part vol.1, pp.3-8 vol.1. La Grange Park, IL, USA, (1997).

2. GE Nuclear Energy, SBWR Standard Safety Analysis Report, Report No. 25A5113 Rev. A, August, (1992).

3. US NRC website: (2002) http://www.nrc.gov/reactors/new-licensing/license-reviews/ap1000.html\#reviews.

4. US NRC website: (2002) http://www.nrc.gov/reactors/new-licensing/license-reviews/esbwr.html\#reviews .

5. Bandurski T. Dreier J. Huggenberger M. Aubert C. Fischer O. Healzer J. Lomperski S. Strassberger H-J. Varadi G. Yadigaroglu G. PANDA passive decay heat removal transient test results. Eighth International Topical Meeting on Nuclear Reactor Thermal-Hydraulics. NURETH-8. New Horizons in Nuclear Reactor Thermal-Hydraulics. Atomic Energy Soc. Japan. Part vol.1, pp.474-84 vol.1. Tokyo, Japan, (1997).

6. Yoshioka Y. Arai K. The analysis of PCCS heat removal performance for the 1300 MWe simplified BWR.Eighth International Topical Meeting on Nuclear Reactor Thermal-Hydraulics. NURETH-8. New Horizons in Nuclear Reactor Thermal-Hydraulics. Atomic Energy Soc. Japan. Part vol.1, pp.468-73 vol.1. Tokyo, Japan (1997).

7. Siddique, M., The Effects of Noncondensable Gases on Steam Condensation under Forced Convection Conditions, Ph.D. Dissertation, Massachusetts Institute of Technology (1992).

8. Siddique, M., Golay, M. W., and Kazimi, M. S., Local Heat Transfer Coefficients for Forced Convection Condensation of Steam in a Vertical Tube in the Presence of a Noncondensable Gas, Nucl. Technol., Vol. 102, 386 (1993).

9. Vierow, K. M., Behavior of Steam-Air Systems Condensing in Concurrent Vertical Downflow, MS Thesis, Department of Nuclear Engineering, University of California at Berkeley (1990).

10. Ogg D. G., Vertical Downflow Condensation Heat Transfer in Gas-Steam Mixture, MS Thesis, Department of Nuclear Engineering, University of California at Berkeley (1991). 
11. Uchida, H., Oyama, A., and Togo, Y., Evaluation of Post-Incident Cooling Systems of Light Water Reactors, Proc. $3^{\text {rd }}$ Int. Conf. Peaceful Uses of Atomic Energy, Vienna, Austria, Vol. 13, p. 93, International Atomic Energy Agency (1964).

12. Wang, D. Y. and Tu, C. J., Effects of Noncondensable Gas on Laminar Film Condensation in a Vertical Tube, Int. J. Heat Mass Transfer, Vol. 31, 2339 (1988).

13. Denny, V. E., Mills, A. F. and Jusionis, V. J., Laminar Film Condensation from a Steam-Air Mixture Undergoing Forced Flow Down a Vertical Surface, J. Heat Transfer, Vol. 93, 297 (1971)

14. Al-Diwani, H. K. and Rose, J. W., Free Convection Film Condensation of Steam in the Presence of Noncondensing Gases, Int. J. Heat Mass Transfer, Vol. 16, 1359 (1973).

15. Oh S. and Revankar S. T. , Boundary Layer Analysis for Steam Condensation in a Vertical Tube with Noncondensable Gases, International Journal of Heat Exchangers, Vol. 5, 93-124 (2005).

16. Oh S. and Revankar S. T., Complete Condensation In a Vertical 1 Tube Passive Condenser, International Communication in Heat and Mass Transfer Vol. 32, 593602 (2005).

17. Oh S. and Revankar S. T., Analysis of the Complete Condensation In A Vertical Tube Passive Condenser, International Communication in Heat and Mass Transfer, Vol. 32, 716-727 (2005).

18. Oh S. and Revankar S. T., Effect of Non-Condensable Gas in a Vertical Tube Condenser Nuclear Engineering and Design, 235, 1699-1712 (2005).

19. Oh S. and Revankar S. T., Investigation of the Noncondensable Effect and the Operational Modes of the Passive Condenser System, J. Nuclear Technology, 152, 71-86 (2005).

20. Oh S. and Revankar S. T., Experimental and theoretical investigation of film condensation with noncondensable gas, International Journal of Heat and Mass Transfer, Vol. 49, 2523-2534 (2006).

21. Revankar, S.T. and Oh, S. 2003. Analytical and experimental study of the effects of noncondensable in a passive condenser system for the advanced boiling water reactor, PU/NE-03-06. School of Nuclear Engineering, Purdue University. 


\section{PROJECT OBJECTIVES}

\subsection{Goals and Objectives}

The goals of this research are to obtain experimental data, assess the RELAP5 code model and develop heat transfer correlation for system code application. Single and multi tube (four tubes) tests are carried out using air as non-condensable gases. The GE ESBER PCCS condenser system design is used as a prototype. The experimental data are used in the development of heat transfer correlation applicable to various flow conditions in PCCS. The RELAP5 code model is developed for PCCS condensation and is assessed.

The objectives of this research are:

- To design and construct a well-scaled condensation test facility with single (5.04 $\mathrm{cm})$ and bundle tube condenser test section.

- To conduct condensation experiment under the typical PCCS operating condition and to obtain database on local and overall condensation heat transfer coefficient as a function of flow condition and inlet non-condensable gas concentration.

- To develop an analytical model for condensation in the vertical tube in the presence of non-condensable gas for PCCS flow conditions and compare with experimental data.

- To develop correlations for heat transfer coefficient for condensation in the presence of non-condensable for use in codes including the effect of the PCCS pool water level change.

- To assess RELAP5 code models for PCCS condensation against experiment data

\subsection{Project Schedule}

Phase 1 - Phase 1 will have a duration of 12 months and will cover the following tasks: (1) Perform scaling analysis for single and multi-tube PCCS condenser design; (2) Perform single $5.04 \mathrm{~cm}$ tube condenser design, loop design, and construction and testing; (3) Steady State experimental data on heat transfer for $5.04 \mathrm{~cm}$ condenser for three PCCS flow conditions: through flow; complete condensation (with zero flow velocity at bottom of the condenser); and cyclic condensation at different secondary 
pool water level; (4)Single tube transient tests with continuous secondary water level change in through flow and complete condensation modes.

Phase 1 Deliverable - A topical report at the end of phase 1 must indicate the following: (1) Scaling parameters for the design of the condenser tube and test conditions; (2) Test facility with single $5.04 \mathrm{~cm}$ condenser tube ready for testing; (3) Experimental database with $5.04 \mathrm{~cm}$ tube for three PCCS flow conditions: through flow; continuous condensation (with zero flow velocity at bottom of the condenser); and cyclic condensation at different secondary pool water level;

Phase 2 - Phase 2 will have duration of 12 months and will begin after Phase 1 . Phase 2 will cover the following tasks: (1) Construct four tube condenser unit and obtain experimental data for three PCCS flow conditions: through flow; continuous condensation (with zero flow velocity at bottom of the condenser); and cyclic condensation at different secondary water level; (2) Transient tests with continuous secondary water level change in through flow and complete condensation modes; (3) Development of analytical model; (4) Comparison of analytical model and experimental data; (5) RELAP5 code modeling of PCCS condensation.

Phase 2 Deliverable - A topical report at the end of phase 2 must indicate the following: (1) Test facility ready for testing with four tube $(5.04 \mathrm{~cm}$ diameter) condenser unit; (2) Experimental database with multi-tube condenser for three PCCS flow conditions: through flow; continuous condensation (with zero flow velocity at bottom of the condenser); and cyclic condensation at different secondary pool water level; (3) Experimental data base on multi-tube transient test (secondary water level change) for through flow and complete condensation modes; (4) Analytical model and results for PCCS condensation; (5) Initial code prediction for single and multi tube PCCS condensation.

Phase 3 - Phase 3 will have duration of 12 months and will begin after Phase 2. Phase 3 will cover the following tasks: (1) Obtain experimental data with $2.54 \mathrm{~cm}$ single tube and additional data with single $5.04 \mathrm{~cm}$ and multi-tube condenser; (2) RELAP5/MOD3 code model for the PCCS condensation and code assessment; (3) Development of PCCS condensation heat transfer correlation. 
Phase 3 Deliverable - A topical report at the end of phase 3 must indicate the following: (1) Additional experimental data with $2.54 \mathrm{~cm}$ and $5.04 \mathrm{~cm}$ condenser tubes and multi-tube unit; (2) TRACE and RELAP5/MOD3 model for Purdue PCCS condensation experiment, code prediction and code assessment results; (3) Practical correlation for PCCS heat transfer. 


\section{SINGLE TUBE EXPERIMENTAL PROGRAM}

The experimental program consists of the design and construction of the experimental loop, setting up experimental procedures, performing condensation tests with and without non-condensable gas at different operation mode and data analysis.

\subsection{Experimental Loop}

The schematic of the experimental loop is shown in Fig 3.1. A $52.5 \mathrm{~mm}$ test section was applied in the loop instead of the previous $26.6 \mathrm{~mm}$ one. Due to the size increase of the test section, as well as the objectives for the experiment, some modifications are necessary and accomplished for the experiment loop.

\section{$\underline{\text { Steam Generator }}$}

The steam generator (SG) is made of schedule 10, $4.06 \mathrm{~m}$ (16 inch) diameter stainless steel pipe. Its total length is $2.26 \mathrm{~m}$. An immersion type sheathed electrical heater of $10 \mathrm{~kW}$ capacity is mounted at the lower flange of this vessel. The vessel is instrumented with thermocouples, pressure gauge and DP cells to measure and monitor temperatures, pressures and water levels. Sight glass is also mounted on the midlevel of the steam generator. The power to the heater is measured with A.C. Voltmeter and Ammeter. A relief valve is mounted at the $26.6 \mathrm{~mm}$ piping connected to the upper shell of steam generator. The set pressure of the relief valve is $150 \mathrm{psig}$. Downstream of the relief valve is routed to blowdown \& secondary steam dump tank.

\section{$\underline{\text { Test Section }}$}

For $52.5 \mathrm{~mm}$ test section, the outside tube assembly is the same as previous 26.6 $\mathrm{mm}$ test section. The inside tube assembly has basically the same design with 26.6 $\mathrm{mm}$ test section. The differences are $50.8 \mathrm{~mm}$ schedule 40 pipe instead of $26.6 \mathrm{~mm}$ pipe and two $50.8 \times 26.6 \mathrm{~mm}$ reducers are welded between $50.8 \mathrm{~mm}$ condenser pipe and $26.6 \mathrm{~mm}$ connecting pipe. 


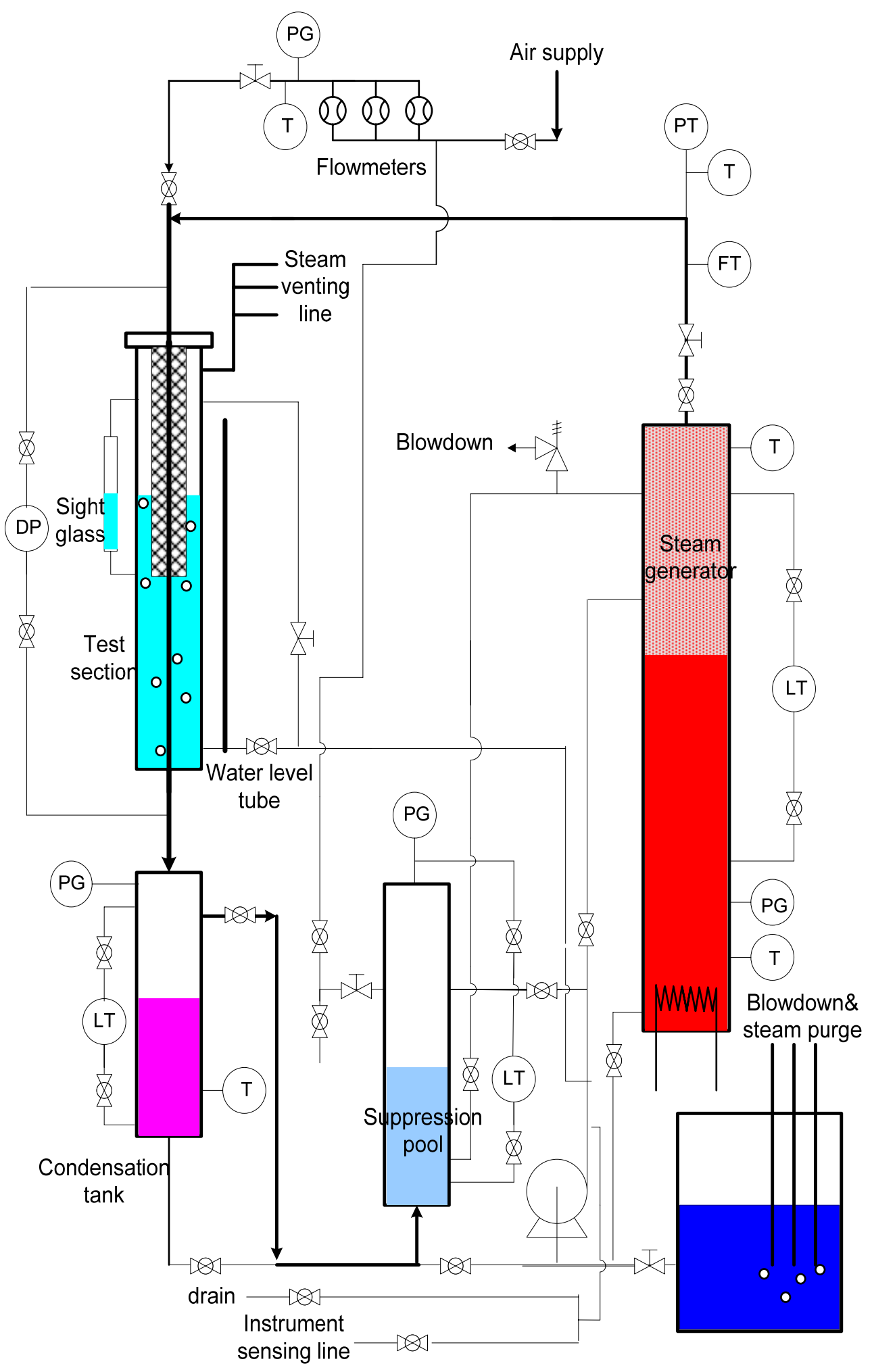

Fig 3.1 Schematic of PCCS Test Loop 
One of the goals of the experiment is to perform the test at different pool water level, new $1 / 2$ inch transparent plastic tubing is connected to the bottom of secondary pool, and the other end of the tubing is open to the atmosphere. Thus, during the experiment, the water level can be watched through the tubing.

For the experiments with $52.5 \mathrm{~mm}$ test section, the condensation rate is faster than the previous tests with $26.6 \mathrm{~mm}$ test section. The condensation tank is much easier to be full and have to be drained. To avoid the harmful effect of hot water to the coolant pump, the drain line of condensation tank is reconnected from the bottom of condensation tank to the bottom of suppression pool which has a large volume and can hold up longer from draining condensed water to storage tank. The $1 / 2$ inch schedule 10 stainless steel tubing is used in the drain line, the same as previous loop.

Maintaining the pool level is very important for the low pool level test, therefore, a $1 / 4$ feed line was connected to the top of secondary pool. The new feed line is capable to give a small but enough flow rates, which minimize the effect of cold water to the boiling pool and hold the pool level as well. The new feed line is made of $1 / 4$ stainless steel tubing and corresponding accessories. A needle valve is used in the feed line to adjust the flow rate slightly.

Local heat flux is another main aim for this research. Since condensation heat transfer can be obtained from the condensation rate which is calculated from the water level change in condensation tank, the local temperature differences between effective wall thicknesses are the rest of parameters in order to determine the local heat flux. To measure the local temperature along the condensation tube, 45 thermocouples are welded on the condensation tube, $9 \mathrm{~T} / \mathrm{Cs}$ for each level and 5 levels altogether. At each level, 4 out of $9 \mathrm{~T} / \mathrm{Cs}$ are welding on the outside surface, another 4 out of $9 \mathrm{~T} / \mathrm{Cs}$ are inserted into the tube wall about 2-3 $\mathrm{mm}$ to give the inside wall temperatures, the rest one goes through the tube wall and reach the center of primary side so that bulk steam-gas mixture temperature can be measured. The detailed layout of the thermocouples is shown in Fig 3.2. 


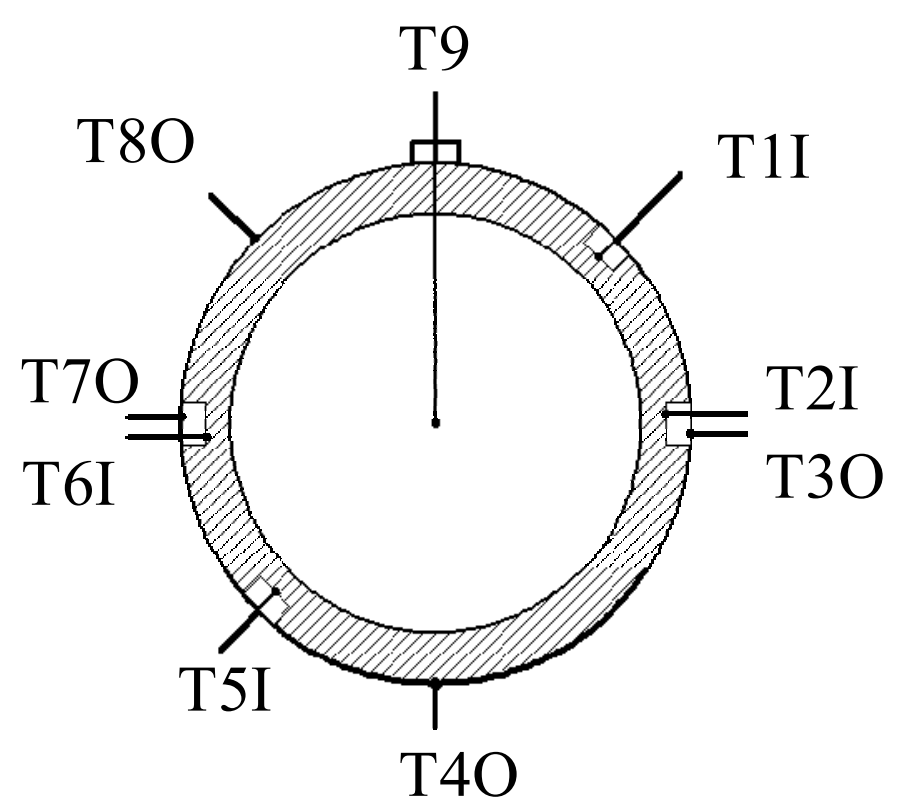

Fig. 3.2 Cross Section of Test Section with T/Cs

The specific design of the PCCS condenser tube test section (T/S) was based on the scaling analysis. The condenser tube is made of schedule 40 Type 304 stainless steel pipe with $52.5 \mathrm{~mm}$ ID and $60.3 \mathrm{~mm}$ OD. A height scaling of 1/2 was taken in the present design. The schematic of $52.5 \mathrm{~mm}$ test section with secondary pool is shown in Figure 3.3. Pool boiling test section is comprised of two subassemblies. One is the condenser outside tube where the boiling takes place and the other is inside condenser tube where the condensation takes place.

The condenser outside tube is common for $52.5 \mathrm{~mm}$ and previous $26.6 \mathrm{~mm}$ test section. The outside tube is made of $152.4 \mathrm{~mm}$ (6 inch) schedule 10 Type 304 stainless steel pipe with a top flange and a bottom plate welded to the pipe. The top flange is a $279.4 \mathrm{~mm}$ (11 inch) diameter and $26.6 \mathrm{~mm}$ thickness with a $168 \mathrm{~mm}$ (6.625 inch) inside hole and 8 bolt holes. The bottom plate is a $168 \mathrm{~mm}(6.625 \mathrm{inch})$ diameter and $6.35 \mathrm{~mm}(1 / 4 \mathrm{inch})$ thickness with a $60.3 \mathrm{~mm}(2.375 \mathrm{inch})$ inside hole and 4 bolt holes. Along the outside surface of the $152.4 \mathrm{~mm}$ ( 6 inch) pipe, various nozzles for thermocouple, sight glass, feed, drain, and steam exit are installed. The three 38.1 $\mathrm{mm}$ (1.5 inch) diameter steam exit nozzles are located at the almost top level of pipe with 120 degree each other. 


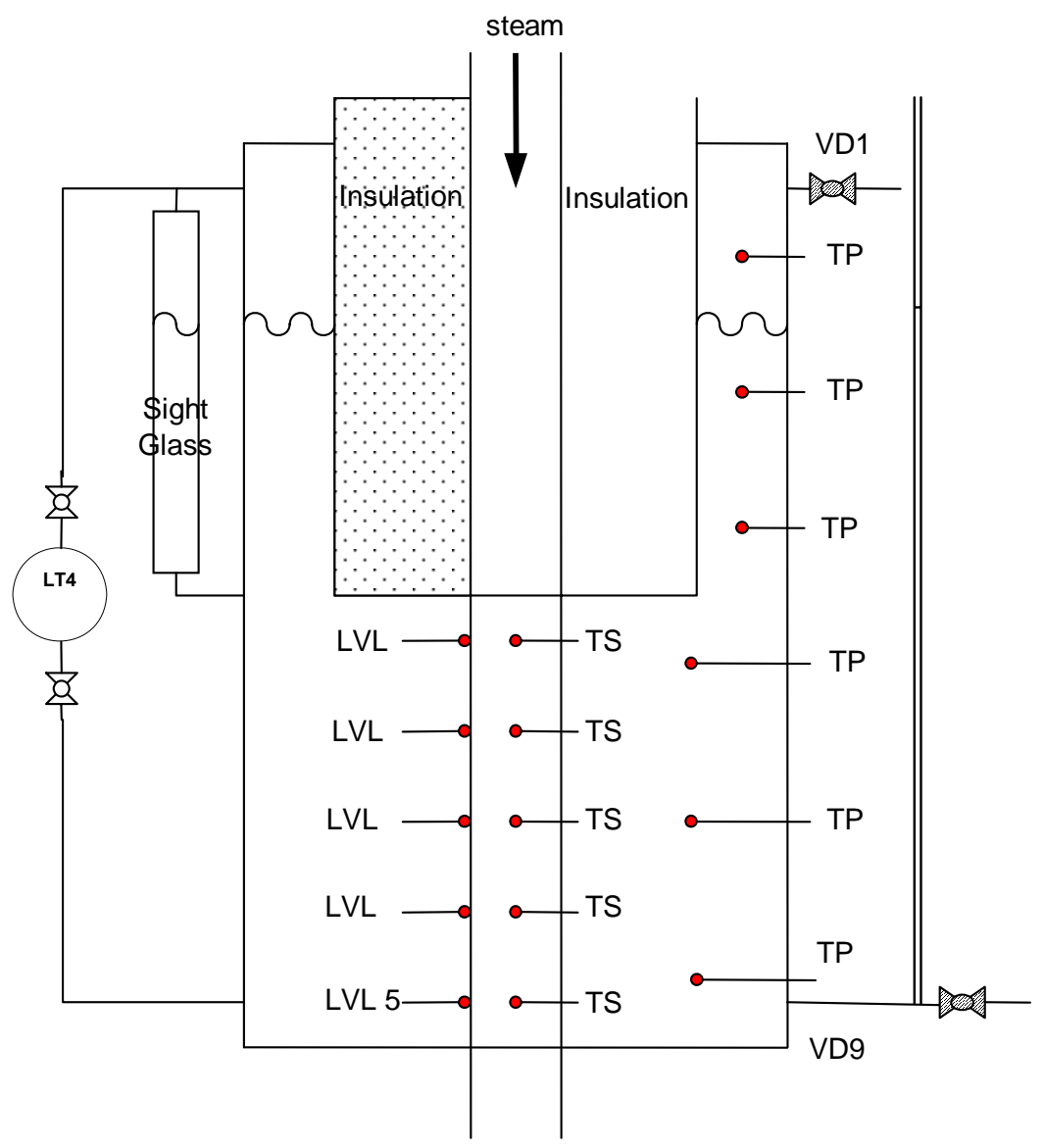

Fig. 3.3 Schematic of $52.5 \mathrm{~mm}$ Test Section with Secondary Pool

The inside condenser tube for $52.5 \mathrm{~mm}$ test section is made of $52.5 \mathrm{~mm}$ schedule 40 Type 304 stainless steel pipe and $101.6 \mathrm{~mm}$ (4 inch) schedule 10 Type 304 stainless steel pipe with a top flange welded to $52.5 \mathrm{~mm}$ pipe, another top flange welded to $101.6 \mathrm{~mm}$ ( $4 \mathrm{inch}$ ) pipe, a middle plate welded to both $52.5 \mathrm{~mm}$ and 4 inch pipe and a bottom flange welded to $52.5 \mathrm{~mm}$ pipe. The top flange welded to $26.6 \mathrm{~mm}$ pipe is for the connection with upstream piping. The top flange welded to $101.6 \mathrm{~mm}$ ( 4 inch) pipe is connected to the top flange of the condenser outside tube. It has 8 bolt holes and 3 holes for thermocouple line outlet. The middle plate welded to both 52.5 $\mathrm{mm}$ and $101.6 \mathrm{~mm}$ (4 inch) pipe act as a border of condenser. $52.5 \mathrm{~mm}$ (1 inch) pipe below this plate is an actual condenser. The gap between $101.6 \mathrm{~mm}$ (4 inch) and 26.6 $\mathrm{mm}$ pipe above this plate will be filled with insulation material. The bottom flange welded to $52.5 \mathrm{~mm}$ pipe is connected the bottom plate of the condenser outside tube. 
For this connection, 4 bolts are welded to the top surface of the bottom flange. At the top and bottom of the inside tube assembly pressure measurement taps are installed.

Active tube length of condensing is $0.978 \mathrm{~m}$ (38.5 inch). Along the active tube, 5 nozzles for inside bulk temperature measurement are welded at different axial and circumferential location. At the opposite side of the nozzle, a thermocouple junction is made to measure the tube outside wall temperature at 5 axial locations.

\section{$\underline{\text { Steam and Air Supply Line }}$}

The steam supply line to the condenser is made of $26.6 \mathrm{~mm}$ (1 inch) stainless steel pipe except the upstream and downstream piping of vortex flow meter. Since the diameter of the vortex flow meter is $19 \mathrm{~mm}(3 / 4 \mathrm{inch})$, the upstream and downstream piping of vortex flow meter is also $19 \mathrm{~mm}(3 / 4 \mathrm{inch})$ piping. To minimize the flow disturbance effect on the flow meter, the length of $19 \mathrm{~mm}(3 / 4 \mathrm{inch})$ upstream piping was selected as greater than the required L/D specified in flow meter installation manual. To determine the flow condition at vortex flow meter, pressure transducer and thermocouple are installed at the downstream of the vortex flow meter. The sensing line to this pressure transducer is routed upward to drain the condensate in the sensing line.

Air supply line is connected to the steam line and suppression pool. Before the connection to steam line, three rotameters with different flow ranges are installed to measure the wide range of air flow rate. A pressure gauge and a thermocouple are also installed to measure pressure and temperature of air.

Pressure tabs are made at upstream and downstream piping of the test section to measure the test section differential pressure. A pressure gauge is also installed at the downstream piping of the tube. To collect the condensate in the DP sensing line, the sensing lines to DP transducer are routed upward and condensate drain lines are connected to the high and low pressure side of sensing lines. If condensate fills the sensing line, normally closed drain valves are opened to drain the condensate.

\section{Condensate Tank}


The condensate tank (CT) collects the condensate. It is made of Schedule 10, 3.05 $\mathrm{m}$ (4 inch) pipe and is mounted vertical. The water level in the suppression pool can be maintained at desired level by continuous bleeding water from the tank.

\section{$\underline{\text { Suppression Pool }}$}

The suppression pool (SP) serves as a collector of the noncondensable gas and the uncondensed steam. During the complete condensation mode, the suppression pool is isolated from the condensing loop. It is made of Schedule 10, $3.05 \mathrm{~m}$ (12 inch) pipe and is mounted vertical. The water level in the suppression pool can be maintained at desired level by continuous bleeding water from the tank. The condenser operating pressure is set by the pressure level in the suppression pool. An airline is connected to the suppression pool to set the pressure higher than the atmosphere pressure. A blowdown line is connected to blowdown $\&$ secondary steam dump tank. The suppression pool is instrumented with thermocouple, pressure gauge and DP cells to measure and monitor temperature, pressure and water level.

\section{Blowdown \& Secondary Steam Dump Tank}

The blowdown \& secondary steam dump tank (BDT) is made of $5 \mathrm{~mm}$ thick stainless steel plate with $0.61 \mathrm{~m}$ (24 inch) width, $0.61 \mathrm{~m}$ (24 inch) depth and $0.91 \mathrm{~m}$ (36 inch) height. It serves as heat \& mass sink and de-ionized water storage. By use of pump, de-ionized water in this tank is supplied to steam generator, suppression pool, secondary pool, condensate tank and instrument sensing line. Water in SG, SP, CT, and secondary pool can be drained to this tank by gravity. The discharges from relief valve at steam generator and from steam/gas space of suppression pool are routed to this tank for the blowdown purpose. The discharge line is submerged into the water space of blowdown \& secondary steam dump tank. The secondary steam generated in the test section is also discharged to this tank through 3 independent 1.25 inch copper tubings. To cool the water in BDT, $1 / 2$ inch copper tubing is submerged in the BDT and the city water flow through the tube.

Table 3.1 List of Instruments 


\begin{tabular}{|c|c|c|c|}
\hline Variable & Process & Instrument & Tag. No. \\
\hline Flow Rate & Steam & Vortex Flow Meter & FT1 \\
\cline { 2 - 4 } & Air & Rotameter & FA1, FA2, FA3 \\
\hline \multirow{4}{*}{ Pressure } & & & PG1 \\
\cline { 2 - 4 } & SG & Pressure Gauge & PT1 \\
\cline { 2 - 4 } & Sortex Flow Meter & Pressure Gauge & PG2 \\
\cline { 2 - 4 } & SP & Pressure Gauge & PG3 \\
\cline { 2 - 4 } & Air Supply line & Pressure Gauge & PG4 \\
\hline Water Level & SG & DP Transducer & LT1 \\
\cline { 2 - 4 } & SP & DP Transducer & LT3 \\
\cline { 2 - 4 } & CT & DP Transducer & LT4 \\
\cline { 2 - 4 } & Secondary Pool & DP Transducer & TS1, TS2 \\
\hline Temperature & SG & Thermocouples & TS3 \\
\cline { 2 - 4 } & Vortex Flow Meter & Thermocouples & TS4-TS8, \\
\cline { 2 - 4 } & Test section & & TP1-TP6 \\
\hline & & Thermocouples & TA1 \\
\cline { 2 - 4 } & Air line & Thermocouples & TS9-TS11 \\
\cline { 2 - 4 } & CT & Thermocouples & DP1 \\
\cline { 2 - 4 } & SP & Poltmeter and Ammeter & - \\
\hline Dower & Test section DP & & \\
\hline
\end{tabular}

\subsection{Experiment procedures}

The test procedures are prepared for the preparatory work, testing and shut down.

\subsubsection{Preparatory Work:}

The preparatory work is comprised of the following steps: (1) filling steam generator, (2) filling suppression pool, (3) filling secondary pool and (4) purging of the instrument line. The following lists the tasks in each of the preparatory steps.

\section{1) Steam Generator Filling}

- Check and verify the normal valve position

- Open VB3 and VB4 for the initial feed operation (These valve should be opened to bleed the air in the loop for the water filling)

- Open VD2 to fill steam generator

- Fill steam generator monitoring the level using sight glass and LT1 signal

- Close VD2

\section{2) Suppression pool Filling}


- Open VD3

- Fill suppression pool monitoring the level using LT2

- Close VD3

3) Secondary Pool Filling

- Open VD9

- Fill secondary pool monitoring the level using sight glass and LT4 signal

Note: Do not fill the full height. Just fill the $3 / 4$ of the full height. Due to the thermal stratification during heating, it is more efficient to heat this level of water first and then fill again the remaining height.

- Close VD9

4) Instrument Line Purging

- Open VD5

- Turn on pump

- Fill and vent the air in the instrument sensing lines for each level transducer (LT1 LT4).

1. Fill the water using the instrument sensing line valves for high pressure side

2. Vent air in sensing line using transmitter venting screw for high pressure side

3. Fill the water using the instrument sensing line valves for low pressure side

4. Vent air in sensing line using transmitter venting screw for low pressure side Note: When filling the condensate tank level instrument, establish the initial CT level by monitoring LT3 signal.

- Close VD5

- Close VB3 and VB4 which were opened for the initial feed operation

\subsubsection{Testing}

The procedures for the test operations are given below.

1) SG Heating

- Check the normal valve position

- Close VS1

- Turn on heater 
- Set the heater controller setpoint about 240C.

2) SG Venting

- When SG water temperature, TS1, reach about 100C, open VS1 for several seconds to vent the air in the SG.

- Verify the SG water temperature, TS1, and SG steam temperature, TS2, are almost same.

3) Loop Heating

- When SG pressure (PG1) reaches about 150 psig, slightly open VS1 to heat up the loop and secondary water pool

- If necessary, close vent valve to SP, VS3, to increase the loop system pressure.

Note: At low pressure, the heat transfer rate to secondary side is small. So, it needs to increase the system pressure (recommended pressure - 30 psig from PG2 reading).

- When the secondary water temperatures (TP4 and TP5) reach about 90C, regulate the VS1 to establish the required steam flow rate.

- When the secondary water temperatures (TP4 and TP5) reach about 100C, fill the secondary pool to the full height by turning on the pump and opening VD10.

- Close VD10

- Turn off the pump

- Open the city water supply valve to cool the BDT

Note:

A. During the loop heating, vent the air in the loop several times by opening the VS3 to establish the pure steam condition in the loop

B. During the loop heating, periodically drain the CT water by opening BD8 if the condensate fills enough the CT

4) Steady State Condition

- Check the steam flow rate to verify the steady state

- Check the steam temperature at flowmeter (TS3) to verify the steady state and the superheat condition 
- Check the secondary water pool temperature to verify the steady state (TS4 TS6 should be almost same temperature)

- Check the test section pressure (PG2) to verify the steady state

5) Initial Condition and Test Method for each Operation Mode

\section{A. Complete Condensation Mode}

- Verify that the VS3 is closed

- Verify that the air in the loop has been vented during the heating period

- Verify the steady state condition described in 4)

- Do the data log described in 6)

\section{B. Periodic Venting Mode}

- Initially establish the Complete Condensation Mode described above

- Open VA3

- Regulate FA1 FA3 to obtain required small amount of air flow

- Select the base pressure, vent DP (Usually $0.5 \mathrm{psi}$ ) and measurement duration

- Start to log the data

- Open VS3 to reduce the test section pressure below the base pressure

- Use stop-watch to log the periodic vent time interval. When the test section pressure reach the base pressure, reset the stop-watch. (start time)

- When the test section pressure reach the base pressure + vent DP, quick open the VS3

- When the test section pressure decrease below to the base pressure, quick close the VS3

Note: To maintain the vent DP properly, it needs some undershooting in the pressure before close the VS3.

- Count the vent number in mind

- Repeat the periodic venting until the predetermined measurement duration

- Log the number of vent and the measurement duration.

\section{Through Flow Mode}

- Verify that the VS3 is opened

- Open VA3 for noncondensable gas test and regulate FA1 FA3 to obtain re- 
quired amount of air flow

- Maintain the test section pressure at a desired level by use of the blowdown valves (VB2 $\sim$ VB4) or air supply line valve (VA4)

- Verify the steady state condition described in 4)

- Do the data log described in 6)

6) Data Log

- When the initial condition is obtained for each operating mode, start to record the DAS.

- Fill the log sheet

Note:

A. During the test, check the test section DP signal. If the condensate fills the DP sensing line, DP output will not show correct signal. For this condition, open the condensate drain valve to drain condensate in the sensing line.

B. During the test, periodically fill the secondary pool with water by use of VD10

C. During the test, periodically drain the condensate tank water by use of VD8

\subsubsection{Shutdown Operation}

The following are the tasks in shutdown of the facility after the test.

1) Loop Cooling

- Turn off the heater

- Close VA3 if necessary

- Wide open VS1

- Open VB2 if necessary

- Periodically fill the secondary pool with water by use of VD10

- Periodically drain the condensate tank water by use of VD8

- When system pressure reach to almost 1 atm, open VB3 \& VB4.

- When no steam is generated from the system, close the city water supply line valve

2) Drain

- Drain the secondary pool water when its temperature decreases below 60C 
- Drain SG, SP, and CT water into the BDT if necessary.

\subsubsection{Transient Operation}

1) For the complete condensation:

- Close the venting line from the condensation tank.

- Start the test from a steady state at complete condensation mode with full height water level.

- As the decrease of secondary water level, system pressure will keep increasing.

- Continuously recording data until the secondary water level decreases to $20 \%$ of full height.

- Drain the condensation tank when the condensation is full during the data acquisition period.

2) For the test with noncondensables:

- Open the venting valve from the condensation tank to get an initial condition at through flow mode.

- In the through flow condition, system pressure will keep the same as the secondary level decreases.

- Continuously recording data until the secondary water level decreases to $20 \%$ of full height.

- Drain the condensation tank when the condensation is full during the data acquisition period.

\subsection{Data reduction}

Data reduction process is the same with previous test but the condenser tube geometry was changed into that of $52.5 \mathrm{~mm}$ test section.

The overall heat transfer coefficient in condenser is defined as follows:

$$
U=\frac{Q_{\text {con }}}{A_{i}\left(T_{S A T}-T_{P}\right)},
$$


where $Q_{c o n}$ is the condensation heat transferred by condenser tube, $A_{i}$ is the heat transfer area of tube inside, $T_{S A T}$ is the saturation temperature at the steam partial pressure $\left(P_{S A T}\right)$ and $T_{P}$ is the secondary pool water temperature.

The condensation heat transferred by condenser tube, $Q_{c o n}$ can be calculated as follow:

$$
Q_{c o n}=m_{c o n} h_{f g}\left(P_{S A T}\right) \text {, }
$$

where $m_{\text {eva }}$ is the condensation mass flow rate calculated from the condensate tank water level difference during the test and $h_{f g}\left(P_{S A T}\right)$ is the latent heat of condensation based on the steam partial pressure $P_{S A T}$. The condensation mass flow rate can be checked by the comparison with the supplied steam flow rate during the complete condensation mode.

This condensation heat transfer rate should be equal to the secondary side heat removal rate, $Q_{\text {tot }}$, which is sum of the evaporative heat transfer rate and the heat loss from the secondary tube surface.

$$
\begin{gathered}
Q_{\text {con }}=Q_{\text {tot }} \\
Q_{\text {tot }}=m_{\text {eva }} h_{f g}\left(T_{P}\right)+Q_{h l},
\end{gathered}
$$

where $m_{\text {eva }}$ is the evaporative mass flow rate calculated from the secondary pool water level difference during test, $h_{f g}\left(T_{P}\right)$ is the latent heat of evaporation based on the secondary pool water temperature, and $Q_{h l}$ is the heat loss rate loss from the secondary tube surface obtained from the heat loss measurement test.

The heat transfer area of tube inside, $A_{i}$, can be calculated as follows:

$$
A_{i}=\pi D_{i} H_{\text {tube }} .
$$

The measured steam bulk temperature was slightly higher than the saturation temperature at the system pressure. It means that the state of the steam-air mixture is superheat. However, the amount of sensible heat transfer is much less than that of condensation heat transfer. So, the sensible heat transfer is ignored. 
The overall heat transfer coefficient is given by the following equation derived by the heat balance among the condenser tube inside, tube wall and tube outside.

$$
U=\left[\frac{1}{h_{c}}+\frac{1 n\left(D_{o} / D_{i}\right) D_{i}}{2 k_{w}}+\frac{D_{i}}{h_{\mathrm{sec}} D_{o}}\right]^{-1} .
$$

The first term of the right hand side of above equation corresponds to the tube side condensation heat transfer, the second term corresponds to the tube wall conduction heat transfer, and the third term corresponds to the secondary side pool boiling heat transfer.

Neglecting the heat transfer along condenser tube length, the condensation heat transfer coefficient, $h_{c}$, is defined as follows:

$$
h_{c}=\frac{Q_{c o n}}{A_{i}\left(T_{S A T}-T_{W i}\right)}
$$

where $T_{W i}$ is the tube inside wall temperature.

The secondary side pool boiling heat transfer coefficient, $h_{\mathrm{sec}}$, is defined as follows:

$$
h_{\mathrm{sec}}=\frac{Q_{\text {con }}}{A_{o}\left(T_{W o}-T_{P}\right)}
$$

where $T_{W o}$ is the tube outside wall temperature and $A_{o}$ is the heat transfer area of tube outside.

$A_{o}$ is expressed as follows:

$$
A_{o}=\pi D_{o} H_{\text {tube }}=\frac{D_{i}}{D_{o}} A_{i}
$$

From equation (5.6), the condensation heat transfer coefficient can be expressed as follows:

$$
\frac{1}{h_{c}}=\frac{1}{U}-\frac{1 n\left(D_{o} / D_{i}\right) D_{i}}{2 k_{w}}-\frac{D_{i}}{h_{\mathrm{sec}} D_{o}}
$$


Substituting eqs. (3.1), (3.2), (3.3), (3.8) and (3.9) to eq. (3.10), the condensation heat transfer coefficient can be simplified as follows:

$$
\begin{aligned}
\frac{1}{h_{c}} & =\frac{A_{i}\left(T_{S A T}-T_{P}\right)}{m_{c o n} h_{f g}\left(P_{S A T}\right)}-\frac{1 n\left(D_{o} / D_{i}\right) D_{i}}{2 k_{w}}-\frac{D_{i} A_{o}\left(T_{W o}-T_{P}\right)}{D_{o} m_{c o n} h_{f g}\left(P_{S A T}\right)} \\
& =\frac{A_{i}\left(T_{S A T}-T_{P}\right)}{m_{c o n} h_{f g}\left(P_{S A T}\right)}-\frac{1 n\left(D_{o} / D_{i}\right) D_{i}}{2 k_{w}}-\frac{A_{i}\left(T_{W o}-T_{P}\right)}{m_{c o n} h_{f g}\left(P_{S A T}\right)} \\
& =\frac{A_{i}\left(T_{S A T}-T_{W o}\right)}{m_{c o n} h_{f g}\left(P_{S A T}\right)}-\frac{1 n\left(D_{o} / D_{i}\right) D_{i}}{2 k_{w}} \\
& =\frac{2 k_{w} A_{i}\left(T_{S A T}-T_{W o}\right)-m_{c o n} h_{f g}\left(P_{S A T}\right) \ln \left(D_{o} / D_{i}\right) D_{i}}{2 k_{w} m_{c o n} h_{f g}\left(P_{S A T}\right)}
\end{aligned}
$$

Finally, the condensation heat transfer coefficient can be expressed with the known or experimentally obtainable values as follows:

$$
h_{c}=\frac{2 k_{w} m_{c o n} h_{f g}}{2 k_{w} \pi D_{i} H_{\text {tube }}\left(T_{S A T}-T_{W o}\right)-m_{c o n} h_{f g} \ln \left(D_{o} / D_{i}\right) D_{i}} .
$$

The condensation mass flow rate can be calculated with the following equation.

$$
m_{\text {con }}=\frac{\Delta H_{r e f}}{\Delta t} \rho_{r e f} A_{C T}
$$

where $\Delta H_{\text {ref }}$ is the condensate tank level difference converted to the reference temperature $(4 \mathrm{C})$ condition, $\Delta t$ is the measurement time, $\rho_{\text {ref }}$ is the density at the reference temperature, and $A_{C T}$ is the cross-sectional area of the condensate tank.

Air mass flow can be calculated and then the non-condensable gas mass fraction can be determined.

$$
\begin{gathered}
m_{\text {air }}=\rho_{\text {air }} V_{\text {air }} \\
V_{\text {air }}=F_{\text {air }} \sqrt{\frac{T_{\text {ref }}}{T_{\text {mes }}} \frac{P_{\text {mes }}}{P_{\text {ref }}}} \\
W_{\text {air }}=\frac{m_{\text {air }}}{m_{\text {air }}+m_{\text {steam }}}
\end{gathered}
$$


where $F_{\text {air }}$ is the air flow reading from rotameter, $T_{\text {ref }}$ is the absolute temperature at standard condition ( $294 \mathrm{~K}$ or $530 \mathrm{R}), \quad T_{\text {mes }}$ is the absolute temperature of air, $P_{\text {ref }}$ is pressure at standard condition ( 1 atm or $14.7 \mathrm{psia}), P_{\text {mes }}$ is the measured pressure of air and $m_{\text {steam }}$ is the steam inlet mass flow rate measured by vortex flow meter.

Vapor partial pressure can be calculated from Gibbs-Dalton ideal gas mixture equation as follow:

$$
\frac{P_{S A T}}{P_{T O T}}=\frac{1-W_{\text {air }}}{1-W_{\text {air }}\left(1-\frac{M_{v}}{M_{a}}\right)}
$$

where, $P_{\text {ТОT }}$ is the total pressure which is the sum of the vapor partial pressure and air partial pressure, $M_{v}$ and $M_{a}$ are the molecular weight of the vapor and air, respectively.

Inlet steam Reynolds number and average condensation Nusselt number can be calculated with the following equation.

$$
\begin{gathered}
\operatorname{Re}_{\text {steam }}=\frac{\rho_{\text {steam }} V_{\text {steam }} D_{i}}{\mu_{\text {steam }}}=\frac{4 m_{\text {steam }}}{\pi D_{i} \mu_{\text {steam }}} \\
N u_{c}=\frac{h_{c} D_{i}}{k_{\text {condensate }}},
\end{gathered}
$$

where $\mu_{\text {steam }}$ is the viscosity of steam and $k_{\text {condensate }}$ is the thermal conductivity of the condensate film.

\subsection{Test results}

Condensation experiments were conducted for three PCCS operation modes, i.e., 1) Through flow mode, 2) Cyclic venting mode, and 3) Complete condensation mode. The complete condensation mode was performed for the pure steam condition changing the inlet steam flow rate. For a given steam flow rate in this mode, the system pressure is uniquely determined by the heat removal capacity of the condenser. The cyclic venting mode was initiated from the complete condensation mode by putting 
small amount of air. Through flow mode was performed with various inlet steam flow rate, inlet air flow rate, and system pressure.

The condensation experiments were conducted at 2 different secondary pool levels: full height and half height. Due to the differences of heat transfer area, the pressure range in which the tests were performed varies for the different pool levels. For complete condensation mode, upper pressure limit was determined by maximum steam supply capacity of steam generator. The upper pressure limit of full height complete condensation test is lower than that of half height test due to poor condensation capacity in half height test. The lower pressure limit was determined by reliable measurement of minimum condensation rate which is same for both full and half height test. All three operation modes were performed for the full height test and half height test.

Table 3.2 Test parameters' range for various operation modes and pool levels

\begin{tabular}{|c|c|c|c|c|}
\hline $\begin{array}{c}\text { Operation } \\
\text { Mode }\end{array}$ & Water Level & $\begin{array}{c}\text { Pressure, } \\
\mathrm{kPa}\end{array}$ & $\begin{array}{c}\text { Steam Flow } \\
\text { rate, } \\
\mathrm{g} / \mathrm{s}\end{array}$ & $\begin{array}{c}\text { NC Gas Frac- } \\
\text { tion }\end{array}$ \\
\hline $\begin{array}{c}\text { Complete } \\
\text { Condensation }\end{array}$ & Full $(1.0 \mathrm{~m})$ & $150 \sim 250$ & $1.2 \sim 4.5$ & 0 \\
\cline { 2 - 5 } & Half $(0.5 \mathrm{~m})$ & $150 \sim 350$ & $1.0 \sim 4.7$ & 0 \\
\hline $\begin{array}{c}\text { Cyclic Vent- } \\
\text { ing }\end{array}$ & Full $(1.0 \mathrm{~m})$ & $160 \sim 230$ & $1.18 \sim 4.2$ & $0.1 \sim 2$ \\
\cline { 2 - 5 } & Half $(0.5 \mathrm{~m})$ & $160 \sim 280$ & $1.0 \sim 4.0$ & $0.1 \sim 2$ \\
\hline \multirow{2}{\text{Through}}{\begin{tabular}{c} 
Flow \\
\cline { 2 - 5 }
\end{tabular}} & Full $(1.0 \mathrm{~m})$ & $160 \sim 230$ & $2.5 \sim 4.1$ & $1 \sim 15$ \\
\hline
\end{tabular}

Transient test is a new task in the experiments compared with the previous research. Data was acquired continuously with the decrease of secondary pool level. The change of system pressure with the secondary pool water level is the main interest in this test. The transient tests were conducted under high and low steam flow rate respectively.

\subsubsection{Complete condensation mode (Full Height)}


To obtain the complete condensation condition, the vent line valve (VS3) to the $\mathrm{SP}$ is closed during the experiment. For a given inlet steam flow rate, the system pressure is uniquely determined by the heat removal capacity of the condenser. If the inlet steam flow rate is large, the system pressure increases to condense all the steam.

Fig. 3.4 shows the mass balance between the steam flow rate measured from vortex flow meter and the condensation rate calculated from the condensation tank level change. At the complete condensation mode, the steam flow rate must be equal to the condensation rate since the venting valve (VS3) is closed during the test. For low flow condition, i.e. steam flow rate is less than $2 \mathrm{~g} / \mathrm{s}$, votex flow meter gives a significant small steam flow rate than the condensation rate. This is the general phenomenon for the vortex flow meter. Except low flow region, steam flow rate is almost equal to condensate rate and measurement error is within $10 \%$. During the experiment, steam flow rate was selected from $1.0 \sim 4.0 \mathrm{~g} / \mathrm{s}$. Condensation rate was used as reference steam flow rate in complete condensation mode. For other two operation modes, complete condensation states were firstly established to get condensation rate as reference steam flow rate, then following cyclic venting and through flow tests were performed with same opening of isolation valve (VS1) in steam line to keep the same steam flow rate. In low flow region, great deviation of votex flow meter's reading and reference steam flow rate was observed and reference steam flow rate was selected as actual steam flow rate in the test. Fig. 3.5 shows the energy balance between the condensation heat transfer rate calculated by the condensation rate and the total heat transfer rate, which is the sum of evaporation heat transfer rate calculated by the secondary pool evaporation rate and heat loss. Heat loss value was determined by the heat loss measurement test as $173 \mathrm{~W}$. 


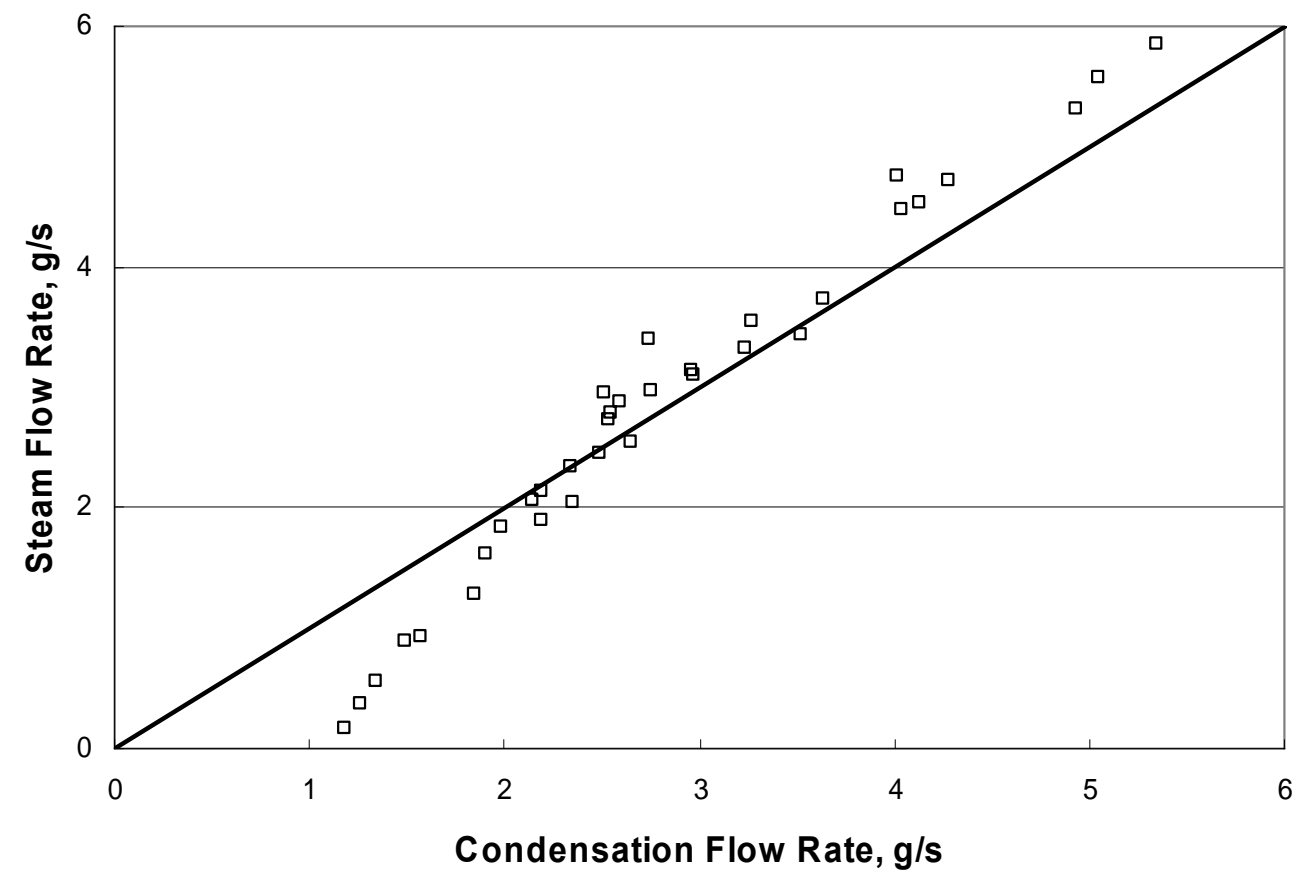

Fig. 3.4 Mass Balance for the Complete Condensation

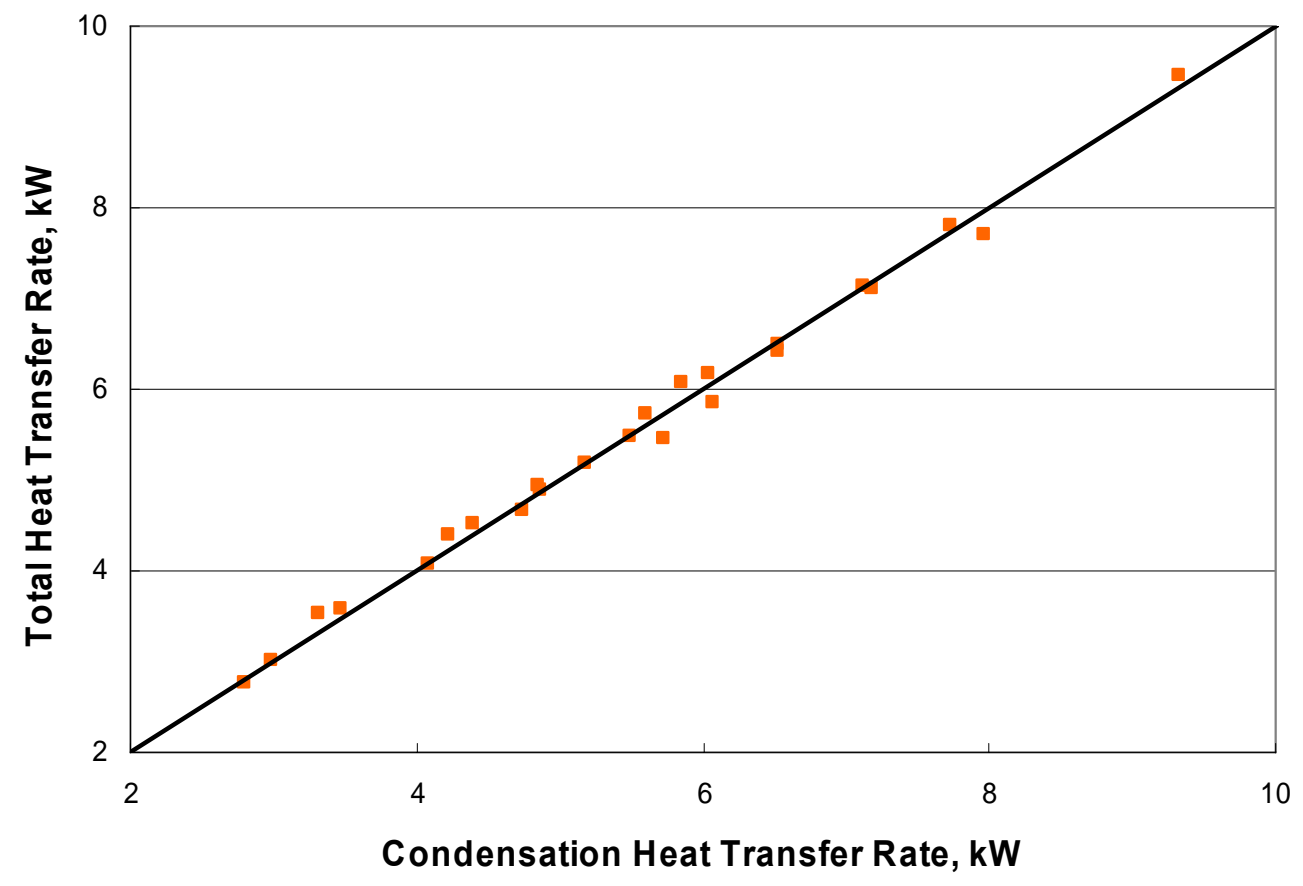

Fig. 3.5 Energy balance: Condensation vs. Evaporation + Heat Loss

Fig. 3.6 shows the comparison of condensation rate vs. system pressure between previous $26.6 \mathrm{~mm}$ test section (TS) and present $52.5 \mathrm{~mm}$ test section. A general trend 
can be observed that condensation rate increases with the increase of system pressure. When system pressure goes up, the bulk steam saturation temperature $\left(\mathrm{T}_{\text {sat }}\right)$ also increases. The temperature difference between tube inside wall $\left(\mathrm{T}_{\mathrm{wi}}\right)$ and steam saturation condition $\left(\mathrm{T}_{\mathrm{sat}}\right)$ is getting greater as the increase of pressure. This temperature difference $\left(\Delta T=T_{\text {sat }}-T_{w i}\right)$ is the driving potential of steam condensation, so condensation rate increases with the increase of driving potential $\Delta \mathrm{T}$. In complete condensation mode, $\Delta \mathrm{T}$ is uniquely determined by system pressure, the condensation rate goes up as system pressure increases.

To compare condensation performance from two test sections more directly, condensation mass flux with condensation driving potential $\Delta \mathrm{T}$ is plotted in Fig. 3.7. Condensation mass flux $\left(m_{c}^{\prime}\right)$ is defined by condensation rate over heat transfer area, as (3.19). By introducing condensation mass flux, the effect of heat transfer area of different test sections can be eliminated. From Fig. 3.7, condensation mass flux in $52.5 \mathrm{~mm}$ TS is smaller than that of $26.6 \mathrm{~mm}$ TS with same $\Delta \mathrm{T}$. This phenomenon can be explained by the smaller condensation heat transfer coefficient (HTC) in $52.5 \mathrm{~mm}$ TS compared with $26.6 \mathrm{~mm}$ TS with same $\Delta \mathrm{T}$. From (5.20), condensation mass flux can be decided by $h_{c}, \Delta \mathrm{T}$ and latent heat $h_{f g}$. When $\Delta \mathrm{T}$ is equal for both two sections, condensation mass flux is proportional to $h_{c}$, because the difference of $h_{f g}$ between two test sections is negligibly small with equal $\Delta \mathrm{T}$. From later discuss, it is shown that the heat transfer coefficient in $52.5 \mathrm{~mm}$ TS is slightly lower than that in $26.6 \mathrm{~mm}$ TS with same $\Delta \mathrm{T}$, so the condensation mass flux of $52.5 \mathrm{~mm}$ TS is smaller than that of $26.6 \mathrm{~mm}$ TS.

$$
\begin{gathered}
m_{c}^{\prime}=\frac{m_{c}}{A} \\
q^{\prime \prime}=\frac{Q}{A}=\frac{m_{c} h_{f g}}{A}=h_{c} \Delta T
\end{gathered}
$$




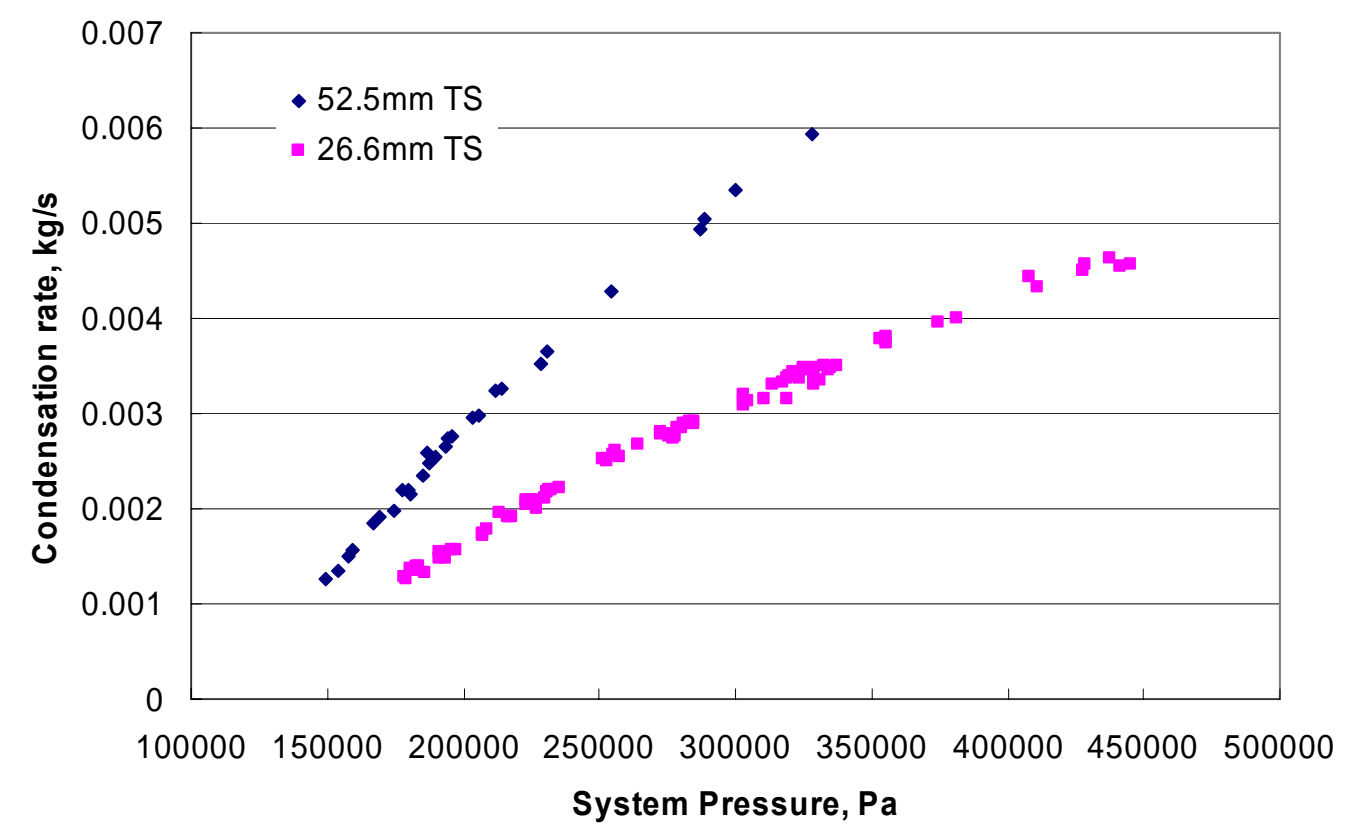

Fig. 3.6 Comparison of condensation rate between $26.6 \mathrm{~mm}$ and $52.5 \mathrm{~mm}$ TS

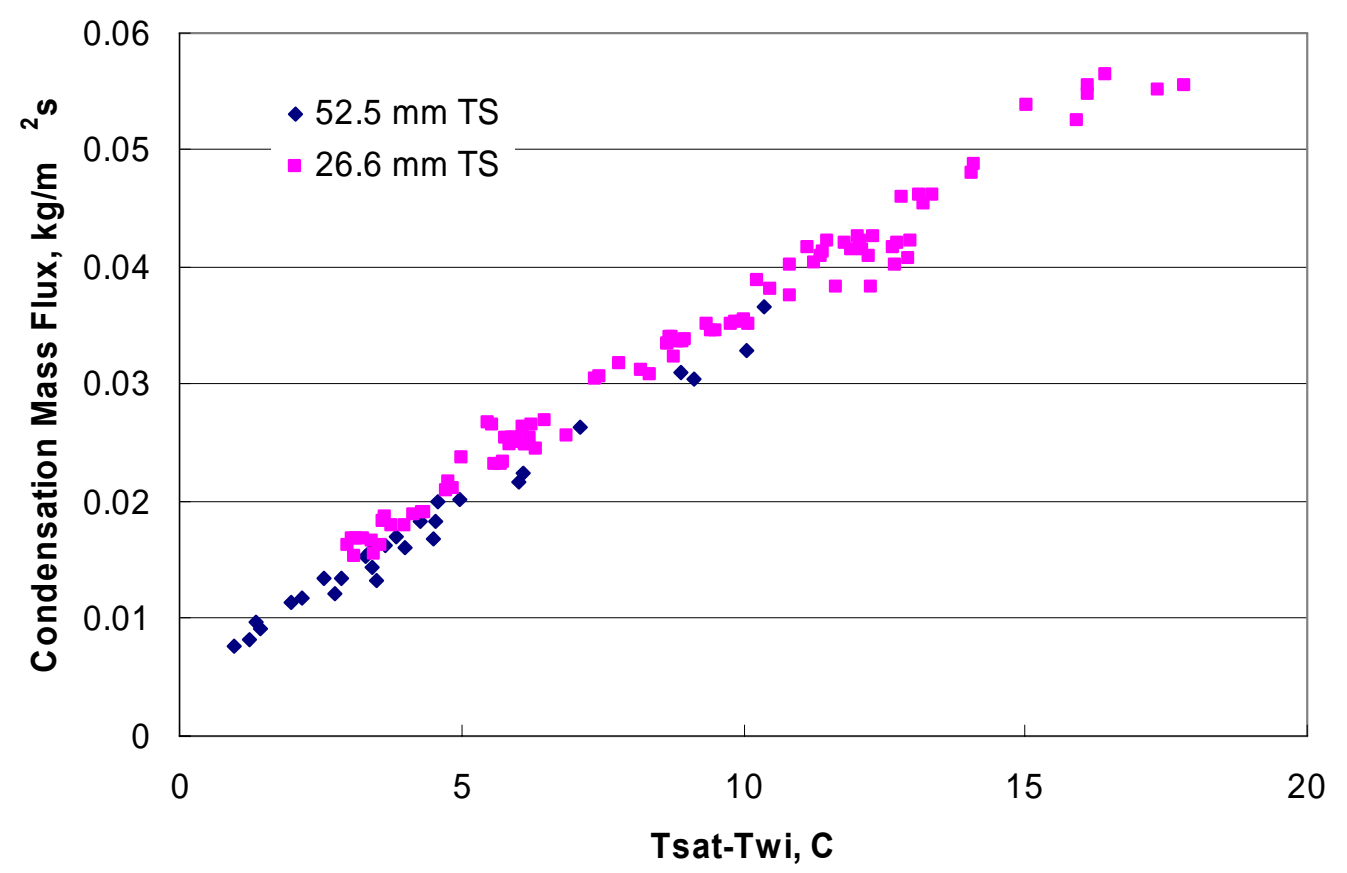

Fig. 3.7 Complete Condensation: Condensation Mass Flux vs. $\Delta \mathrm{T}$

Fig. 3.8 shows the heat transfer coefficients of condensation, secondary pool and overall heat transfer from $52.5 \mathrm{~mm}$ TS tests. Fig. 3.9 shows various heat transfer coef- 
ficients from $26.6 \mathrm{~mm}$ TS tests. The general trend of HTCs vs. system pressure is the same for both two test sections. The total heat removal rate increases with system pressure due to the larger condensation driving force $\Delta \mathrm{T}$ at high pressure condition. The tube outside wall temperature increases slightly with system pressure. So the secondary HTC increases with the same rate of heat removal. The overall HTC remains almost constant since the temperature difference (Tsat-Tpool) increases with the same rate of heat removal. The condensation HTC decreases with the increase of system pressure because liquid film around the inside tube wall is getting thicker when the heat removal rate increases. Thick liquid film increases the heat transfer resistance which results that temperature difference (Tsat-Twi) increases more rapidly than the increase of heat removal rate.

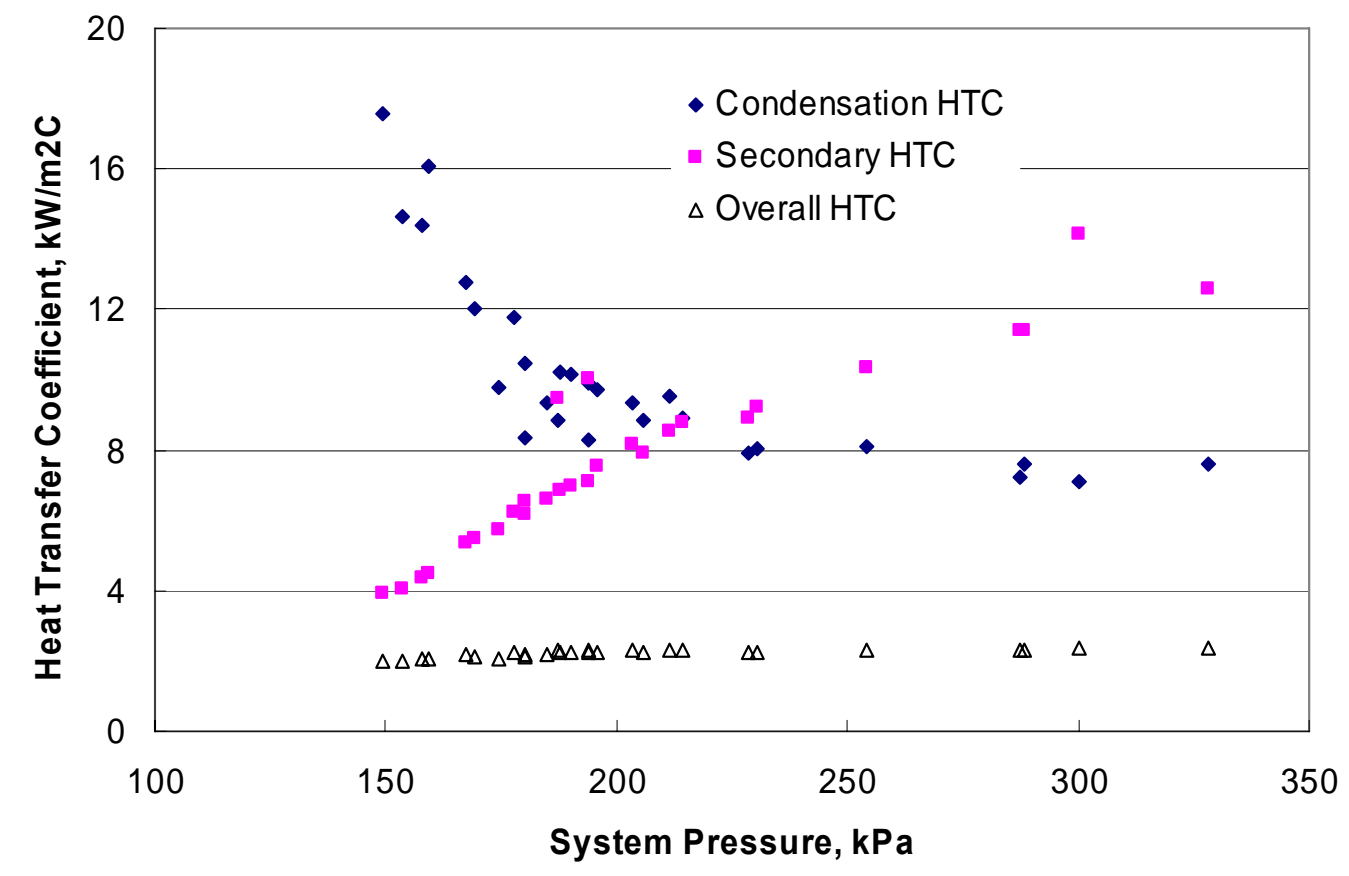

Fig. 3.8 Complete Condensation: Heat Transfer Coefficients for $52.5 \mathrm{~mm}$ TS 


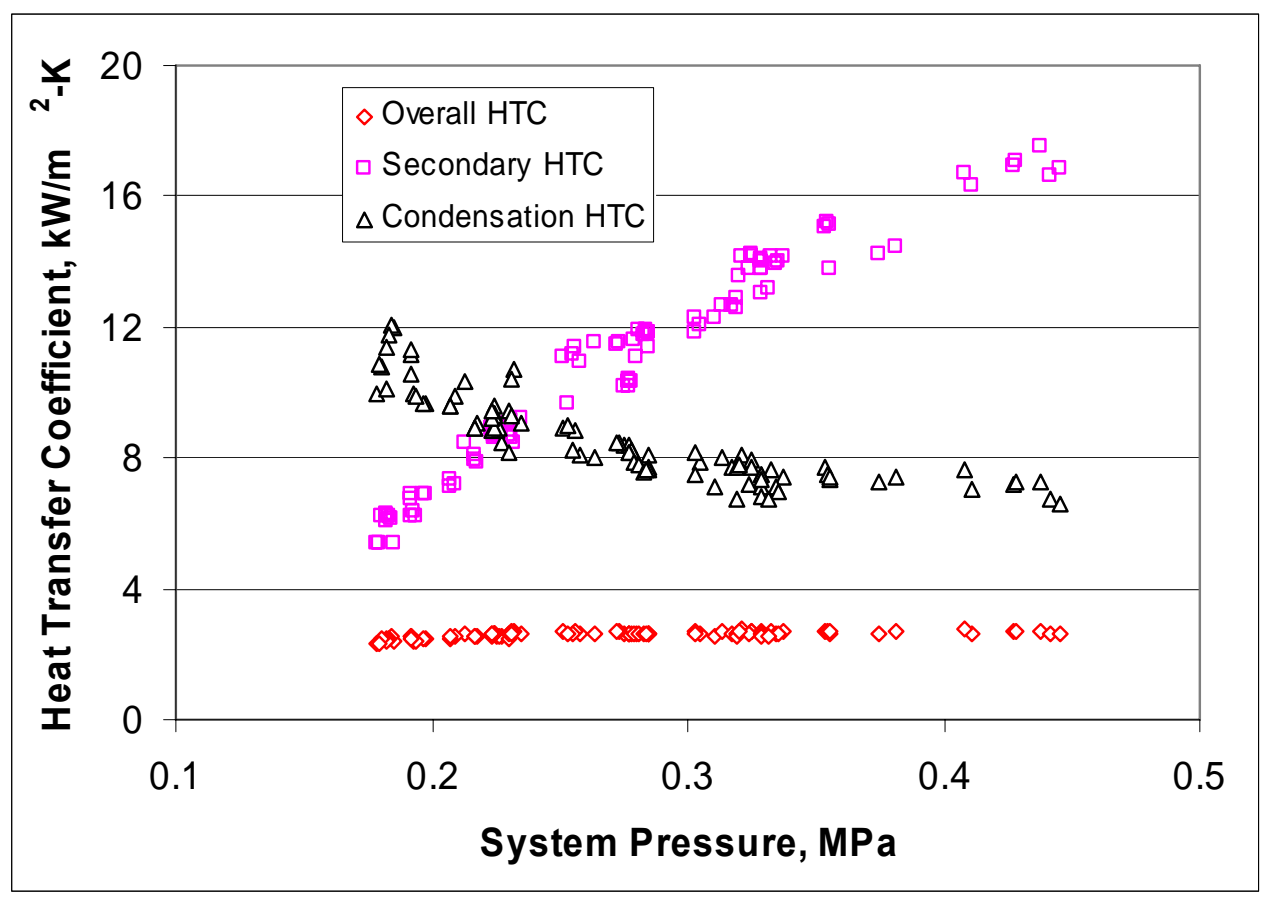

Fig. 3.9 Complete Condensation: Heat Transfer Coefficients for $26.6 \mathrm{~mm}$ TS

(From Purdue Data, 2004)

A comparison of condensation heat transfer coefficients from $52.5 \mathrm{~mm}$ TS and 26.6mm TS is shown in Fig. 3.10. The condensation heat transfer coefficient of 26.6 $\mathrm{mm}$ TS is higher than that of $52.5 \mathrm{~mm}$ TS with same $\Delta \mathrm{T}\left(\mathrm{T}_{\mathrm{sat}}-\mathrm{T}_{\mathrm{wi}}\right)$. Experiment data shows that at with same $\Delta \mathrm{T}$ condensation rate of $52.5 \mathrm{~mm}$ TS is smaller than twice of the condensation rate from $26.6 \mathrm{~mm}$ TS, which means the incoming steam flow rate for $52.5 \mathrm{~mm}$ TS is no more than twice of that for $26.6 \mathrm{TS}$. The ratio of tube cross section area between $52.5 \mathrm{~mm}$ and $26.6 \mathrm{~mm}$ TS is about 4, thus in gas region steam velocity for $52.5 \mathrm{~mm}$ is smaller than that of $26.6 \mathrm{~mm}$ TS. A higher steam velocity can bring a larger interfacial shear to reduce the liquid film thickness and heat transfer resistance. So the heat transfer resistance in $26.6 \mathrm{~mm}$ TS is less than that in $52.5 \mathrm{~mm}$ TS at same $\Delta \mathrm{T}$, which results in a higher heat transfer coefficient. This conclusion can be verified by the model analysis results and discuss again in Chapter 4 .

From classic Nusselt solution for pure steam filmwise condensation, as (3.21), the condensation heat transfer coefficient should be the same for both $52.5 \mathrm{~mm}$ TS and $26.6 \mathrm{~mm}$ TS at same $\Delta \mathrm{T}$, because the length of two condenser tubes are equal. The discrepancy between the prediction of Nusselt solution and experiment data is 
due to the assumption of stagnant vapor (zero interracial shear) in Nusselt solution is not satisfactory in the experiment. The existence of interfacial shear can reduce the liquid film thickness and heat transfer resistance which increase condensation heat transfer coefficient.

$$
h_{L}(z)=\left(\frac{4 \cdot \mu_{L} \cdot z \cdot\left(T_{I}-T_{W}\right)}{k_{L}^{3} \cdot \rho_{L} \cdot\left(\rho_{L}-\rho_{G}\right) \cdot g \cdot h_{f g}}\right)^{-1 / 4}
$$

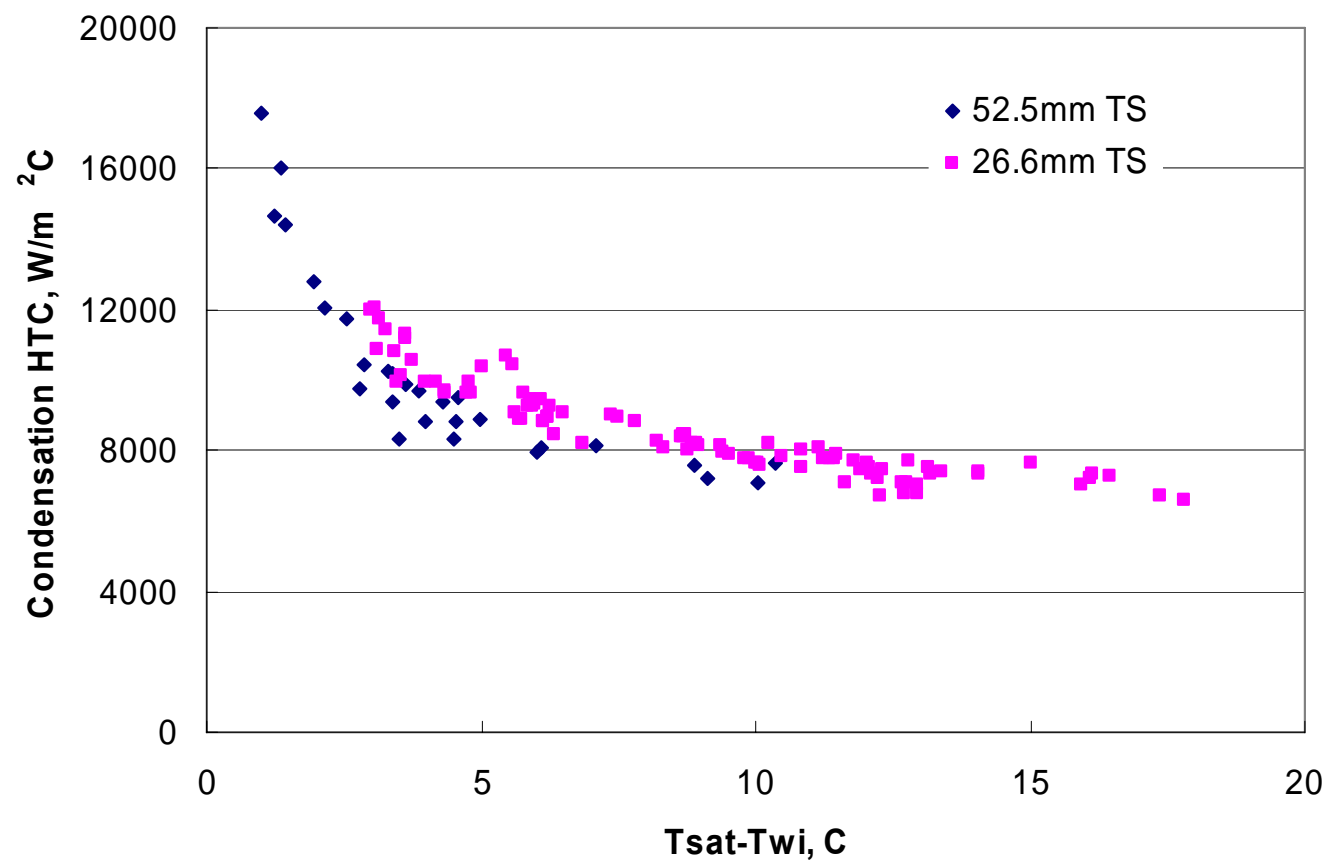

Fig. 3.10 Comparison of Condensation HTC vs. $\Delta \mathrm{T}$ between $26.6 \mathrm{~mm}$ and $52.5 \mathrm{~mm}$

\subsubsection{Cyclic venting mode (Full height)}

Cyclic venting mode is initiated from the Complete Condensation Mode by putting small amount of air. As air is accumulating in the condenser, the condensation performance is degraded and this lead to the increase of the system pressure. Besides this effect, adding the air itself also increases the system pressure. From the prototype design, the hydrostatic head is approximately 1psi according to the submergence of PCCS vent line in the SP. Our test facility is designed for $1 / 2$ height scaling, the head due to submergence of the vent line (DPvent) in the SP is 0.5 psi. So, when the pressure increases about 0.5 psi from the base pressure, the vent line valve (VS3) is 
quickly opened by manually to discharge the air and reduce the pressure. After the venting, the vent valve is quickly closed by manually. This process is repeated for the pre-determined test time.

Cyclic venting data:

Figs. 3.11-3.13 show the results of the cyclic venting mode with different amount of noncondensable gas fraction for a typical test condition of $\mathrm{P}=180 \mathrm{kPa}$, $\mathrm{Mst}=2.35 \mathrm{~g} / \mathrm{s}$. All these tests are preformed for DPvent $=0.5 \mathrm{psi}$.

Venting frequency and period are shown in Fig. 3.11 with the increase of noncondensable fraction. When the venting valve is closed, noncondensable gas is aaccumulated in the condenser tube. The system pressure keeps rising until DPvent is reached and venting valve is opened manually. Higher noncondensable gas fraction can result in a faster accumulation of noncondensable gas in the condenser tube and accelerate the rise of system pressure so that DPvent can be reached more quickly. Hence, venting frequency keeps rising with noncondensable gas fraction. Venting period is the inverse of venting frequency and thus decreases with noncondensable gas fraction. If the noncondensable gas fraction is large enough, the venting period will go to zero. It means the continuous venting, i.e., through flow mode. On the opposite, if the noncondensable gas fraction goes to zero, the venting period will go to the infinite. It means no venting, i.e., continuous condensation mode. Therefore, through flow mode and continuous condensation mode can be considered as one of the limiting condition of the cyclic venting mode.

Fig. 3.12 shows the condensation rate and Fig. 3.13 shows the condensation heat transfer coefficient. It is obvious that then condensation performance is degraded with the noncondensable gas fraction. Both condensation rate and condensation HTC decrease with the increase of noncodensable gas. The condensation becomes deteriorating due to the rising of mass transfer resistance coming from the accumulation of noncondensable gas in condenser tube. 


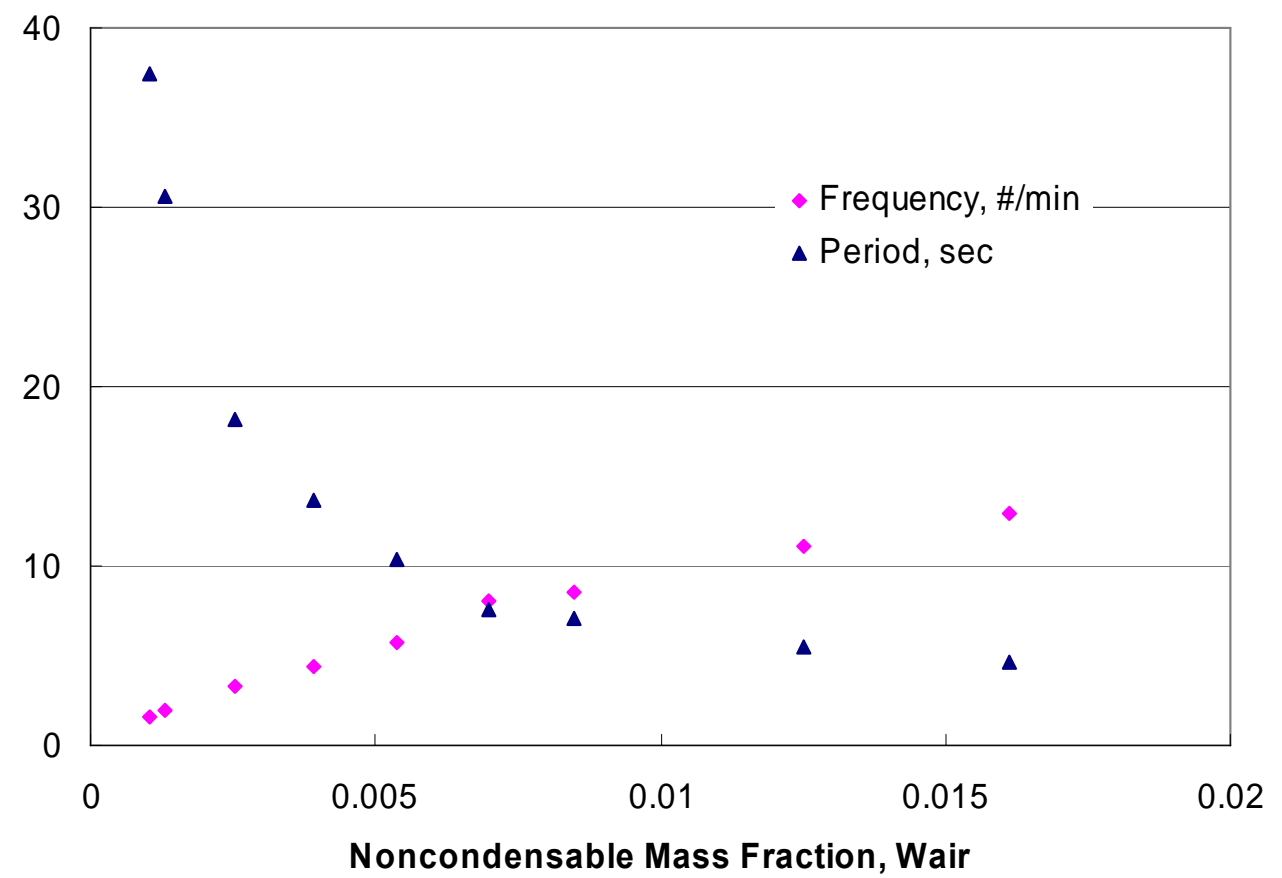

Fig. 3.11 Venting Frequency and Period for $\mathrm{P}=180 \mathrm{kPa}, \mathrm{Mst}=2.35 \mathrm{~g} / \mathrm{s}$

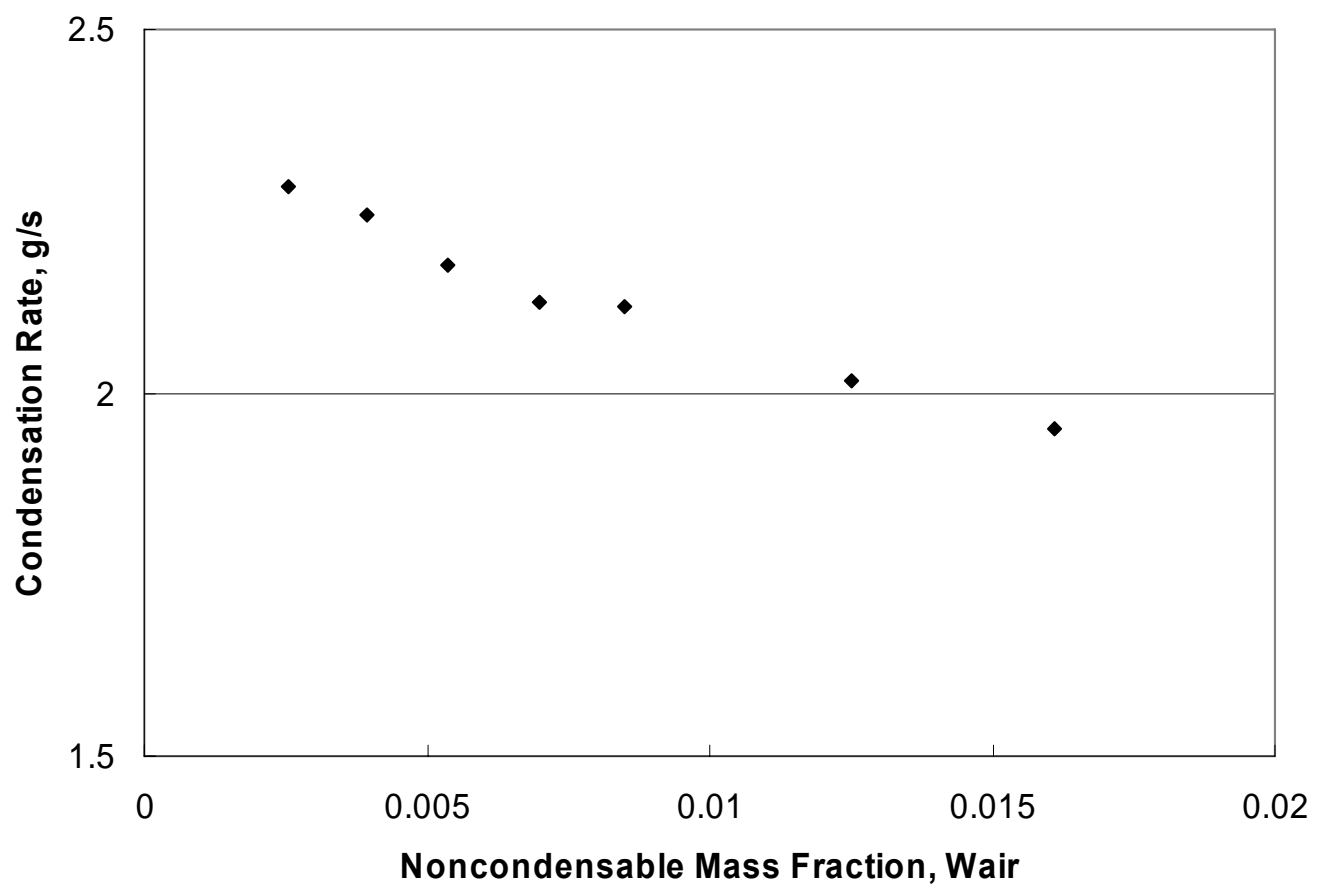

Fig. 3.12 Cyclic Venting: Condensation Rate for $\mathrm{P}=180 \mathrm{kPa}, \mathrm{Mst}=2.35 \mathrm{~g} / \mathrm{s}$ 


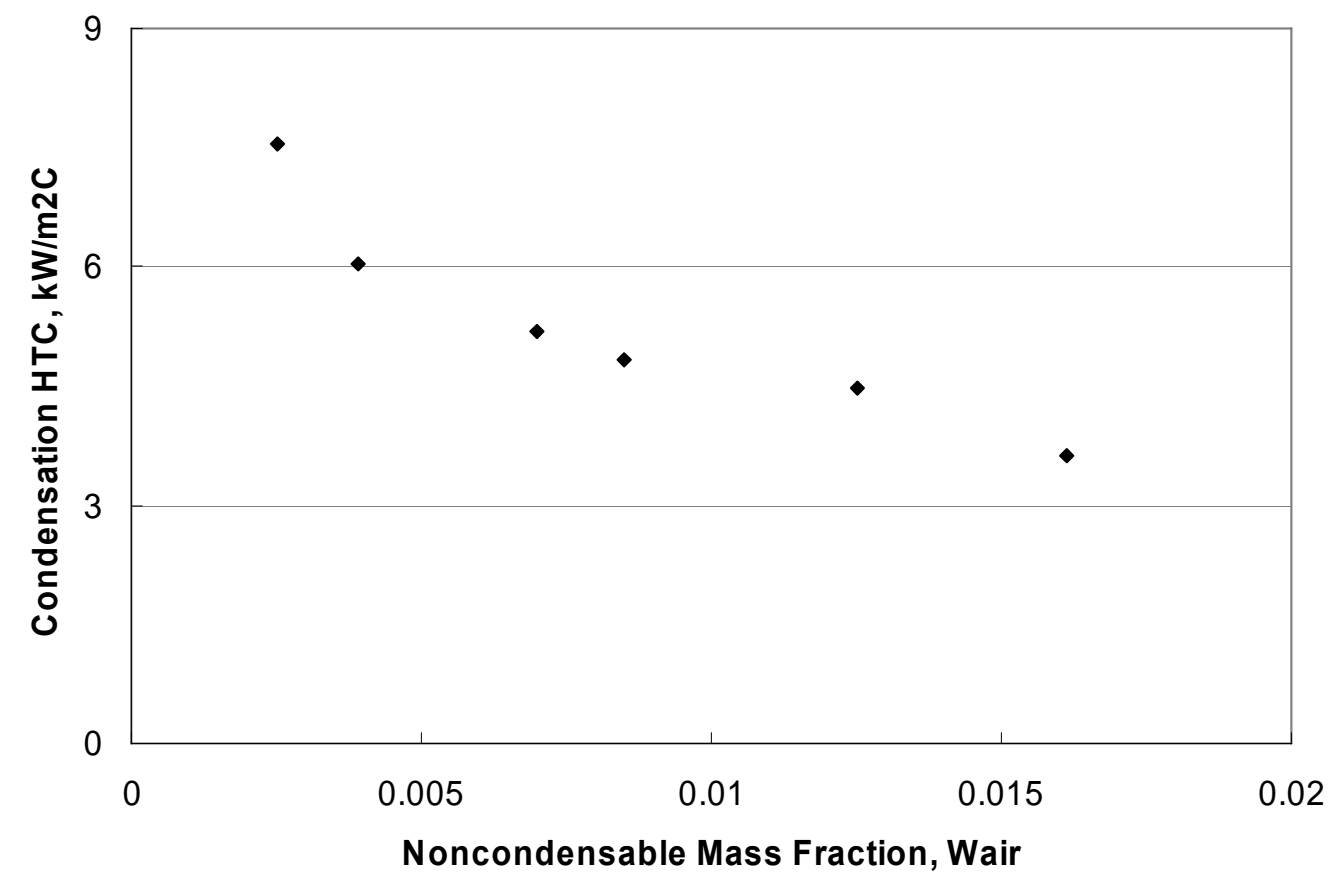

Fig. 3.13 Cyclic Venting: Condensation HTC for $\mathrm{P}=180 \mathrm{kPa}$, Mst=2.35g/s

Figs. 3.14-3.15 show the venting frequencies and periods at different pressure. It is clear that venting frequency increase with system pressure for a given noncondnesable mass fraction. Then trend of periods with system pressure is just on the opposite. At high pressure condition, noncondensable gas flow rate is larger due to the high steam flow rate. The accumulation of noncondensable gas is faster than low pressure condition in condenser tube. Hence, venting happens more frequently and venting period is shorter. 


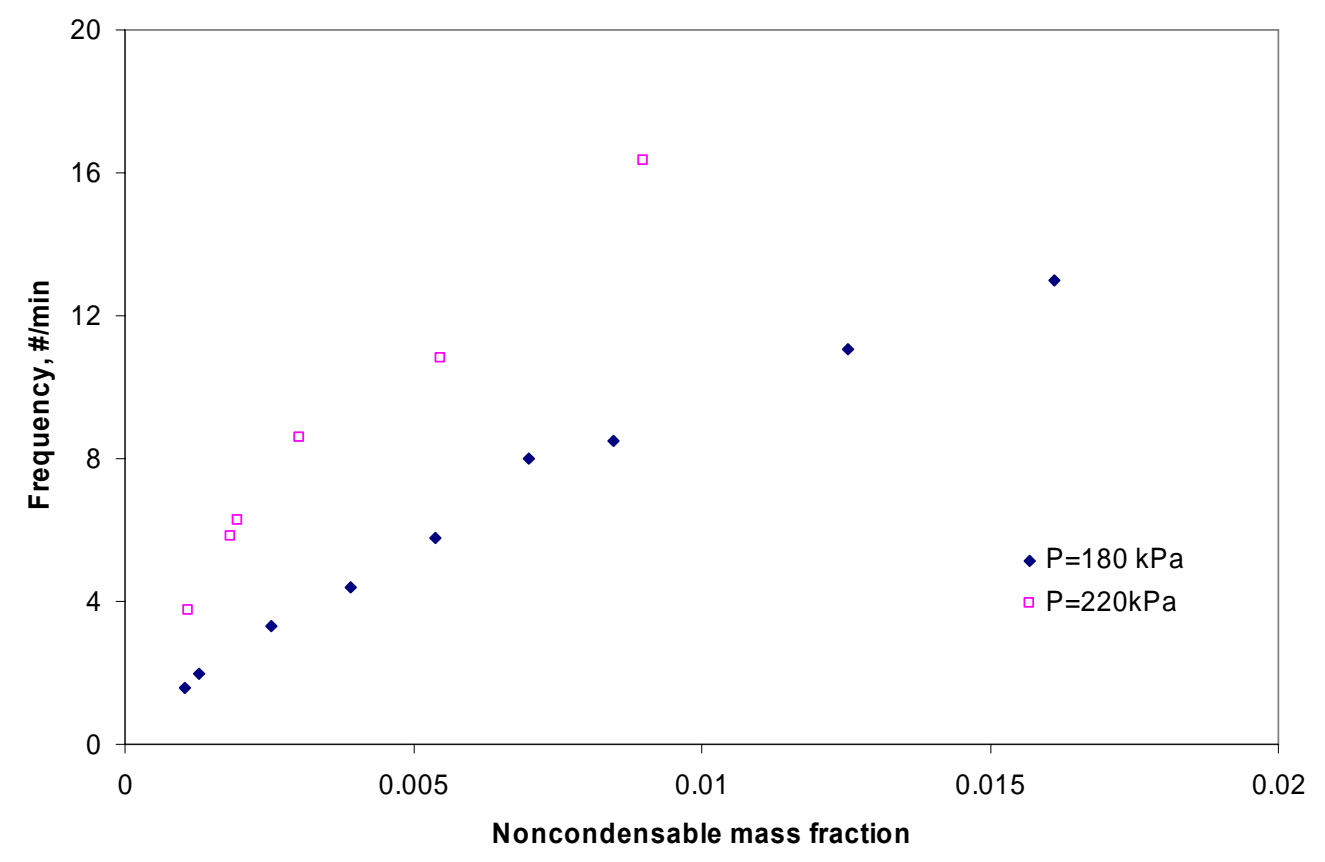

Fig. 3.14 Comparison of venting frequency for different pressures

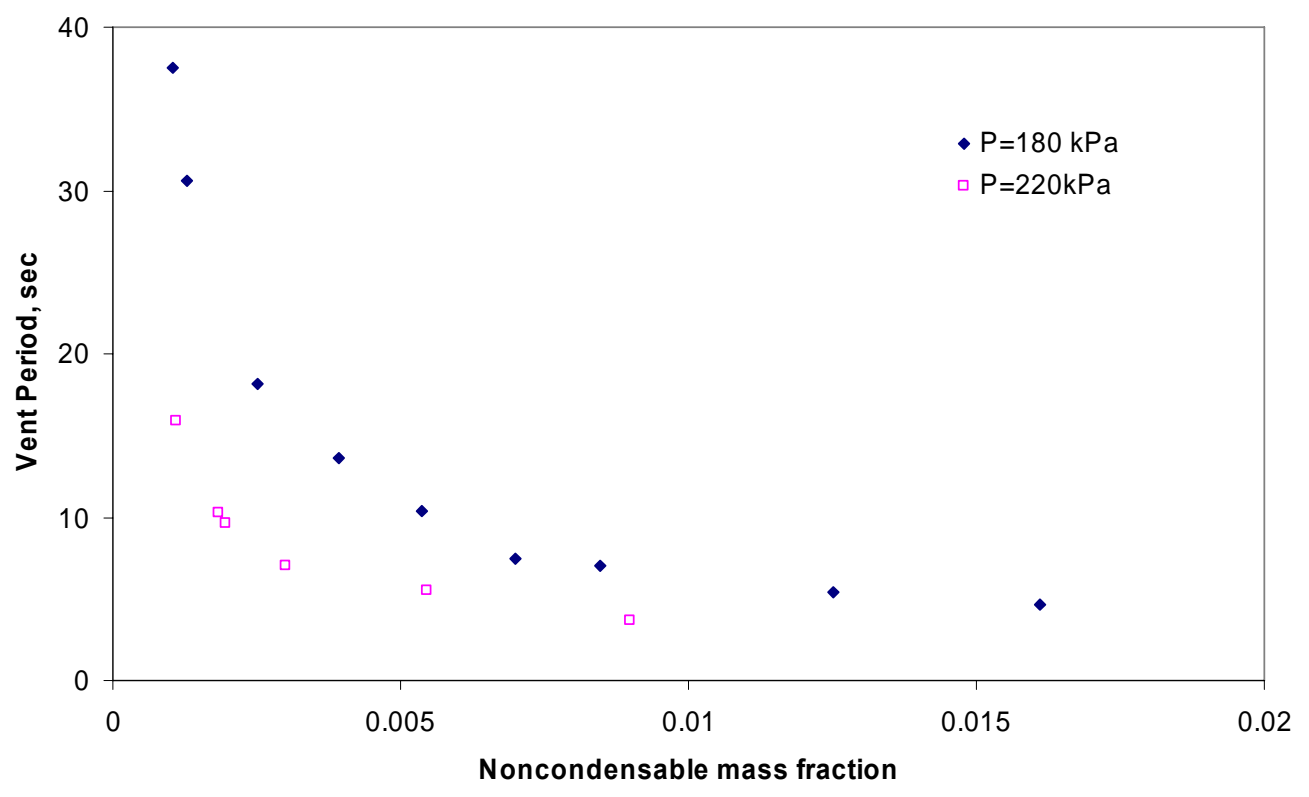

Fig. 3.15 Comparison of venting period for different pressures

Complete Condensation + Cyclic Venting + Through Flow Data 
Fig 3.16-3.23 show results of the 3 PCCS operation modes, i.e., complete condensation, cyclic venting and through flow mode. For a given system pressure and steam flow rate, tests for three modes were conducted. In those figures, 4 sets of data for different system pressure $(235,220,190,150 \mathrm{kPa})$ are presented. For each pressure condition, condensation rate and condensation heat transfer coefficient are shown.

In each single run, the test starts from complete condensation mode. In complete condensation test, venting valve (VS3) was closed and no air was supplied to experiment loop. All steam was condensed in condenser tube and System pressure was uniquely determined by incoming steam flow rate. From this complete condensation mode, cyclic venting was tested by flowing small amount of air into loop. The system pressure begins rising once venting valve (VS3) was closed. When the system pressure reaches the level of base pressure+DPVent, VS3 is opened manually to vent noncondensable gas. As the system pressure drops back to the base pressure, VS3 is closed and system pressure starts rising again. This process is repeated for the predetermined test time. As noncondensable fraction increase to a remarkable level, cyclic venting mode can not be realized any more due to high venting frequency and through flow mode was achieved. In through flow mode test, venting valve (VS3) was always open to maintain the system pressure.

From the figures showing the condensation rate and the condensation HTC, the condensation performance degraded due to the existence the noncondensable gas. Condensation rate and condensation HTC keep decreasing as noncondensable gas fraction increases. It should be also noted that the cyclic venting mode data and through flow data can be joined smoothly at the maximum noncondensable gas fraction for the venting mode. This phenomenon is shown very well in the Figs. 3.16-3.17. For this data set, the through flow mode data are obtained for very low noncondensable gas fraction to compare directly with cyclic venting mode. As shown in these figures, there is almost no difference between the through flow and cyclic venting mode.

It should be noted that the cyclic venting data obtained from current test loop can not be directly used for prototype condition since the DW volume is not properly scaled. If the DW volume is well scaled in current loop, i.e., there is a large DW vol- 
ume, it will take long time to accumulate the $\mathrm{NC}$ gas in condenser, which results in longer venting period and lower condensation performance.

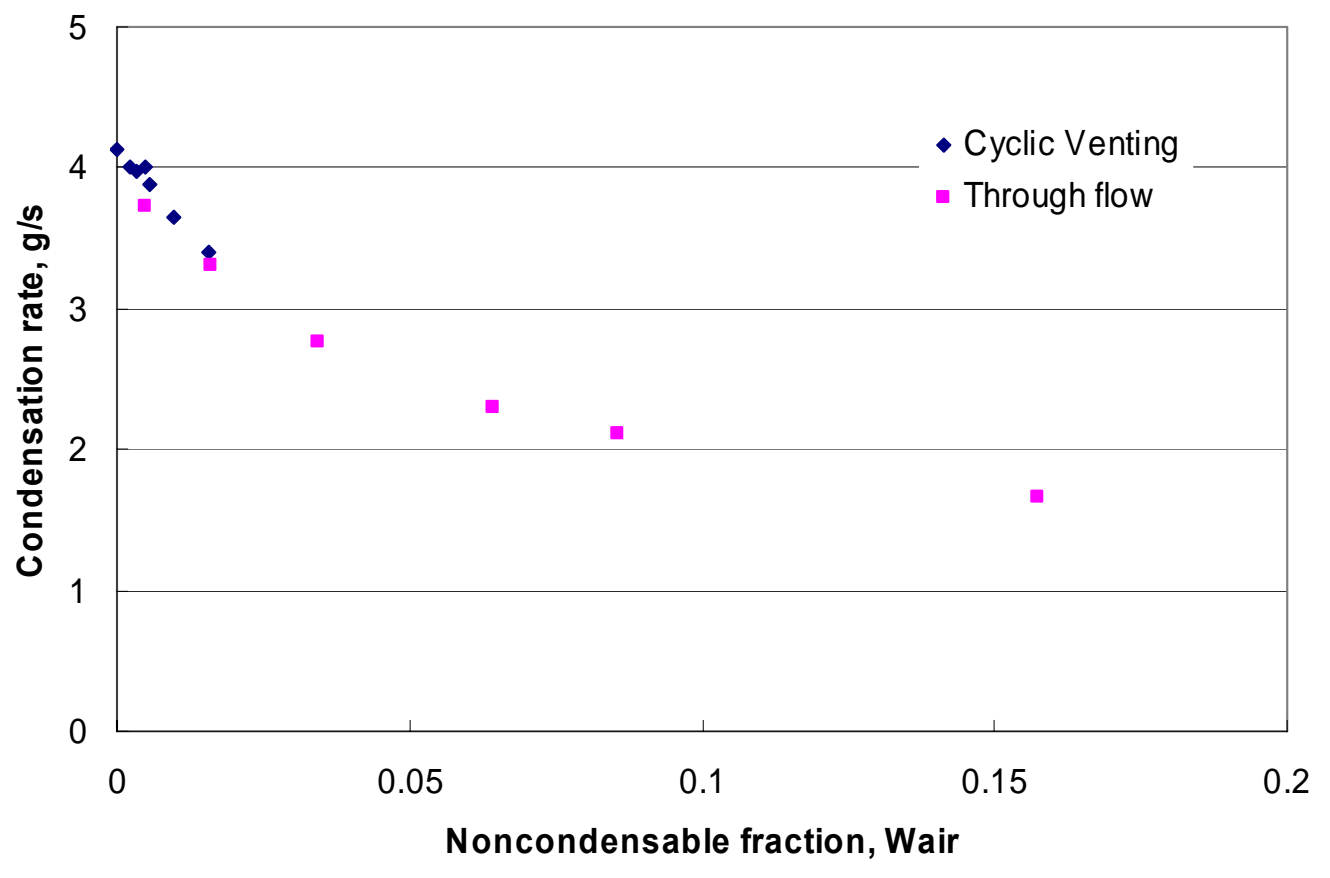

Fig. 3.16 Condensation Rate for $\mathrm{P}=235 \mathrm{kPa}$

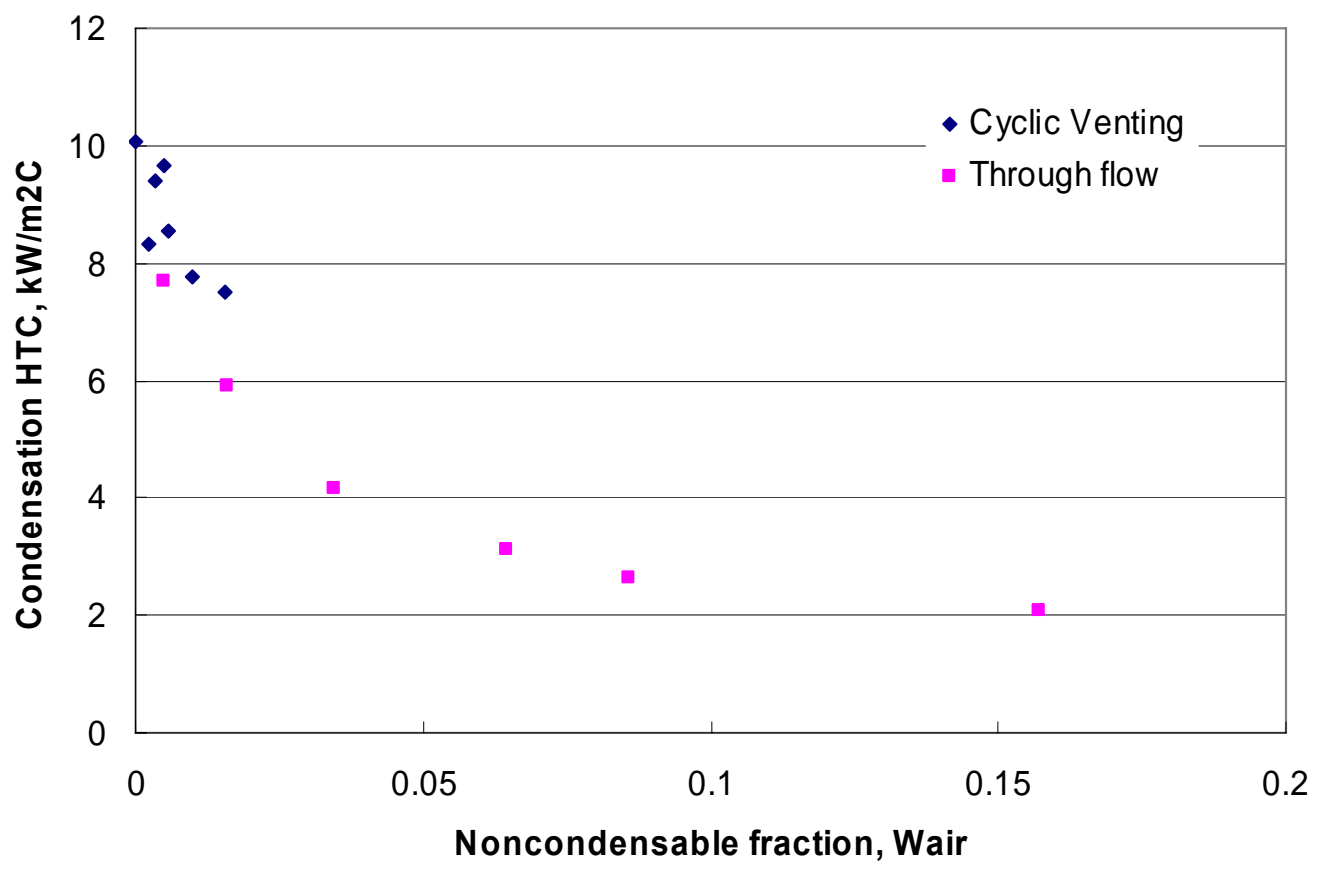

Fig. 3.17 Condensation $\mathrm{HTC}$ for $\mathrm{P}=235 \mathrm{kPa}$ 


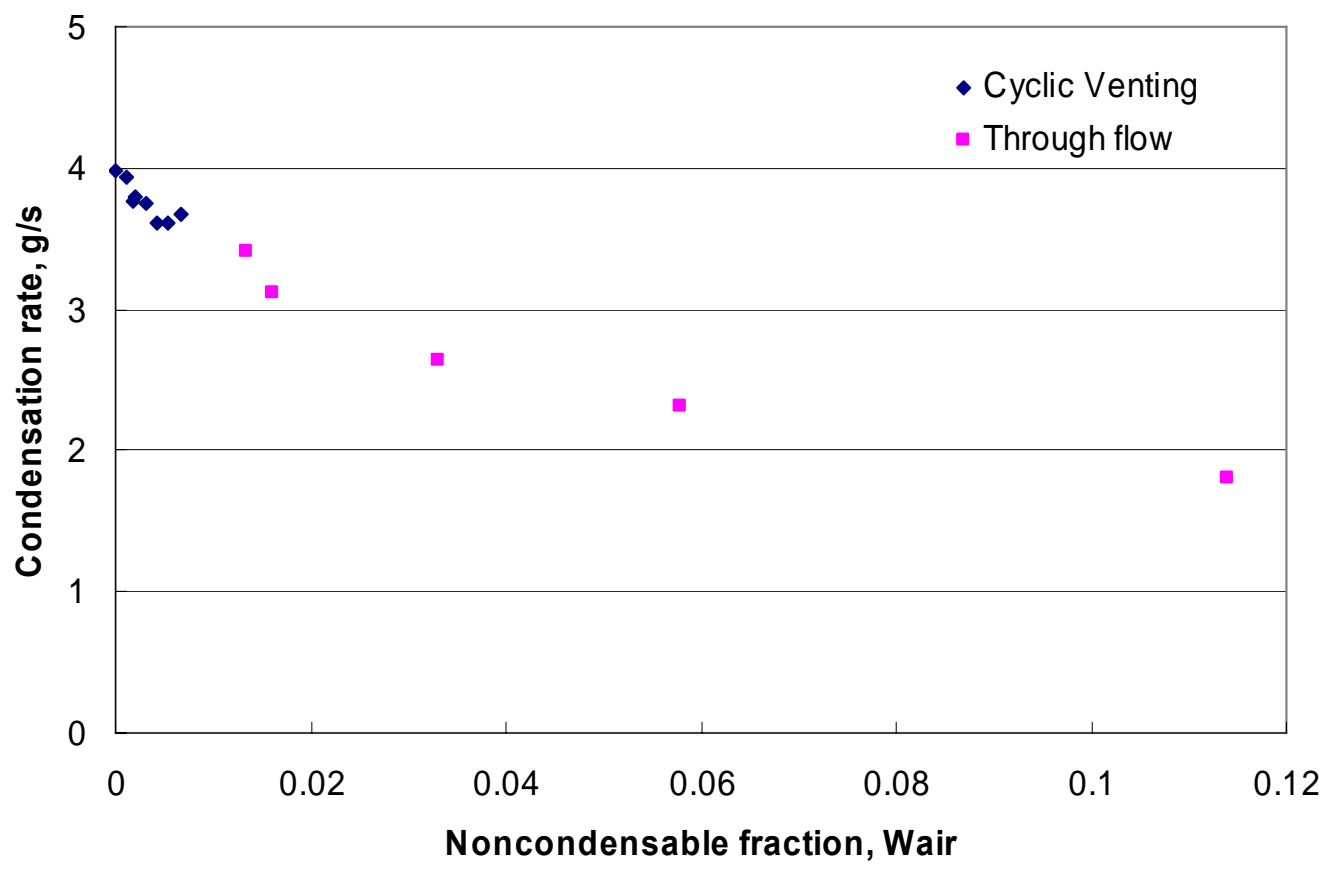

Fig. 3.18 Condensation Rate for $\mathrm{P}=220 \mathrm{kPa}$

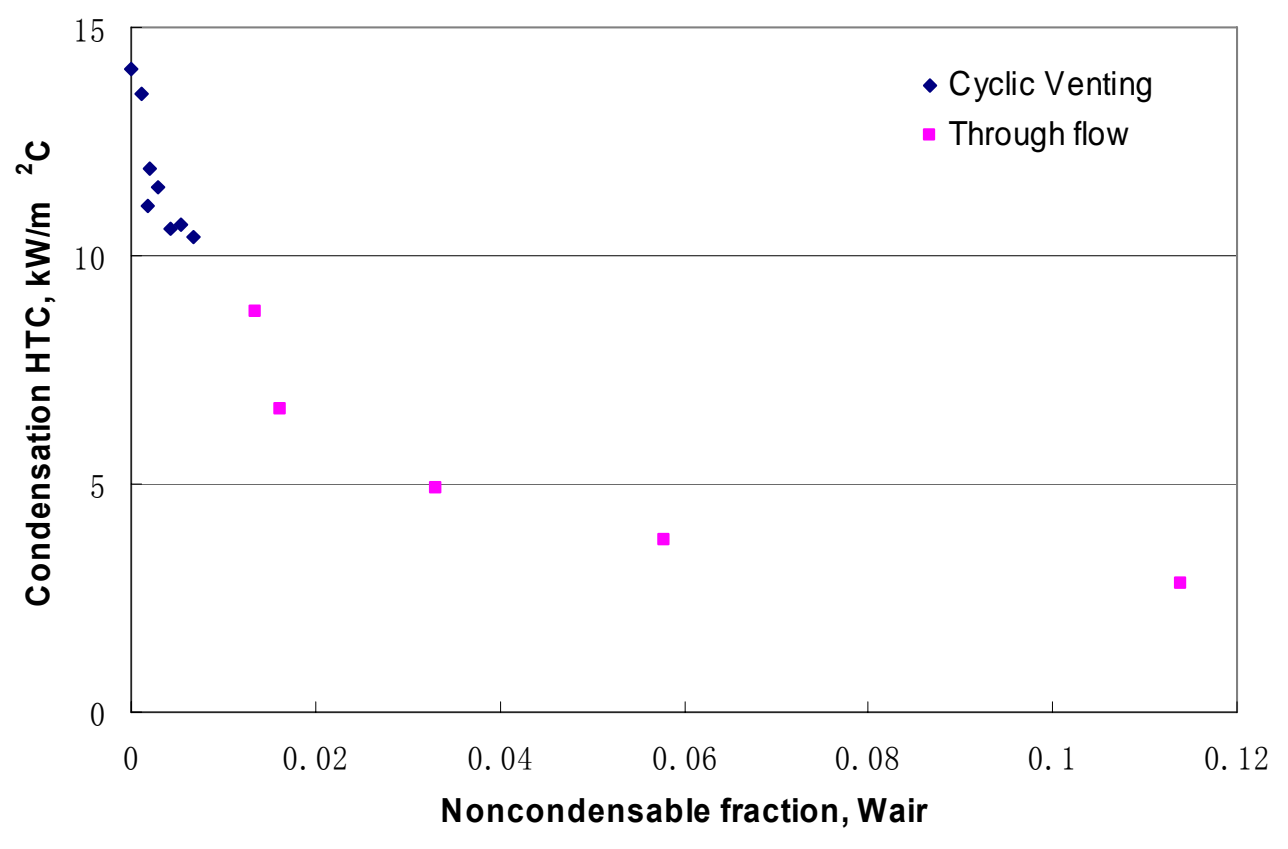

Fig. 3.19 Condensation $\mathrm{HTC}$ for $\mathrm{P}=220 \mathrm{kPa}$ 


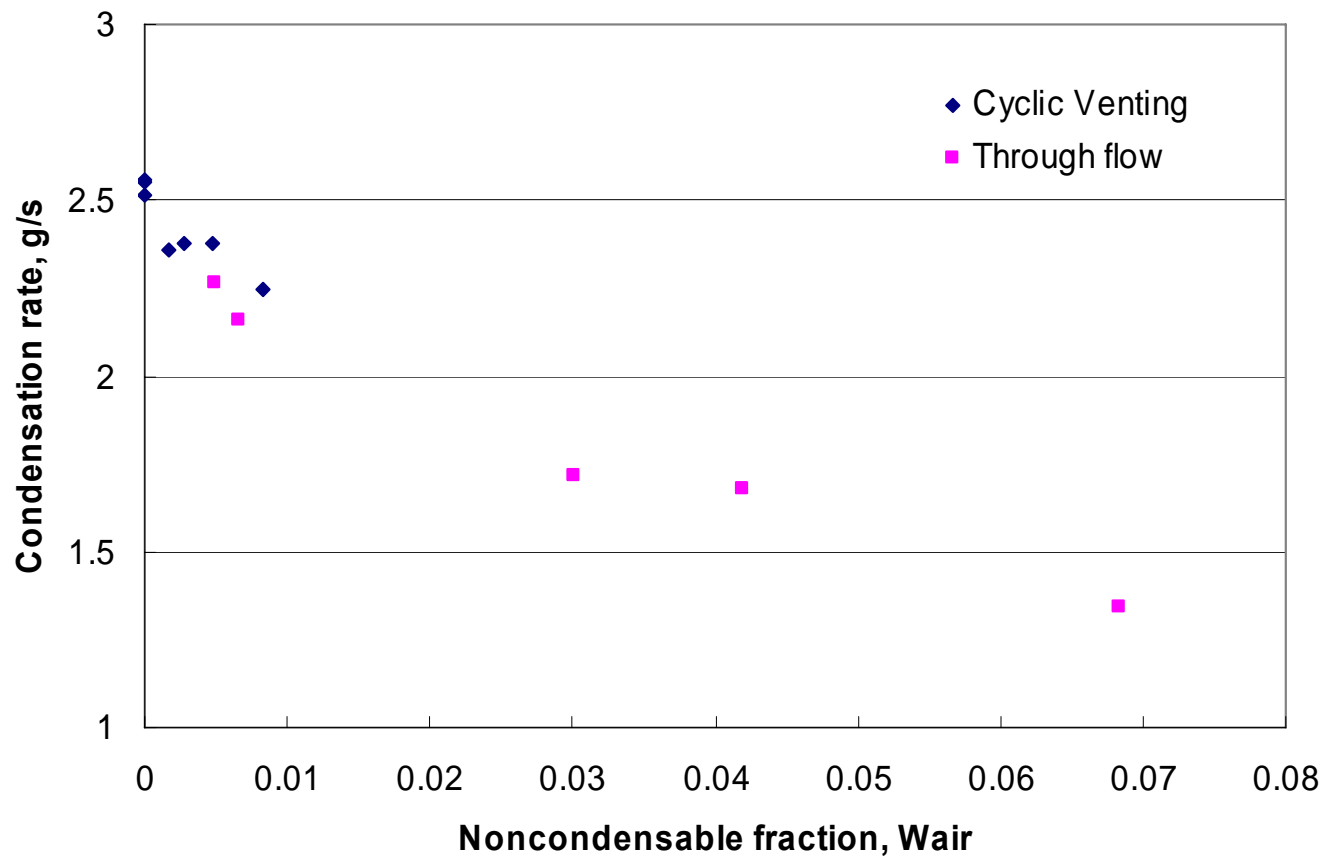

Fig. 3.20 Condensation Rate for $\mathrm{P}=190 \mathrm{kPa}$

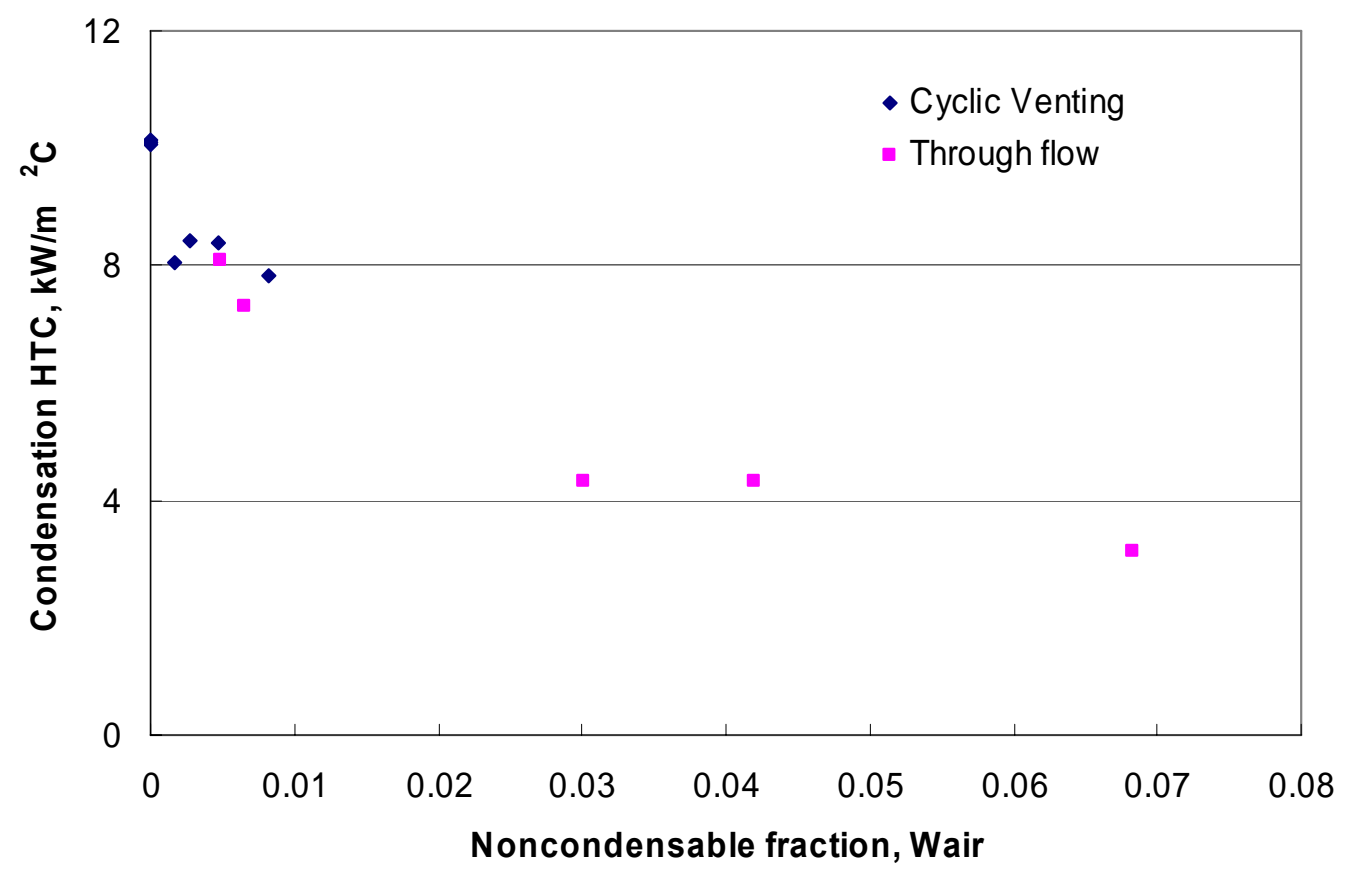

Fig. 3.21 Condensation HTC for $\mathrm{P}=190 \mathrm{kPa}$ 


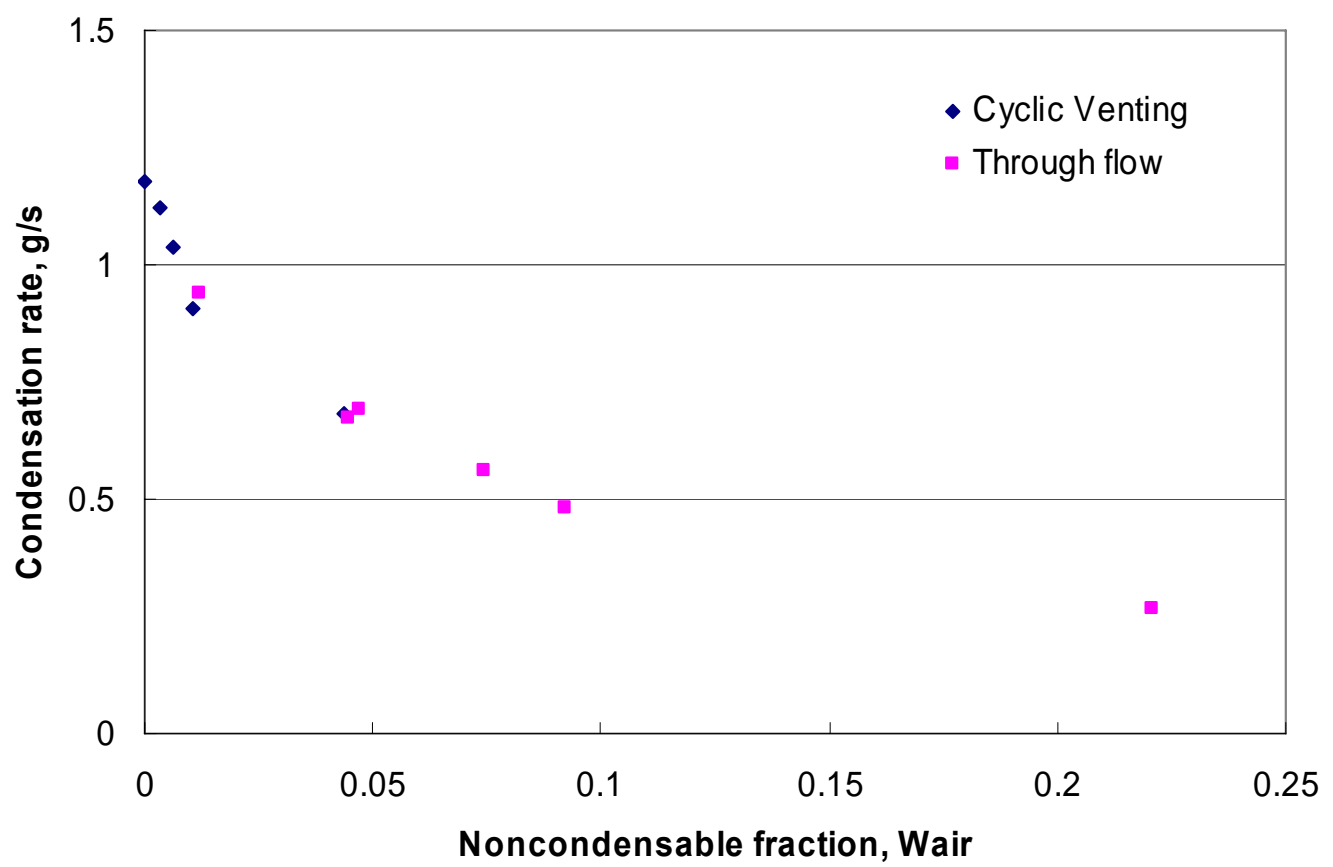

Fig. 3.22 Condensation Rate for $\mathrm{P}=150 \mathrm{kPa}$

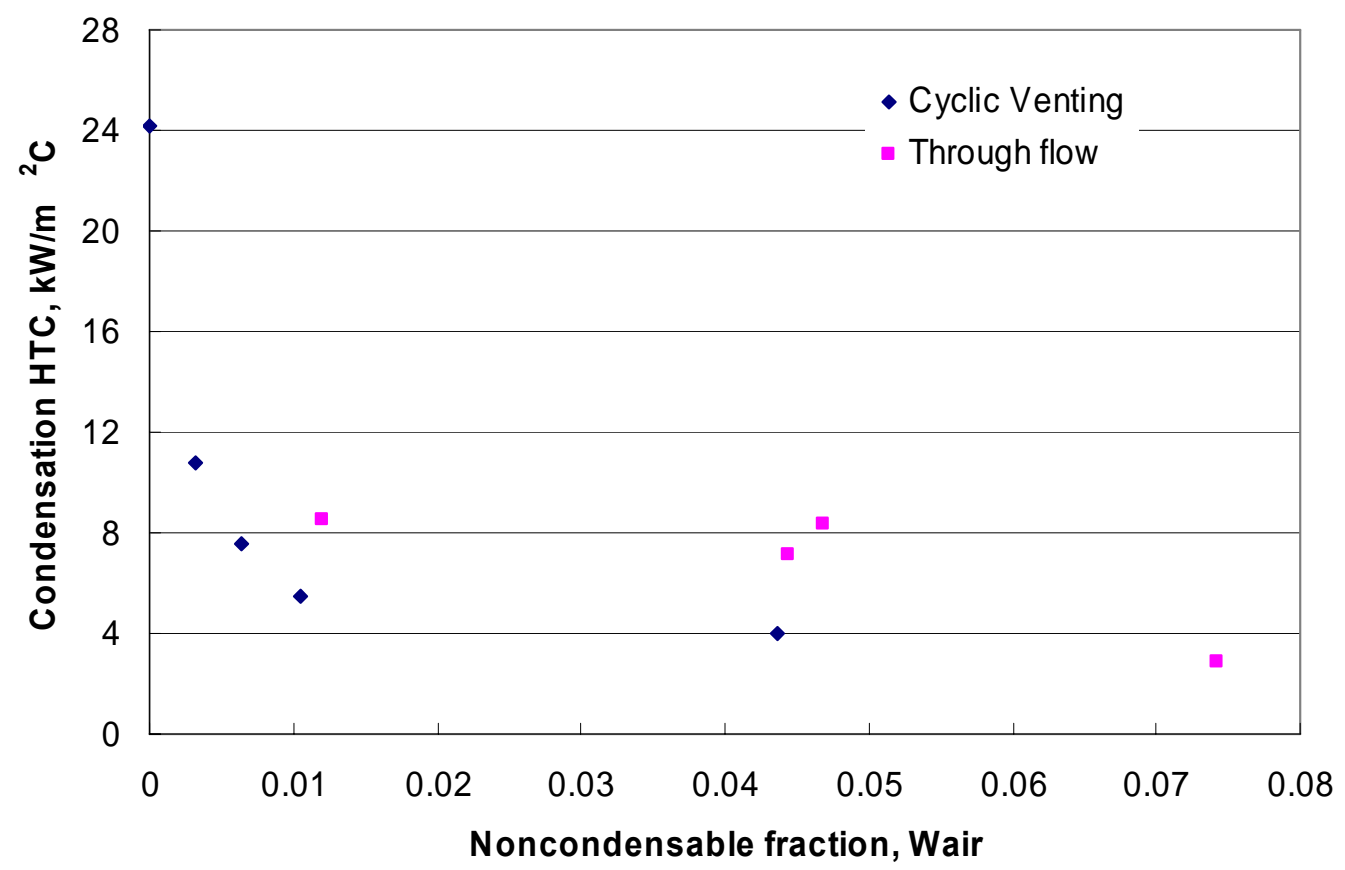

Fig. 3.23 Condensation HTC for $\mathrm{P}=150 \mathrm{kPa}$

Generally, the condensation degrades with the increase of noncondensable fraction. The results from different pressure condition gave the same trend of condensa- 
tion rate and condensation heat transfer coefficient. However, at low pressure condition, such as $\mathrm{P}=150 \mathrm{kPa}$, the heat flux is small so that temperature difference between primary and secondary sides of condenser tube is small. A large error for the temperature difference between outside wall and pool was introduced by the measurement errors of temperatures. Because the heat transfer coefficient was calculated from this $\Delta \mathrm{T}$, the error is propagated to the heat transfer coefficient and the calculation results for HTC scattered intensely, as shown in Fig. 3.23. For high pressure condition, a clear decreasing trend of HTC with the increase of noncondensable fraction is shown in those figures.

\subsubsection{Through Flow Mode}

For the through flow mode, the vent line valve (VS3) was always open to vent the air and the uncondensed steam to the SP. Some data for the through flow mode has been already presented in the previous section to compare with the cyclic venting mode data. In this section, additional data are shown to investigate the effects of the non- condensable gas mass fraction, system pressure and inlet steam flow rate.

\section{$\underline{\text { Pure Steam Data as a Function of Pressure }}$}

Figs. 3.24-3.25 show the effect of system pressure for pure steam condition (inlet steam flow rate $=4.0 \mathrm{~g} / \mathrm{s}$ ) for through flow mode. As shown in Fig. 3.24, the condensation rate almost linearly increases with system pressure, which means heat removal capacity of condenser tube also linearly increases with system pressure. Driving force of the condensation performance is the difference between the condenser saturation temperature and secondary pool temperature. Since the secondary pool temperature is maintained with constant temperature and the condenser saturation temperature almost linearly increases with system pressure, the condensation performance, i.e., the condensation rate also linearly increases with system pressure. Fig. 3.25 shows the various heat transfer coefficients with system pressure. Overall HTC is almost constant with system pressure because $\left(\mathrm{T}_{\mathrm{sat}}-\mathrm{T}_{\mathrm{p}}\right)$ increases with the same rate of heat removal. Secondary HTC increases with the same rate of heat removal, i.e., system pressure because $\left(\mathrm{T}_{\mathrm{wo}}-\mathrm{T}_{\mathrm{p}}\right)$ increases slightly with system pressure. Condensation HTC decreases with system pressure because liquid film thickness inside the tube is greater 
at high pressure condition which increases the heat transfer resistance so that $\left(\mathrm{T}_{\mathrm{sat}}-\mathrm{T}_{\mathrm{wi}}\right)$ increases more rapidly than the increase of heat removal rate. This trend is very similar to the results of complete condensation mode as shown in Figs. 3.6 and 3.8.

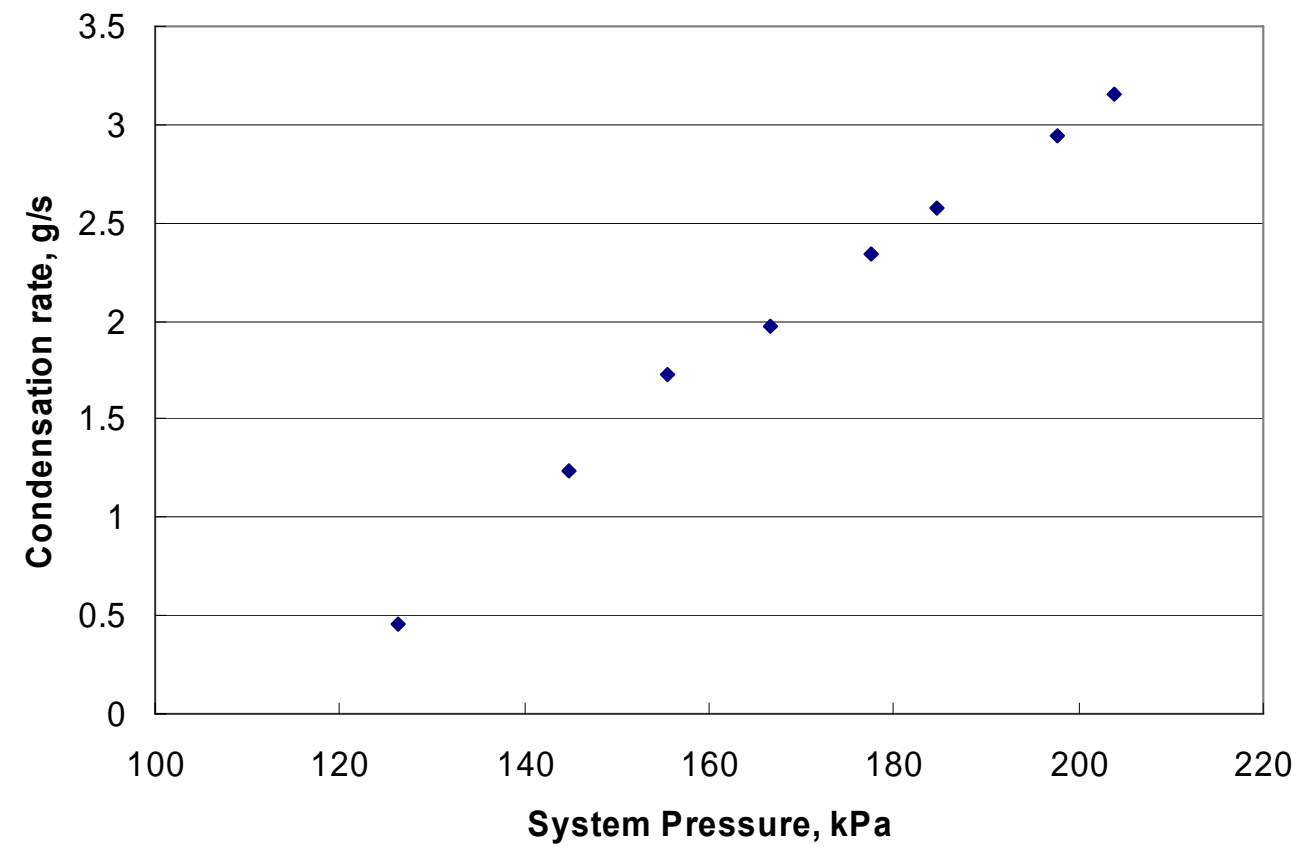

Fig. 3.24 Pure Steam Through Flow: Condensation Rate, Mst=4.0 g/s

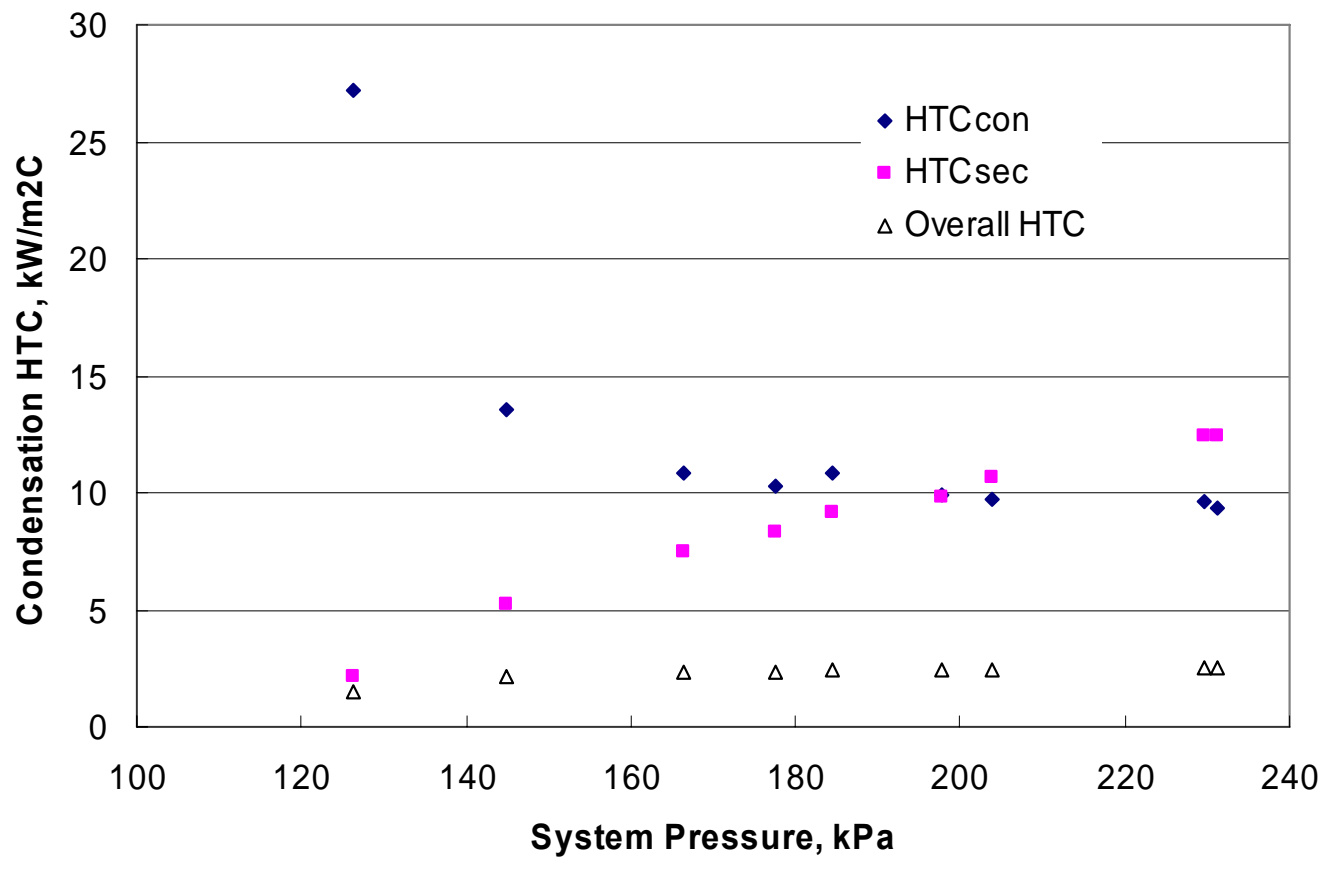

Fig. 3.25 Pure Steam Through Flow: Condensation HTC, Mst=4.0 g/s 


\section{$\underline{\text { Effect of Noncondensable Gas }}$}

Figs. 3.26-3.27 show the effects of noncondensable gas mass fraction when system pressure is $200 \mathrm{kPa}$, inlet steam flow rate is $4.0 \mathrm{~g} / \mathrm{s}$. As shown in these figures, condensation rate and condensation HTC decrease with noncondensable gas concentration. Only small amount of the noncondensable gas can significantly degrade the performance of the condensation. Since the noncondensable gas is impermeable to the liquid film, it is accumulated at the film-gas interface so its concentration is very high. This high noncondensable gas concentration region is propagating to the gas core region by mass diffusion. So the boundary layer thickness is thicker and the concentration level is increasing with the condenser tube length. Steam in the gas core region must diffuse long distance in high noncondensable gas concentration boundary layer to condense at the interface. The developing noncondensable gas boundary layer acts as a strong resistance to the condensation.

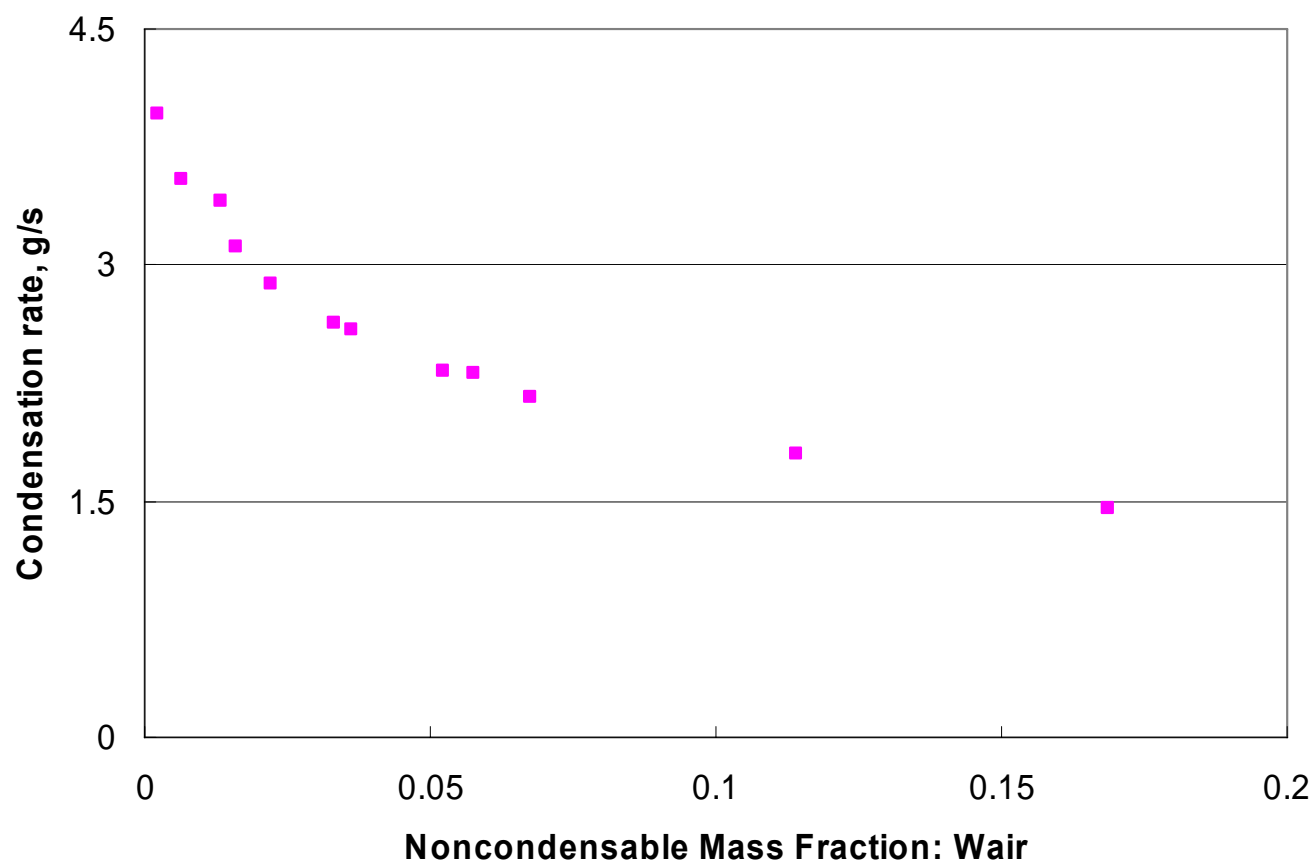

Fig. 3.26 Through Flow: Condensation Rate at $\mathrm{P}=200 \mathrm{kPa}, \mathrm{Mst}=4.0 \mathrm{~g} / \mathrm{s}$ 


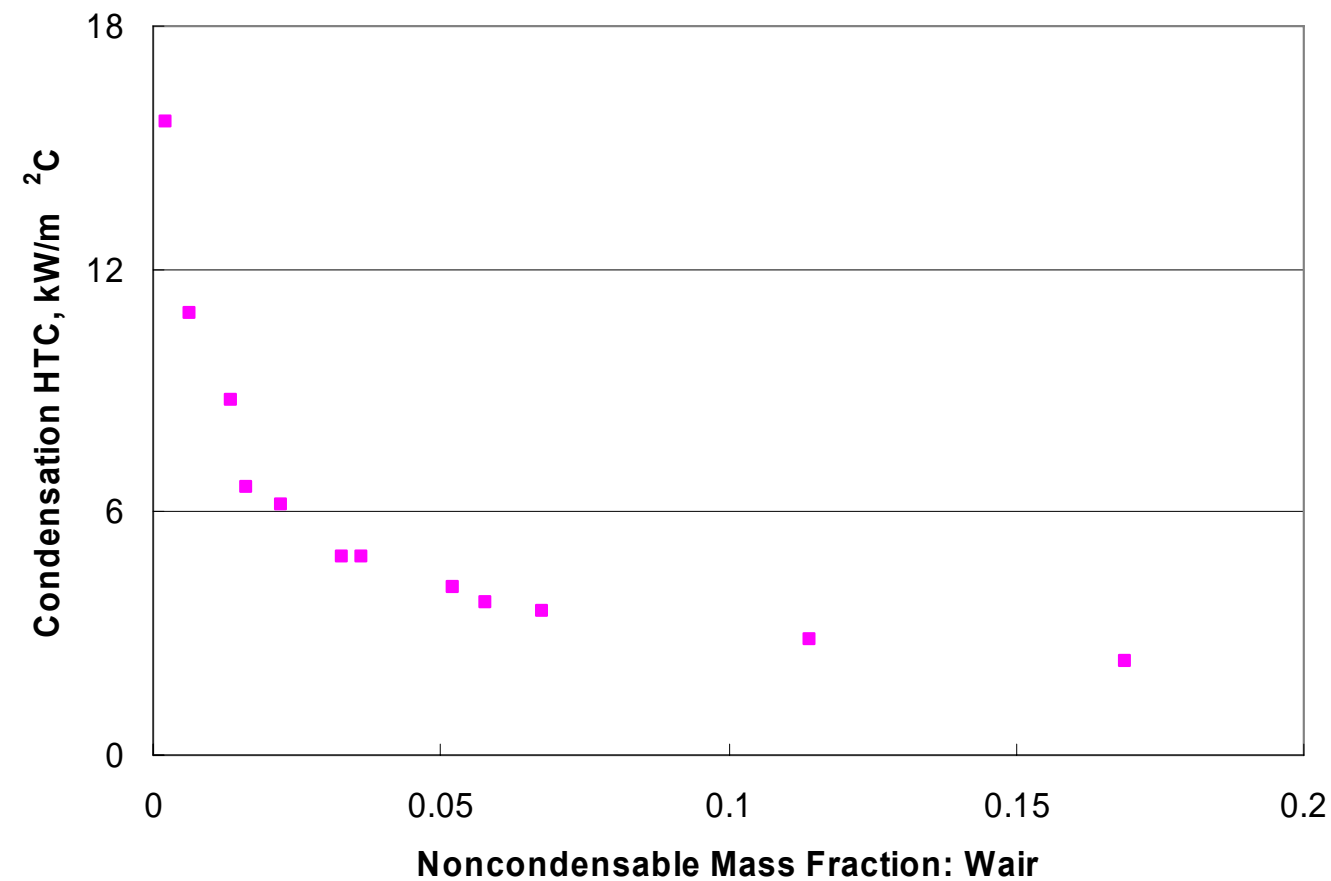

Fig. 3.27 Through Flow: Condensation HTC at $\mathrm{P}=200 \mathrm{kPa}, \mathrm{Mst}=4.0 \mathrm{~g} / \mathrm{s}$

\section{$\underline{\text { Effect of Steam Flow Rate }}$}

Figs. 3.28-3.29 show the condensation performance at given pressure $\mathrm{P}=176 \mathrm{kPa}$ and various inlet steam flow rate. Similarly, Figs. 3.30-3.31 show the condensation performance for $\mathrm{P}=200 \mathrm{kPa}$ and various inlet steam flow rate. From these figures, the condensation performance gets better with inlet steam flow rate. As inlet steam flow rate increases, interfacial shear also increases. This results in thinner liquid film, i.e., smaller resistance in heat transfer. Higher interfacial shear also enhance the heat transfer by early transition from laminar to turbulent flow in film region. Turbulence enhances the heat transfer by promoting the interface waviness and rippling as well as by mixing in the film inside region. 


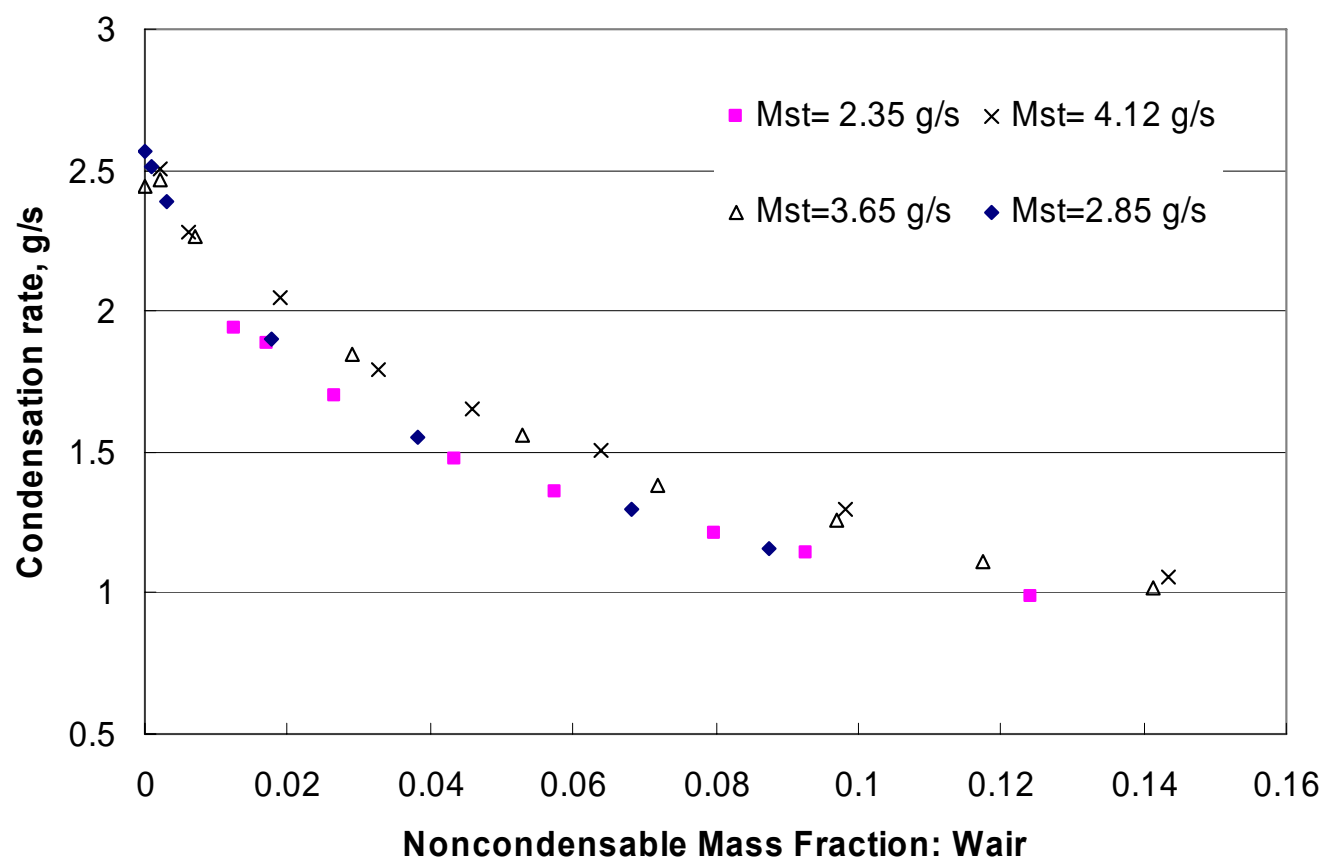

Fig. 3.28 Through Flow: Condensation Rate at $\mathrm{P}=176 \mathrm{kPa}$

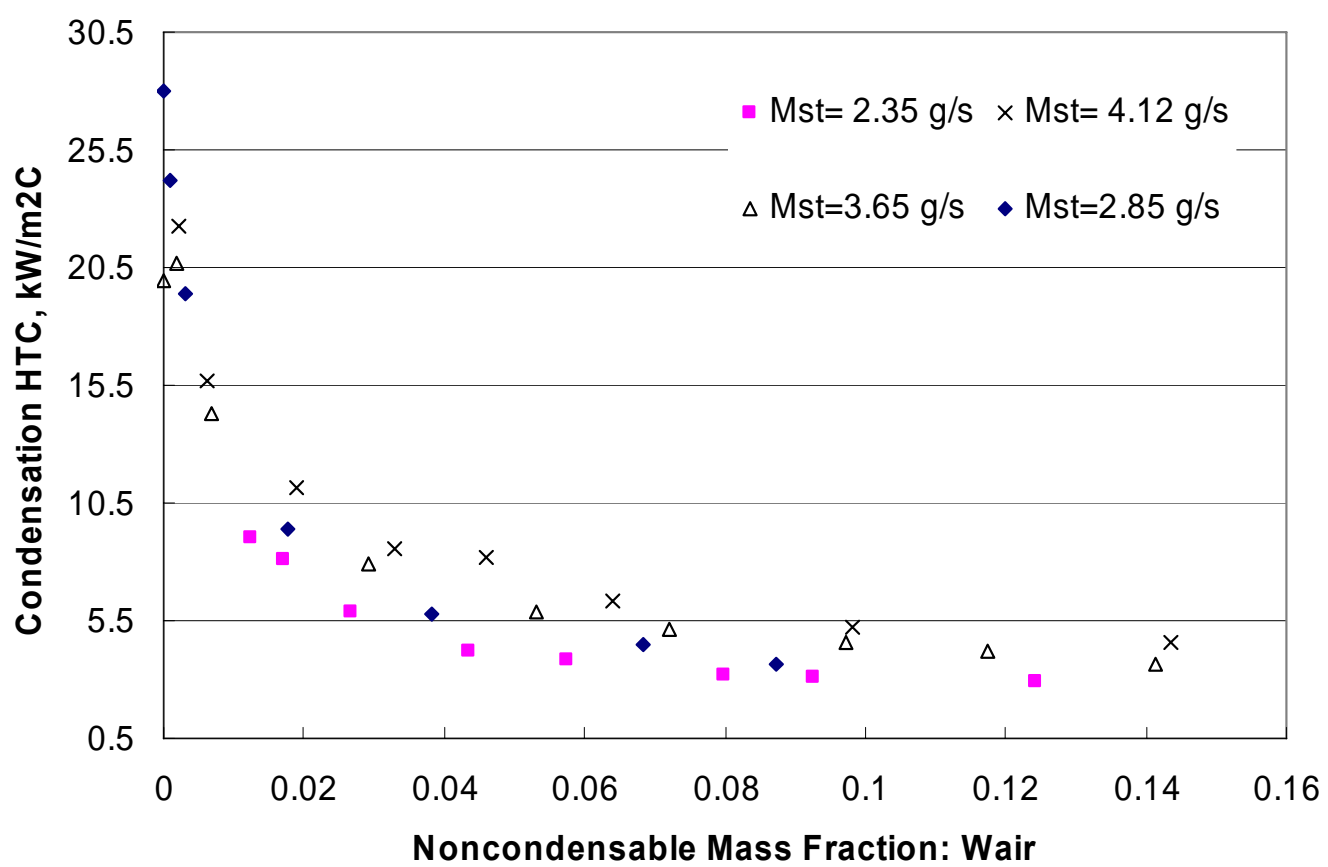

Fig. 3.29 Through Flow: Condensation HTC at $\mathrm{P}=176 \mathrm{kPa}$ 


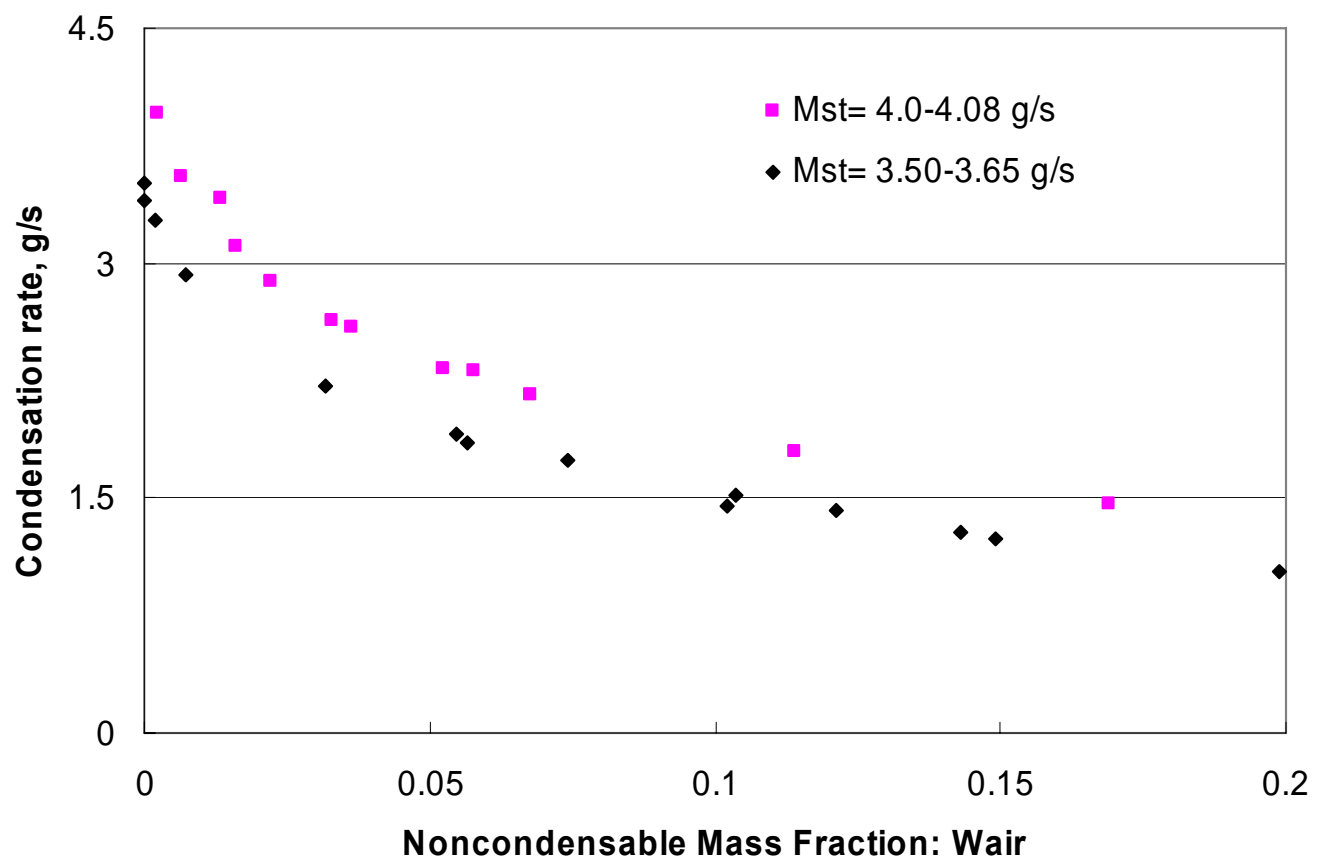

Fig. 3.30 Through Flow: Condensation Rate at $\mathrm{P}=200 \mathrm{kPa}$

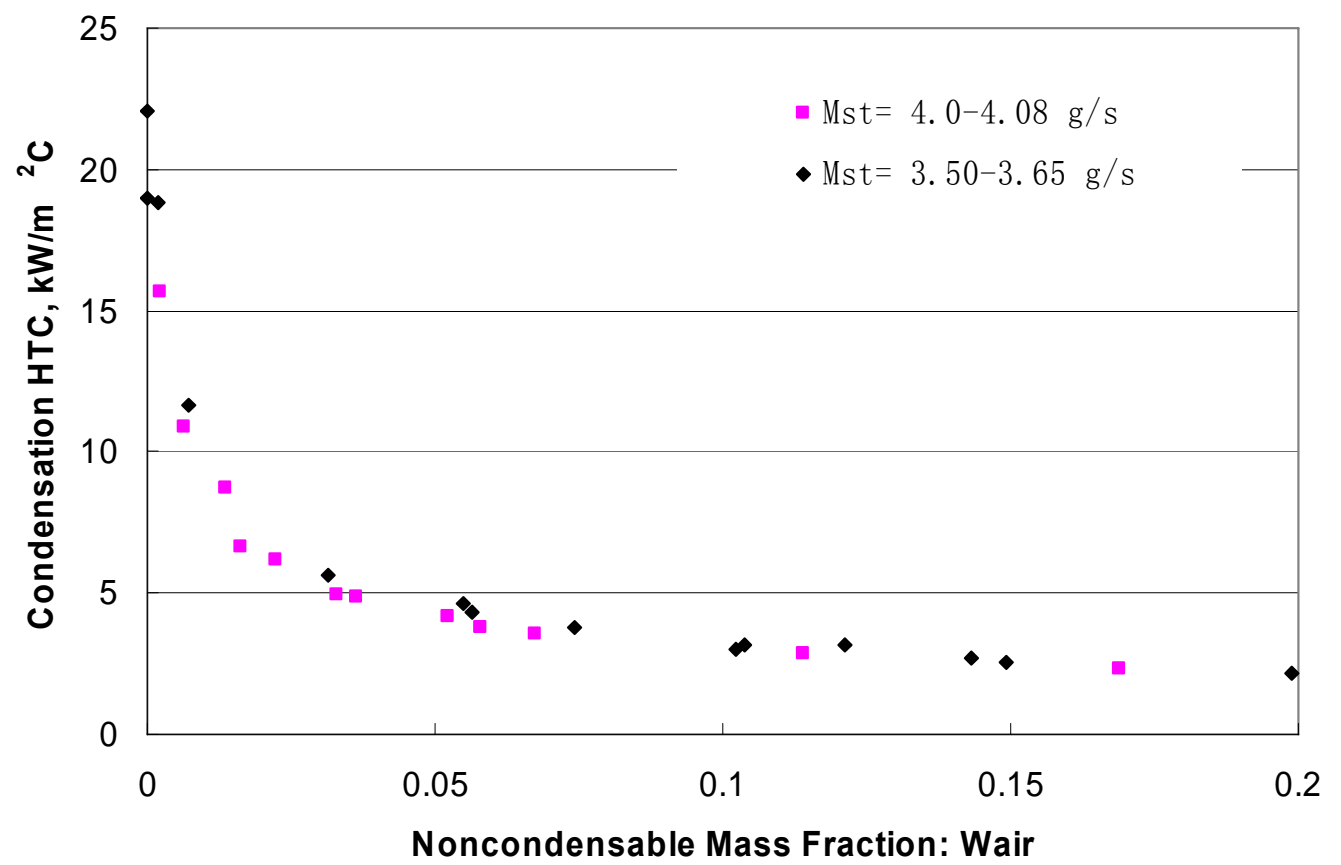

Fig. 3.31 Through Flow: Condensation HTC at P=200 kPa

Effect of System Pressure 
Figs. 3.32 and 3.33 show the condensation rate and condensation heat transfer coefficient with noncondnesable mass fraction for difference system pressure when nominal inlet steam flow is $4.0 \mathrm{~g} / \mathrm{s}$. Figs. 3.34 and 3.35 show condensation performance parameters for different system pressure when nominal inlet steam flow is 3.6 g/s. Condensation rate increases with system pressure. However, the condensation HTC decreases with system pressure. These results are consistent with the pure steam cases and the complete condensation mode discussed earlier.

As system pressure increase, the driving force of condensation, temperature difference between steam saturation and tube inside wall, increases due to the rapid increase of steam saturation temperature. Large driving force enhances the condensation performance, so condensation rate increases as a result of large $\Delta \mathrm{T}$, i.e., high system pressure. The liquid film thickness is getting greater with the increase of condensation rate, thus the heat transfer resistance caused by liquid film is getting larger with the increase of condensation rate, which results in the decrease of condensation HTC. This result is consistent with the classical Nusselt(1916) solution, shown in (3.21). Although the classic Nusselt solution is derived from pure steam condition, the general trend of the relation between condensation HTC and film thickness is also valid when noncondensable gas exists.

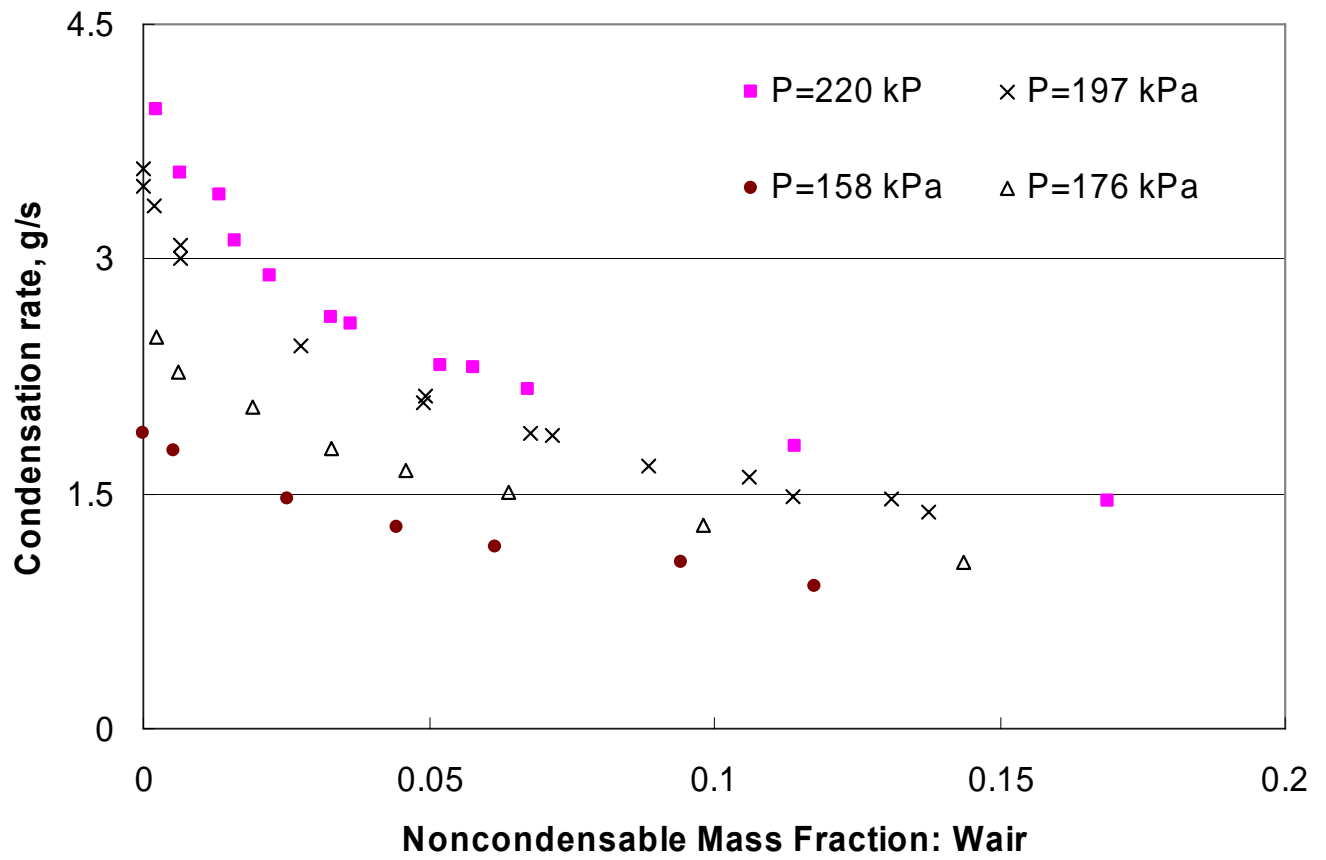

Fig. 3.32 Through Flow: Condensation rate at Mst=3.98 4.12 g/s 


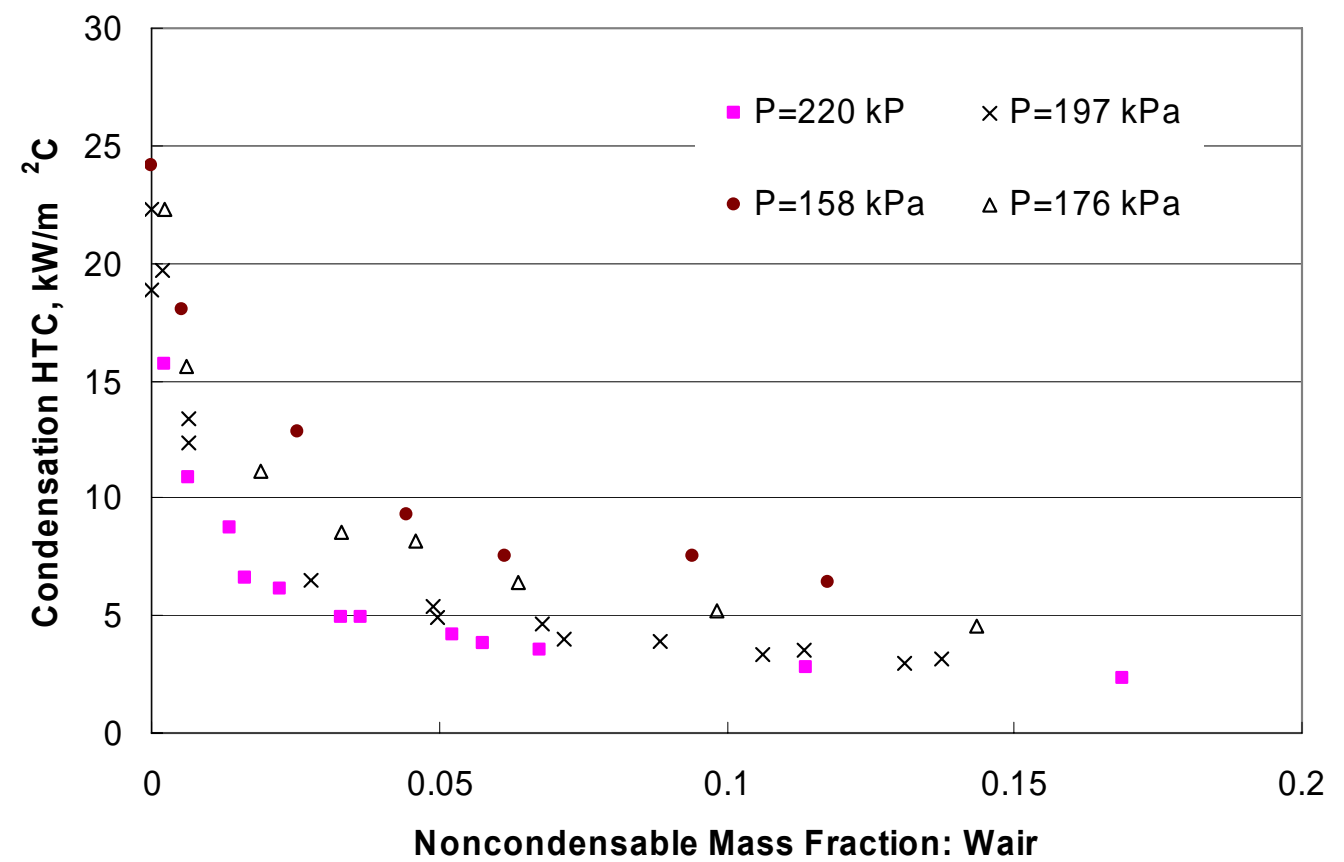

Fig. 3.33 Through Flow: Condensation HTC at Mst=3.98 4.12 g/s

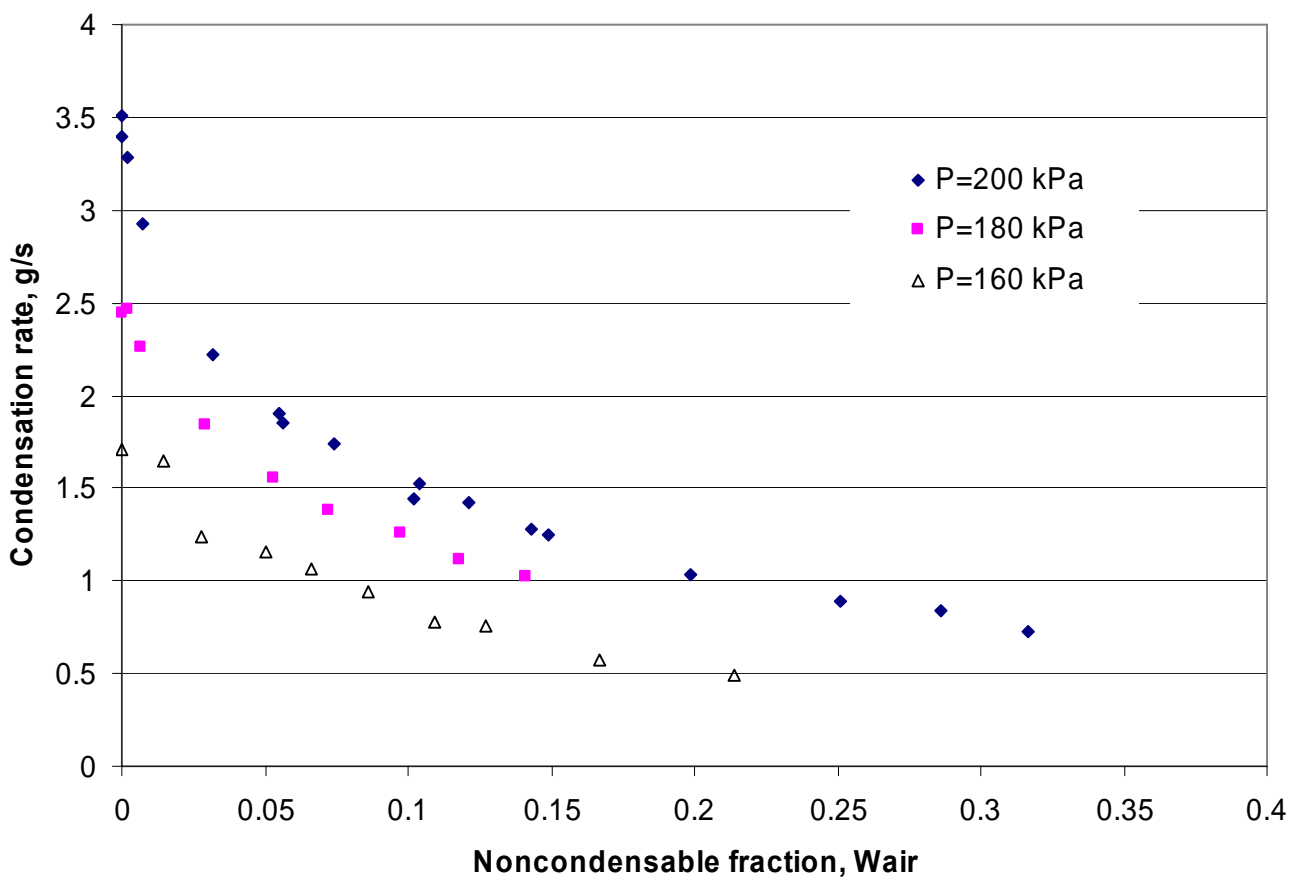

Fig. 3.34 Through Flow: Condensation rate at Mst=3.5 3.65 g/s 


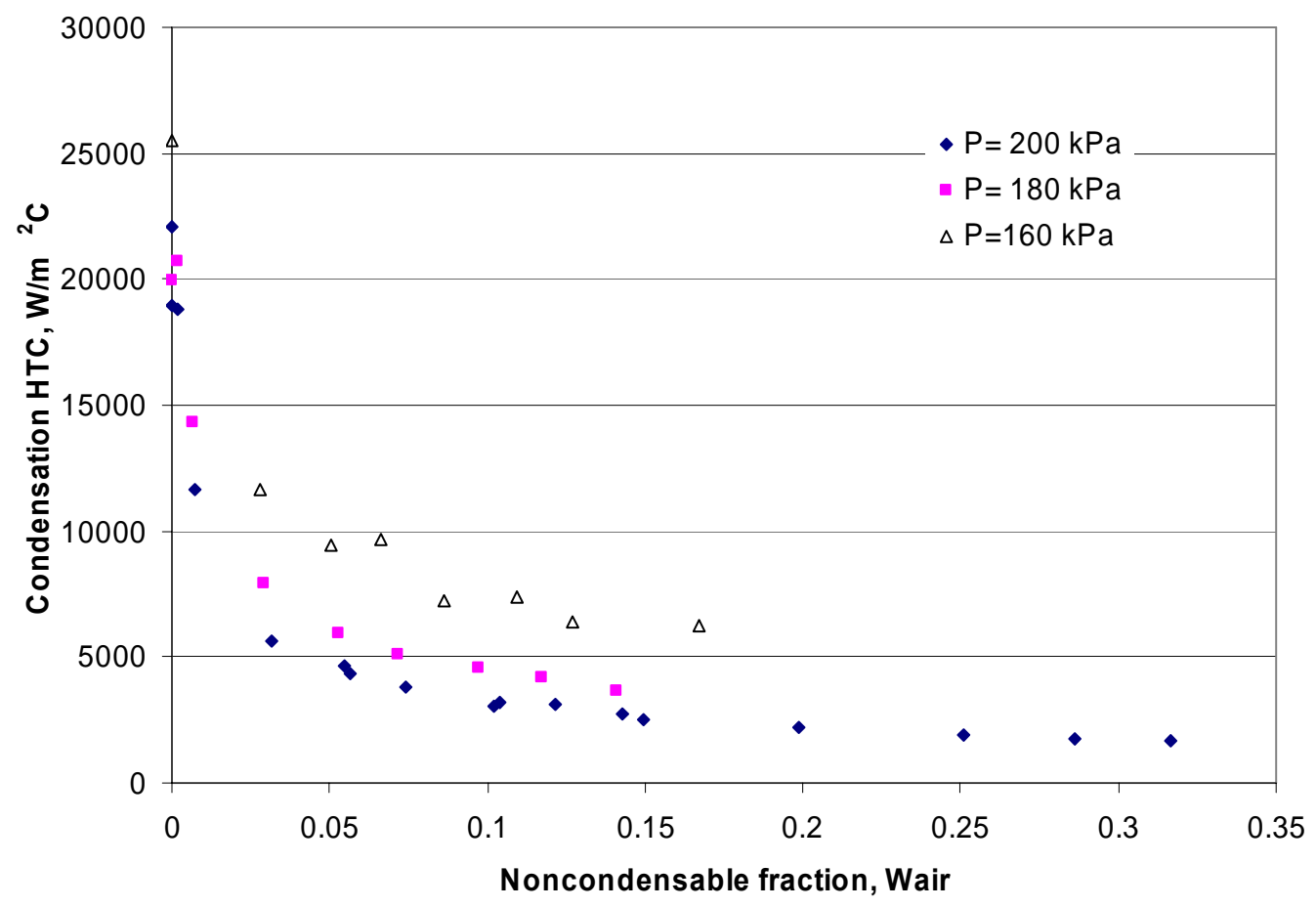

Fig. 3.35 Through Flow: Condensation HTC at Mst=3.5 3.65 g/s

\subsubsection{Half height test}

The test procedures of half height test for all three operation modes: complete condensation, cyclic venting and through flow are almost same with full height test. In half height test, the secondary pool water level was held at the middle height of the condenser tube and the active tube length for half height test is $0.5 \mathrm{~m}$. To maintain the pool level, continuous feeding water into secondary pool is necessary for the tests and achieved by connecting a $1 / 4$ inch stainless steel feed line to the top of secondary pool. The actual water level was watched by a plastic tube and recorded by a DP cell.

\section{1) Complete Condensation}

Fig. 3.36 shows the condensation rate vs. system pressure in half and full height test. As discussed early, condensation rate is rising with the increase of system pressure in both two cases. However, due to the smaller heat transfer area, the condensation rate of half height test is lower than that of full height test at same pressure condition. According to the scaling analysis using Nusselt solution, shown in (3.22)-(3.25), condensation rate is proportional to $\mathrm{L}^{3 / 4}, \mathrm{~L}$ is active length of condenser. The active 
length ratio between half height and full height test is 0.51 , thus the ratio of condensation rate should be close to $(0.51)^{3 / 4}=0.604$. However the ratio of condensation rate from the experiment result is 0.71 . This discrepency may be caused by the measurement error of the secondary pool water level in half height test.

$$
\begin{gathered}
A_{R}=d_{R} \cdot L_{R}=0.51 \\
\left(h_{\text {avg }}\right)_{R}=\left(L_{R}\right)^{-1 / 4}=0.51 \\
\left(q^{\prime \prime}\right)_{R}=\left(m_{c}^{\prime \prime}\right)_{R}=\left(h_{\text {avg }}\right)_{R}=\left(L_{R}\right)^{-1 / 4}=1.183 \\
(Q)_{R}=\left(m_{c}\right)_{R}=\left(q^{\prime \prime}\right)_{R} \cdot A_{R}=\left(L_{R}\right)^{3 / 4}=0.604
\end{gathered}
$$

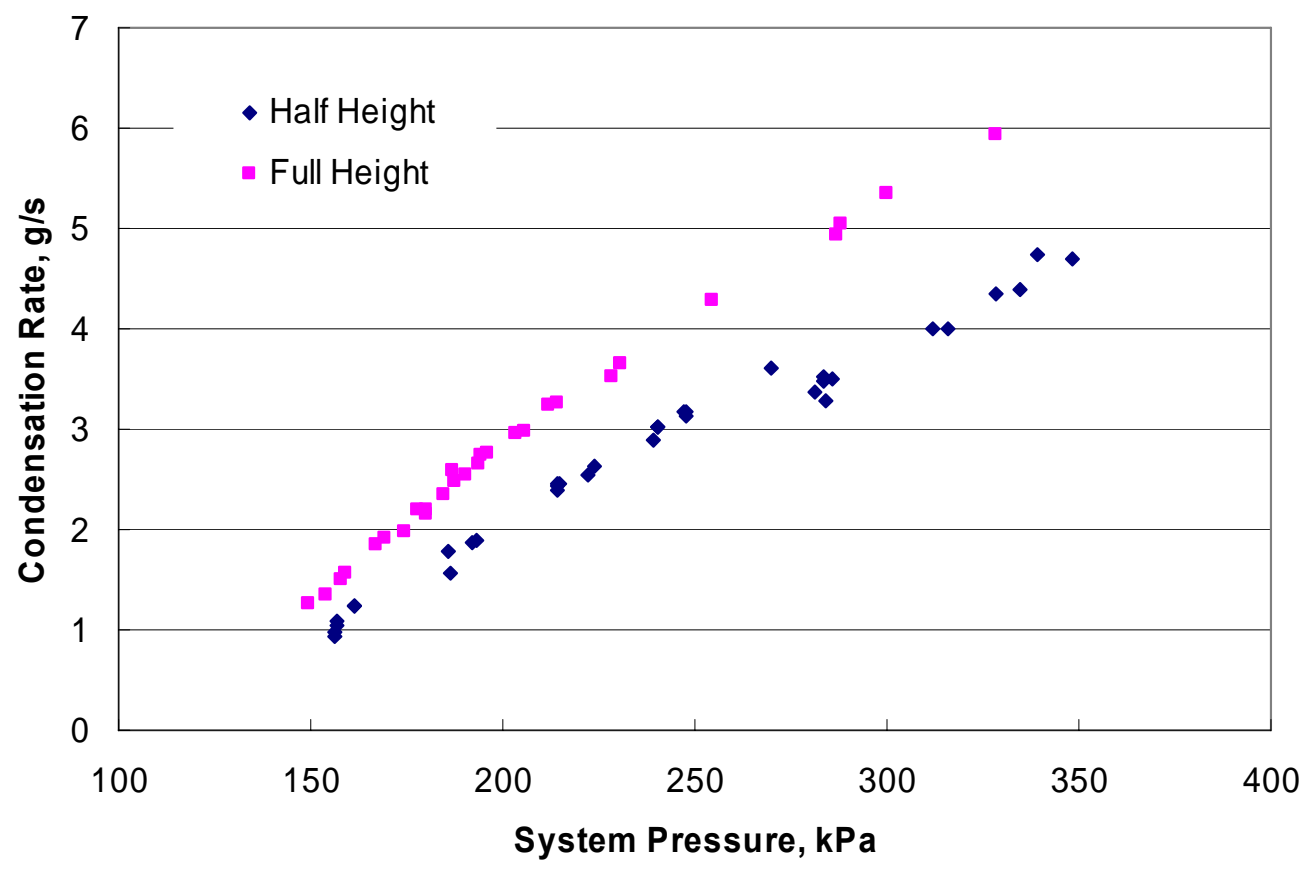

Fig. 3.36 Complete Condensation: Condensation Rate for Half and Full Height Test 


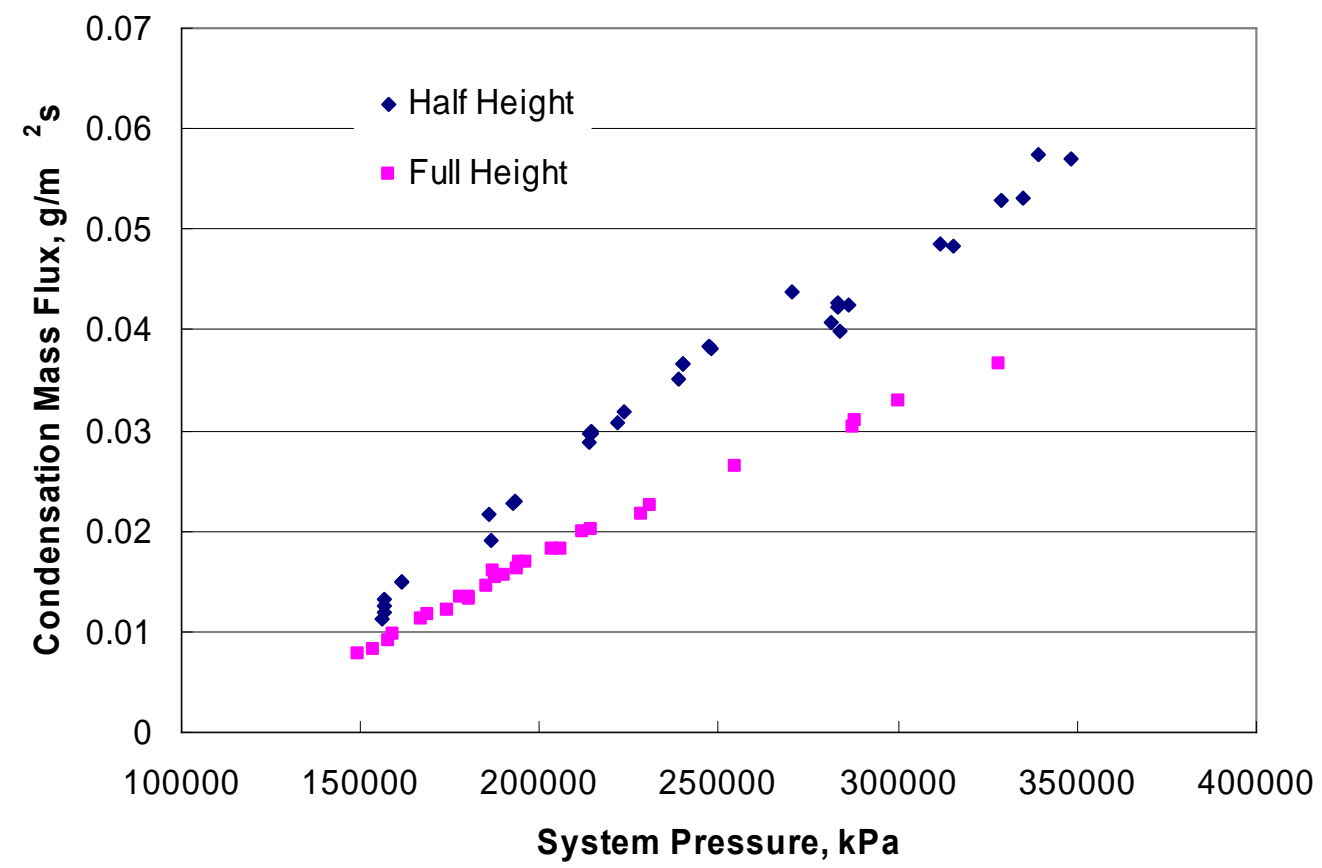

Fig. 3.37 Condensation Mass Flux in Half Height and Full Height Test

To eliminate the effect of different heat transfer area, condensation mass flux vs. system pressure is plotted as in Fig. 3.37. Ideally, condensation mass flux ratio for two test sections must be equal to $\left(L_{R}\right)^{-1 / 4}=(0.5)^{-1 / 4}=1.19$. However, due to measurement error of pool water level the condensation mass flux ratio from experiment data is 1.4 , an estimation of measurement error is about $17 \%$.

\section{2) Cyclic venting}

Figs. 3.38-3.40 show the results of the cyclic venting mode with different amount of noncondensable gas fraction for half height test. The venting pressure threshold (DPvent) was set as 0.5 psi. Compared with full height test, similar trends are observed from Fig. 5.38 for venting frequency and period with the increase of noncondensable fraction. Venting frequency increases with noncondensable gas fraction and period decreases correspondingly, which is due to the faster accumulation of noncondensable gas in contender tube with high noncondensable gas fraction. These trends are consistent with the results from full height tests.

The condensation rate and condensation HTC are shown in Figs 3.39 and 3.40 respectively. They both decrease with the noncondensable fraction. This is due to the 
increase of mass transfer resistance caused by thicker noncondensable gas concentration boundary layer at the interface.

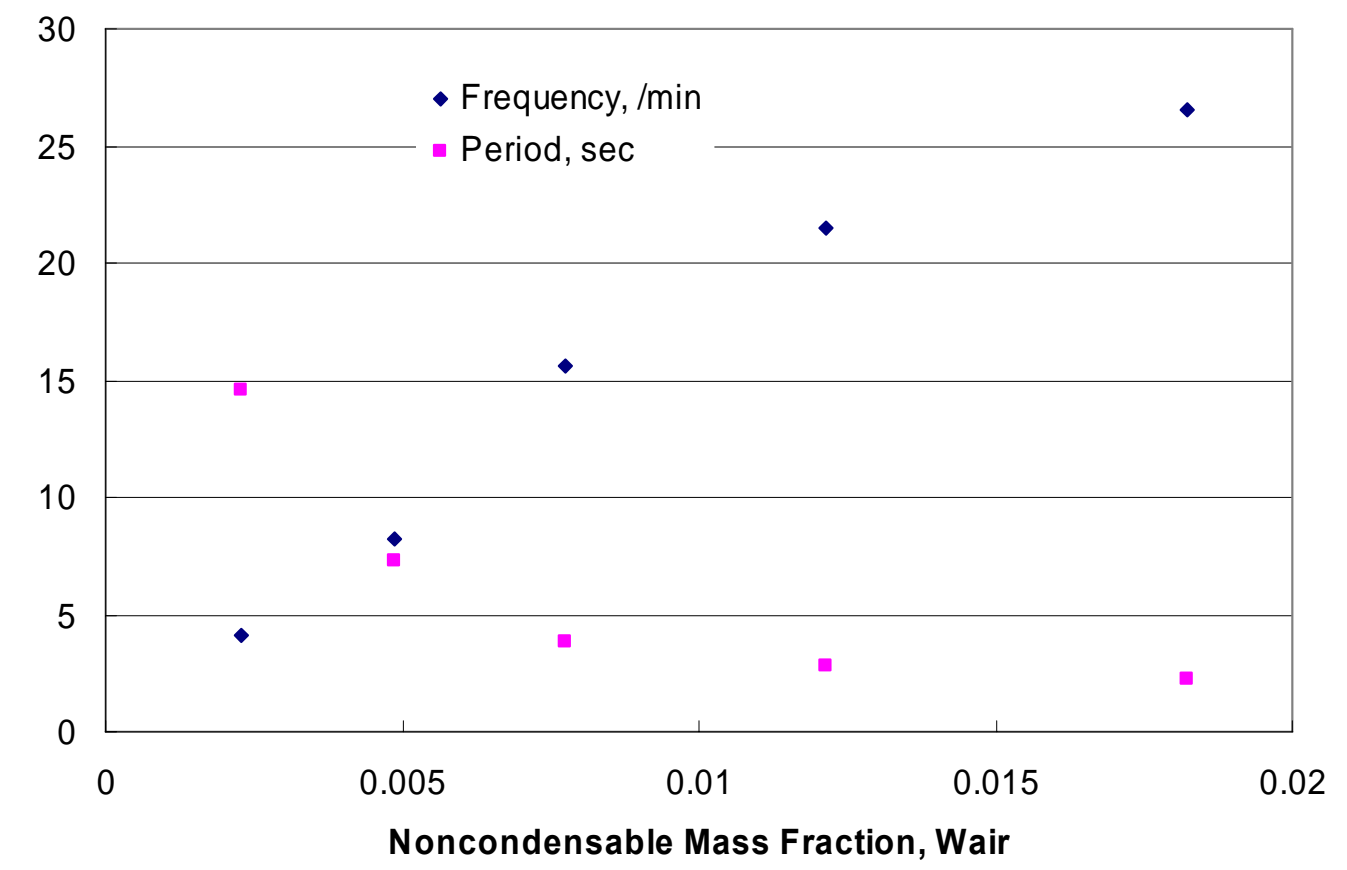

Fig. 3.38 Venting Frequency and Period at $\mathrm{P}=280 \mathrm{kPa}$ in Half Height Test

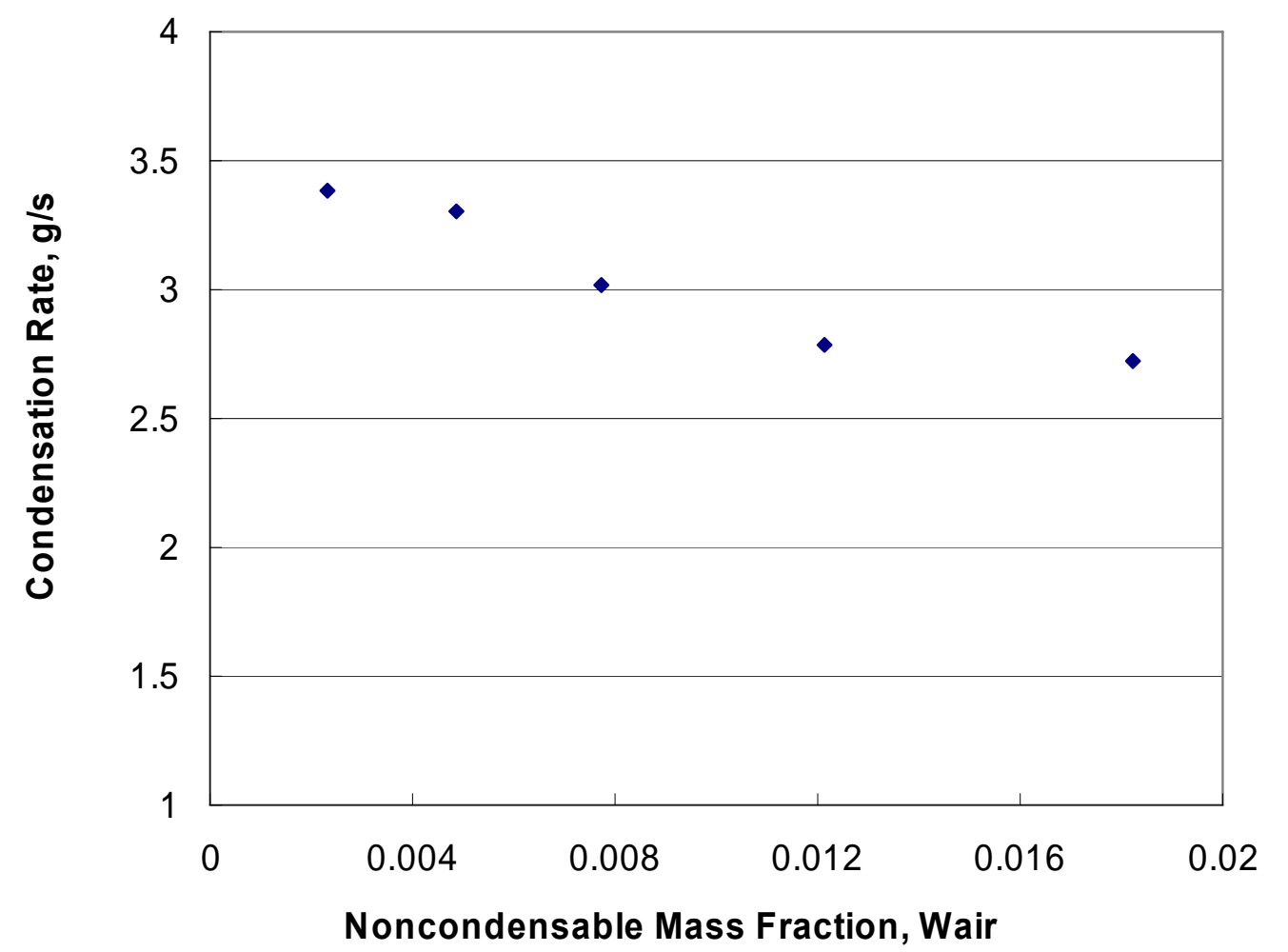

Fig. 3.39 Cyclic venting: Condensation Rate for Half Height Test, $\mathrm{P}=280 \mathrm{kPa}$ 


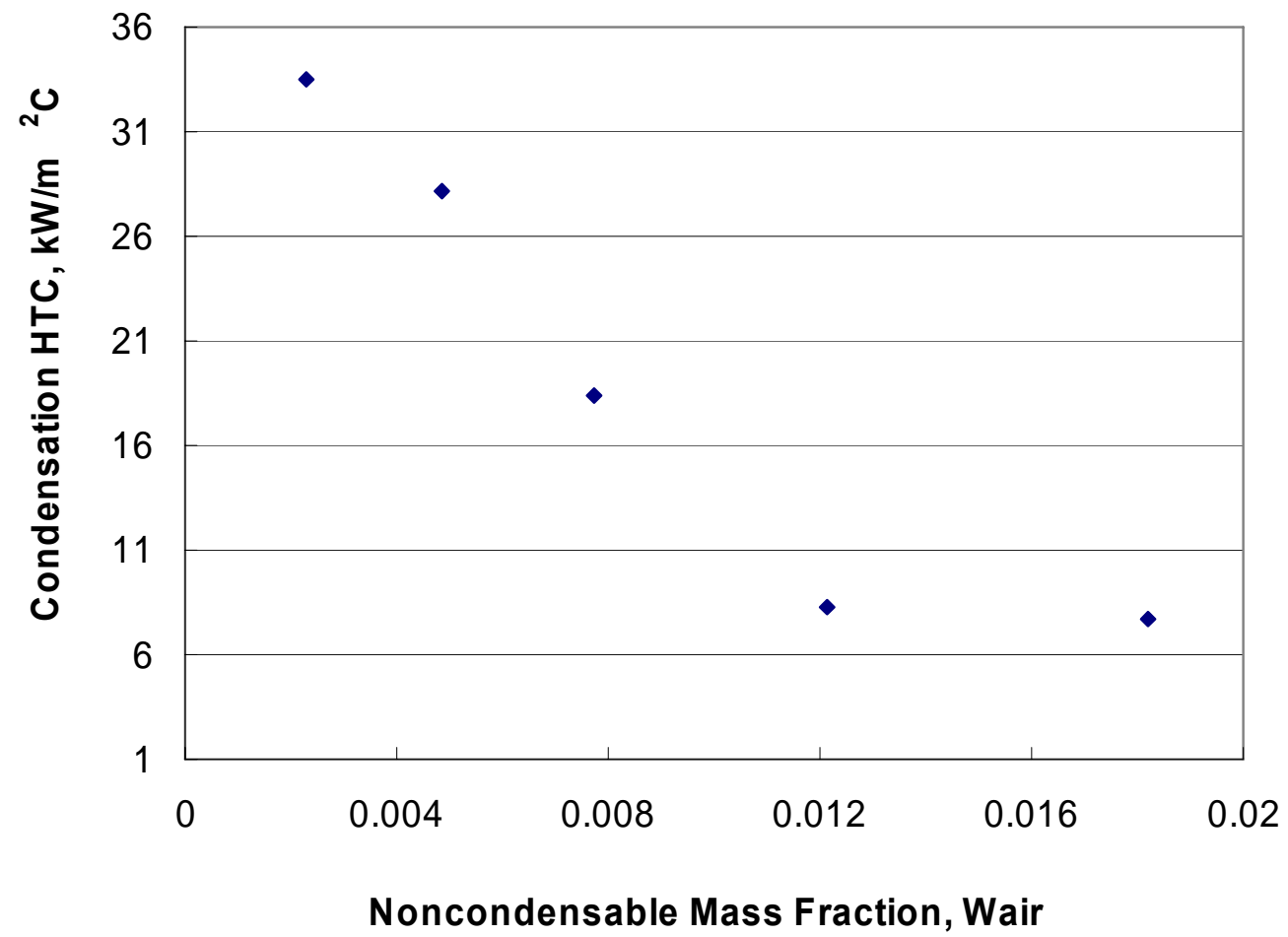

Fig. 3.40 Cyclic Venting: Condensation HTC for Half Height Test, $\mathrm{P}=280 \mathrm{kPa}$

\section{3) Through flow}

The condensation rate and condensation heat transfer coefficient with noncodensable mass fraction for difference system pressure are shown in Figs. 3.41 and 3.42 when nominal inlet steam flow rate is $4.0 \mathrm{~g} / \mathrm{s}$. Although the inlet steam flow rate is almost the same for different cases, condensation rate increase with system pressure and condensation heat transfer coefficient decrease with system pressure. The general trends from half height test are consistent with the results from full height test. The results are consistent with full height test's result. 


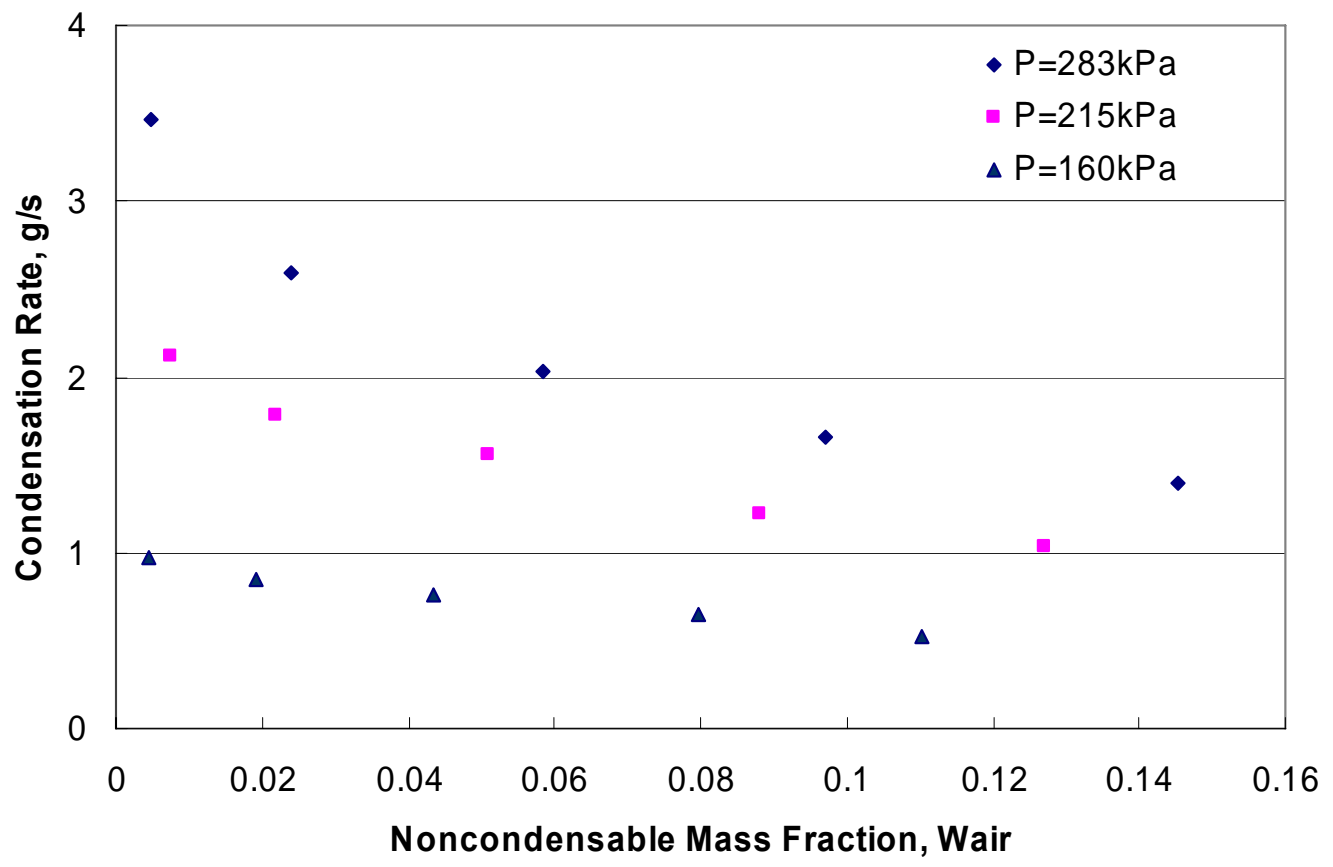

Fig. 3.41 Through Flow: Condensation Rate for Half Height Test, Mst=4.0-4.1g/s

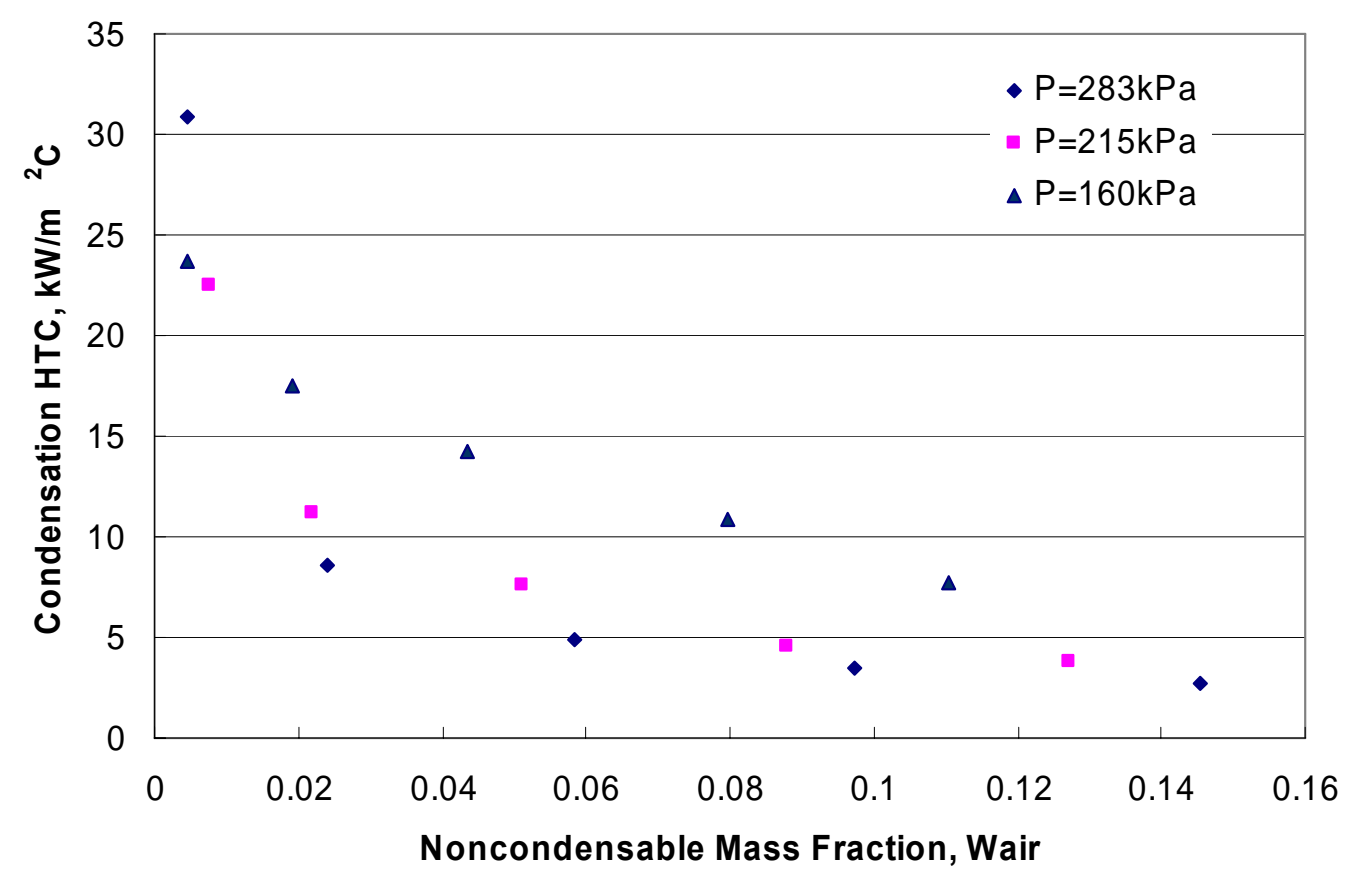

Fig. 3.42 Through Flow: Condensation HTC for Half Height Test, Mst=4.0-4.1g/s

The effect of steam flow rate is shown in Fig. 3.43-3.44. From these figures, the condensation rate and condensation HTC increase with inlet steam flow rate. A higher 
steam flow rate can increase interfacial shear, this results in thinner liquid film which gives smaller heat transfer resistance. Higher steam flow rate also results in an early transition from laminar to turbulent flow in film region, which enhances the heat transfer by intensify the interface waviness as well as by better mixing inside film region. The stable steam flow rate was obtained by keeping the same flow control valve opening with constant steam generator and suppression pool pressure condition, so that chocking flow condition can be obtained for different noncondensable gas fraction.

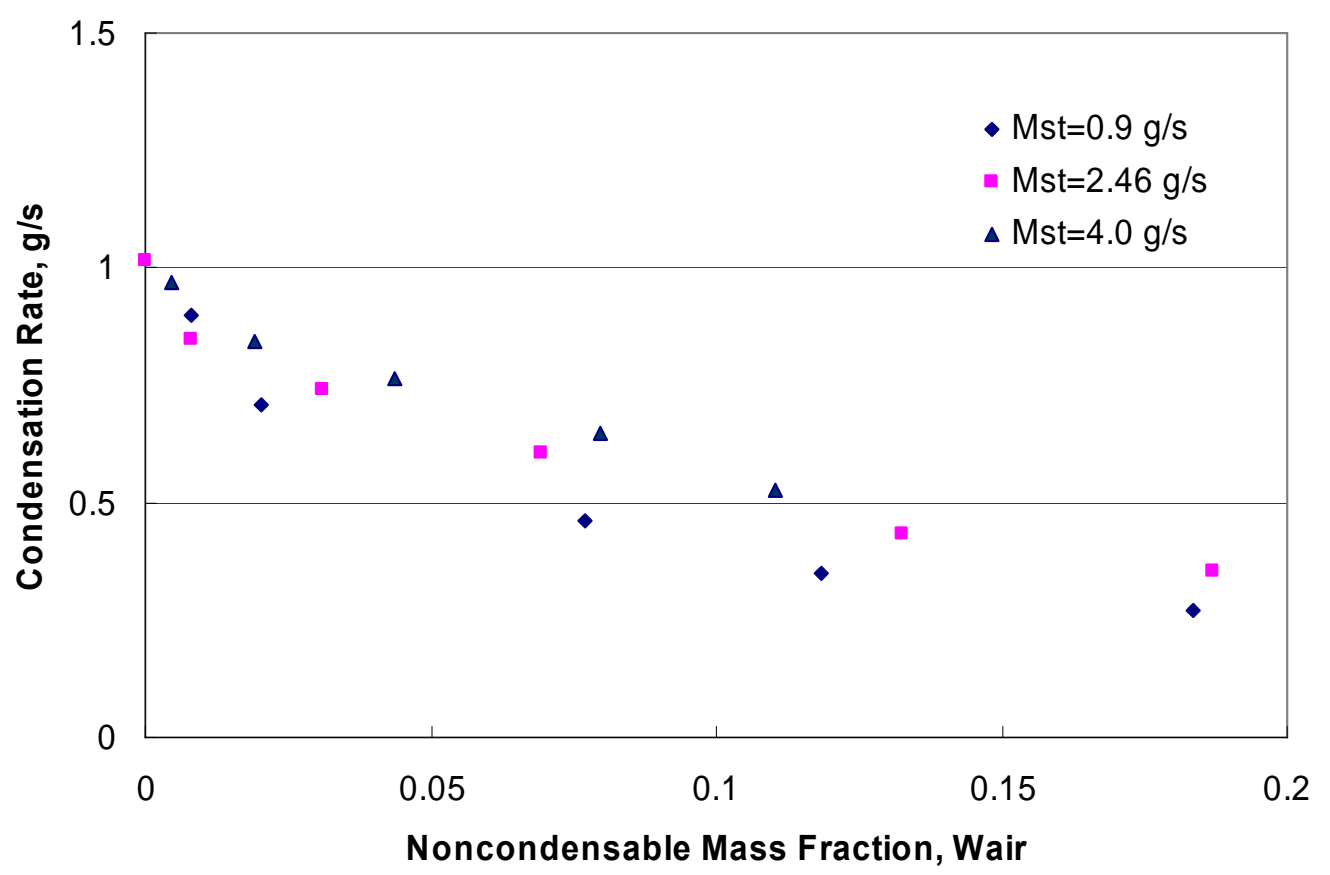

Fig. 3.43 Through Flow: Condensation Rate for Half Height Test, $\mathrm{P}=160 \mathrm{kPa}$ 


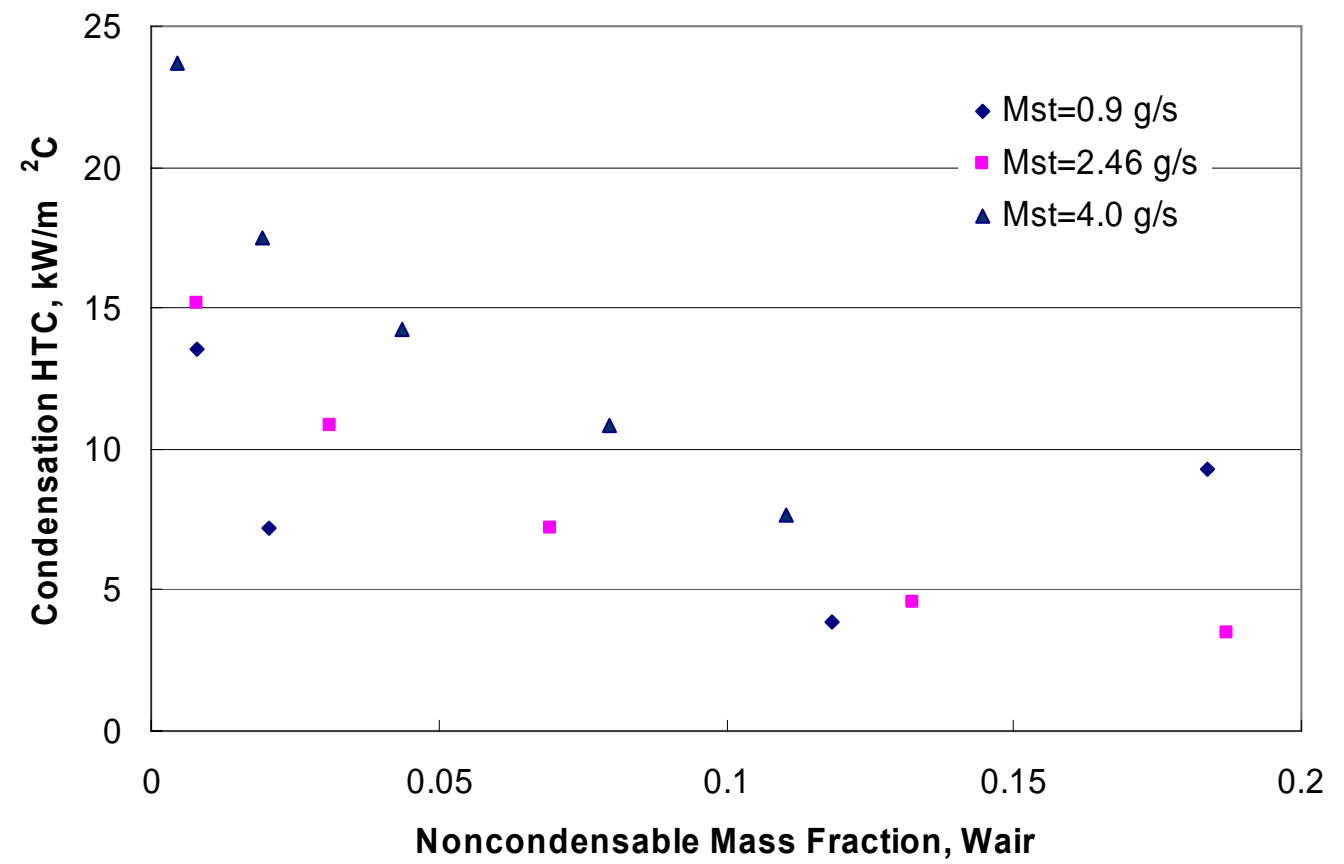

Fig. 3.44 Through Flow: Condensation HTC for Half Height Test, $\mathrm{P}=160 \mathrm{kPa}$

A comparison of condensation rate and condensation HTC between full height and half height test under similar system condition $(\mathrm{P}=160 \mathrm{kPa}, \mathrm{Mst}=4.0 \sim 4.1 \mathrm{~g} / \mathrm{s})$ is shown in Fig. 35.45 and 3.46. Because the heat transfer area of full height test is almost twice of half height test, under same inlet condition, such as pressure, steam flow rate and noncondensable fraction, more steam are condensed in the condenser tube, as shown in Fig. 3.44, condensation rate of full height test is higher than that of half height test. From Fig. 3.45, condensation HTC of half height test is higher than that of full height. This results from the difference of active length of condenser tube between full height and half height test. The active length in half height test is only half of the total length of condenser tube. For half height test, the liquid film developing along the tube is thinner than that of full height test case. This brings a smaller heat transfer resistance for half height test, so the heat transfer coefficient is higher. 


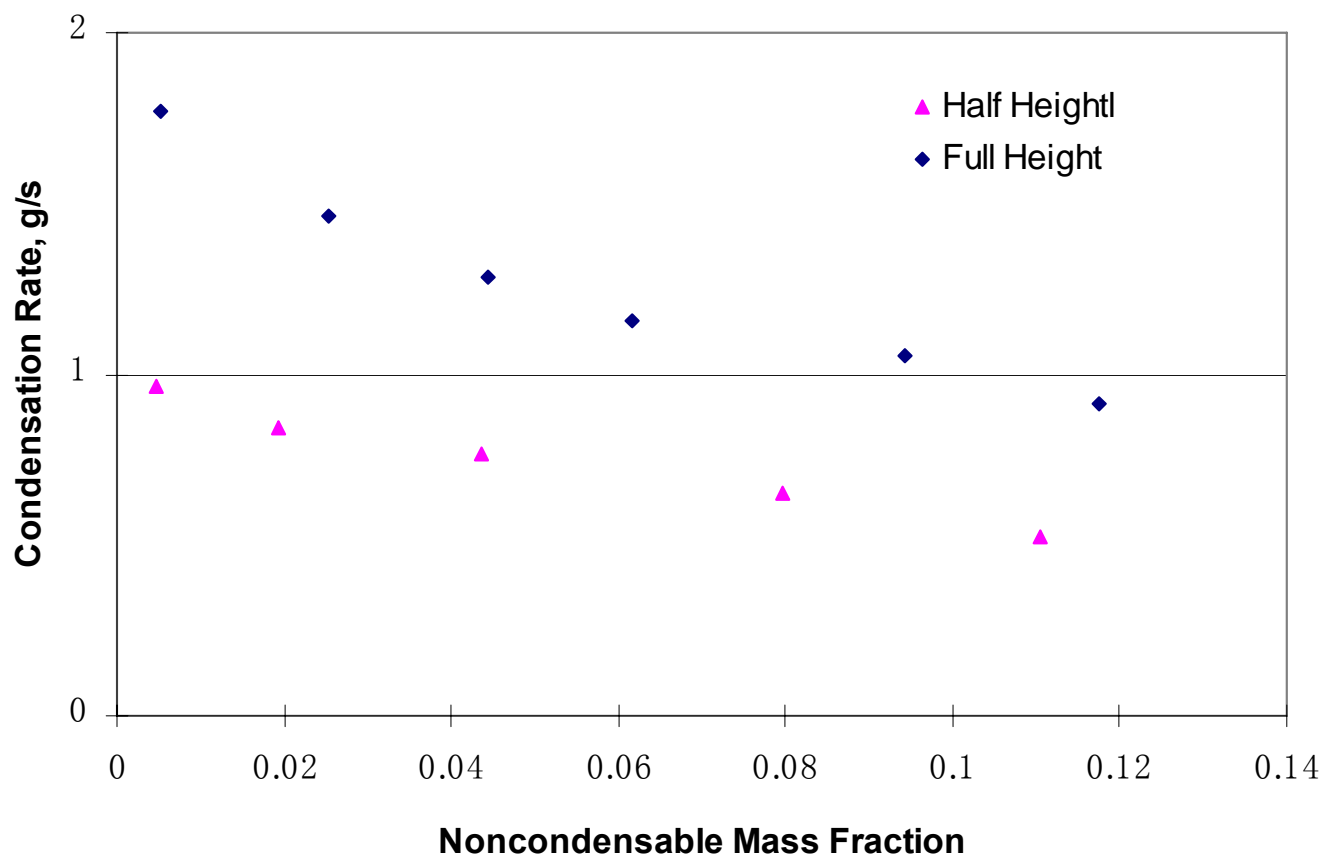

Fig. 3.45 Through Flow: Condensation Rate, $\mathrm{Mst}=4.0-4.1 \mathrm{~g} / \mathrm{s}, \mathrm{P}=160 \mathrm{kPa}$

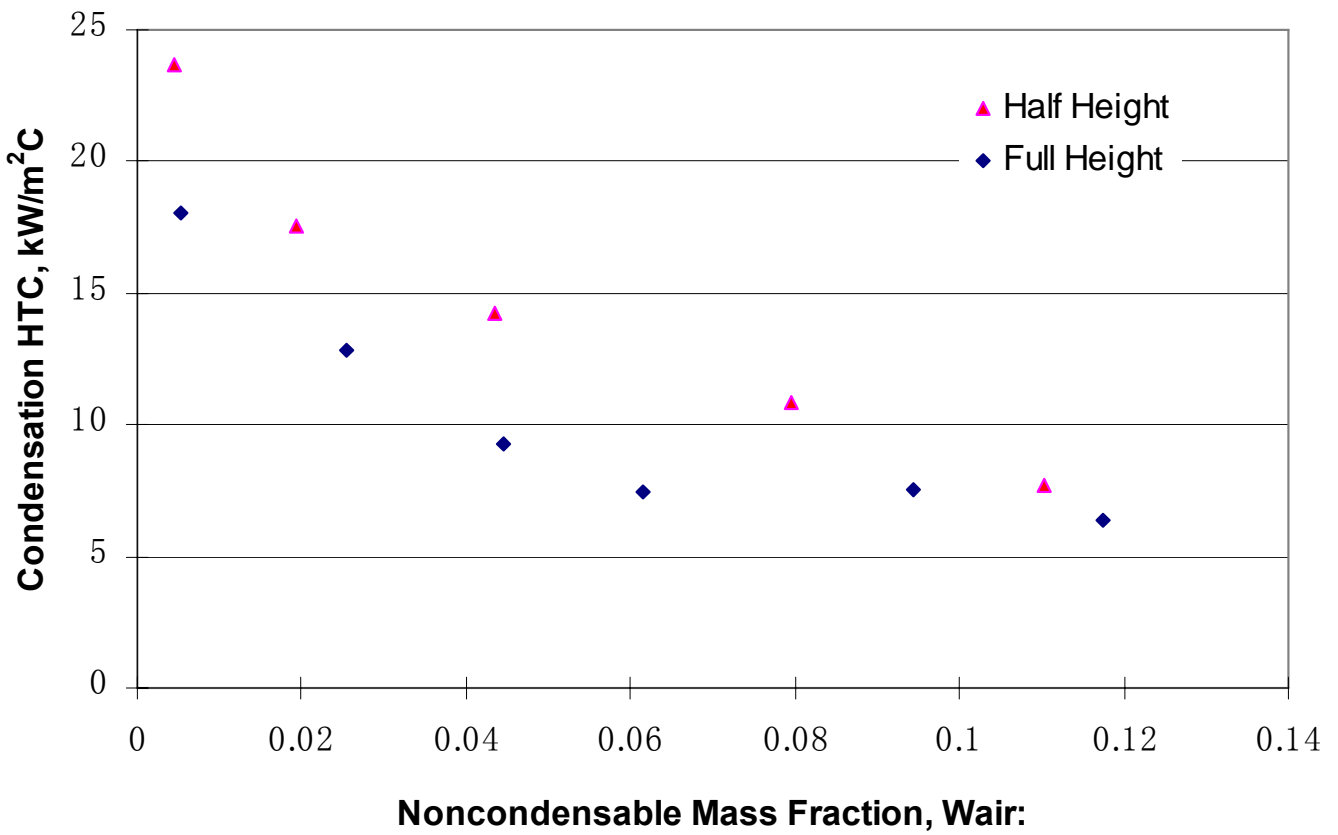

Fig. 3.46 Through Flow: Condensation HTC, Mst=4.0-4.1g/s,P=160kPa

\subsection{Transient operation}




\subsubsection{Objective}

One of the important goals of this project is to obtain a database on the transient operation of the PCCS condenser which is hardly found from previous steam condensation experiments in a vertical tube. Transient operation mainly means changes in secondary pool water level. With the continuous condensation occurring at the inside wall of condensing tube, the water level of secondary pool keeps decreasing. When the water level in secondary pool drops down below the top of condensing tube, the condensing tube are partly or even completely exposed to the atmosphere which results in the loss of cooling at secondary side. The change of secondary cooling condition will greatly affect the condensation in primary side. Important parameters of primary side, such as pressure, condensation rate, condensation heat transfer coefficient, show different trend of variation from the steady state test.

The interest of the transient test mainly comes from the operation mode of prototype PCCS design during long term cooling period. This mode happens in the very late stage of the accident consequences in which PCCS is running with a small steam flow rate at low pressure. The duration of this period is designed for at least 3 days long so that the pool water level is going to drop below the top of condensing tube bundle. A former integral tests carried out with PANTHERS facility [1] have shown interesting heat transfer behavior of the PCCS condenser with the pool water level change as shown in Figure 3.46. Decrease of water level to the top header initially decreases the inlet steam pressure indicating slight heat transfer enhancement. When the water level is below $3 / 4$ of the tube height the inlet steam pressure increases with decrease in the water level indicating decrease in PCCS heat transfer rate. However the inlet steam pressure increase is not linear. The present experimental work investigated in detail the effect of PCCS pool water level change on the PCCS heat transfer characteristics for complete condensation and through flow mode with or without the presence of non-condensable gas. 


\section{PANTHERS/PCC Test T54 Inlet Pressure Response to Pool Water Level}

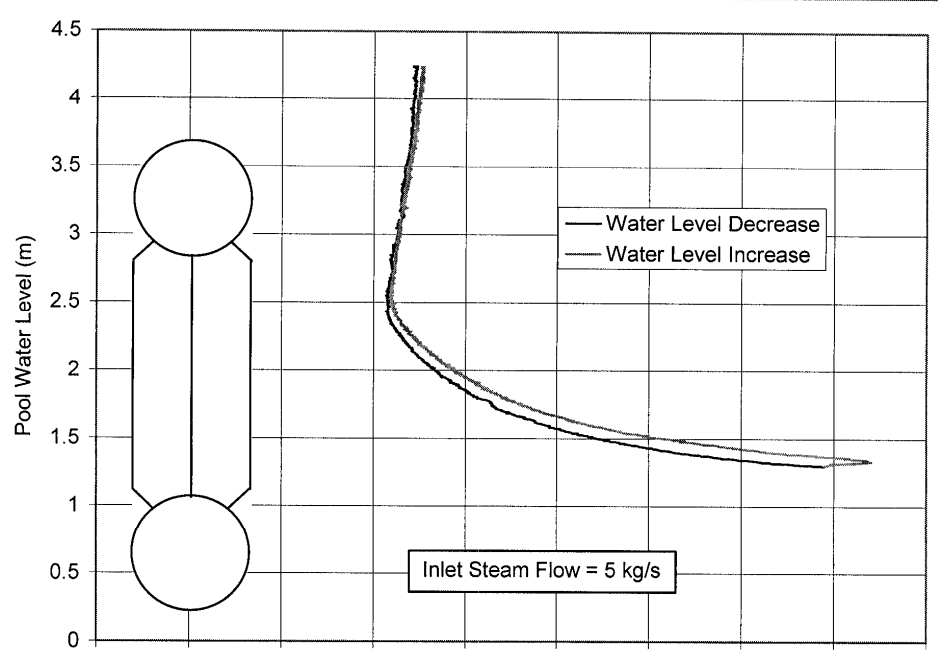

Inlet Pressure $(\mathrm{kPa})$

Figure 3.46 PANTHER PCCS test results for pool water level change and its effect on inlet steam pressure. (Figure is reproduced from the NRC web site [1]: http://www.nrc.gov/reactors/new-licensing/license-reviews/esbwr.html\#reviews).

\subsubsection{Test Loop and Data Reduction Methods}

A detailed description of the test loop and data reduction methods was presented in the previous report [2]. In this report a brief summary is presented for the completeness of the materials.

The test loop is comprised of steam generator (SG), instrumented condenser with secondary pool boiling section, condensation tank, suppression pool, storage tank, air supply line, and associated piping and instrumentation. The SG is a $0.4 \mathrm{~m}$ diameter, $2.26 \mathrm{~m}$ long stainless steel tank. An immersion type sheathed electrical heater of $10 \mathrm{~kW}$ capacity is mounted at the bottom of this vessel. This vessel is also instrumented with thermocouples, a pressure gauge and a Differential Pressure cell to measure and monitor temperature, pressure and water level. 
For the pool boiling heat removal at the secondary side, test section is designed with two subassemblies, primary condensing tube with insulation housing and secondary boiling tube. The specific design of condensing tube is based on scaling analysis from the PCCS design of ESBWR. The active condensing tube length and inside diameter of the primary condensing tubes are $0.9 \mathrm{~m}$ and $52.5 \mathrm{~mm}$, respectively. Two thermocouples at each axial level are installed for outside wall temperature measurement. From the top to the bottom of each condensing tube, five penetrations are designed for inserting thermocouples into the inside of tubes. These thermocouples reach the center of tubes and measure the bulk temperatures of steam-air mixture. The annulus between the primary condensing tube and the secondary boiling tube is filled with water and serves as water pool. During the test, steam generated in the pool is discharged through three steam exit nozzles located symmetrically at the top of the secondary boiling tube.

Condensation tank (CT) collects the condensate. Condensation rate is measured from the water level change in the condensation tank during tests. The suppression pool (SP) serves as a collector of the NC gas and the uncondensed steam. The condenser operating pressure is set by the pressure level in the SP.

The measured steam bulk temperature was slightly higher than the saturation temperature at the system pressure. This implies that the state of the steam-air mixture is at superheat. However, the amount of sensible heat transfer is much less than that of condensation heat transfer. So, the sensible heat transfer is ignored in data reduction. The overall heat transfer coefficient in condenser is defined as follows:

$$
U=\frac{Q_{\text {con }}}{A_{i}\left(T_{S A T}-T_{P}\right)}
$$

The condensation heat transferred by condenser tube, $Q_{c o n}$ can be calculated as follow:

$$
\begin{array}{r}
Q_{\text {con }}=m_{\text {con }} h_{f g}\left(P_{S A T}\right) \\
m_{\text {con }}=\frac{\Delta H_{r e f}}{\Delta t} \rho_{\text {ref }} A_{C T}
\end{array}
$$

where $m_{c o n}$ is the condensation mass flow rate calculated by Eq. (3.28) from the condensate tank water level difference during the test and $h_{f g}\left(P_{S A T}\right)$ is the latent heat 
of condensation based on the steam partial pressure $P_{S A T}$. The condensation mass flow rate can be checked by the comparison with the supplied steam flow rate during the complete condensation mode.

This condensation heat transfer rate should be equal to the secondary side heat removal rate, $Q_{\text {tot }}$, which is sum of the evaporative heat transfer rate and the heat loss from the secondary tube surface.

The overall heat transfer coefficient can also be given by the following equation (3.29) derived by the heat balance among the condenser tube inside, tube wall and tube outside.

$$
U=\left[\frac{1}{h_{c}}+\frac{\ln \left(D_{o} / D_{i}\right) D_{i}}{2 k_{w}}+\frac{D_{i}}{h_{\mathrm{sec}} D_{o}}\right]^{-1}
$$

The first term of the right hand side of above equation corresponds to the tube side condensation heat transfer, the second term corresponds to the tube wall conduction heat transfer, and the third term corresponds to the secondary side pool boiling heat transfer. Neglecting the heat transfer along condenser tube length, the condensation heat transfer coefficient, $h_{c}$, is defined as follows:

$$
h_{c}=\frac{Q_{\text {con }}}{A_{i}\left(T_{S A T}-T_{W i}\right)}
$$

The secondary side pool boiling heat transfer coefficient, $h_{s e c}$, is defined as follows:

$$
h_{\mathrm{sec}}=\frac{Q_{\mathrm{con}}}{A_{o}\left(T_{W o}-T_{P}\right)}
$$

From equation (3.4), the condensation heat transfer coefficient can be expressed as follows:

$$
\frac{1}{h_{c}}=\frac{1}{U}-\frac{1 n\left(D_{o} / D_{i}\right) D_{i}}{2 k_{w}}-\frac{D_{i}}{h_{\mathrm{sec}} D_{o}}
$$

Finally, the condensation heat transfer coefficient can be expressed with the known or experimentally obtainable values.

Air mass flow can be calculated and then the non-condensable gas mass fraction can be determined.

$$
\begin{gathered}
m_{\text {air }}=\rho_{\text {air }} V_{\text {air }} \\
W_{\text {air }}=\frac{m_{\text {air }}}{m_{\text {air }}+m_{\text {steam }}}
\end{gathered}
$$


Vapor partial pressure can be calculated from Gibbs-Dalton ideal gas mixture equation as follow:

$$
\frac{P_{S A T}}{P_{T O T}}=\frac{1-W_{a i r}}{1-W_{a i r}\left(1-\frac{M_{v}}{M_{a}}\right)}
$$

The average NC mass fraction is the arithmetic mean of the tube inlet and outlet $\mathrm{NC}$ gas mass fraction. The actual distribution of NC gas mass fraction along the condenser tube might not be linear. However, the effect of nonlinear w distribution on latent heat, $h_{f g}\left(P_{S A T}\right)$ is not significant because $h_{f g}$ is a weak function of pressure. The analysis result shows the maximum error of $h_{f g}$ is less than $7.5 \%$ for the limiting nonlinear $\mathrm{W}$ profile (e.g. step change of $\mathrm{W}$ in the tube).

\subsubsection{Transient Test Procedures and Test Matrix}

The transient tests are carried out in two operation modes: complete condensation mode and through flow mode. In the tests of each mode, condensation performance with or without non-condensable gas is recorded as the secondary water level continuously decreases. Six different cases are designed for the experiment. The test matrix is shown in Table 3.2.

Table 3.1 Test matrix for transient condensation experiment of $52.5 \mathrm{~mm}$ single tube

\begin{tabular}{|c|c|c|c|}
\hline & $\begin{array}{c}\mathrm{P}=230 \mathrm{kPa} \\
\text { Mst=4.9 g/s }\end{array}$ & $\begin{array}{c}\mathrm{P}=200 \mathrm{kPa} \\
\mathrm{Mst}=2.9 \mathrm{~g} / \mathrm{s}\end{array}$ & $\begin{array}{c}\mathrm{P}=150 \mathrm{kPa} \\
\mathrm{Mst}=1.5 \mathrm{~g} / \mathrm{s}\end{array}$ \\
\hline Wair $=0 \%$ & $\checkmark$ & $\checkmark$ & $\checkmark$ \\
\hline Wair $=0.1 \%$ & $\checkmark$ & $\checkmark$ & $\checkmark$ \\
\hline
\end{tabular}

Transient test procedures:

1) For the complete condensation:

- Close the venting line from the condensation tank.

- Start the test from a steady state at complete condensation mode with full height water level.

- As the decrease of secondary water level, system pressure will keep increasing. 
- Continuously recording data until the secondary water level decreases to $20 \%$ of full height.

- Drain the condensation tank when the condensation is full during the data acquisition period.

2) For the test with a noncondensable gas:

- Open the venting valve from the condensation tank to get an initial condition at through flow mode.

- In the through flow condition, system pressure will keep the same as the secondary level decreases.

- Continuously recording data until the secondary water level decreases to $20 \%$ of full height.

- Drain the condensation tank when the condensation is full during the data acquisition period.

\subsubsection{Test Results}

\section{1) Complete condensation mode}

In complete condensation mode, the venting valve is always closed during the test. As secondary water level keep dropping down, more and more portion of condensing tube is exposed and loses secondary cooling. Therefore, condensation performance also decreases with secondary water level. The uncondensed steam thus accumulates in the condensing tube and condensation tank. The system pressure is increasing continuously as shown in Figure 3.47. 


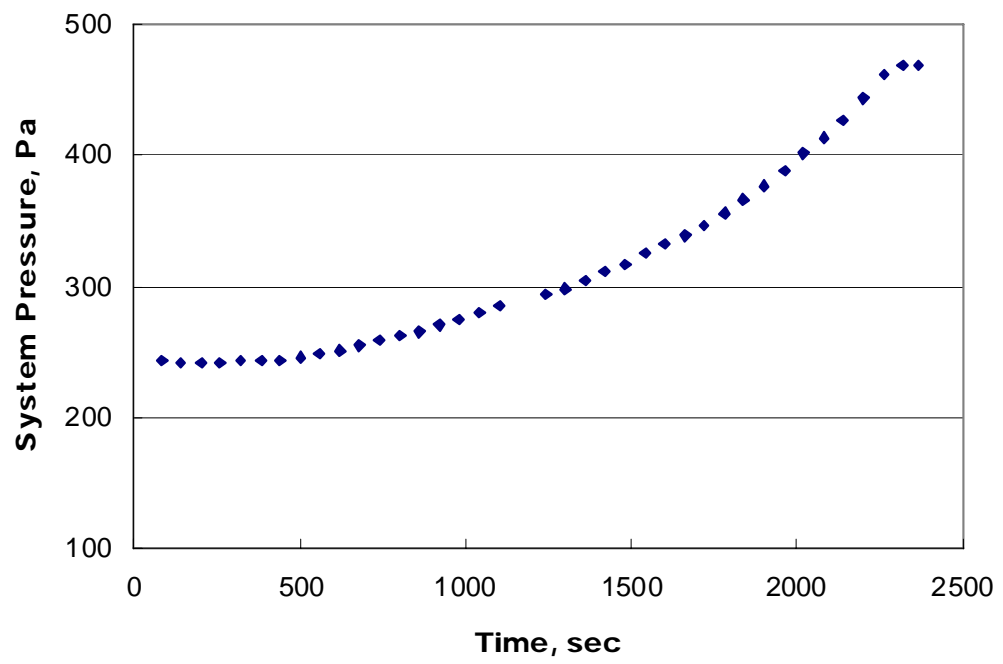

Figure 3.47 System Pressure vs. Time : Complete Condensation, Mst=3.34g/s

During the whole transient test of complete condensation, all the incoming steam is condensed in condensing tube. Thus, when a constant incoming steam flow rate is held, no remarkable variation of the condensation rate is observed from experiment data in Figure 3.48.

From the discussion of steady state test, condensation heat transfer coefficient is the sole function of system pressure. This conclusion is also verified in transient test. As the water level decreasing, condensation heat transfer coefficient should be decreasing with system pressure. However, the wave shape of condensation HTC from the experiment data is due to the limitation of experiment apparatus. During the transient test, the condensation tank has to be drained periodically when the tank is full. The condition of complete condensation is then changed when the drain line of the condensation tank is open. After the tank is drained up, drain line is closed and the system takes some time to come back to previous working condition. In Figure 3.6, the down coming curve represents the condensation HTC in normal complete condensation mode, the up going curve represents the draining period of the condensation tank. 


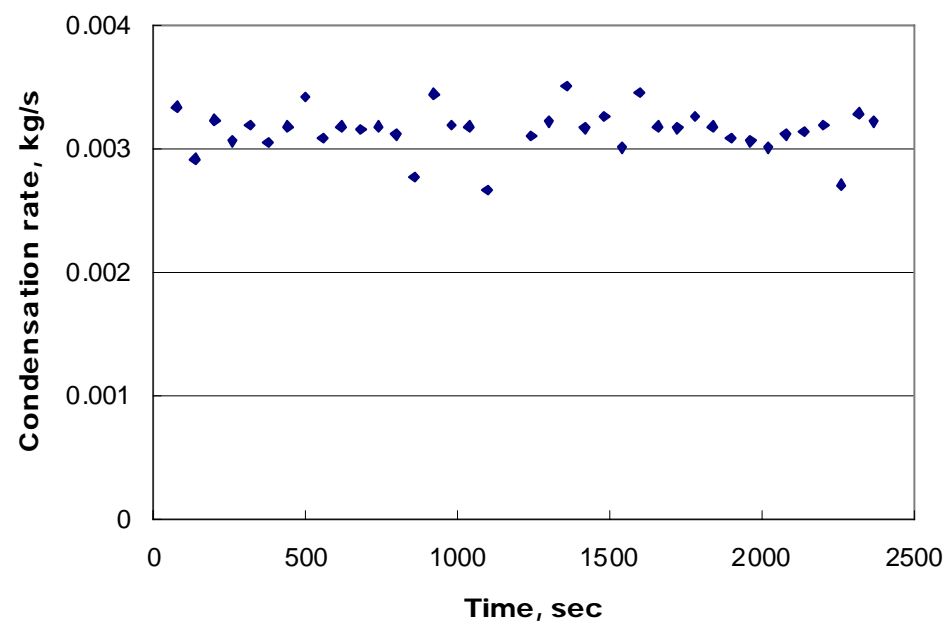

Figure 3.48 Condensation rate vs. Time : Complete Condensation, $\mathrm{Mst}=3.34 \mathrm{~g} / \mathrm{s}$

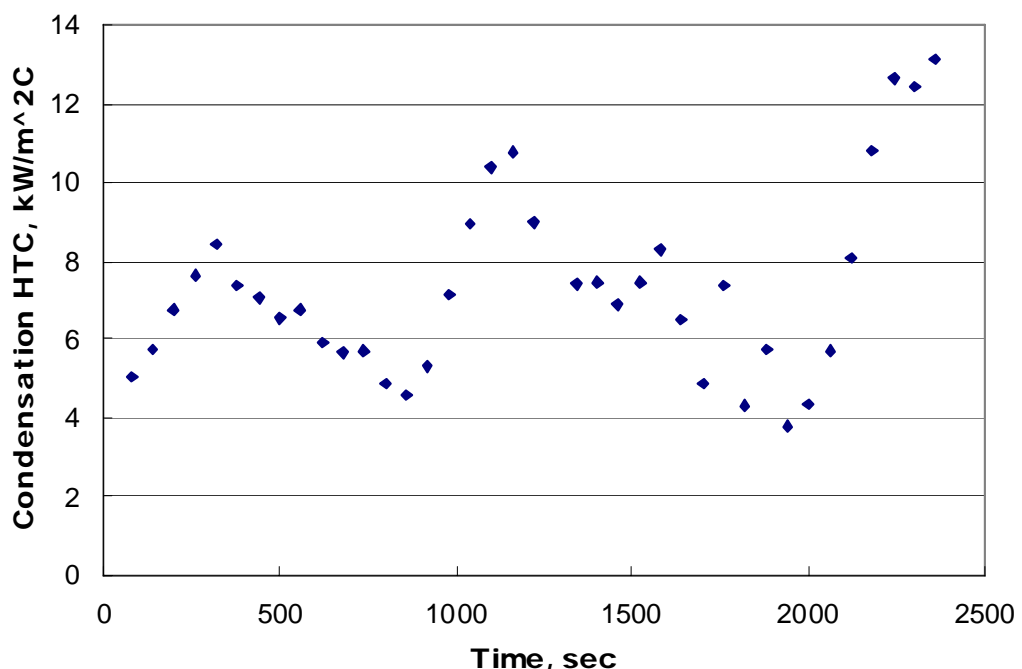

Figure 3.49 Condensation HTC vs. Time : Complete Condensation,

$$
\mathrm{Mst}=3.34 \mathrm{~g} / \mathrm{s}
$$

2) Through flow mode

In the transient tests of through flow mode, the system is connected to the atmosphere by keeping the venting line of condensation tank always open. The regulation valve at the outlet of venting line is adjusted from time to time to hold the system pressure same as shown in Figure 3.50. 


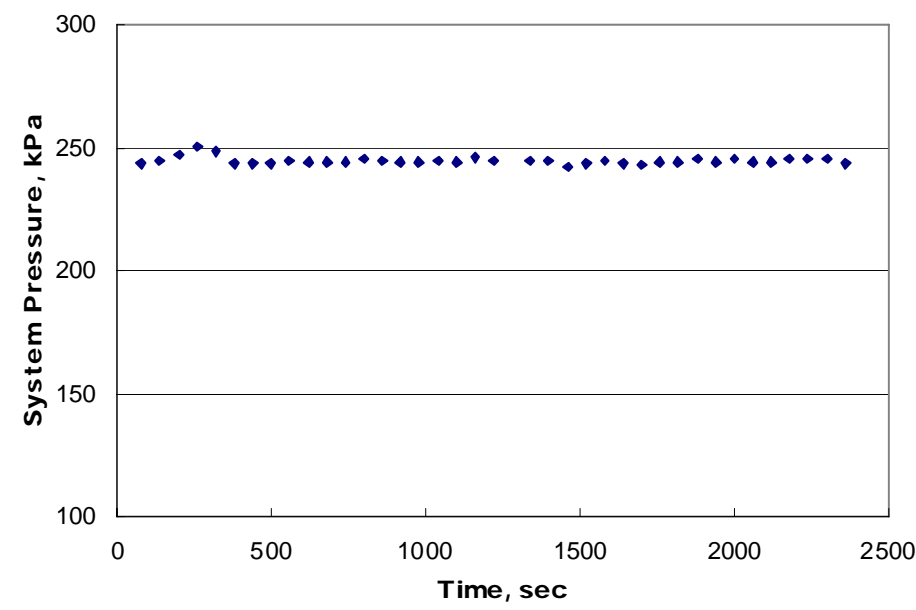

Figure 3.50 System Pressure vs. Time : Through flow, Mst=3.4g/s

Due to the decrease of secondary water level, the cooling condition outside the condensing tube is getting worse. The effective length of condensing tube which is the length below pool water level is proportional to the condensation heat transfer rate as well as the system pressure is constant. Then, it is not surprising to see that the condensation rate keeps decreasing with time in Figure 3.51.

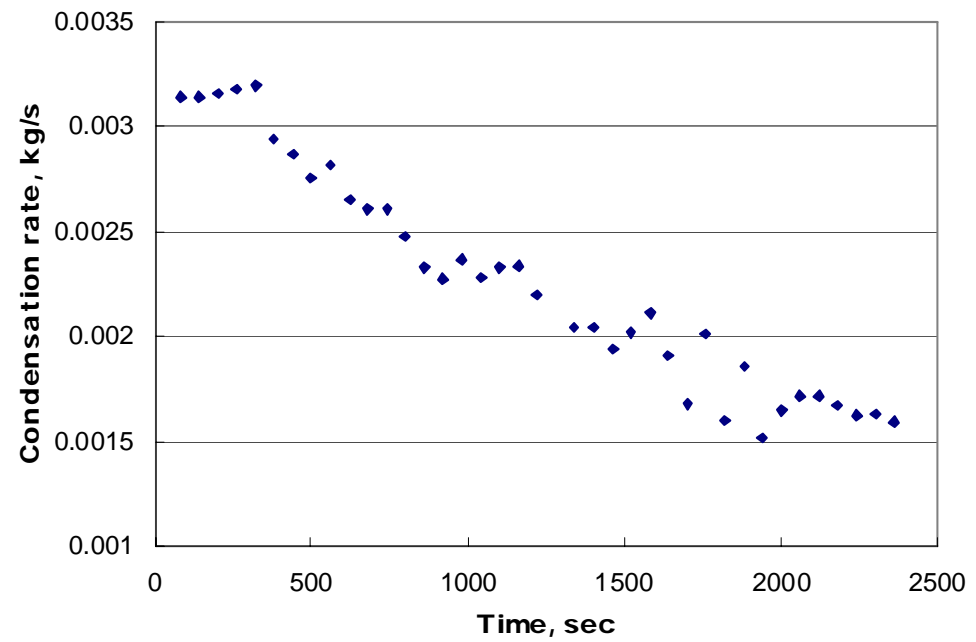

Figure 3.51 Condensation rate vs. Time : Through flow, Mst=3.4g/s

The variation of condensation HTC in through flow mode is similar to that in complete condensation mode. A wave shape curve is also obtained as time goes by as shown in Figure 3.52. The reason resulting in this kind of curve shape also 
comes from the volume limitation of condensation tank and the disturbance to the system from draining the tank.

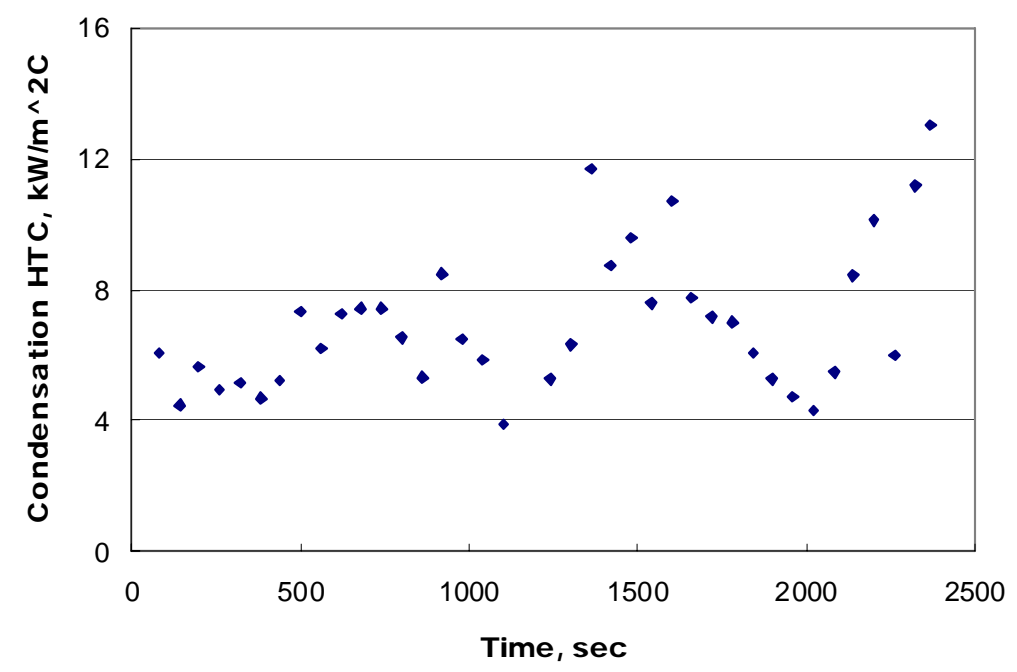

Figure 3.52 Condensation HTC vs. Time : Through flow, Mst=3.4g/s

\subsubsection{Conclusion}

In prototype PCCS design, long term cooling is a very long stage. The change of pool water level is thus very small. The quasi-steady state is a valid assumption for the real PCCS. However, in the transient test, the change of various parameters is much faster compared with those in prototype PCCS. So a simulation in level of quantitatively study is very difficult from current experiment loop. However, the general trend of each parameter can be obtained and they are consistent with the prediction and other experiment results.

\subsection{References}

1. US NRC website: http://www.nrc.gov/reactors/new-licensing/licensereviews/esbwr.html\#reviews (2002).

2. Revankar, S. T., Gao, H, Oh, S, Experimental and thermalhydraulic code assessment of the transient behavior of the passive condenser system in an advanced boiling water reactor, DOE/NEER Progress Report, PU/NE-05-11, Purdue University, 2005. 


\section{ANALYSIS PROGRAM}

\subsection{Boundary Layer Model}

\subsubsection{Introduction}

As it is known to all, the existence of non-condensable gas can greatly reduce condensation performance. In the PCCS condenser tube, depending on the noncondensable gas concentration in the drywell, the non-condensable gas accumulates at the liquid-vapor interface. This reduces the partial pressure of the vapor for a fixed total pressure, thus reducing the saturation temperature at which condensation occurs. The mass transfer resistance between bulk mixture and condensation interface becomes predominant compared with the thermal resistance in pure steam condensation. The gas concentration along the length of the tube varies and hence the local heat transfer coefficient. Based on previous experiment work, analytical and empirical models have been developed by a lot of researchers, such as Vierow and Schrock [1], Peterson et al [2], Siddique et al [3] and Kuhn et al. [4]. Vierow and Schrock [1] described the local heat transfer coefficient from the Nusselt analysis would be enhanced by the interfacial shear and degraded by the presence of the gas. A "degradation factor", defined as the ration of the experimental heat transfer to the Nusselt value was correlated as function of local gas mass fraction and the mixture Reynolds number. The mechanistic model by Peterson et al [2] used the thermal resistance in series with the parallel steam-gas mixture sensible and condensation resistance. A similar approach was used by Siddique et al [3].

A new analytical model has been developed by Revankar and Oh for the forced flow condensation inside vertical tube [5]. The model predicts the pressure gradient and condensation heat transfer coefficient for turbulent core vapor flow and laminar and turbulent film on the tube wall. In the model the core flow is assumed to be a mixture of vapor and gas. A new eddy viscosity model similar to Chen and $\mathrm{Ke}$ [6] is introduced which is divided into three regions: the inner region in liquid condensate near the wall; the interface region including both liquid and vapor-gas boundary; and the outer region for vapor-gas mixture. . The governing equations include:

1) Turbulent Gas-Vapor Mixture -mass and momentum conservation equations. The analysis for the derivation of the integral-differential equation for the velocity distri- 
bution is based on the paper by Kinney and Sparrow [7]. One of the boundary condition includes the molar average condensation velocity, which is function of the gas concentration [2].

2) Laminar Film - The analysis similar to Nusselt hydrodynamic model [8] with interface shear.

3) Transition from laminar to turbulent film - The transition from laminar to turbulent region is given as a function of liquid film Reynolds number and interface shear.

4) Turbulent film- vapor condensation velocity is derived using force balance and energy equation for the turbulent film.

5) Additional Equations - Species (non-condensable) concentration equation, turbulent transport equations for three regions; inner, interface and outer region similar to Chen and $\mathrm{Ke}[6]$.

Oh's model has been tested for the experiment cases of Kuhn (1995), Siddique (1992), and present Purdue data (Revankar and Oh 2003). These condensation experiments were conducted in a vertical tube condenser with air as NC gas. The computation results compared well with experiment data. In this project, the further improvement of this model will be fulfilled by varying secondary heat transfer coefficient for following PCCS flow conditions with secondary water level change:

(1) Forced flow condensation.

(2) Complete condensation mode. In this case the inlet steam/non-condensable mixture flow velocity decreases to zero near the bottom of the condenser tube.

(3) Cyclic condensation mode. For this flow condition a net increase in pressure gas-vapor pressure due to accumulation of gas is assumed for each sweep of calculation through the length of the tube. Thus the pressure and gas concentration is updated for each calculation step. The gas-vapor velocity at the bottom of the tube is assumed to be zero. When the condenser tube pressure exceeds the PCCS vent line submergence, the gas is assumed to be removed. The next calculation steps repeat the previous steps with initial pressure condition.

The intense modeling improvement will be performed in the third phase of this project. However, some basic calculations by applying this model to $26.6 \mathrm{~mm}$ TS and $52.5 \mathrm{~mm}$ TS experiments have been done as the study and test of this model. 
4.1.2 Physical Model and Formulation of Oh’s Boundary Layer Model

\subsubsection{Gas Region}

Boundary layer equations for the mass, momentum, energy and species in steamgas mixture region are as follows:

Conservation of Mass

$$
\frac{\partial \rho \mathrm{u}}{\partial \mathrm{z}}+\frac{1}{r} \frac{\partial \mathrm{r} \rho \mathrm{v}}{\partial \mathrm{r}}=0
$$

Conservation of z-Directional Momentum

$$
\frac{\partial \rho \mathrm{uu}}{\partial \mathrm{z}}+\frac{1}{\mathrm{r}} \frac{\partial \mathrm{r} \rho \mathrm{vu}}{\partial \mathrm{r}}=-\frac{d \mathrm{p}}{d \mathrm{z}}+\frac{1}{\mathrm{r}} \frac{\partial}{\partial \mathrm{r}}\left(r \mu \frac{\partial u}{\partial \mathrm{r}}\right)+\rho g
$$

Conservation of Energy

$$
\frac{\partial \rho C_{p} \mathrm{u} T}{\partial \mathrm{z}}+\frac{1}{\mathrm{r}} \frac{\partial \mathrm{r} \rho C_{p} \mathrm{vT}}{\partial \mathrm{r}}+\frac{1}{r} \frac{\partial}{\partial \mathrm{r}}\left[r\left(C_{p g}-C_{p v}\right) j_{g}^{\prime \prime} T\right]=\frac{1}{\mathrm{r}} \frac{\partial}{\partial \mathrm{r}}\left(\mathrm{r} k \frac{\partial T}{\partial r}\right)
$$

Third term in left hand side of energy equation represents a net enthalpy change

due to the diffusion mass fluxes $j_{g}^{\prime \prime}$ and $j_{v}^{\prime \prime}\left(=-j_{g}^{\prime \prime}\right)$. Diffusion mass flux for NC gas can be represented by the Fick's law as follows;

$$
j_{g}^{\prime \prime}=-\rho D \frac{\partial \mathrm{W}}{\partial \mathrm{r}}
$$

Conservation of Species

$$
\frac{\partial \rho \mathrm{u} W}{\partial \mathrm{z}}+\frac{1}{\mathrm{r}} \frac{\partial \mathrm{r} \rho \mathrm{vW}}{\partial \mathrm{r}}=\frac{1}{\mathrm{r}} \frac{\partial}{\partial \mathrm{r}}\left(r \rho D \frac{\partial W}{\partial r}\right)
$$

All transport properties for momentum, energy and species are the sum of the molecular and turbulent transport terms as follows;

$$
\begin{aligned}
& \mu=\mu^{m}+\mu^{t} \\
& k=k^{m}+k^{t} \\
& D=D^{m}+D^{t}
\end{aligned}
$$

\subsubsection{Liquid Film Region}

For the liquid film, all the physical properties are assumed as constant and flow condition is laminar. Validity of the laminar film assumption will be discussed in section 4.1.3. Boundary layer equations for the mass, momentum, and energy in liquid region are as follows: 
Conservation of Mass

$$
\frac{\partial \mathrm{u}_{\mathrm{L}}}{\partial \mathrm{z}}+\frac{1}{r} \frac{\partial r \mathrm{v}_{\mathrm{L}}}{\partial r}=0
$$

Conservation of z-Directional Momentum

$$
\mathrm{u}_{\mathrm{L}} \frac{\partial \mathrm{u}_{\mathrm{L}}}{\partial x}+\mathrm{v}_{\mathrm{L}} \frac{\partial \mathrm{u}_{\mathrm{L}}}{\partial \mathrm{r}}=-\frac{1}{\rho_{L}} \frac{d p}{d x}+\frac{v_{\mathrm{L}}}{\mathrm{r}} \frac{\partial}{\partial r}\left(r \frac{\partial \mathrm{u}_{\mathrm{L}}}{\partial r}\right)+g
$$

Conservation of Energy

$$
\mathrm{u}_{\mathrm{L}} \frac{\partial \mathrm{T}_{\mathrm{L}}}{\partial \mathrm{z}}+\mathrm{v}_{\mathrm{L}} \frac{\partial \mathrm{T}_{\mathrm{L}}}{\partial \mathrm{r}}=\frac{\alpha_{\mathrm{L}}}{\mathrm{r}} \frac{\partial}{\partial \mathrm{r}}\left(r \frac{\partial \mathrm{T}_{\mathrm{L}}}{\partial \mathrm{r}}\right)
$$

Since the NC gas is impermeable, there is no species equation for the film region. Film region governing equations are transformed using the coordinate transformation $(z, r) \Rightarrow(\xi, \eta)$ as follows:

$$
\xi=z, \eta=\frac{R-r}{\delta}
$$

Here, liquid film thickness, $\delta$, is only a function of the axial direction z. By this transformation, dimensional radial coordinate is changed to the non-dimensional wall coordinate where $\eta=0$ at the wall and $\eta=1$ at the interface.

Conservation of Mass

$$
\frac{\partial \mathrm{u}_{\mathrm{L}}}{\partial \xi}-\frac{\eta}{\delta} \frac{d \delta}{d z} \frac{\partial \mathrm{u}_{\mathrm{L}}}{\partial \eta}-\frac{1}{(R-\delta \eta) \delta} \frac{\partial}{\partial \eta}\left\{(R-\delta \eta) \mathrm{v}_{\mathrm{L}}\right\}=0
$$

Conservation of z-Directional Momentum

$$
\mathrm{u}_{\mathrm{L}} \frac{\partial \mathrm{u}_{\mathrm{L}}}{\partial \xi}-\left(\frac{\eta}{\delta} \frac{d \delta}{d z} \mathrm{u}_{\mathrm{L}}+\frac{\mathrm{v}_{\mathrm{L}}}{\delta}\right) \frac{\partial \mathrm{u}_{\mathrm{L}}}{\partial \eta}=-\frac{1}{\rho_{L}} \frac{d p}{d z}+g+\frac{v_{L}}{(R-\delta \eta) \delta^{2}} \frac{\partial}{\partial \eta}\left\{(R-\delta \eta) \frac{\partial \mathrm{u}_{\mathrm{L}}}{\partial \eta}\right\}
$$

Conservation of Energy

$$
\mathrm{u}_{\mathrm{L}} \frac{\partial \mathrm{T}_{\mathrm{L}}}{\partial \xi}-\left(\frac{\eta}{\delta} \frac{d \delta}{d z} \mathrm{u}_{\mathrm{L}}+\frac{\mathrm{v}_{\mathrm{L}}}{\delta}\right) \frac{\partial \mathrm{T}_{\mathrm{L}}}{\partial \eta}=\frac{\alpha_{L}}{(R-\delta \eta) \delta^{2}} \frac{\partial}{\partial \eta}\left\{(R-\delta \eta) \frac{\partial \mathrm{T}_{\mathrm{L}}}{\partial \eta}\right\}
$$

\subsubsection{Interfacial Jump Condition and Boundary Condition}

The present problem is a two-phase, two-component flow with annular flow regime. General balance equations for each phase are presented in previous section. The two sets of nonlinear partial differential equations for the vapor-gas mixture and liq- 
uid film are coupled at the interface. To solve the two-phase flow, the interface jump conditions for mass, momentum, energy and species at the liquid-gas interface are needed.

Mass

$$
m_{c}^{\prime \prime}=\Delta m_{L}^{\prime \prime}
$$

Momentum

$$
\tau_{I}=-\left.\mu_{L} \frac{\partial \mathrm{u}_{L}}{\partial \mathrm{r}}\right|_{I}=-\left.\mu \frac{\partial \mathrm{u}}{\partial \mathrm{r}}\right|_{I}
$$

Energy

$$
q_{I}^{\prime \prime}=-\left.k_{L} \frac{\partial \mathrm{T}_{L}}{\partial \mathrm{r}}\right|_{I}=-\left.k \frac{\partial \mathrm{T}}{\partial \mathrm{r}}\right|_{I}+m_{c}^{\prime \prime} h_{f g}
$$

Species

$$
j_{g I}^{\prime \prime}=-\left.\rho D \frac{\partial W}{\partial \mathrm{r}}\right|_{I}=-m_{c}^{\prime \prime} W_{I}
$$

Boundary conditions at the tube wall, tuber center, and interface can be specified as follows:

At interface:

$$
u_{L I}=u_{I}, T_{L I}=T_{I}
$$

At $r=0$ (tube center line),

$$
\frac{\partial \mathrm{u}}{\partial \mathrm{r}}=\frac{\partial \mathrm{T}}{\partial \mathrm{r}}=\frac{\partial W}{\partial \mathrm{r}}=0, \mathrm{v}=0
$$

At $r=R$ (wall),

$$
\mathrm{u}_{L}=0, T_{L}=T_{W}
$$

\subsubsection{Turbulent Model}

Several turbulent models has been applied in this model, such as Mixing length model, Van Driest model, Kinney model, Kays model and Reichardt model. By testing different models in the calculation for the experiment cases of Kuhn (1995), Siddique (1992), and present Purdue data (Revankar and Oh 2003), Modified Reichardt model shows the best agreement between analysis results and experiment data. Therefore, Modified Reichardt model was applied to perform the analysis of experiment data from $26.6 \mathrm{~mm}$ TS and $52.5 \mathrm{~mm}$ TS. 
Prandlt-Nikuradse model (Yih and Liu 1983) for the eddy diffusivity of momentum is divided into three conventional regions, i.e., laminar sublayer, buffer, and turbulent core region.

$$
\begin{gathered}
\frac{v^{\mathrm{t}}}{v^{\mathrm{m}}}=0 \quad \text { for } \quad 0 \leq \mathrm{y}^{+} \leq 5 \\
\frac{v^{\mathrm{t}}}{v^{\mathrm{m}}}=\frac{\mathrm{y}^{+}-5}{5} \text { for } 5 \leq \mathrm{y}^{+} \leq 26 \\
\frac{v^{\mathrm{t}}}{v^{\mathrm{m}}}=\frac{\mathrm{y}^{+}}{2.5} \text { for } 26 \leq \mathrm{y}^{+}
\end{gathered}
$$

Reichardt (1951) proposed the eddy diffusivity applicable to all regions in the turbulent pipe flow.

$$
\frac{v^{\mathrm{t}}}{v^{\mathrm{m}}}=\frac{\mathrm{y}^{+}}{2.5} \cdot \frac{1}{6} \cdot\left[1+\frac{r}{R}\right] \cdot\left[1+2 \cdot\left(\frac{r}{R}\right)^{2}\right]
$$

By combining Prandlt-Nikuradse model and Reichardt model, modified Reichardt model is used; for the laminar sublayer and buffer region Prandlt-Nikuradse model is used and for the turbulent core region Reichardt model is used. For the present analysis of the gas core region in the annular flow, $\mathrm{y}^{+}$is modified to consider the film thickness as follows;

$$
\mathrm{y}^{+}=(R-\delta-r) \frac{u^{*}}{v^{m}}
$$

Also the friction velocity $u^{*}$ is defined by the interface shear instead of the traditional wall shear as follows;

$$
u^{*}=\left(\tau_{I} / \rho\right)^{0.5}
$$

Boundary layer model introduced in this chapter was published in Oh and Revankar (2005a).

\subsubsection{Analysis Result}

The calculation for $26.6 \mathrm{~mm}$ and $52.5 \mathrm{~mm}$ TS cases was performed by using Oh's boundary layer model. The base case was selected from Purdue data (Revankar and Oh 2003) with $26.6 \mathrm{~mm}$ test section. The inlet condition in base case includes the steam flow rate of $5.09 \mathrm{~g} / \mathrm{s}$, the inlet air flow rate of $0.201 \mathrm{~g} / \mathrm{s}$ and inlet pressure of $259 \mathrm{kPa}$. To show the effect of noncondensable gas, another inlet condition for $26.6 \mathrm{~mm}$ TS case was designed with same inlet steam flow 
rate and pressure but different inlet air flow rate. The inlet conditions for 52.5 $\mathrm{mm}$ TS were determined from the up-scaling of $26.6 \mathrm{~mm}$ TS. The ratio of inlet flow rate was selected as the ratio of heat transfer area, i.e. the ratio of tube inner diameters for both test sections have same length. The inlet noncondensable fraction and inlet pressure were selected as the same value in corresponding $26.6 \mathrm{~mm}$ TS cases.

$$
\begin{gathered}
\left(M_{G, \text { in }}\right)_{R}=A_{R}=d_{R} \cdot L_{R}=0.5067 \\
\left(\operatorname{Re}_{\text {in }}\right)_{R}=\left(\frac{\rho_{G} \cdot V_{\text {in }} \cdot d}{\mu_{G}}\right)_{R}=\left(\frac{4 \cdot m_{G, \text { in }}}{\pi \cdot d \cdot \mu_{G}}\right)_{R}=\left(\frac{m_{G, i n}}{d}\right)_{R}=1
\end{gathered}
$$

The inlet conditions are summarized in Table 4.1

Table 4.1 Summary of the inlet condition for the calculation (Tube length: $1.0 \mathrm{~m}$ )

\begin{tabular}{|c|c|c|c|c|c|}
\hline $\begin{array}{c}\text { Run } \\
\text { No. }\end{array}$ & $\begin{array}{c}\text { Inlet } \\
\text { steam } \\
\text { flow rate, } \\
\mathrm{g} / \mathrm{s}\end{array}$ & $\begin{array}{c}\text { Inlet Air } \\
\text { flow rate, g/s }\end{array}$ & $\begin{array}{c}\text { Inlet non- } \\
\text { condensable } \\
\text { Fraction }\end{array}$ & $\begin{array}{c}\text { Inlet Pres- } \\
\text { sure, kPa }\end{array}$ & $\begin{array}{c}\text { Tube } \\
\text { ID, mm }\end{array}$ \\
\hline 26 & 5.09 & 0.201 & $4 \%$ & 259 & 26.6 \\
\hline $26 \mathrm{a}$ & 10.18 & 0.402 & $4 \%$ & 259 & 52.5 \\
\hline 27 & 5.09 & 0.509 & $10 \%$ & 259 & 26.6 \\
\hline $27 \mathrm{a}$ & 10.18 & 1.02 & $10 \%$ & 259 & 52.5 \\
\hline 28 & 5.09 & 1.18 & $20 \%$ & 259 & 26.6 \\
\hline $28 \mathrm{a}$ & 10.19 & 2.02 & $20 \%$ & 259 & 52.5 \\
\hline
\end{tabular}

Fig. 4.1 shows that the local condensation HTC decreases with condenser tube length for both two test sections. At the region near to the inlet of tube, condensation is starting and the liquid film is very thin, condensation performs very well due to the small heat transfer resistance. As a result, a high condensation HTC can be reached. With the continuous condensation of steam, the film thickness increases rapidly so that the heat transfer resistance is getting greater. Another factor is that more and more noncondensable gas accumulates at the gasliquid interface along the condenser tube length; the mass transfer resistance increases very fast and becomes dominant resistance for preventing condensation. 
Thus the condensation HTC drops sharply with the increase of heat transfer resistance and mass transfer resistance along the tube.

Fig. 4.2 shows the increase of liquid film thickness with the tube length. The film thickness of $52.5 \mathrm{~mm}$ TS case is greater than that of $26.6 \mathrm{~mm}$ TS case which indicates a greater heat transfer resistance for $52.5 \mathrm{~mm}$ TS. The inlet steam/gas mixture flow rate of $52.5 \mathrm{~mm}$ TS is twice of that flow rate of $26.6 \mathrm{~mm}$ TS from up-scaling. However, the ratio of tuber cross-section area between 2 test sections is 4 . Therefore, the downward vapor velocity in $52.5 \mathrm{~mm}$ TS is only half of that in $26.6 \mathrm{~mm}$ TS which gives a smaller interfacial shear and results in a thinner liquid film in $26.6 \mathrm{~mm}$ TS.

Degradation of condensation due to the NC gas is also shown in Fig. 4.3. In this figure, the ratio of the calculated condensation HTC to the Nusselt solution is plotted for different inlet conditions. From this figure more degradation is observed for $52.5 \mathrm{~mm}$ test section, this is because more noncondensable gas accumulates at the liquid-gas interface. It also should be noted that the calculated HTC at the inlet region of tube is greater than the Nusselt solution due to the high interfacial shear at small noncondensable fraction (4\%), which results in a thinner film thickness.

The calculation results for different NC gas fraction are compared in Figs. 4.1-4.3. The condensation performance is deteriorating as the increase of NC gas fraction. For higher NC fraction, more noncondensable gas is accumulated at the liquid-gas interface which resists the mass transfer through the interface. In Fig. 4.3, the deviation of condensation HTC between Nusselt solution and calculated HTC is getting greater for higher NC fraction which also indicates the degradation of condensation. 


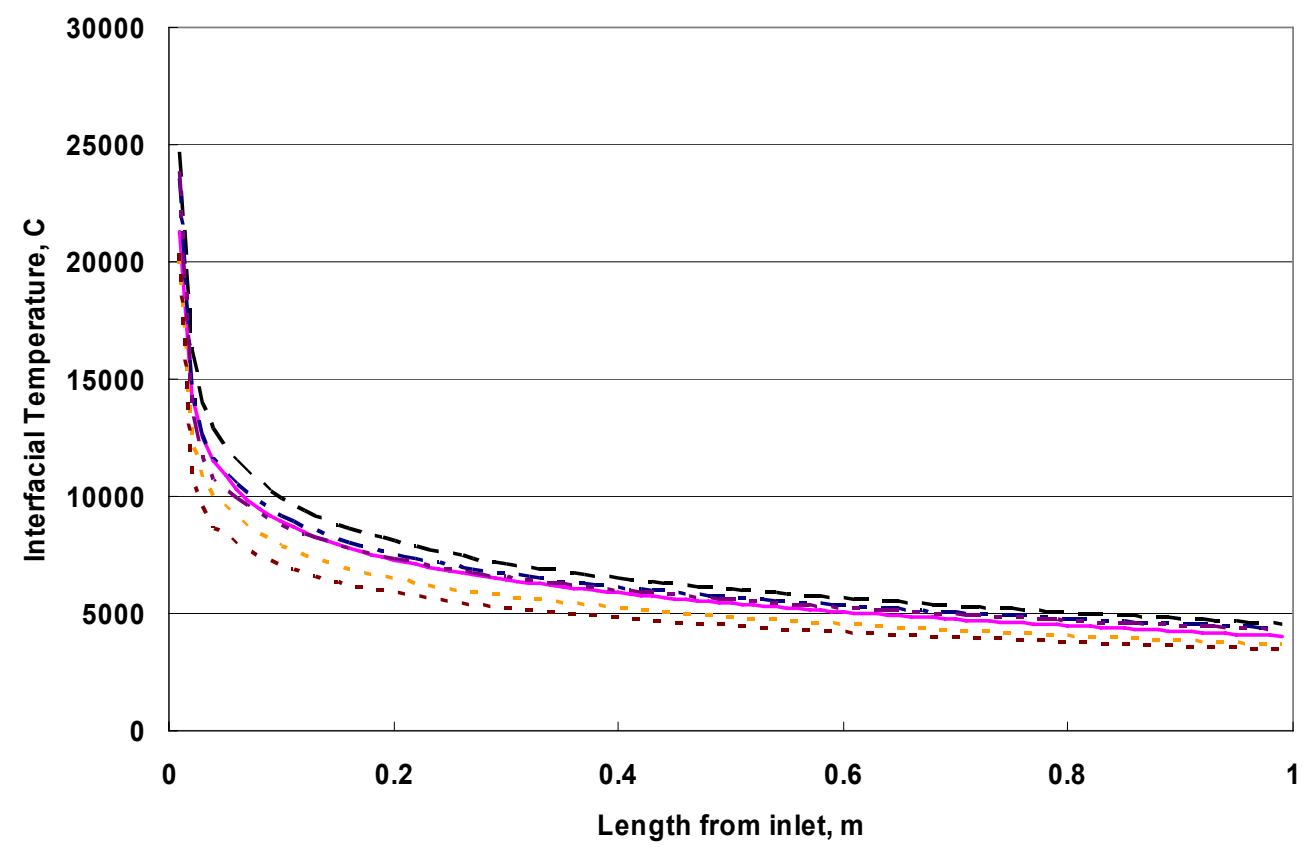

$-26(\mathrm{ID}=26.6 \mathrm{~mm}, \mathrm{Win}=4 \%) \quad \longrightarrow 26 \mathrm{a}(\mathrm{ID}=52.5 \mathrm{~mm}, \mathrm{Win}=4 \%) \quad-\quad-27(\mathrm{ID}=26.6 \mathrm{~mm}, \mathrm{Win}=10 \%)$

- - - 27a(ID=52.5mm,Win=10\%) - - 28(ID=26.6mm,Win=20\%) - - - 28a(ID=52.5mm,Win=20\%)

Fig. 4.1 HTC profile along tube length with same noncondensable fraction

$(\mathrm{Min}=5.09 \mathrm{~g} / \mathrm{s}$ for $26.6 \mathrm{~mm} \mathrm{ID}, \mathrm{Min}=10.2 \mathrm{~g} / \mathrm{s}$ for $52.5 \mathrm{~mm} \mathrm{ID})$

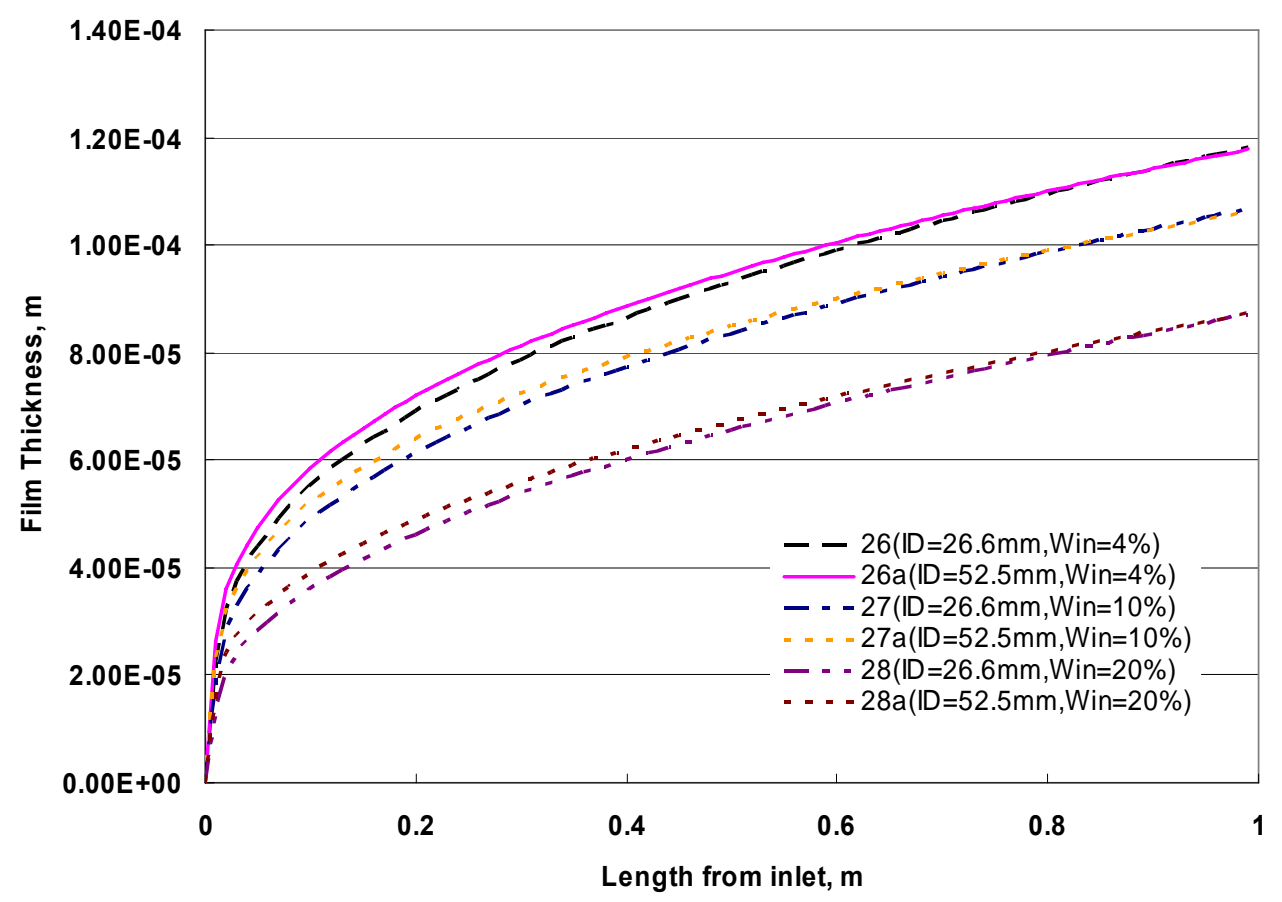

Fig. 4.2 Film thickness with tube length

$(\mathrm{Min}=5.09 \mathrm{~g} / \mathrm{s}$ for $26, \mathrm{Min}=10.2 \mathrm{~g} / \mathrm{s}$ for $26 \mathrm{a})$ 


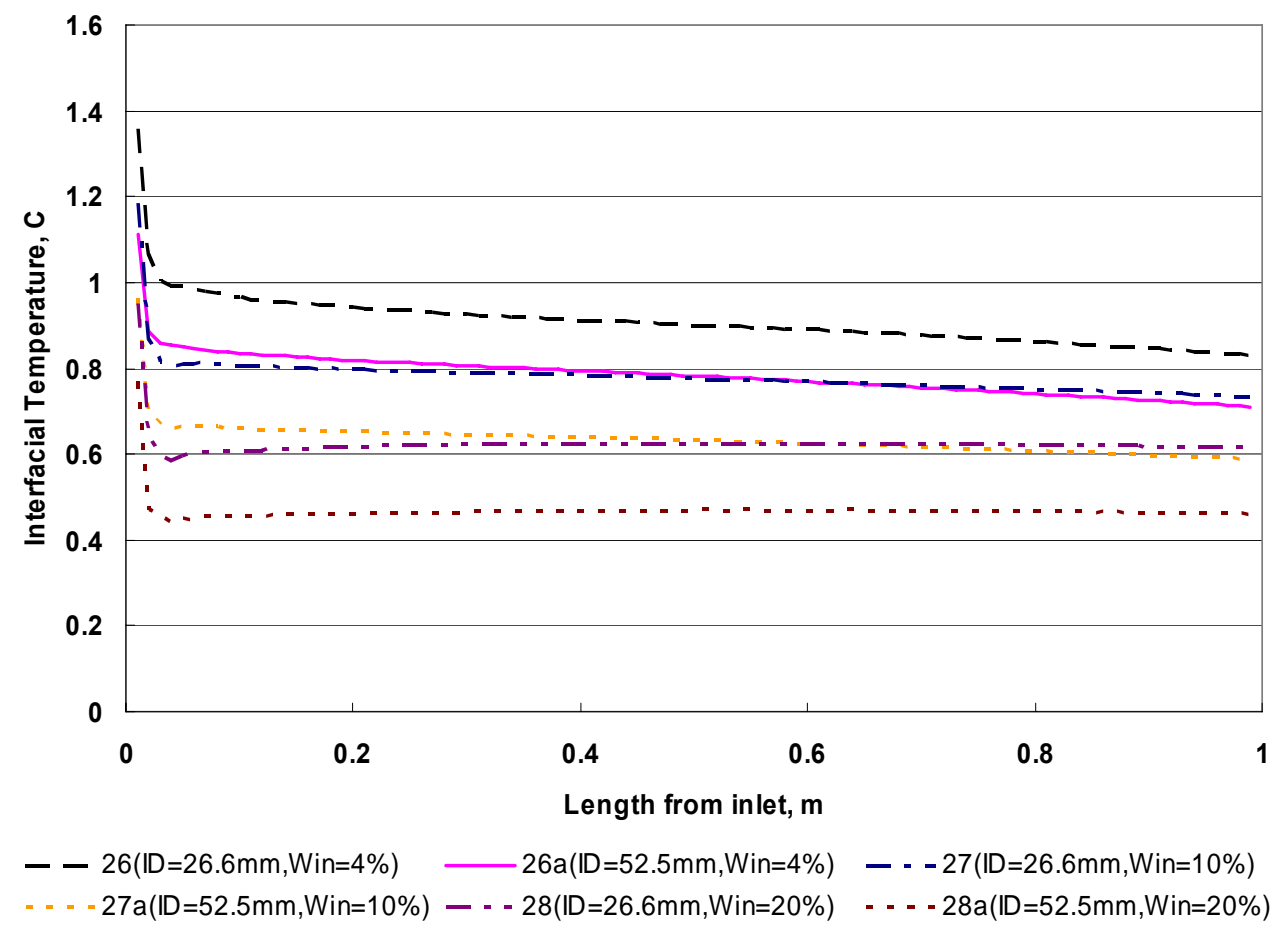

Fig. 4.3 HTC comparison with Nusselt solution

$(\mathrm{Min}=5.09 \mathrm{~g} / \mathrm{s}$ for $26, \mathrm{Min}=10.2 \mathrm{~g} / \mathrm{s}$ for $26 \mathrm{a})$

Figs. 4.4 and 4.5 present the bulk and the interface NC gas mass fraction, respectively. As steam is condensing along the condenser tube, the bulk NC gas mass fraction is monotonically increasing with tube length. However, three regions can be identified with respect to the interface $\mathrm{NC}$ gas mass fraction along the condenser tube. First region shows a sharp increase of the interface NC gas mass fraction at the tube inlet. At this region, condensation is starting and condensing rate is so high that large portion of the $\mathrm{NC}$ gas is accumulating at the interface and the diffusion of the $\mathrm{NC}$ gas to the mixture core region is not well established. For this reason, the interface NC gas mass fraction increases rapidly. Second region shows a small decrease and stagnation of the interface NC gas mass fraction right after the first region. At this region, the condensing rate is moderate and the diffusion rate of the $\mathrm{NC}$ gas is high since the gradient of the NC gas mass fraction between interface and mixture core is large. Finally, a smooth increasing region of the interface NC gas mass fraction follows the second region. 
From Fig. 4.4, the bulk non-condensable gas fraction of $52.5 \mathrm{~mm}$ test section is smaller than that of $26.6 \mathrm{~mm}$ test section. This is mainly due to the smaller condensation HTC in $52.5 \mathrm{~mm}$ test section, compared with $26.6 \mathrm{~mm}$ test section. The condensation rate in $52.5 \mathrm{~mm}$ test section is less than twice of that in $26.6 \mathrm{~mm}$ test section. So the bulk steam concentration in $52.5 \mathrm{~mm}$ TS is reducing slowly so that the bulk gas fraction increasing slowly. However, from Fig. 4.5, the noncondensable gas fraction at the liquid-gas interface for $52.5 \mathrm{~mm}$ test section is greater than that of $26.6 \mathrm{~mm}$ test section. As discussed above, the bulk mixture velocity in $52.5 \mathrm{~mm}$ test section is smaller than that in $26.6 \mathrm{~mm}$ test section. Therefore, the convection between interface region and core region is not efficient so that more noncodensable gas accumulates at the interface which gives a higher interfacial NC concentration.

Fig. 4.5 shows the interface temperature distribution. Interface temperature is the saturation temperature of the steam partial pressure at the interface. The steam partial pressure is a direct function of the $\mathrm{NC}$ gas mass fraction, i.e., it decreases as NC gas mass fraction increases. Therefore, the interface temperature follows inversely the trends of the interface $\mathrm{NC}$ gas mass fraction; the interface temperature shows a sharp decrease at the first region, a small increase and stagnation at the second region, and finally a smooth decrease at the third region.

The effect of different inlet NC gas fractions is distinct in Figs. 4.4-4.6. A higher inlet $\mathrm{NC}$ gas fraction directly results in a higher Bulk and interfacial NC fraction and a lower interfacial temperature. 


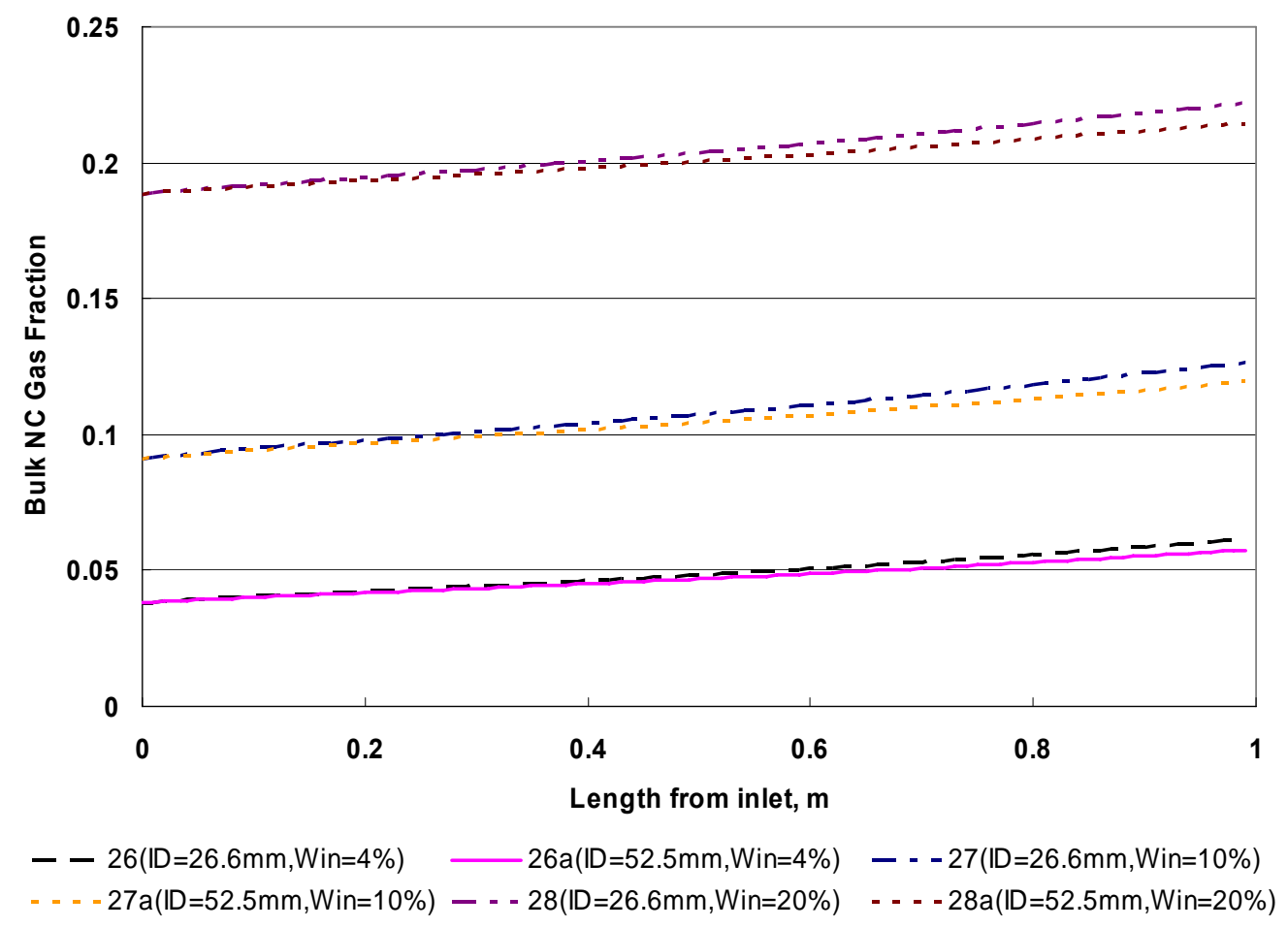

Fig. 4.4 Bulk Gas Concentration Profile with Tube Length

$(\mathrm{Min}=5.09 \mathrm{~g} / \mathrm{s}$ for $26, \mathrm{Min}=10.2 \mathrm{~g} / \mathrm{s}$ for $26 \mathrm{a})$

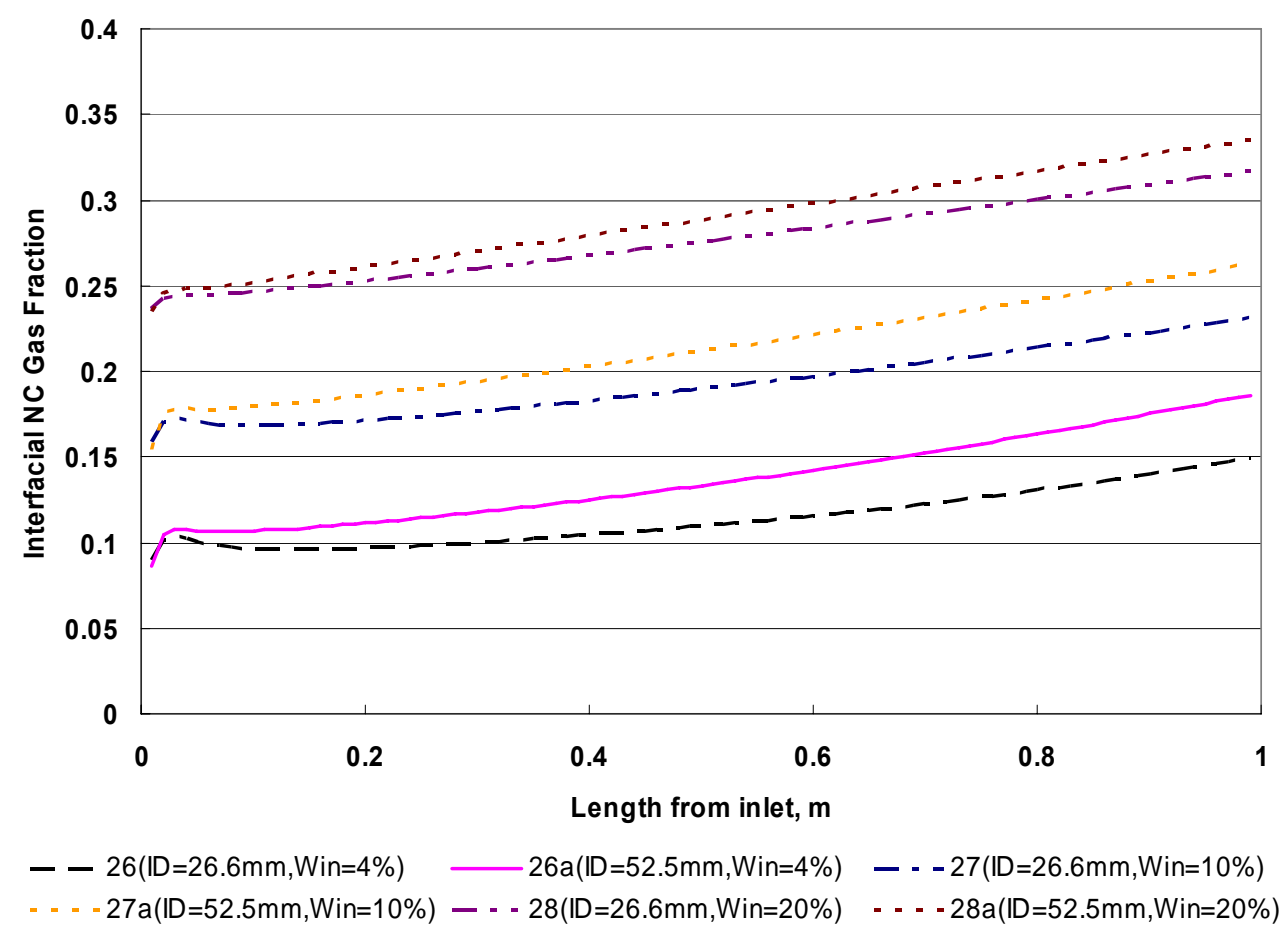

Fig. 4.5 Interfacial Gas Concentration Profile with Tube Length

$(\mathrm{Min}=5.09 \mathrm{~g} / \mathrm{s}$ for $26, \mathrm{Min}=10.2 \mathrm{~g} / \mathrm{s}$ for $26 \mathrm{a})$ 


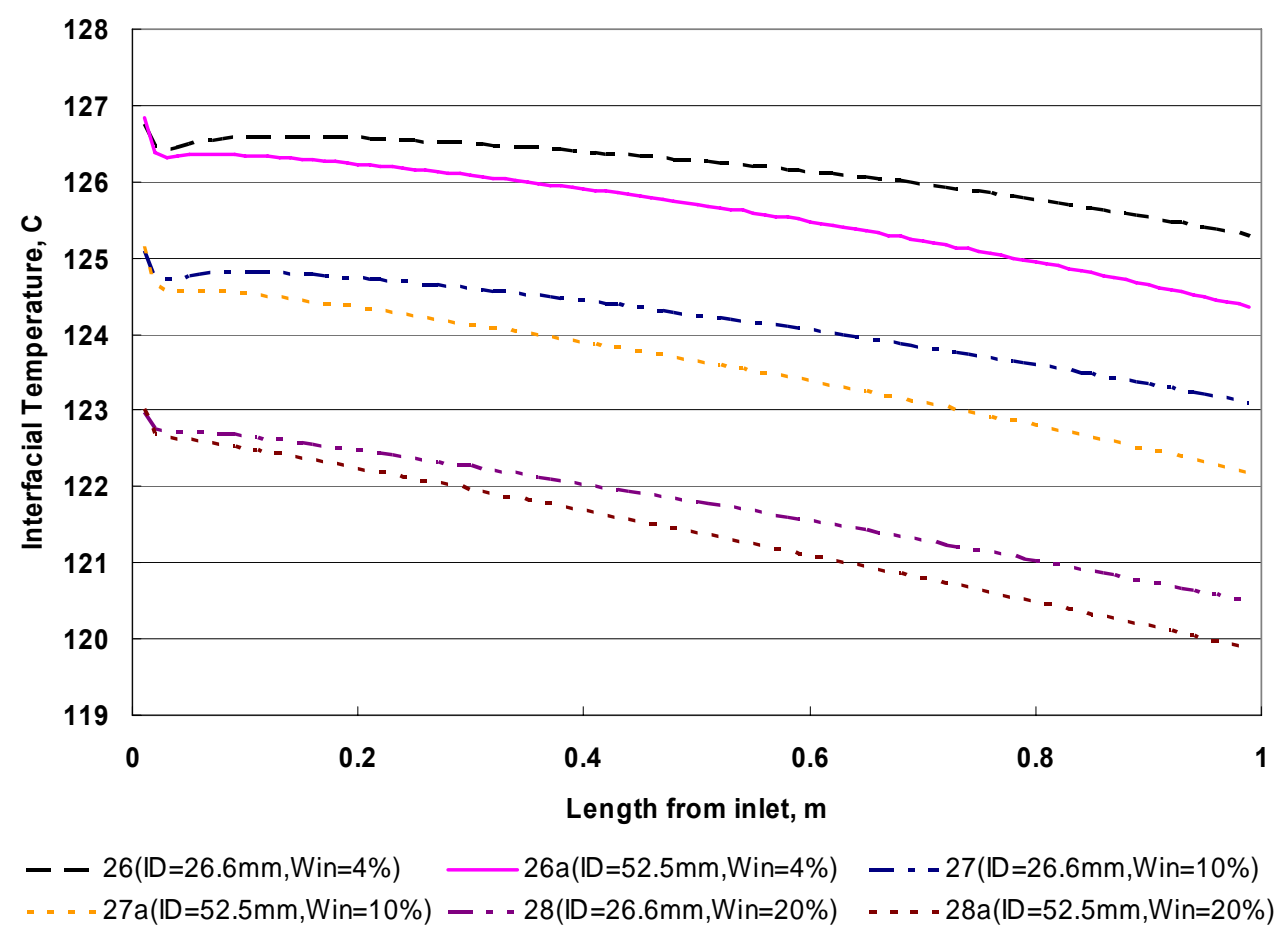

Fig. 4.6 Interfacial Temperature Profile with Tube Length

$(\mathrm{Min}=5.09 \mathrm{~g} / \mathrm{s}$ for $26, \mathrm{Min}=10.2 \mathrm{~g} / \mathrm{s}$ for $26 \mathrm{a})$

Liquid Reynolds number profile is shown in Fig. 4.7 for two test sections. Generally, liquid film Reynolds number increases with tube length because of the increase of film velocity, the highest Reynolds number at outlet of tube for all calculation cases is less than 450. The outlet Reynolds numbers are much lower than the transition Reynolds number, which is given as 1500-1600 from Rohsenow's model. So the assumption of laminar film in the analysis is considered as validated. Usually, momentum and energy transfer in liquid film can be enhanced by the film wave even though film flow itself is laminar. It should be also noted that for larger steam flow rate and longer condenser tube, the film could be transitional region or turbulent region near the exit region.

A higher condensation performance is also investigated for small inlet NC gas fraction from Fig. 4.7. For small inlet NC fraction, film Reynolds number is greater which means more condensation rate in the condenser tube with same diameter. 


$$
\operatorname{Re}_{f}=\frac{\rho_{f} \cdot V_{f} \cdot d}{\mu_{f}}=\frac{4 \cdot m_{\text {cond }}}{\pi \cdot d \cdot \mu_{f}}
$$

From (4.31), film Reynolds number is proportional to the ratio of condensation rate over tube diameter. This ratio of $52.5 \mathrm{~mm}$ test section is less than the ratio of $26.6 \mathrm{~mm}$ test section, because the condensation rate of $52.5 \mathrm{~mm}$ test section is less than twice of that in $26.6 \mathrm{~mm}$ test section. So the Reynolds number for $52.5 \mathrm{~mm}$ test section case is smaller than that of $26.6 \mathrm{~mm}$ test section case with same inlet $\mathrm{NC}$ fraction.

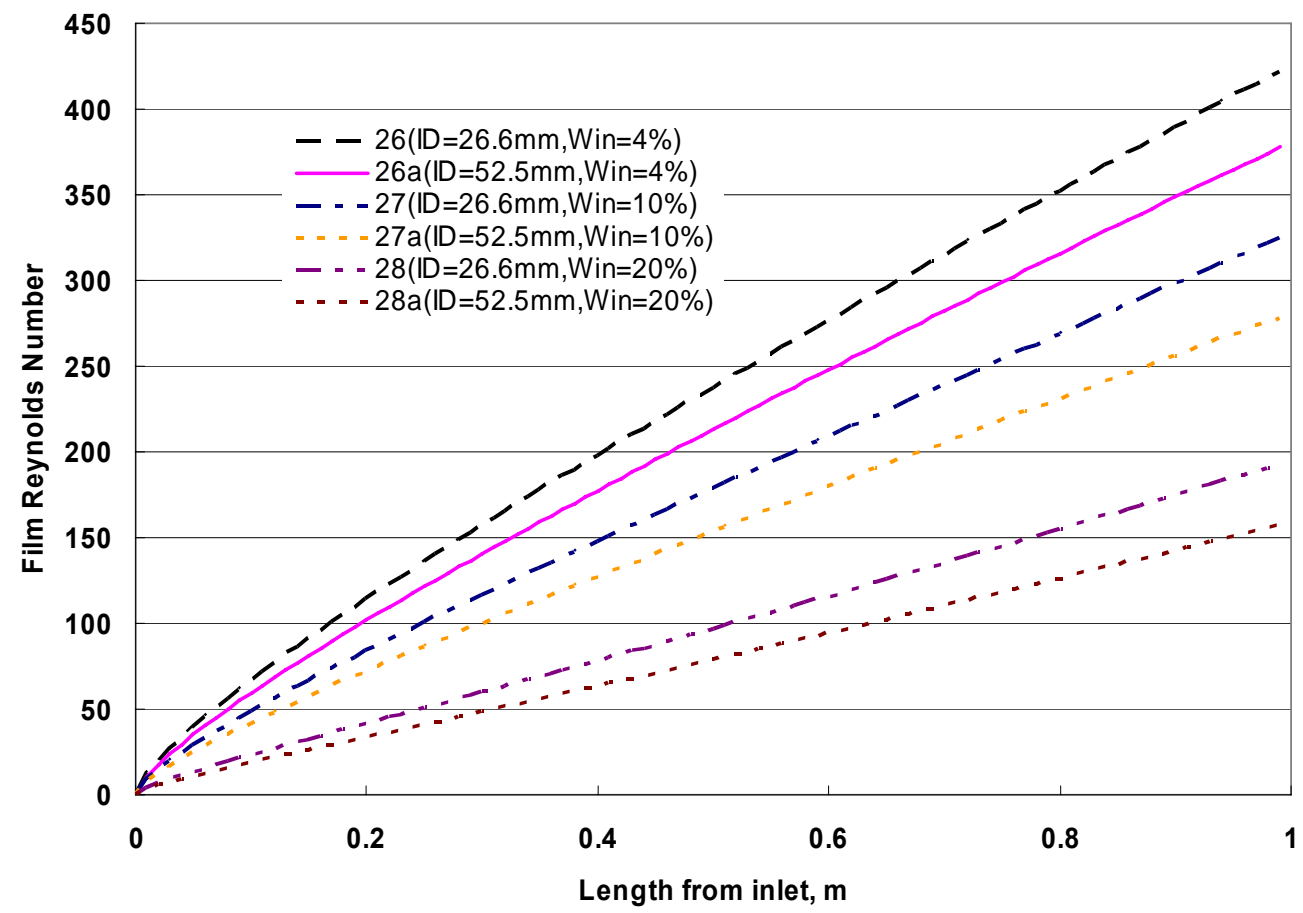

Fig. 4.7 Liquid Film Region Reynolds Number

Fig. 4.8 presents the boundary layer thickness for axial velocity $\left(\delta_{M}\right)$, temperature $\left(\delta_{H}\right)$ and NC gas mass fraction $\left(\delta_{W}\right)$ for Purdue data's run number $=26$. The boundary layer thickness is the length from the interface to the location where the relative variation of the quantity is $99 \%$ of total variation. For example, velocity boundary layer thickness can be determined as follows;

$$
0.99=\frac{u\left(y=\delta_{M}\right)-u_{I}}{u(r=0)-u_{I}}
$$


The boundary layer thickness for velocity, temperature and NC gas mass fraction is developing with very similar way Dimensionless profiles for axial velocity, temperature and $\mathrm{NC}$ gas mass fraction after $\mathrm{z}=7 \mathrm{~cm}$ are plotted in Figs. 4.9-4.11, respectively. Dimensionless axial velocity is defined as follows;

$$
\text { Dimensionless } u=\frac{u-u\left(y=\delta_{M}\right)}{u_{I}-u\left(y=\delta_{M}\right)}
$$

Dimensionless temperature and NC gas mass fraction are defined by the same way as defined in eq. (3.33). From these figures, it can be noted that the profiles in the boundary layer are very similar for the three variables as well as for different axial locations after $\mathrm{z}=7 \mathrm{~cm}$. This analysis is performed for $2.66 \mathrm{~cm}$ inner diameter tube. So, the profiles are almost self-similar only after 2 L/D length. These results support the self-similar profile assumption and integral analysis method in the previous researches.

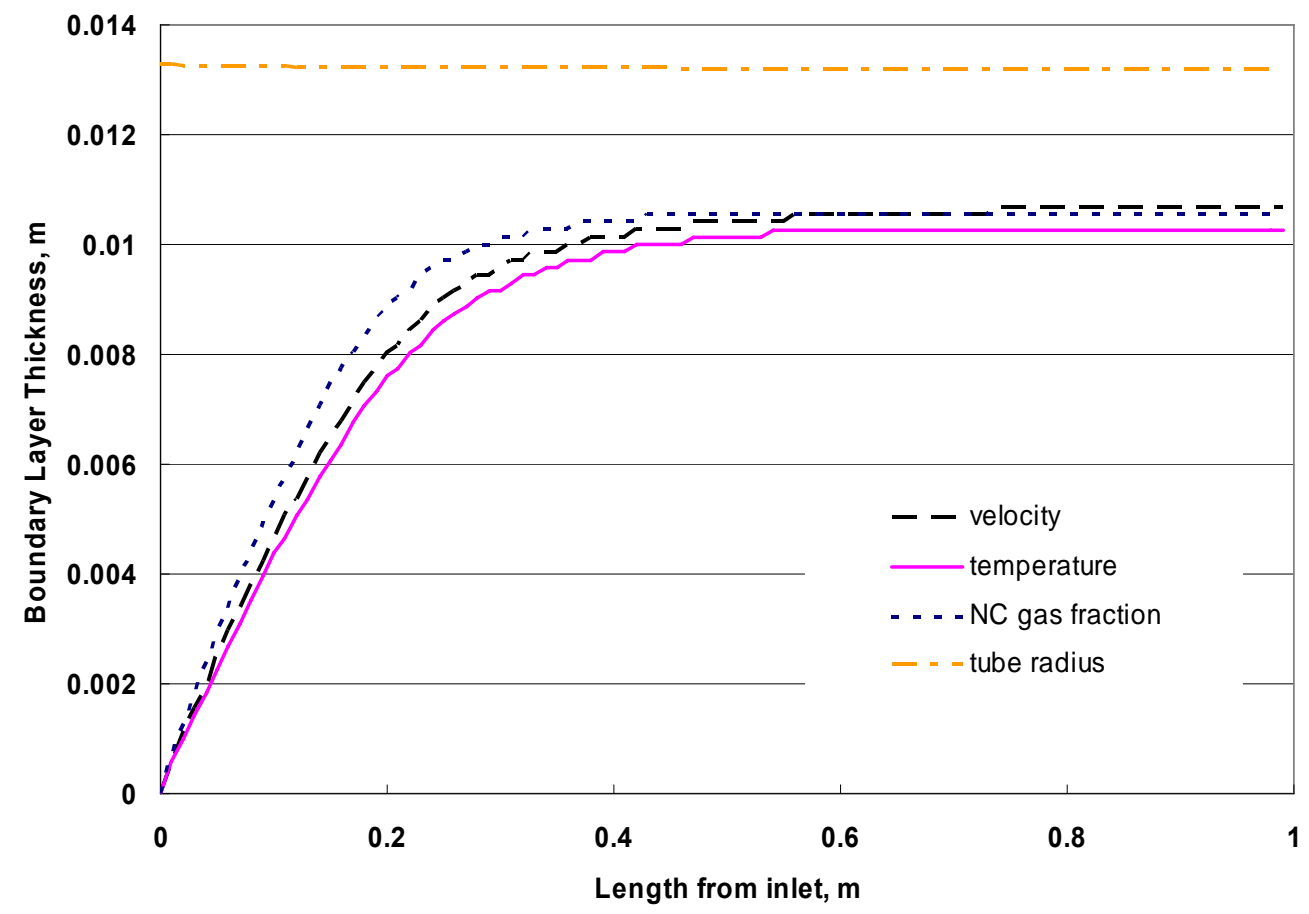

Fig. 4.8 Boundary Layer Thickness for Purdue Data's run number=26 


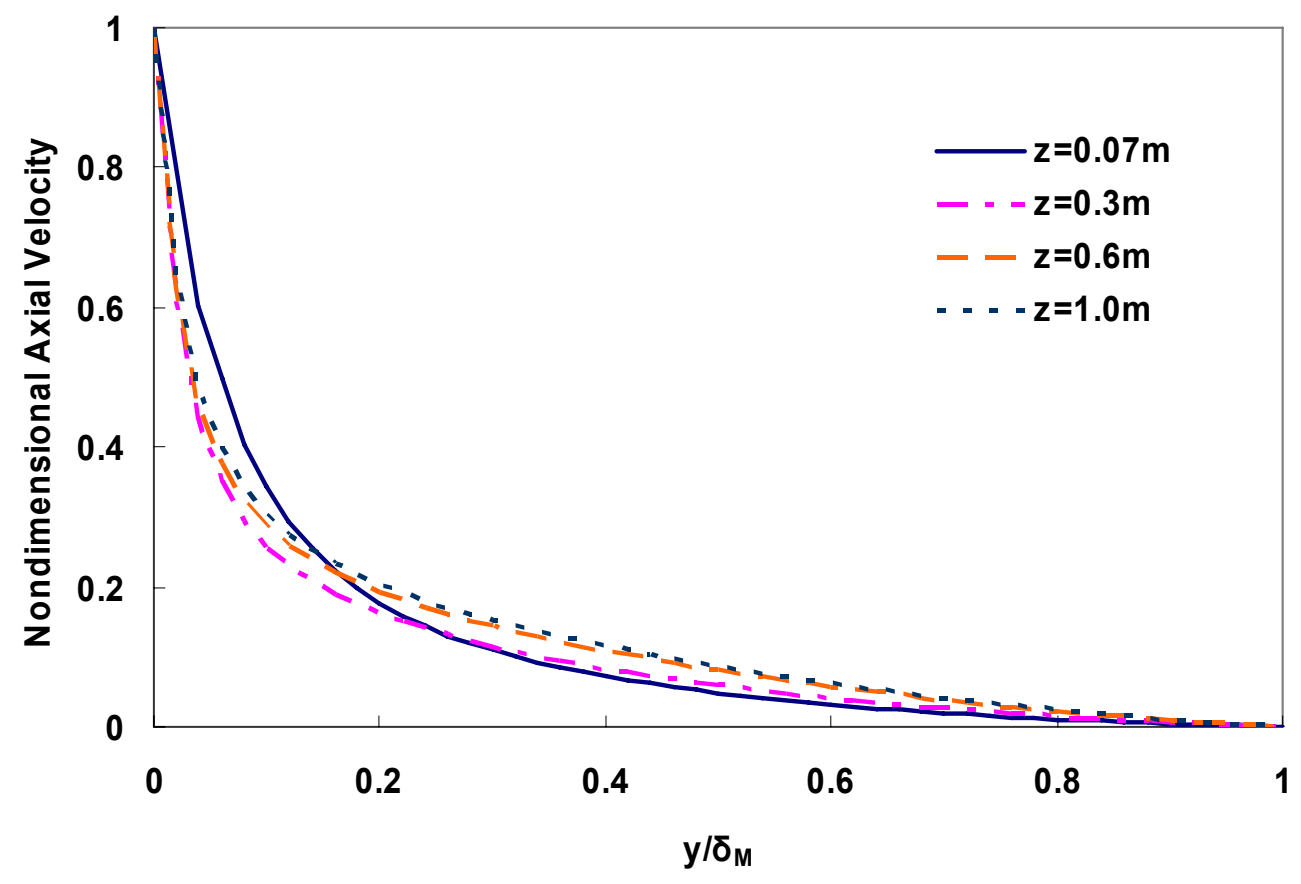

Fig. 4.9 Dimensionless Axial Velocity for Purdue Data's run number=26

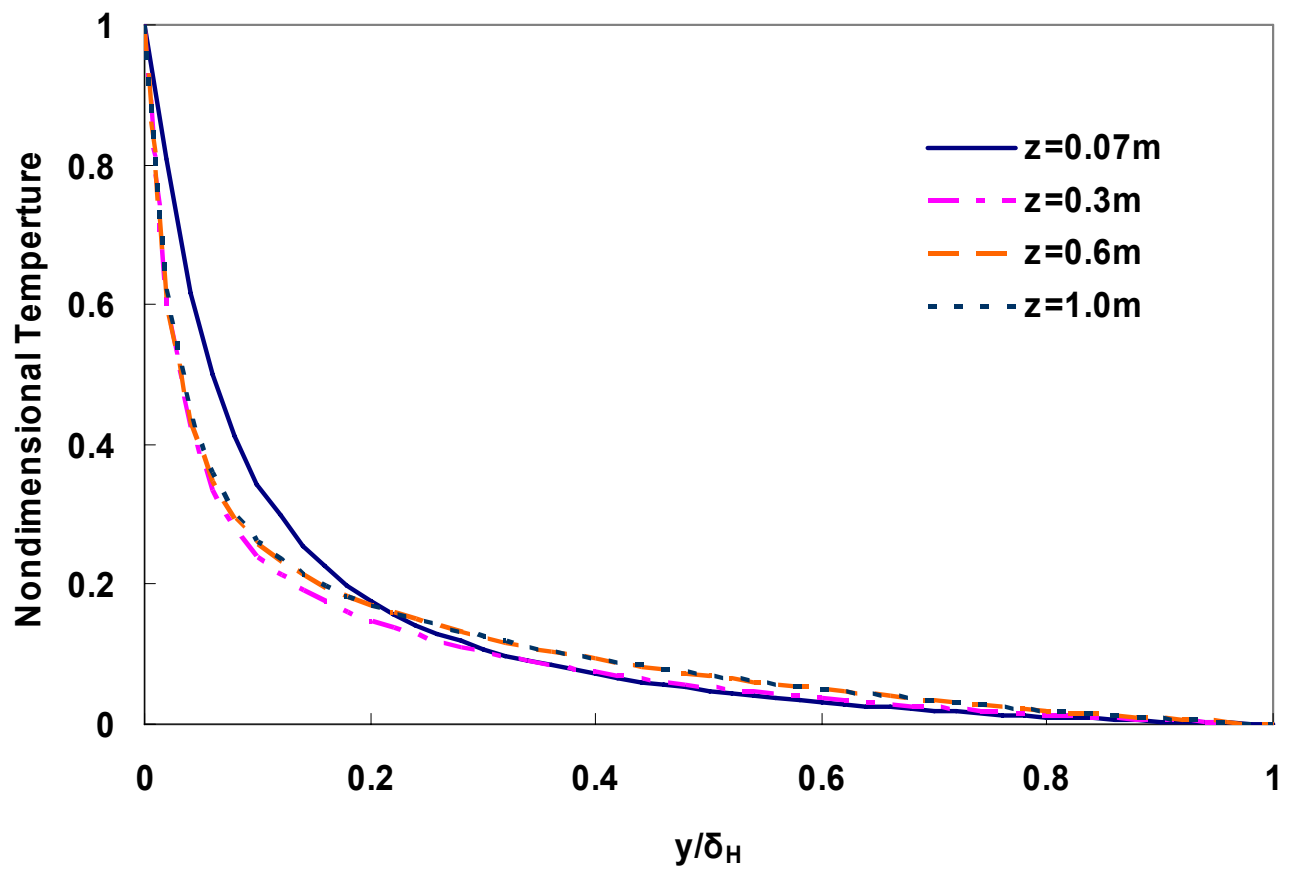

Fig. 4.10 Dimensionless Temperature for Purdue Data's run number=26 


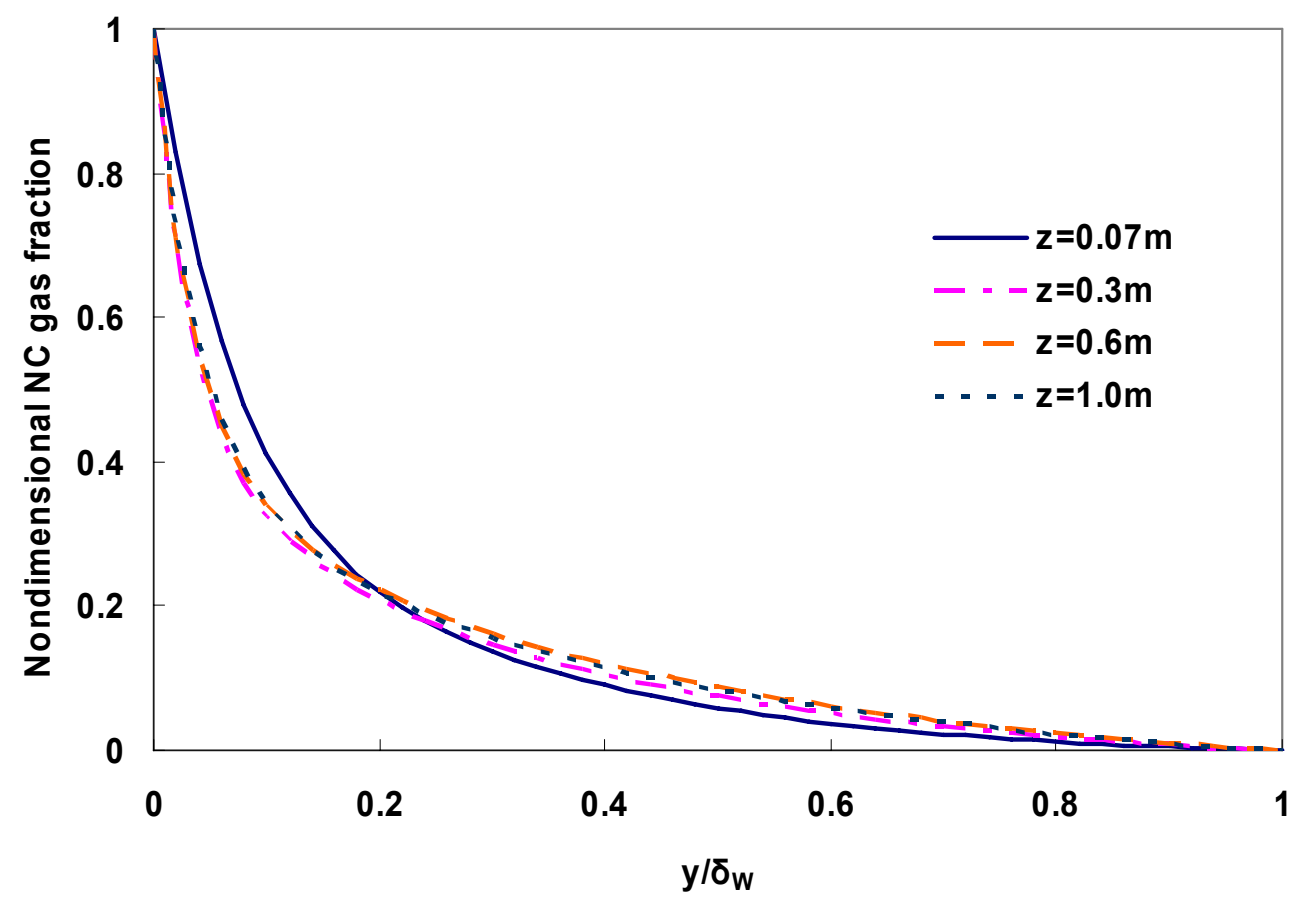

Fig. 4.11 Dimensionless NC Gas Mass Fraction for Purdue Data's run number $=26$

\subsubsection{Conclusion}

Oh's boundary layer model was developed for the prediction of the filmwise steam condensation with noncondensable gas in a vertical tube. Full set of the governing equations for liquid film and steam-air mixture regions are solved by the numerical method. The predictions from this model are compared with the experimental data and the agreement is satisfactory.

The calculation results from this model to condenser tubes with different diameters are shows the effects of tube size to condensation performance. For larger diameter tube, condensation rate is greater due to the increase of heat transfer area, but condensation HTC is smaller due to the thicker liquid film around inside tube wall. The analysis results also clearly prove the great deterioration of condensation performance when $\mathrm{NC}$ gas existence.

\subsection{Heat and Mass Analogy Model}




\subsubsection{Heat and Mass Analogy Model Comparison}

In this section, predictions from heat and mass analogy model [9] are presented. The heat and mass analogy method is based on the heat balance at the liquid-gas interface, where the heat transferred from the vapor-gas boundary layer is equated to the heat transferred through the condensate film. The heat transfer from the gas region is the sum of the sensible cooling of bulk mixture and latent heat of condensation. To balance the heat transfer rate between film and mixture regions, the interface temperature is determined iteratively. These procedures are repeated along the condenser length.

\subsubsection{Energy Balance}

The physical model of the film condensation in a tube is shown in Figure 4.1. Variables or properties related with liquid film, vapor, and $\mathrm{NC}$ gas are respectively denoted with subscript L, v, and g. However, those related with vapor-gas mixture have no subscript for simplicity in the presentation of equations. The vapor-gas mixture is assumed to be saturated for the present model. Heat transfer in the gas-vapor mixture region consists of the latent heat of condensation and sensible heat transfer. Then heat flux at the mixture-liquid film interface can be written as

$$
\mathrm{q}_{\text {TOT }}=\mathrm{q}_{\text {cond }}+\mathrm{q}_{\text {sen }}=\mathrm{m}_{\mathrm{c}}^{\prime \prime} \cdot \mathrm{h}_{\mathrm{fg}}+h_{\text {sen }} \cdot\left(T_{\text {SAT }}-T_{I}\right) \text {. }
$$

All the flux terms in this analysis such as heat flux, mass flux, and diffusion flux are based on the tube inside surface area. The gas region heat transfer rate must be balanced with heat transfer rate at film region, i.e.,

$$
\mathrm{q}_{\text {тот }}=\mathrm{q}_{\mathrm{L}}=h_{\mathrm{L}} \cdot\left(T_{I}-T_{\text {Wi }}\right) \text {. }
$$

From the latent heat of condensation and the temperature difference between interface and bulk saturation, a condensation HTC $\left(h_{\text {cond }}\right)$ can be defined as

$$
h_{\text {cond }} \equiv \frac{\mathrm{m}_{\mathrm{c}} \cdot \mathrm{h}_{\mathrm{fg}}}{\left(T_{S A T}-T_{I}\right)} .
$$




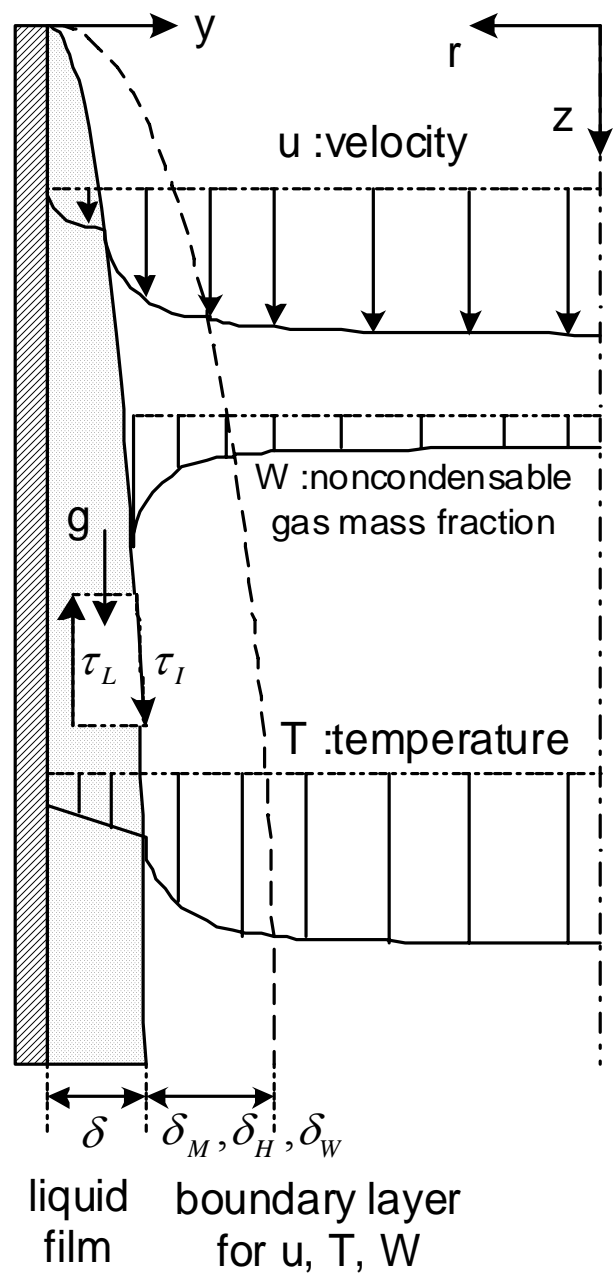

Figure 4.12 Physical model for film condensation

By substituting Eq. (4.36) into (4.34) and equating to Eq. (4.35),

$$
h_{L} \cdot\left(T_{I}-T_{W i}\right)=\left(h_{\text {cond }}+h_{\text {sen }}\right) \cdot\left(T_{S A T}-T_{I}\right) .
$$

Total condensation HTC for the annular film condensation can be defined as

$$
h_{c} \equiv \frac{\mathrm{q}_{\text {TOT }}}{\left(T_{S A T}-T_{W i}\right)} .
$$

It should be noted that $h_{\text {cond }}$ is the HTC defined as Eq. (4.36) which takes account of the condensation heat transfer in gas region only. However, $h_{c}$ is total condensation HTC defined as Eq. (4.38) which reflects the heat transfer resistance of film, gas region condensation, and gas region sensible heat transfer. To avoid the confusion 
between these two condensation HTC, $h_{\text {cond }}$ is called as gas region condensation HTC, hereafter.

Total resistance of heat transfer which is an inverse of total condensation HTC can be expressed as sum of individual resistance.

$$
\frac{1}{h_{c}}=\frac{1}{h_{L}}+\frac{1}{h_{\text {cond }}+h_{\text {sen }}}
$$

To obtain $h_{c}$, the heat transfer components $\left(h_{L}, h_{\text {cond }}\right.$ and $\left.h_{\text {sen }}\right)$ should be estimated and the procedures to calculate these components are presented in the following sections.

\subsubsection{Liquid Film Model}

For the liquid film, the force balance in the control volume in Figure 4.12 can be described as

$$
\tau_{L}=\left(\rho_{L}-\rho\right) \cdot g \cdot(\delta-y)+\tau_{I}
$$

Liquid film is assumed to be laminar for the film thickness calculation. For laminar film, the velocity profile in the liquid film can be obtained from the above equation.

$$
u_{L}(y)=\frac{\left(\rho_{L}-\rho\right) \cdot g}{\mu_{L}}\left(\delta \cdot y-\frac{y^{2}}{2}\right)+\frac{\tau_{I}}{\mu_{L}} y
$$

The first term in the right hand side of above equation is the parabolic velocity distribution, which is exactly same with Nusselt analysis for no interfacial shear. The second term is the linear velocity distribution due to the interfacial shear. The liquid film mass flow rate $\left(m_{L}\right)$ can be calculated by integrating the velocity profile. Then, mass balance in liquid film can be expressed with respect to the film thickness as follows:

$$
\Gamma \equiv \frac{m_{L}}{\pi \cdot d}=\frac{\left(\rho_{L}-\rho\right) \cdot g}{3 v_{L}} \delta^{3}+\frac{\tau_{I}}{2 v_{L}} \delta^{2}
$$

Above equation can be simplified by use of dimensionless parameter as 


$$
\operatorname{Re}_{L} \equiv \frac{4 \Gamma}{\mu_{L}}=\frac{4}{3}\left(\delta^{*}\right)^{3}+2 \cdot \tau_{I}^{*} \cdot\left(\delta^{*}\right)^{2}
$$

By solving Eq. (4.43), film thickness can be calculated. If there is no interfacial shear, the Nusselt film thickness [10] can be explicitly obtained.

For laminar film, the temperature distribution in the film region is almost linear. Therefore film heat transfer coefficient can be written as

$$
h_{L}=\frac{k_{L}}{\delta} .
$$

Film Nusselt number is defined as follow:

$$
N u_{L} \equiv \frac{h_{L} \cdot L^{*}}{k_{L}}
$$

From Eqs. (4.44) and (4.45), film Nusselt number for laminar film can be expressed as

$$
N u_{L}=\frac{L^{*}}{\delta}=\frac{1}{\delta^{*}} .
$$

Above theoretical Nusselt number is based on the assumption of smooth liquid film. However, actual film surface shows waviness and rippling. The waviness and rippling enhance the heat transfer in the film. Also, turbulent film transition can occur at very low film Reynolds number for high interfacial shear condition. Hughmark [11] developed model for liquid film thickness based on many experimental data. The model showed that the dimensionless film thickness for very small film Reynolds number is continuously matching with one for very high film Reynolds number, i.e., turbulent film. It means that transition to turbulent film can occur at very small film Reynolds number. To take into account the heat transfer enhancement due to film wave and turbulent effects, McAdams [12] modified Eq. (4.46) by the multiplication factor of 1.2.

Blangetti et al [13] developed the empirical film model applicable to a wide range of film Reynolds number as 


$$
N u_{L}=\left(N u_{L, a m}^{4}+N u_{L, t u r}^{4}\right)^{1 / 4}
$$

Laminar film Nusselt number $\left(N u_{\text {L,lam }}\right)$ is the theoretical value as shown in Eq. (4.46). For turbulent film Nusselt number $\left(N u_{L, t u r}\right)$ they suggested the following empirical equation.

$$
N u_{L, t u r}=c 1 \cdot \operatorname{Re}_{L}^{c 2} \cdot \operatorname{Pr}_{L}^{c 3} \cdot\left(1+c 4 \cdot\left(\tau_{I}^{*}\right)^{c 5}\right)
$$

where, c1-c5 are constant depending on the dimensionless shear stress, $\tau_{I}{ }^{*}$.

To take into account the effects of film waviness and transition regime between laminar and turbulent film, Blangetti model in Eq. (4.47) is used for the present analysis. The heat transfer in the film region is coupled with the momentum, energy, and mass transfer in the gas region through the parameters such as film thickness, interfacial shear stress, and film flow rate. The transport phenomena in the gas region are discussed in the next section. Film properties are evaluated at the film temperature, which is the arithmetic mean of the inside wall temperature and interface temperature.

\subsubsection{Momentum, Heat and Mass Transfer in Gas Region}

The momentum, heat and mass transfer and the effects of suction in the gas region are discussed in this section. Since the condensation can be regarded as a kind of wall suction, the results of the transpiration effects could be applied to the condensation problem. Characteristics of the momentum, heat and mass transfer are affected dramatically for the transpiration boundary layer such as suction or blowing at the wall. For arbitrary variation of the suction or blowing velocity, Couette flow analysis has been used [13]. Although the derivation procedure in Couette flow analysis is based on constant suction or blowing velocity for the external boundary layer, it can be used for arbitrary changing suction or blowing velocity by assuming that the suction or blowing velocity is constant at each small domain of calculation. Also, it is assumed to be valid for internal boundary layer such as a pipe flow. The effect of transpiration was formulated by the ratio of the dimensionless transport quantity with transpiration to one without transpiration as a function of blowing parameter. The dimensionless quantities for momentum, heat and mass transfer are friction coefficient $(f)$, heat transfer Stanton number $(S t)$ and mass transfer Stanton number $\left(S t_{m}\right)$, respectively. These 
quantities and the corresponding blowing parameters are defined in Table 2. Subscript 0 in Table 3 represents the quantity without transpiration. It should be noted that the blowing parameter is negative for suction and positive for blowing and suction enhances the momentum, heat and mass transfer, i.e., condensation is characterized with the enhanced transport mechanism at the interface due to the surface suction effect.

Now, we need to find the correlations at no transpiration boundary. A large number of the correlation for momentum, heat and mass transfer without transpiration has been developed in pipe flow $[14,15]$. A proper choice of the transport correlations is crucial for the heat and mass analogy model. To choose most appropriate correlations, a boundary layer model [16] is used. In the boundary layer model, two sets of governing equations for liquid film and vapor-gas mixture regions were numerically solved and the model was validated with various available condensation data. From the analysis results, the best fitting correlations for momentum, heat and mass transfer are selected and summarized in Table 4.2. A detailed procedure can be found in Oh [17].

Table 4.2 Correlations, transpiration effects and blowing parameters $[14,15]$

\begin{tabular}{|c|c|c|c|c|}
\hline \multirow{2}{*}{$\begin{array}{l}\text { Transport } \\
\text { Mode }\end{array}$} & \multicolumn{2}{|c|}{ Correlations } & \multirow{2}{*}{ Transpiration Effect } & \multirow{2}{*}{$\begin{array}{l}\text { Blowing } \\
\text { Parameter }\end{array}$} \\
\hline & $\begin{array}{l}\text { Laminar } \\
\text { Flow }\end{array}$ & Turbulent Flow & & \\
\hline $\begin{array}{c}\text { Momentum } \\
f_{0}\end{array}$ & $f_{0}=\frac{16}{\operatorname{Re}_{d}}$ & $f_{0}=0.079 \cdot \operatorname{Re}_{d}^{-0.25}$ & $\frac{f / 2}{(f / 2)_{0}}=\frac{b_{f}}{\exp \left(b_{f}\right)-1}$ & $b_{f}=\frac{m^{\prime \prime} / G_{\infty}}{(f / 2)_{0}}$ \\
\hline $\begin{array}{c}\text { Heat } \\
S t_{0} \text { or } N u_{0}\end{array}$ & $N u_{0}=4.364$ & $N u_{b}=0.022 \cdot \operatorname{Re}_{d}^{0.8} \cdot \operatorname{Pr}^{0.5}$ & $\frac{S t}{S t_{0}}=\frac{b_{h}}{\exp \left(b_{h}\right)-1}$ & $b_{h}=\frac{m^{\prime \prime} / G_{\infty}}{S t_{0}}$ \\
\hline $\begin{array}{c}\text { Mass } \\
S t_{m 0} \text { or } S h_{0}\end{array}$ & $S h_{0}=4.364$ & $S h_{b}=0.022 \cdot \mathrm{Re}_{d}^{0.8} \cdot S c^{0.5}$ & $\frac{S t_{m}}{S t_{m 0}}=\frac{g_{m}}{g_{m 0}}=\frac{b_{m}}{\exp \left(b_{m}\right)-1}$ & $b_{m}=\frac{m^{\prime \prime} / G_{\infty}}{S t_{m 0}}$ \\
\hline
\end{tabular}

For the momentum transfer, interfacial friction factor is determined as follows: First, the interfacial friction factor for no suction condition $\left(f_{0}\right)$ is estimated using the gas mixture Reynolds number. Then, the blowing parameter for momentum transfer $\left(b_{f}\right)$ is calculated. In the actual analysis, the mass flux terms for suction/blowing (m”) and free stream $\left(\mathrm{G}_{\infty}=\rho_{\infty} \mathrm{u}_{\infty}\right)$ in the blowing parameters are modified with condensation mass flux $\left(\mathrm{m}_{\mathrm{c}}{ }^{\prime}\right)$ and bulk mixture mass flux $\left(\rho \mathrm{u}_{\mathrm{avg}}\right)$ for the previous iteration, respectively. Finally, the interfacial friction factor with suction effect $(f)$ can be determined from the momentum transfer blowing parameter $\left(b_{f}\right)$ and the interfacial fric- 
tion factor for no suction condition $\left(f_{0}\right)$ using the expression in Table 3. Interfacial shear stress is calculated using the following definition of the interfacial friction factor.

$$
f \equiv \frac{\tau_{I}}{\rho \cdot\left(u_{\text {avg }}-u_{L, \text { avg }}\right)^{2} / 2}
$$

Here, it should be noted that the velocity component in the above equation must be a relative velocity between the gas and film regions.

For the sensible heat transfer, sensible heat transfer Nusselt number $\left(N u_{s e n}\right)$ is determined by the similar procedure using the heat transfer blowing parameter $\left(b_{h}\right)$ and the heat transfer Stanton number for no suction condition $\left(S t_{0}\right)$. The sensible heat transfer coefficient $\left(h_{\text {sen }}\right)$ is calculated using the following definition.

$$
N u_{\text {sen }} \equiv \frac{h_{\text {sen }} \cdot d}{k}
$$

For the mass transfer, mass transfer Sherwood number (Sh) is also determined using the mass transfer blowing parameter $\left(b_{m}\right)$ and the mass transfer Stanton number for no suction condition $\left(S t_{m 0}\right)$. Mass transfer conductance $\left(g_{m}\right)$ extracted from the mass transfer Sherwood number can be related with the diffusive mass flux of NC gas as

$$
g_{m} \equiv \frac{j_{v, I}}{W_{v, I}-W_{v, b}}=\frac{j_{g, I}}{W_{g, I}-W_{g, b}}=\frac{j_{I}}{W_{I}-W_{b}}
$$

In the above equation, the relationships of $j_{v}+j_{g}=0, W_{v}+W_{g}=1$ are used and subscript $\mathrm{g}$ for $j_{g}$ and $W_{g}$, is omitted for simplification. Since the radial velocity of the NC gas is zero at the interface, the diffusive mass flux of $\mathrm{NC}$ gas at the interface $\left(j_{I}\right)$ can be expressed as follows using the definition of the NC gas diffusive mass flux, $j_{g} \equiv \rho_{g}$ $\left(\mathrm{v}_{g}-\mathrm{v}\right)$.

$$
j_{I}=-W_{I} m_{c}
$$

Combining Eqs. (4.51) and (4.52), the condensation mass flux can be determined. 
The relationship between vapor partial pressure and NC gas mass fraction at interface or bulk is expressed from Gibbs-Dalton ideal gas mixture equation.

$$
\frac{p_{v}}{p_{\text {TОT }}}=\frac{1-W}{1-W\left(1-M_{v} / M_{g}\right)}
$$

Mixture viscosity, mixture thermal conductivity and mass diffusion constant are calculated using the theory of the gas transport properties [18]. Specific heat capacity for the mixture is simply calculated by mass fraction weighted average.

$$
C p=W \cdot C p_{g}+(1-W) \cdot C p_{v}
$$

\subsubsection{Calculation Procedure}

The calculation procedures are summarized as follows:

1) Specify inlet and boundary conditions

2) Initialize the variables and parameters for next axial node

3) Assume interface temperature, condensation mass flux, interface shear and calculate relevant parameters

4) Calculate film thickness from film mass balance

5) Calculate film Nusselt number

6) Calculate blowing parameters

7) Calculate interfacial friction factor, heat transfer Nusselt number and mass transfer Sherwood number

8) Calculate total condensation heat transfer coefficient

9) Calculate total heat flux, condensation mass flux and interfacial shear

10) If interface temperature, condensation mass flux, total heat flux and interface shear converge, go to step 11). If not, update interface temperature and go to step 4) for the next iteration

11) Go to step 2) for the next axial node

\subsubsection{Analysis Results}

The heat and mass analogy model is run for both $26.6 \mathrm{~mm}$ and $52.5 \mathrm{~mm}$ ID experiment conditions. Figure 4.2 compares the tube average condensation HTC for 
various conditions with inlet NC gas mass fraction for $26.6 \mathrm{~mm}$ ID tube. Figure 4.13 (a) shows the effects of pressure for a given inlet steam flow rate of $3.8 \mathrm{~g} / \mathrm{s}$ and Figure 4.13 (b) shows the effects of inlet steam flow rate for a given system pressure of 0.34 $\mathrm{MPa}$. The analogy model predicts very well the general trend of experimental data: The condensation HTC decreases with the increase of the NC gas fraction and system pressure and it increases with the increase of inlet steam flow rate. For low inlet NC gas mass fraction cases, the model underestimates the heat transfer coefficient. This trend is mainly due to the heat transfer enhancement from the film waviness. A large amount of condensation due to low inlet $\mathrm{NC}$ gas mass fraction results in higher film Reynolds number. As the film Reynolds number increases, the effect of the film waviness acts more role in the heat transfer mechanism. The wave itself increases the condensation surface area and it enhances the thermal mixing in the liquid film. Figure 4.14 compares the calculated and the measured average condensation HTC for the $26.6 \mathrm{~mm}$ ID tube data.

Figure 4.15 presents the results of the analogy model for $52.5 \mathrm{~mm}$ ID tube data. Each plot in the figure shows condensation mass flow rate, heat flux, and average HTC with various air mass fractions for system pressure of 185-187 $\mathrm{kPa}$. In contrast to the $26.6 \mathrm{~mm}$ ID tube cases, the model underestimates the experimental data especially for low inlet NC mass fraction cases. It is not clear what is the reason for the mismatch. One of the possible reasons would be the fact that the experimental error for the low pressure condition is quite large. As defined by Eq. (4.16), the condensation HTC is inversely proportional to the driving temperature difference, i.e., $\left(\mathrm{T}_{\mathrm{SAT}}-\right.$ $\mathrm{T}_{\mathrm{Wi}}$ ). As system pressure decreases, the driving temperature difference also decreases. A small amount of temperature error could propagate into a large error of the condensation HTC. However, the similar trends are investigated in the condensation mass flow rate and condensation heat flux plots in Figure 4.15, which have no relation with the driving temperature difference. Therefore, the analogy model could have its limitations on the low pressure condition. The calculated and the measured average condensation HTC for the $52.5 \mathrm{~mm}$ ID tube data are compared in Figure 4.5 where the mismatch is evident for high HTC cases, low pressure or low NC gas mass fraction conditions. 


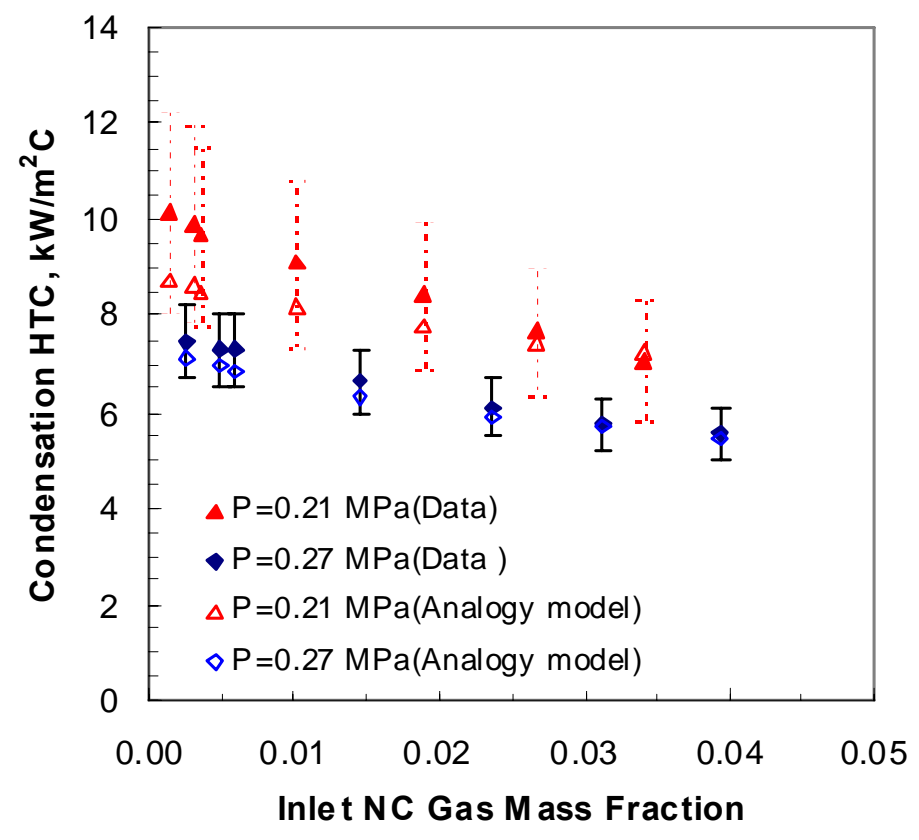

a) Inlet steam flow $=3.8 \mathrm{~g} / \mathrm{s}$

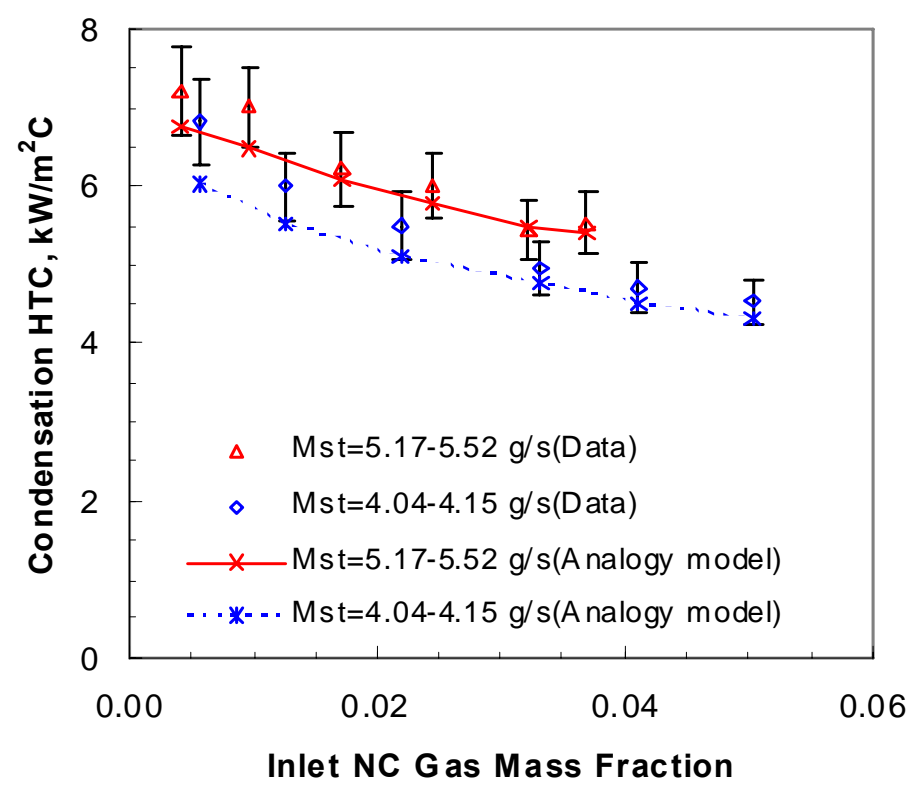

b) System pressure $=0.34 \mathrm{MPa}$

Figure 4.13 Comparison of average condensation HTC with respect to inlet NC gas mass fraction for $26.6 \mathrm{~mm}$ ID tube 


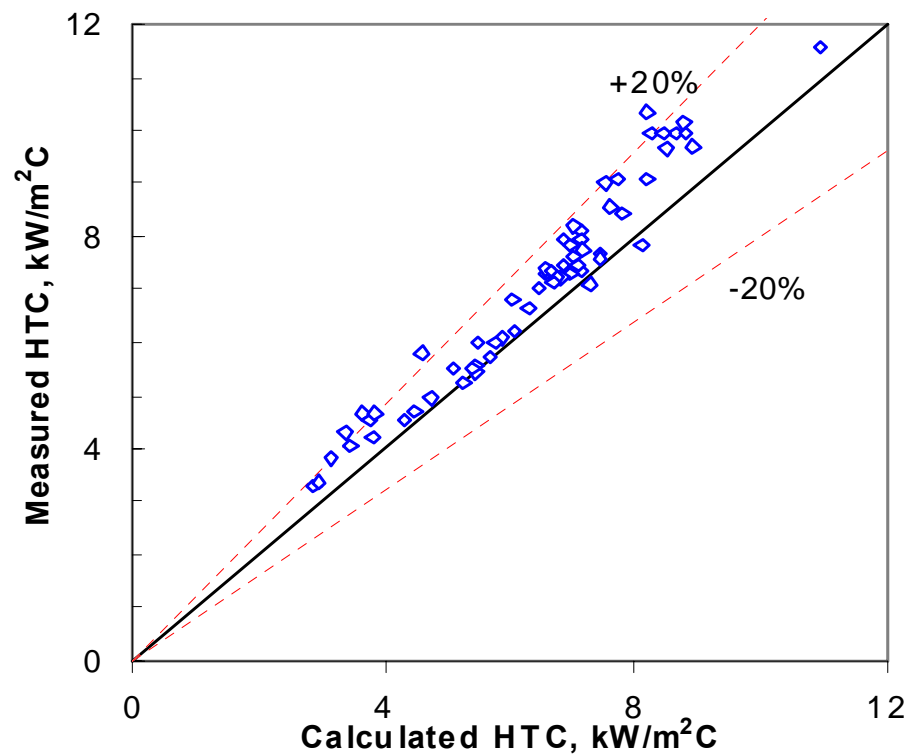

Figure 4.14 Comparison of average condensation HTC with analogy model for $26.6 \mathrm{~mm}$ ID tube

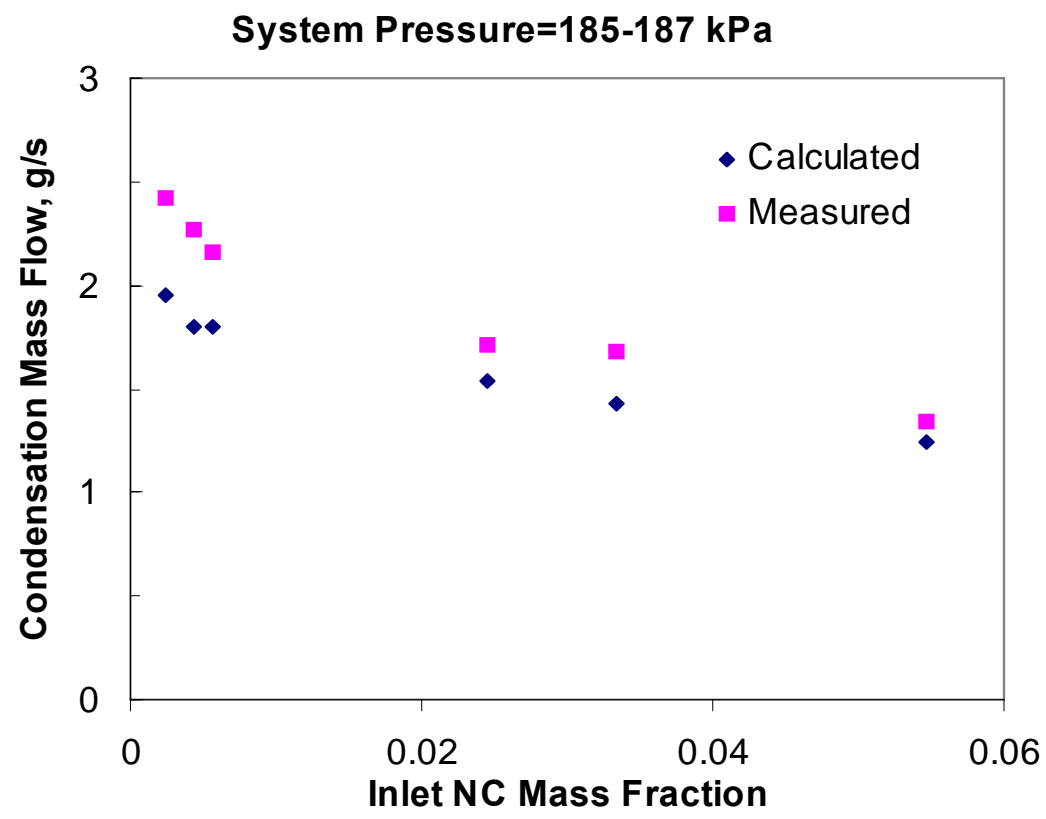

a) Condensation Mass Flow Rate

Figure 4.15 Analogy model predictions for $52.5 \mathrm{~mm}$ ID tube with system pressure of $185-187 \mathrm{kPa}$ 


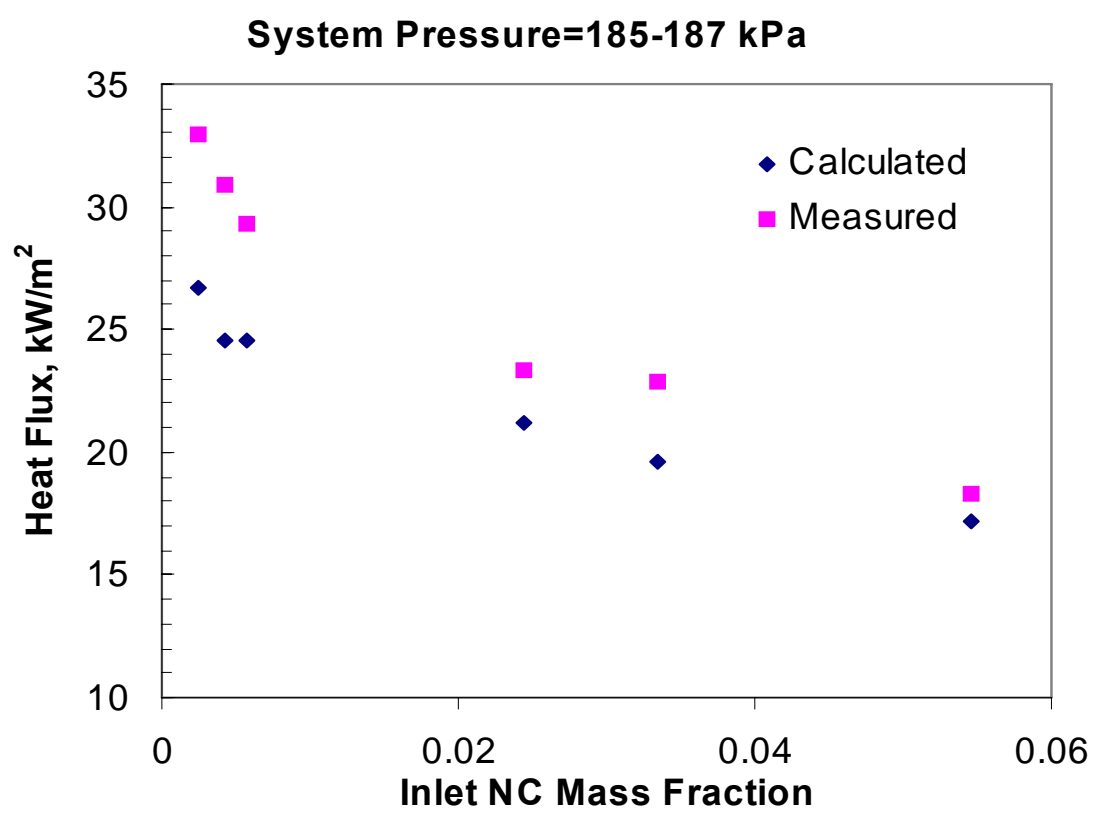

b) Condensation Heat Flux

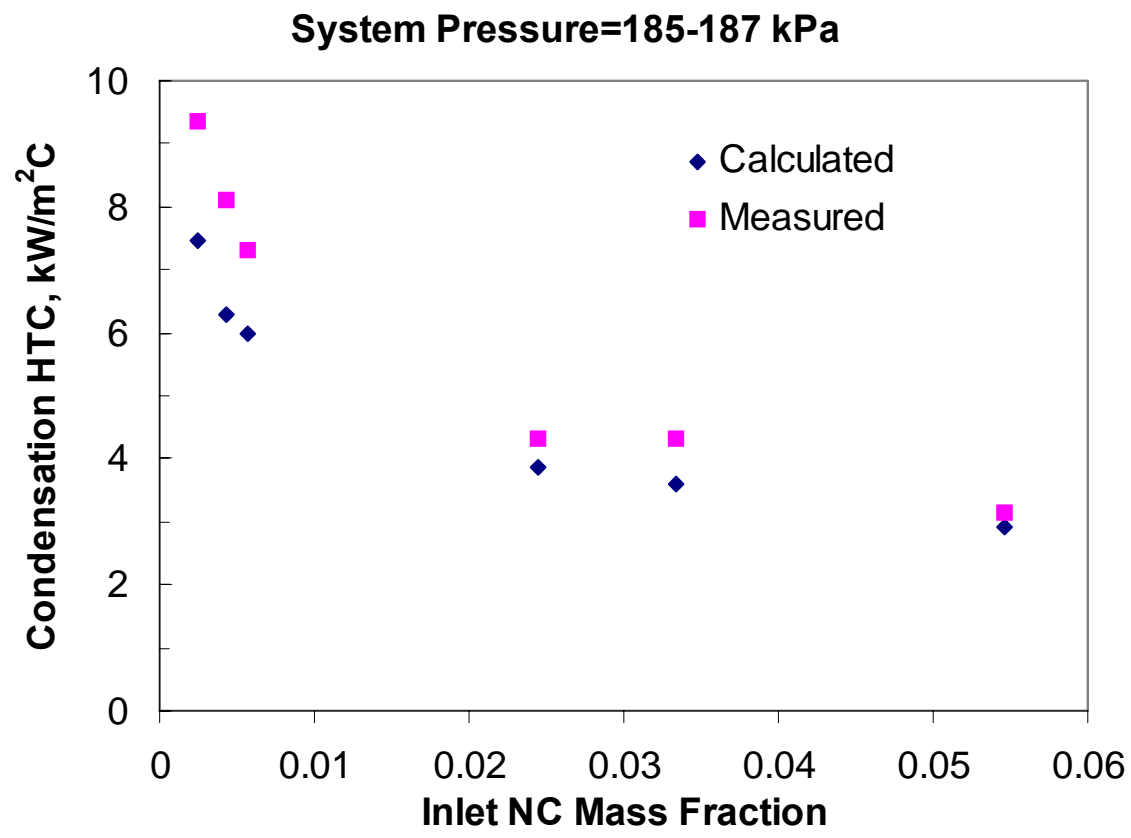

c) Condensation Heat Transfer Coefficient

Figure 4.15 Analogy model predictions for $52.5 \mathrm{~mm}$ ID tube with system pressure of $185-187 \mathrm{kPa}$ (Continued) 


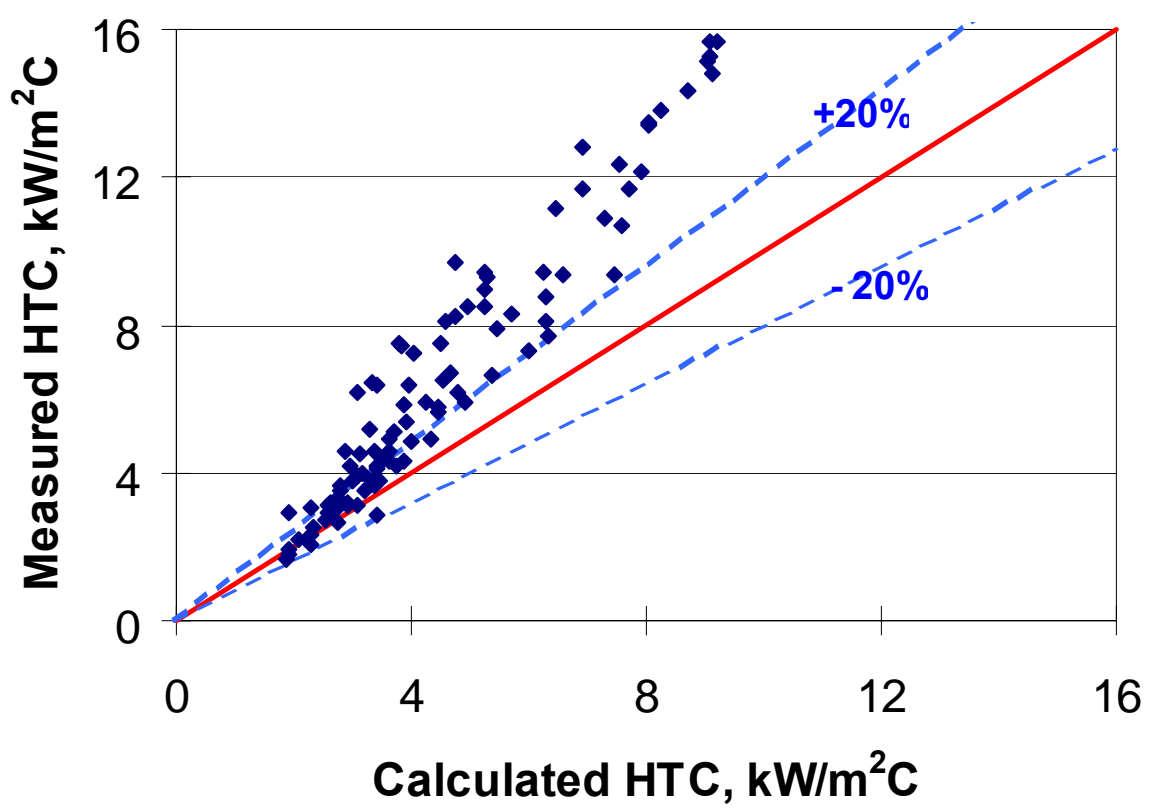

Figure 4.16 Comparison of average condensation HTC with analogy model for $52.5 \mathrm{~mm}$ ID tube

Developed heat and mass analogy model is also tested for Kuhn's [19] experimental conditions. Kuhn performed the condensation experiment with secondary jacket cooling method with $47.5 \mathrm{~mm}$ ID, $2.1 \mathrm{~m}$ length condenser tube. He reported the local condensation HTC up to $1.5 \mathrm{~m}$ from the tube inlet. The experiment cases used in this paper is the run number 212 and 2112: nominal inlet steam flow rate of $50 \mathrm{~kg} / \mathrm{hr}$, system pressure of $0.41 \mathrm{MPa}$. Inlet air mass fractions for the run number 212 and 2112 are $2 \%$ and $34 \%$, respectively. The comparison of the local condensation HTC between data, the present heat and mass analogy model, and the boundary layer model [16] is presented in Figure 4.17. The relative error of the local condensation HTC was reported as $18.7 \%$ [19] and the error bars are drawn based on this value. Both models predict very well the data. For low inlet NC gas fraction $(2 \%)$ case, both models slightly underestimate the local condensation HTC near the end of tube (1.5 m from inlet). This trend is also due to the film waviness, explained previously. The film Reynolds numbers at $1.5 \mathrm{~m}$ from inlet are around 1100 for low inlet $\mathrm{NC}$ gas fraction (2\%) case and around 500 for high fraction (34\%) case. The results of the analogy model are almost identical to those of the boundary layer model except for the tube inlet region. As discussed in Sec. 4.2.1.3, the momentum, heat and mass transfer cor- 
relations applied in the analogy model are validated with the boundary layer model. This is the reason why the analogy model results are very similar to the boundary layer analysis results. Also, the discrepancy between two models at tube inlet region is originated from the fact that the correlations for the momentum, heat and mass transport used in the analogy model is based on the fully developed flow condition.

The heat and mass transfer analogy model has been used to predict condensation heat transfer properties for several PCCS operating conditions. Pure steam cases have been studied with the analogy model. The pure steam cases were run to calculate both averaged and local heat transfer properties. For averaged calculations, the analogy model predicts an averaged property across the entire axial length of the condenser for each case. Average properties are calculated for several steady state system pressure conditions and for each of the three sizes of condensers used in experiments. The three condenser sizes analyzed by the analogy model are 1" half length, 2 " half length, and 2" full length. For local heat transfer calculations, the analogy model predicts local properties for single cases to develop a trend across the axial length of the condenser. The axial profiles developed can then be compared across different steady state system pressure conditions. The axial profile plots generated in this section compare between three cases: low pressure, intermediate pressure, and high pressure.

Averaged condensation heat transfer coefficients and average heat flux outputs from the analogy model are displayed in Fig. 4.17 and 4.18 respectively. The results are presented across several system pressures, ranging from around $150 \mathrm{kPa}$ to 350 $\mathrm{kPa}$. The general trend of the condensation heat transfer coefficient is a decrease with increasing system pressure. As the system pressure gets larger, the difference between the condenser wall temperature and the bulk temperature increases faster than the condensate rate does. Since the temperature difference increases faster, the condensation heat transfer coefficient will decrease with system pressure. The average heat flux shows to increase almost linearly with system pressure for each of the condenser sizes. This is as expected, because the higher the flow pressure in the condensing tubes the higher the heat transfer rate will be. Both of the condensation heat transfer coefficients and the heat flux show little variation between the three different condenser sizes. The calculations take into account the condenser area, so 
change in dimensions should not drastically change these types of heat transfer properties.

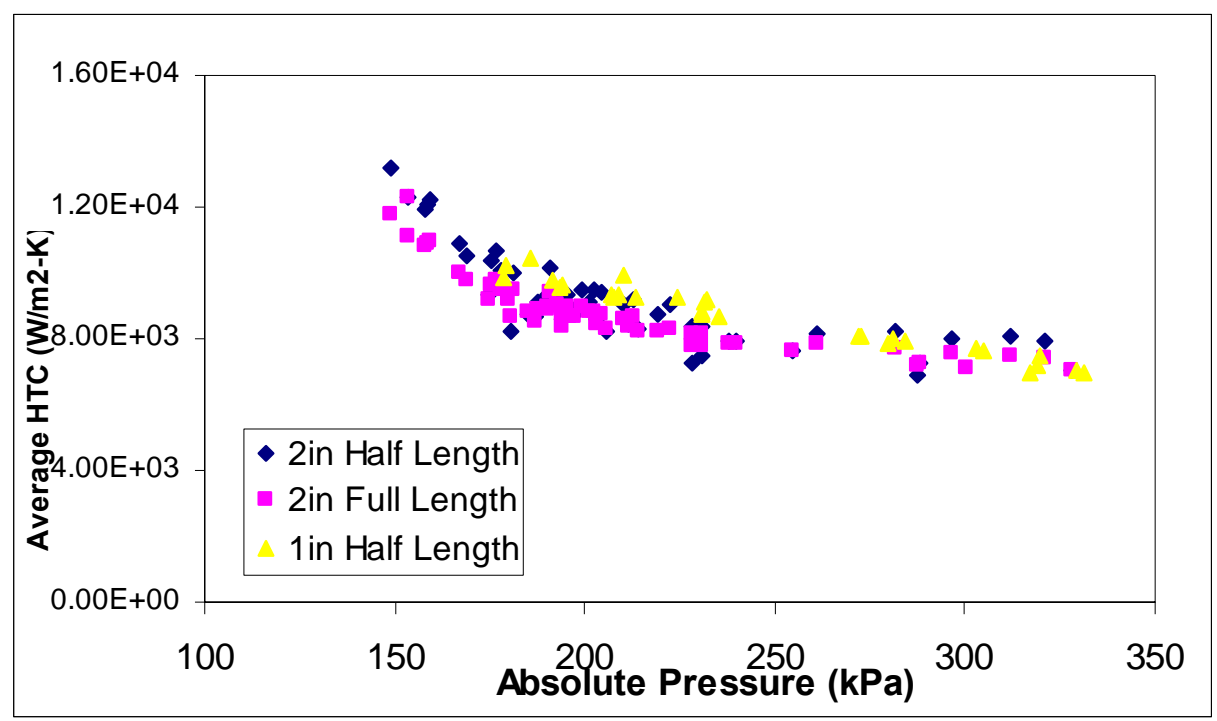

Figure 4.17 Average condensation heat transfer coefficients as a function of system pressure, for pure steam cases predicted by the heat and mass transfer analogy model

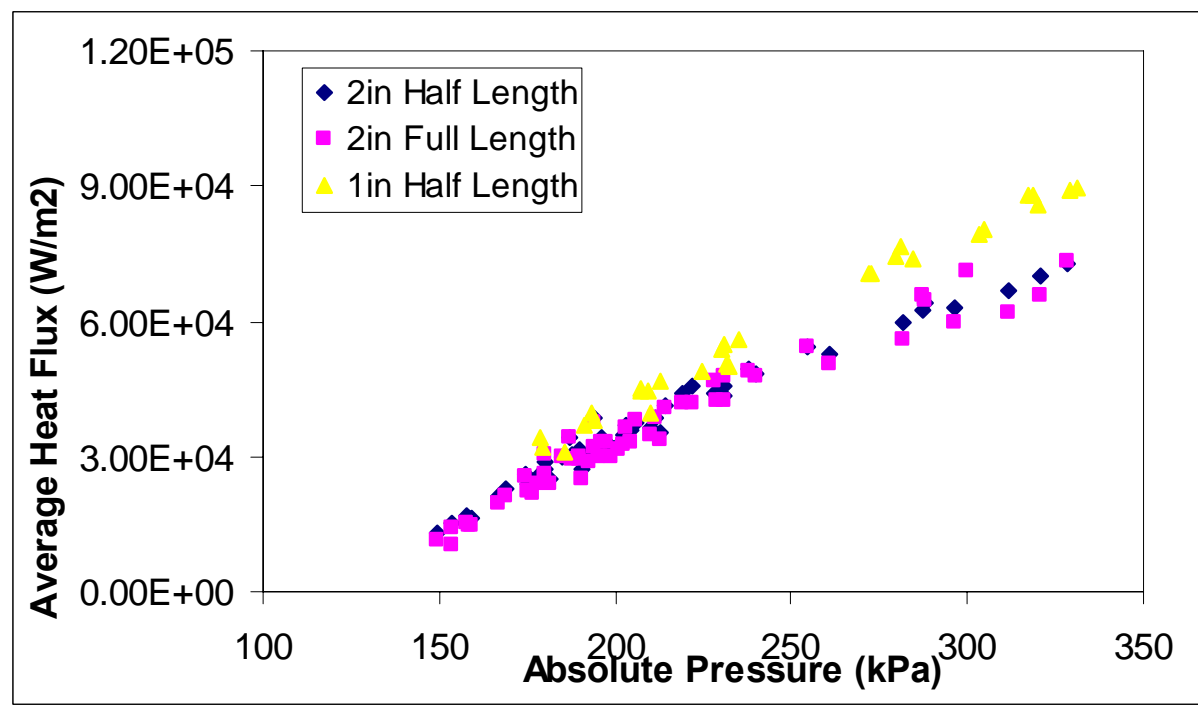

Figure 4.18 Average condenser heat flux as a function of absolute system pressure, for pure steam cases predicted by the heat and mass transfer analogy model

Several local heat transfer properties have been plotted using the analogy model for three different pure steam steady state pressures: $180 \mathrm{kPa}, 238 \mathrm{kPa}, 328 \mathrm{kPa}$. 
The properties that have been calculated and presented are for condensation heat transfer coefficient, total heat transfer coefficient, heat flux, bulk Reynolds number, and film resistance. Each of the local calculations is plotted as a function of axial length for a $2 "$ full length condensing tube. The axial profile for the condensation heat transfer coefficient reaches a maximum close to the entrance of the condenser and then decreases for the remainder of the length. The higher the system pressure, the higher the condensation heat transfer coefficients are. This is the opposite in the case for the total heat transfer coefficient. Lower system pressures produce higher total heat transfer coefficient axial profiles. And for total heat transfer coefficients, the maximum point occurs at the entrance and then decreases thereafter. The profiles produced for the local heat fluxes appear similar to the total heat transfer coefficients, hitting a maximum at the entrance and then a continual decrease. However, the heat flux increases for increasing system pressures. The bulk Reynolds number shows an almost linear decrease from the entrance point to the bottom of the condenser tube. The trends also show that a higher system pressure will result in a higher bulk Reynolds number. The liquid film resistance shows a hyperbolic like profile, starting with zero at the entrance and increasing along the length of the condenser. The reason for having zero resistance at the entrance is due to not having any film thickness. The resistance of the liquid film to the heat transfer increases, as the thickness of the film increases down the axial length of the condenser. And also as expect, the liquid film resistance increases with increasing system pressure. 


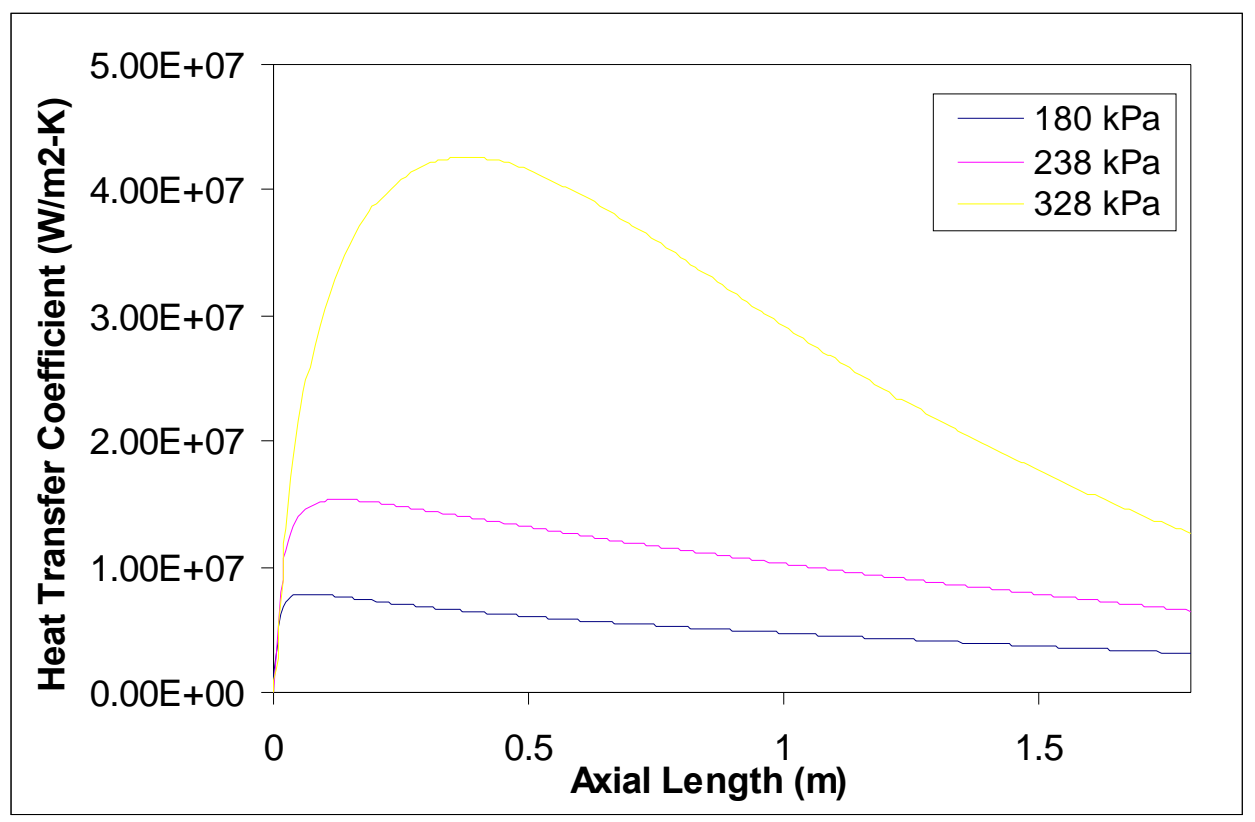

Figure 4.19 Local condensation heat transfer coefficients as a function of axial length, for 2" full length pure steam cases predicted by the heat and mass transfer analogy model

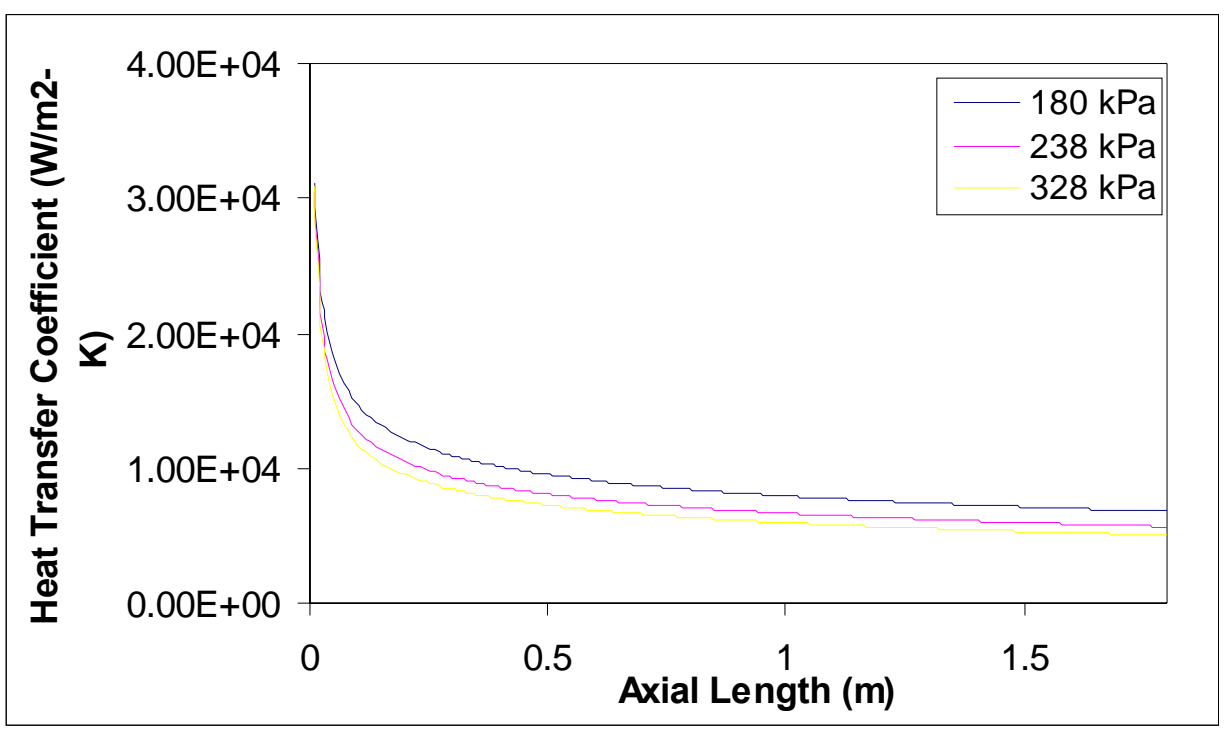

Figure 4.20 Local total heat transfer coefficients as a function of axial length from the entrance, for 2" full length pure steam cases predicted by the heat and mass transfer analogy model 


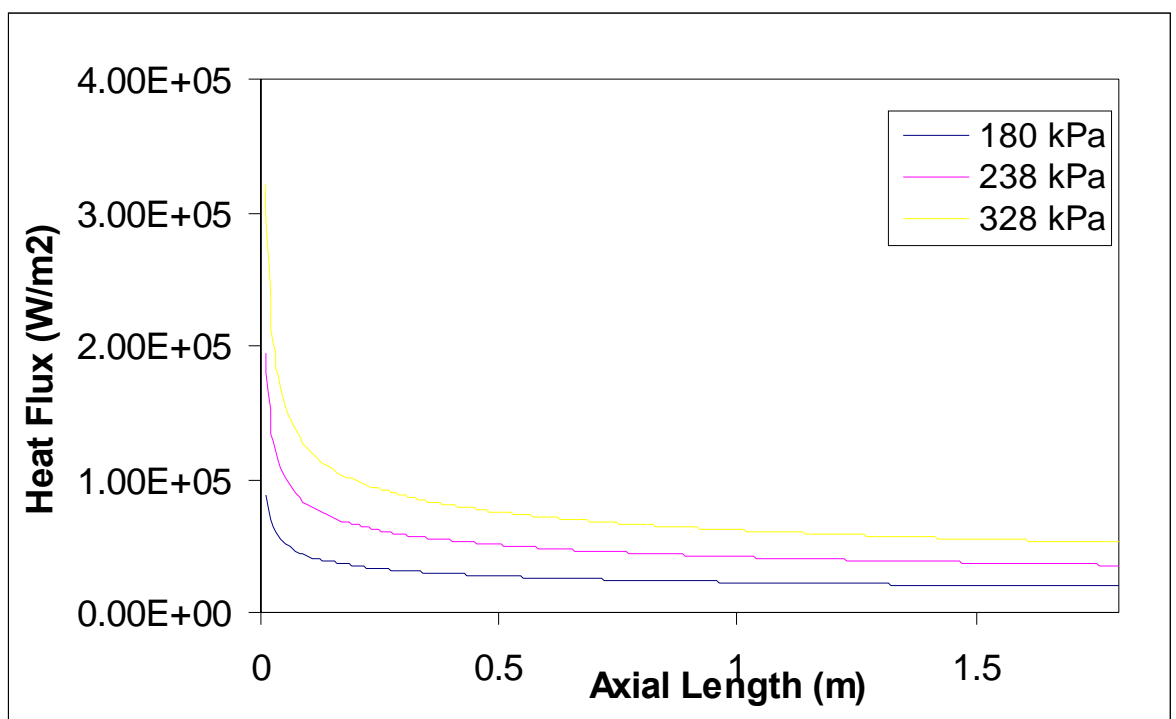

Figure 4.21 Local heat flux as a function of axial length from the entrance, for 2" full length pure steam cases predicted by the heat and mass transfer analogy model

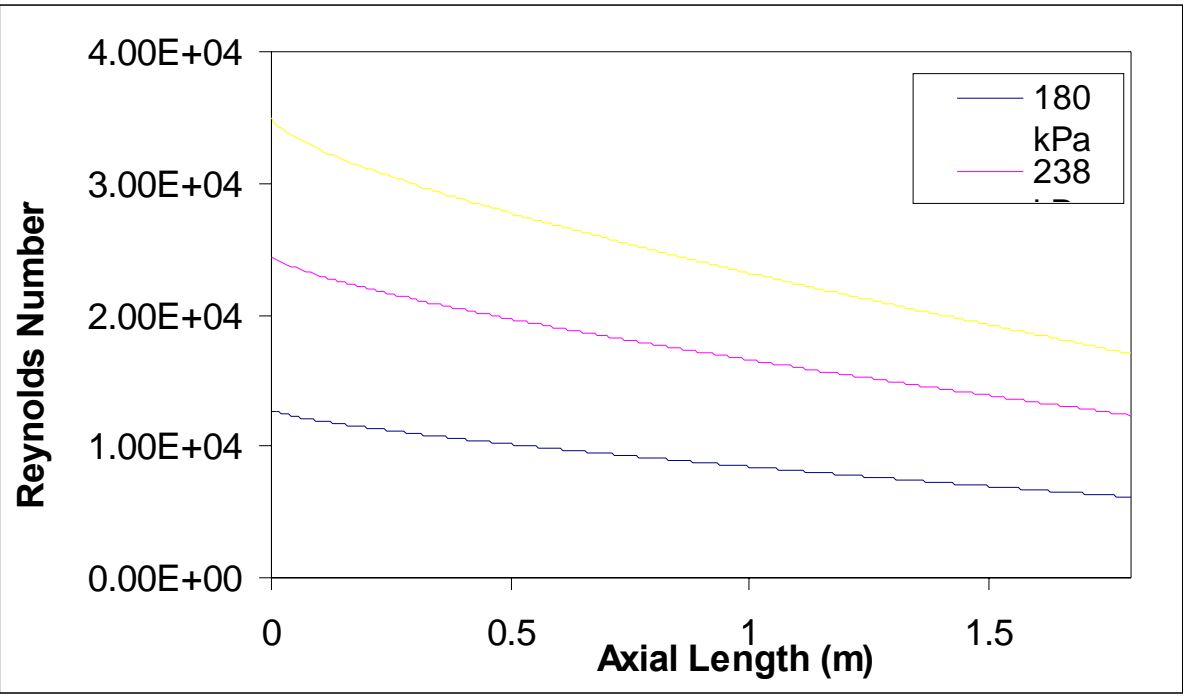

Figure 4.22 Local bulk Reynolds number as a function of axial length from the entrance, for 2" full length pure steam cases predicted by the heat and mass transfer analogy model 


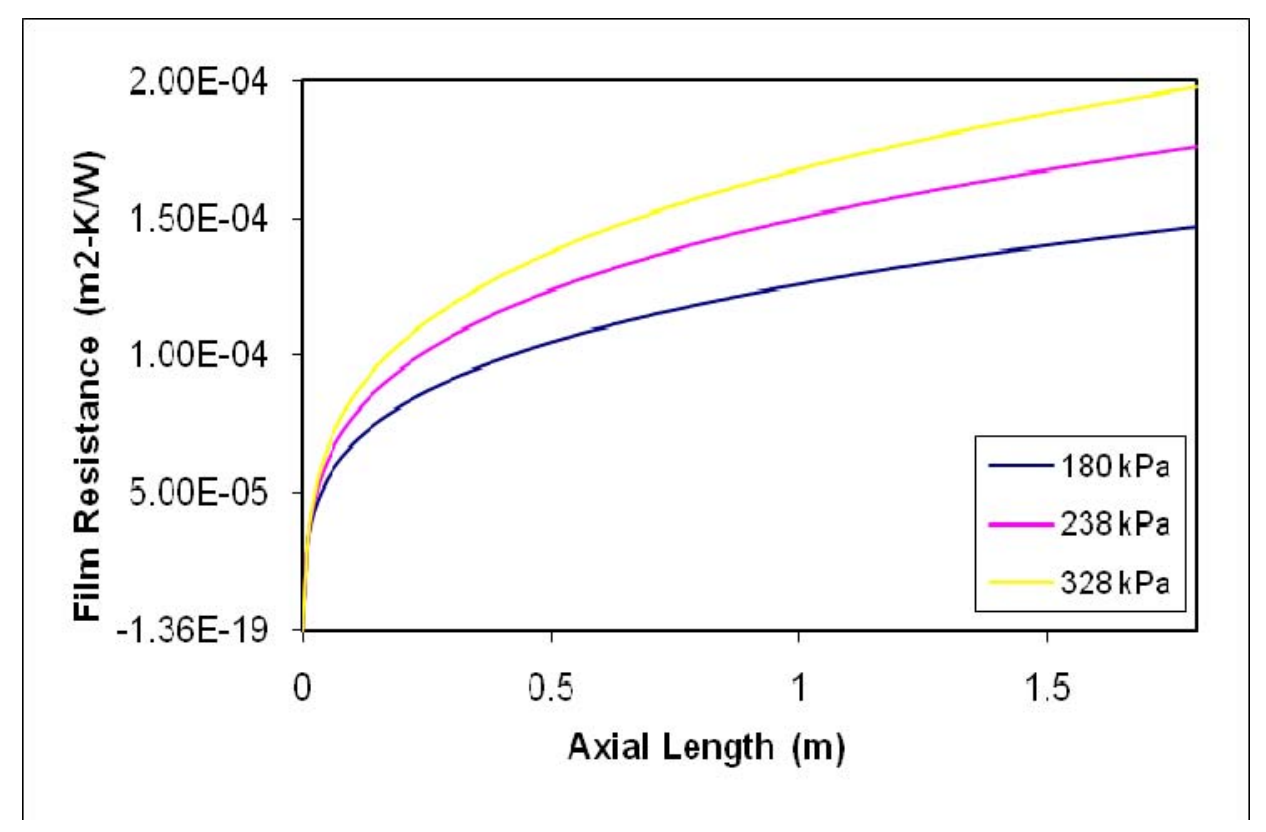

Figure 4.23 Local film resistance as a function of axial length from the entrance, for 2 " full length pure steam cases predicted by the heat and mass transfer analogy model

\subsubsection{Summary}

A heat and mass analogy model is developed to predict the filmwise condensation with the noncondensable gas. This model uses the momentum, heat, and mass transport correlations selected from the general relationships which have the strong theoretical background and the less empiricism. The effects of the surface suction at the condensation interface were taken into account in the correlations. The analysis results of the model were compared with the average condensation heat transfer coefficient data in the previous $26.6 \mathrm{~mm}$ ID and present $52.5 \mathrm{~mm}$ ID experiment and the local condensation heat transfer coefficient data in Kuhn's experiment [19] and the agreement was satisfactory except for high heat transfer coefficient cases such as very low pressure or small NC gas mass fraction conditions. 


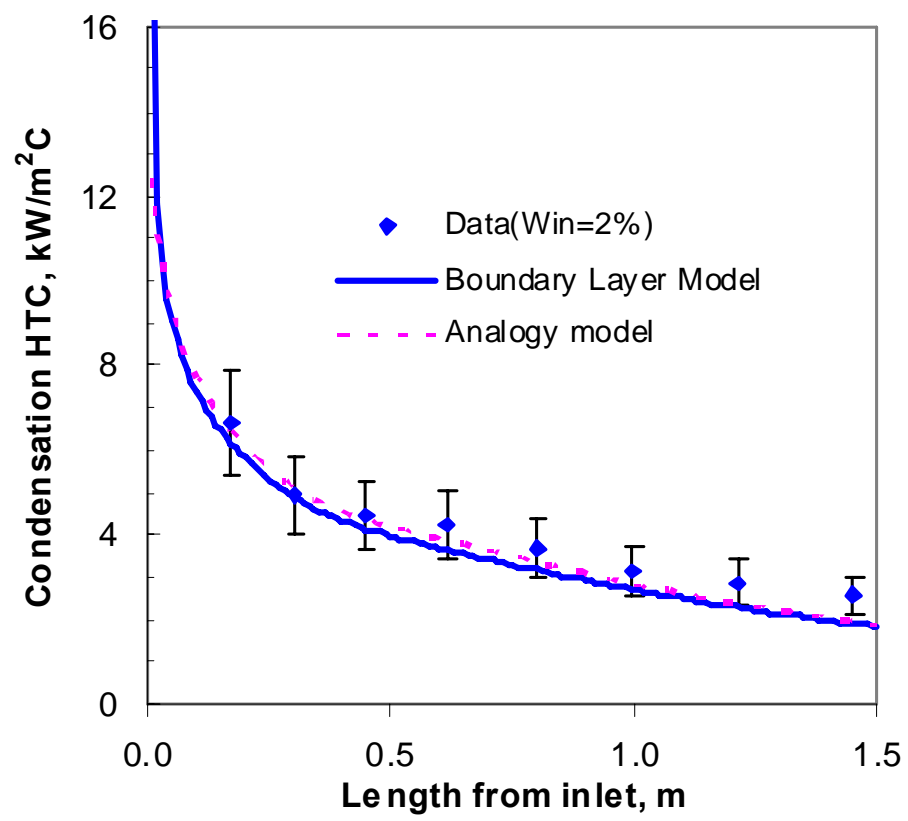

a) Inlet NC gas mass fraction $=2 \%$

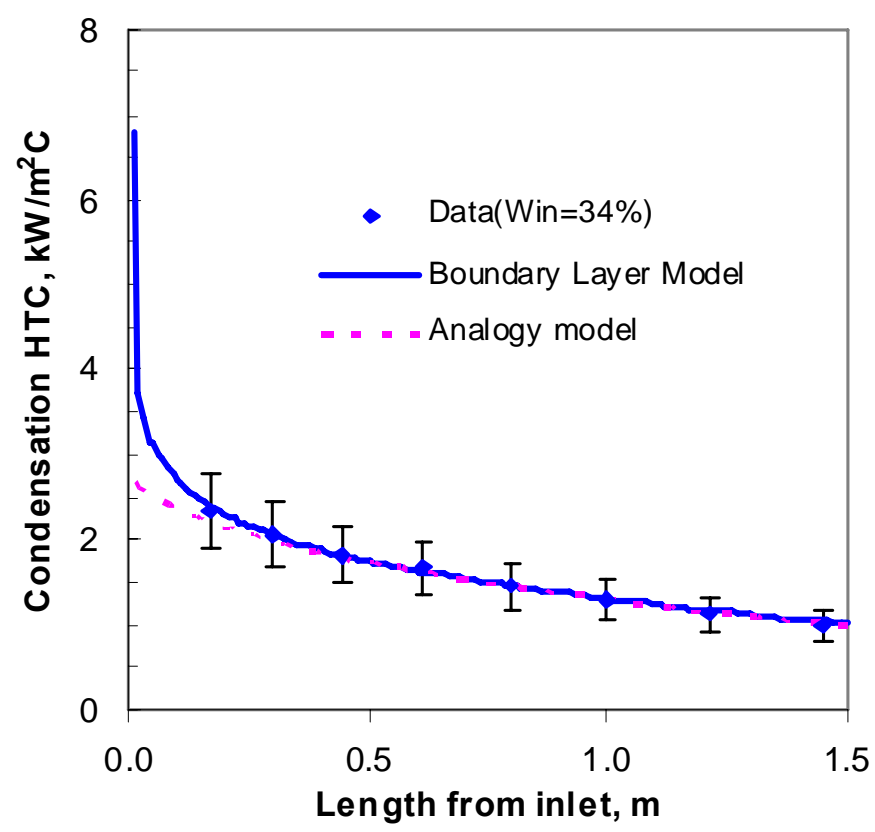

b) Inlet NC gas mass fraction $=34 \%$

Figure 4.24 Comparison of local condensation HTC for Kuhn's experiment 


\subsection{RELAP5 Condensation Model Assessment}

In this section, experimental data are compared with code predictions from RELAP5 with two condensation models. A detailed description including the code nodalization scheme is presented in the previous NEER report [20].

RELAP5 is a light water reactor transient analysis code developed by U.S. Nuclear Regulatory Commission for reactor licensing, operator guideline evaluation and correlation benchmarking. This code can be used to simulate a wide variety of thermal-hydraulic transient in nuclear and non-nuclear systems. RELAP5/MOD3.3 beta version is used to assess the build-in film condensation models in this paper. Experiment data of both $26.6 \mathrm{~mm}$ and $52.5 \mathrm{~mm}$ ID condensing tubes are used for complete condensation cases.

There are two models embeded in RELAP5 for film condensation phenomena: the default model and the alternative model. The defult model uses classic Nusselt film condensation model[10] for laminar flow and Saha correlation[21] for turbulent film. The alternative model uses Nusselt model with correction factor, called University of California at Berkeley (UCB) multipliers[22]. Experiments are simulated with these two models and the results are compared in this paper.

The RELAP5 nodalization schematic for the test loop and the detailed description of the nodalizaion is presented in [20].

To compare with the condensation rate and condensation HTC from the experiment data, the condensate output is integrated in the codensing tube model of RELAP5. The temperatures along the tube model are averaged to get mean temperature. From integrated condensate rate and mean temperature, the average condensation HTC is defined and calculated from RELAP5 output.

Figure 4.25 shows the condensation rate with system pressure for the default and alternative model for $52.5 \mathrm{~mm}$ ID tube. Both two models underestimate the condensation rate, especially the default model. For UCB model, the predicted condensation rate is close to the experiment result although it is slightly lower. The 
discrepency between test data and two models is getting larger with system pressure. In high pressure region, this discrepency is quite remarkable. The reason for this discrepency comes from the assumption of no interfacial shear and staganent steam in Nusselt solution which is used in both two models. Figure 4.26 presents the condensation HTC with system pressure for $52.5 \mathrm{~mm}$ ID tube. The prediction of default model is close to test data in high pressure region, however, the UCB model shows very week pressure dependency. In low pressure region, both default and UCB model are all deviated greatly from experiment data. One of the reasons for this large deviation is that experiment data itself has very big measurement errors in low pressure region. When system pressure is low, the heat transfer rate is small, which resulting in a small driving temperature condition between primary and secondary sides of test section. The measurement errors are so big comparing with actual temperature difference that the measured $\Delta \mathrm{T}$ inevitably deviates from real value. Actually, the measurement error for temperature is the main sorce of total experiment error.

Figure 4.27 shows the trend of saturation temperature and inside tube wall temperature with system pressure for $52.5 \mathrm{~mm}$ ID tube tests. The default model predicts almost same inside wall temperatures with experiment data, that is also why the condensation HTC from the default model follows the same trend with experiment data. However, the inside wall temperatures from UCB model is higher than test data, which means a smaller temperature difference between inside wall temperature and saturation temperature. So with the similar condensation rate between the UCB model prediction and test data, the condensation HTC from the UCB model is higher than test data, as it is shown in Figure 4.26.

Figure 4.28 shows the RELAP5 predictions for both $26.6 \mathrm{~mm}$ and $52.5 \mathrm{~mm}$ ID tube tests. For either model, the code prediction results are very close between two tubes. This trend is also shown by experimental results discussed before.

As a summary, the default model shows better agreement on condensation HTC but underestimats condensation rate quite a lot. However, the UCB model predicts condensation rate rather well but gives large deviation on condensation HTC. The 
negligible effect of tube diameter to the condensation performance is also predicted by RELAP5 code. The code analysis results shows an improved condensation model of RELAP5 is needed.

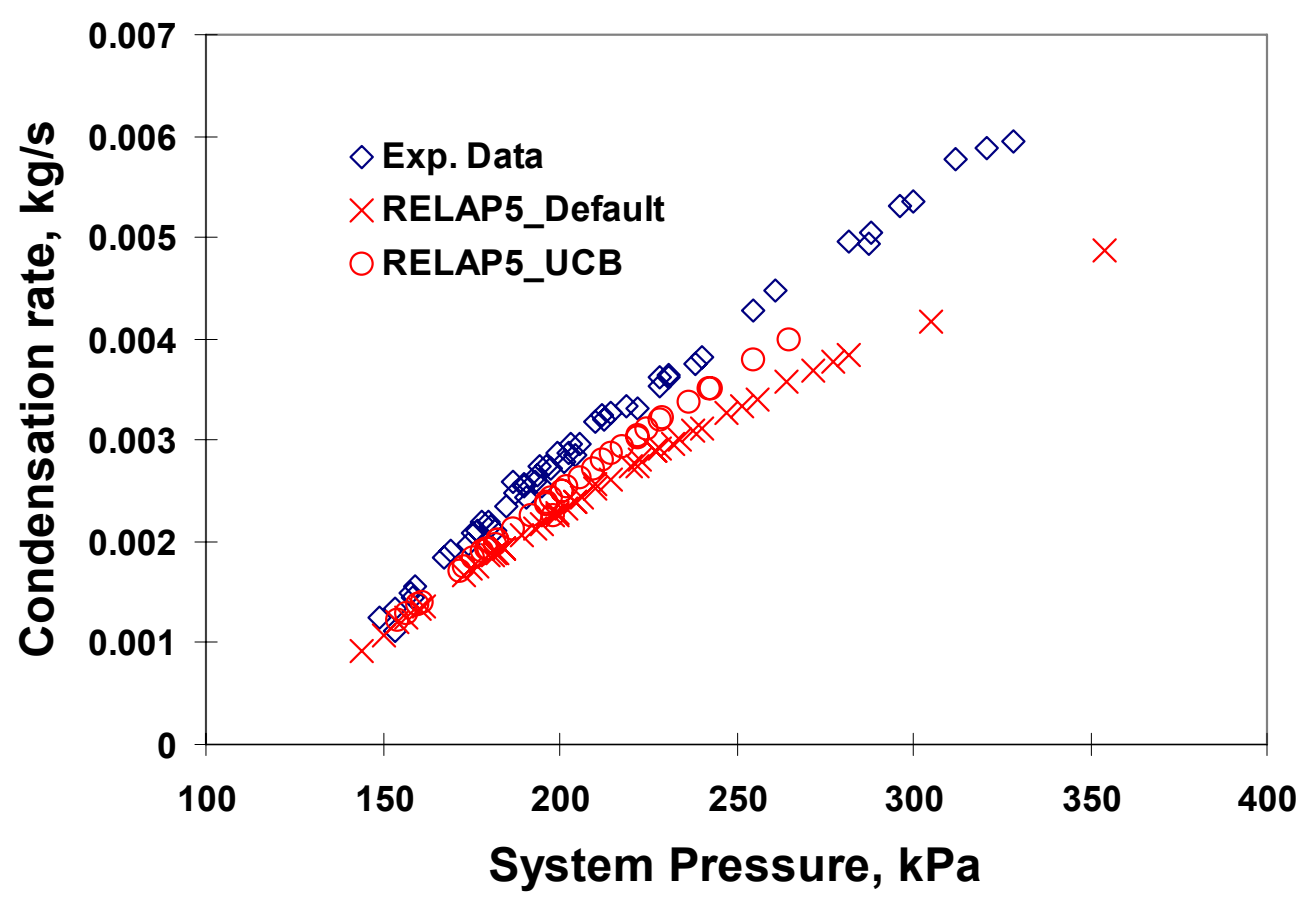

Figure 4.25 Condensation rate with system pressure for $52.5 \mathrm{~mm}$ ID tube 


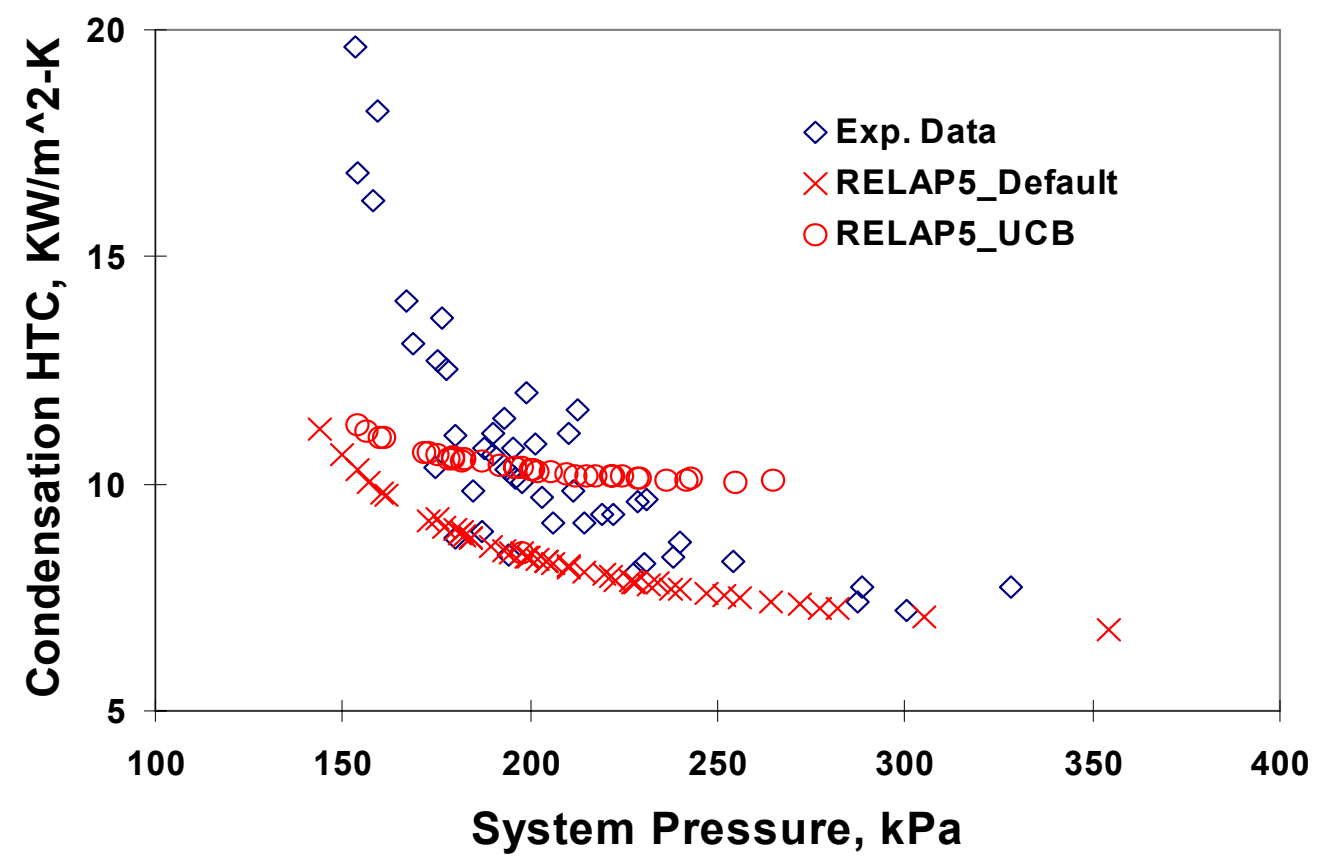

Figure 4.26 Condensation HTC with system pressure for $52.5 \mathrm{~mm}$ ID tube

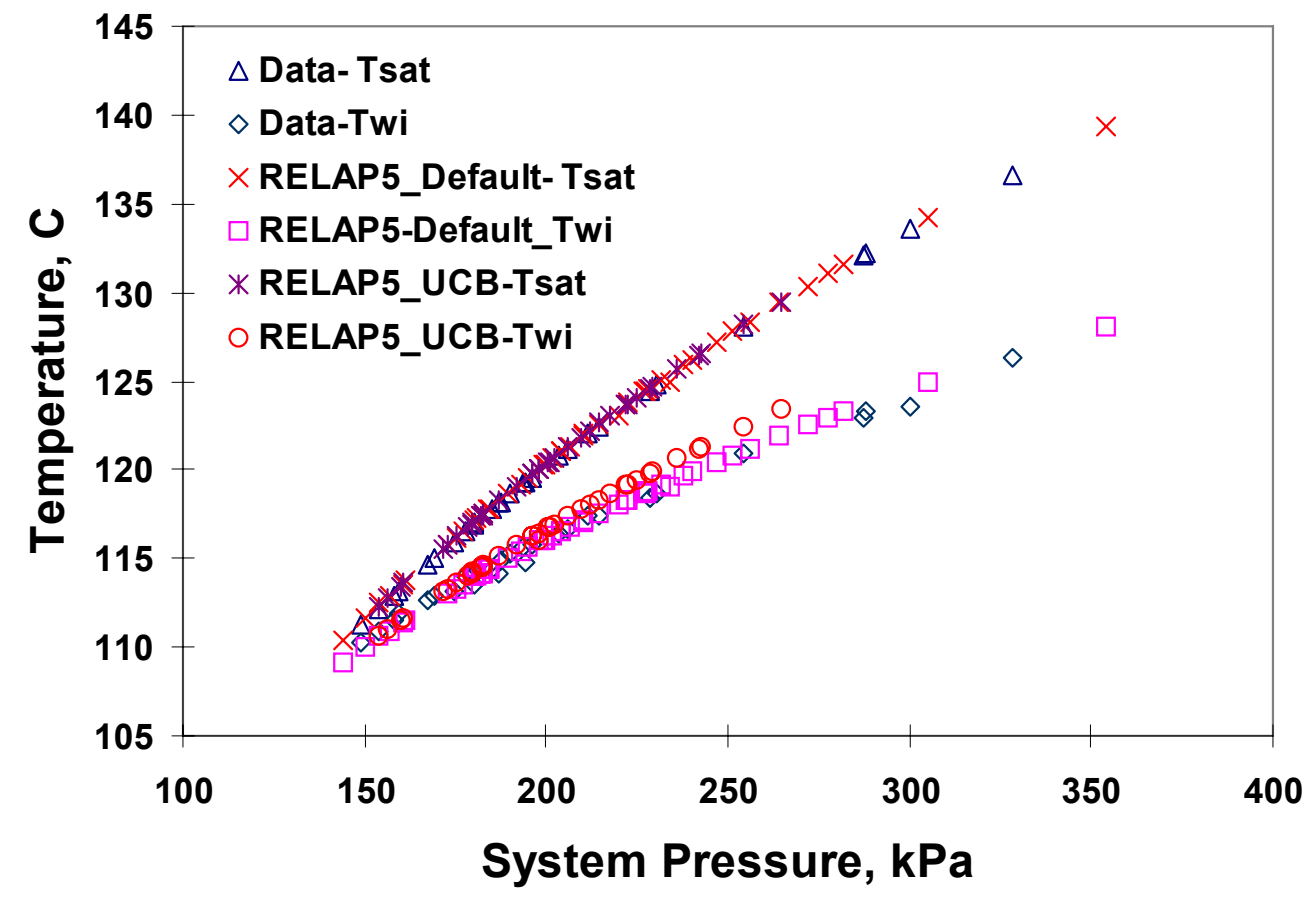

Figure 4.27 RELAP5 predicted temperature with system pressure for $52.5 \mathrm{~mm}$ ID tube 


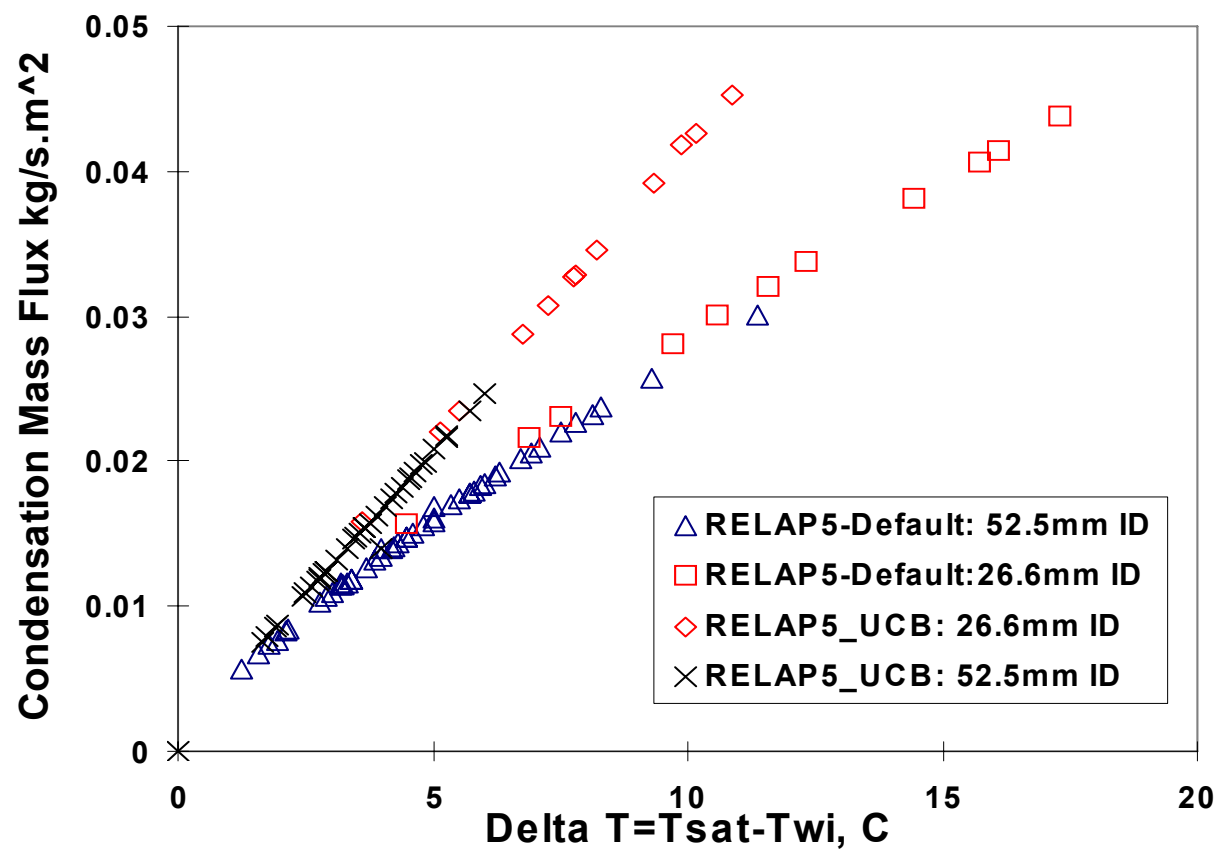

Figure 4.28 Condensation mass flux comparison between $26.6 \mathrm{~mm}$ and $52.5 \mathrm{~mm}$ ID tubes

Figures 4.29-34 show the comparisons among 1" and 2" single tube data by experiment and Relap5.

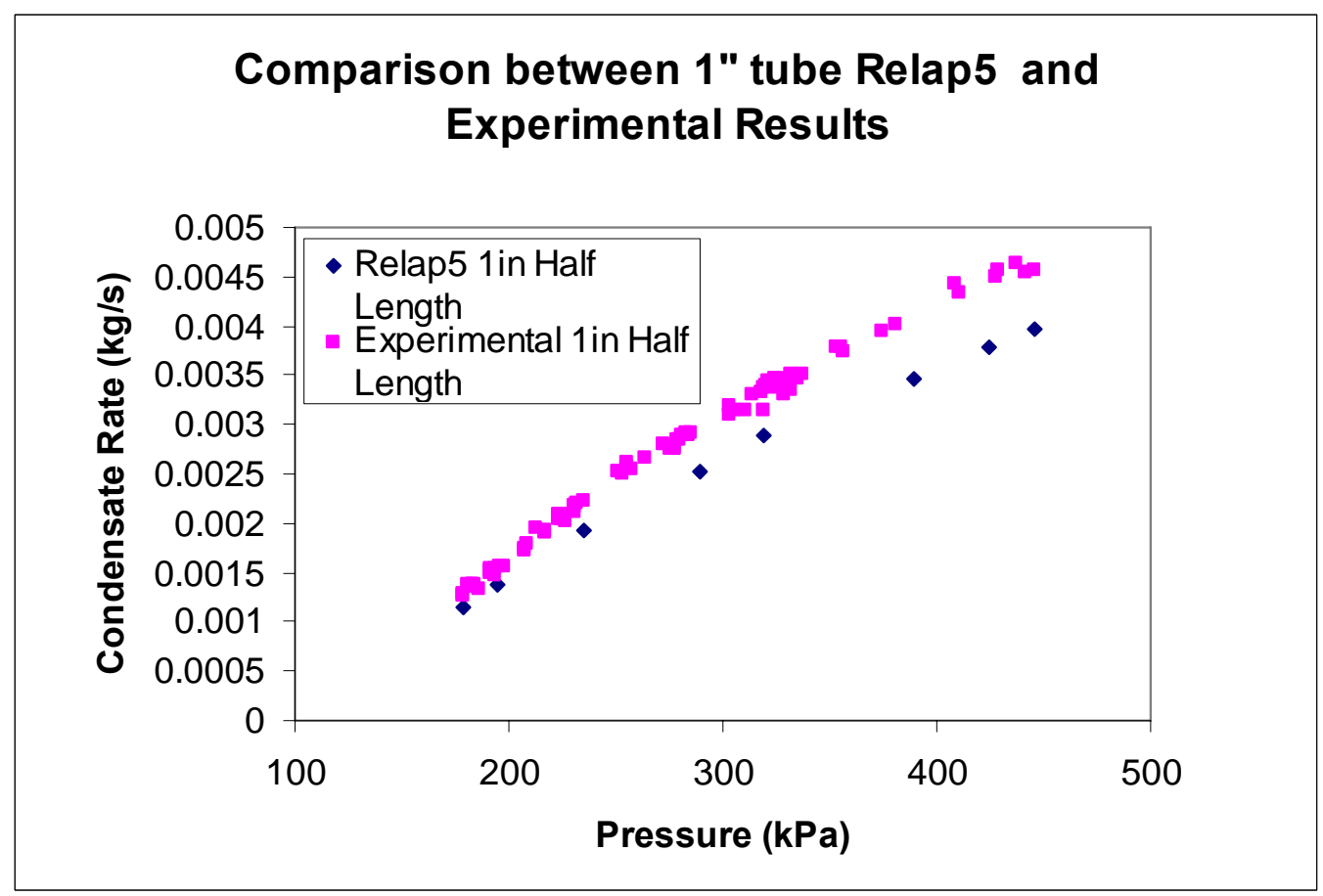

Figure 4.29 Comparison between 1" tube Relap5 and Experimental Results 


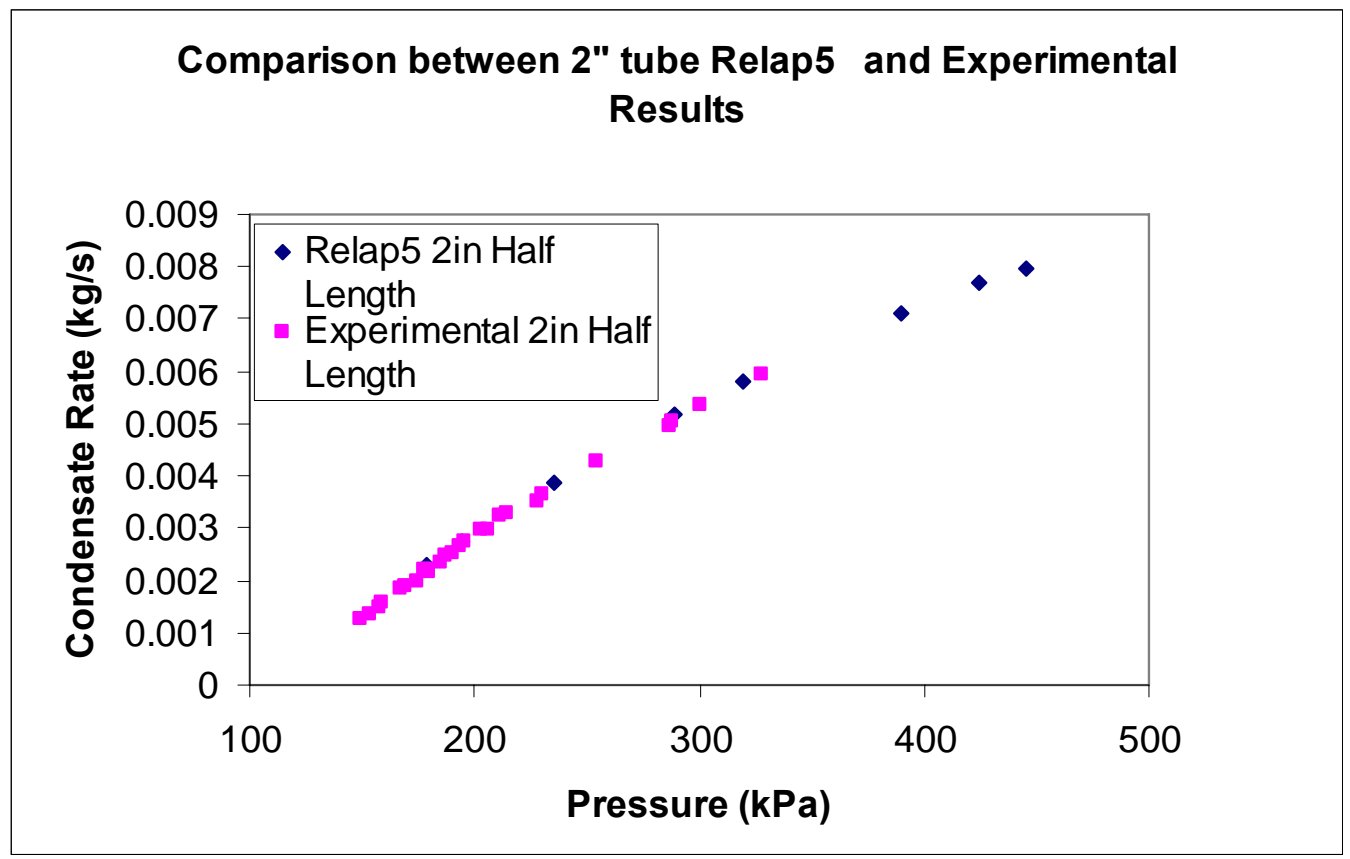

Figure 4.30 Comparison between 2" tube Relap5 and Experimental Results

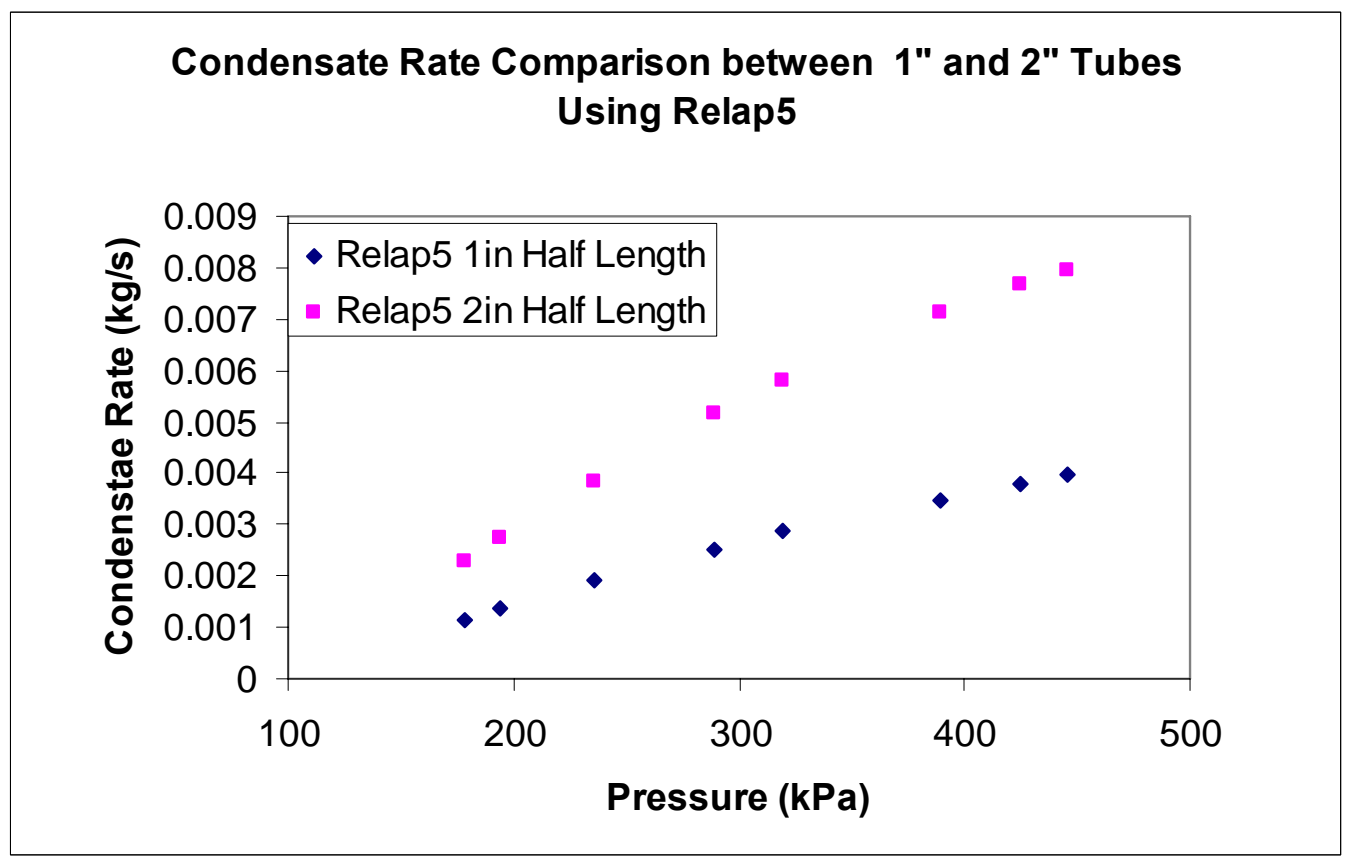

Figure 4.31 Condensation Rate Comparison between 1" and 2" tubes using Relap5 


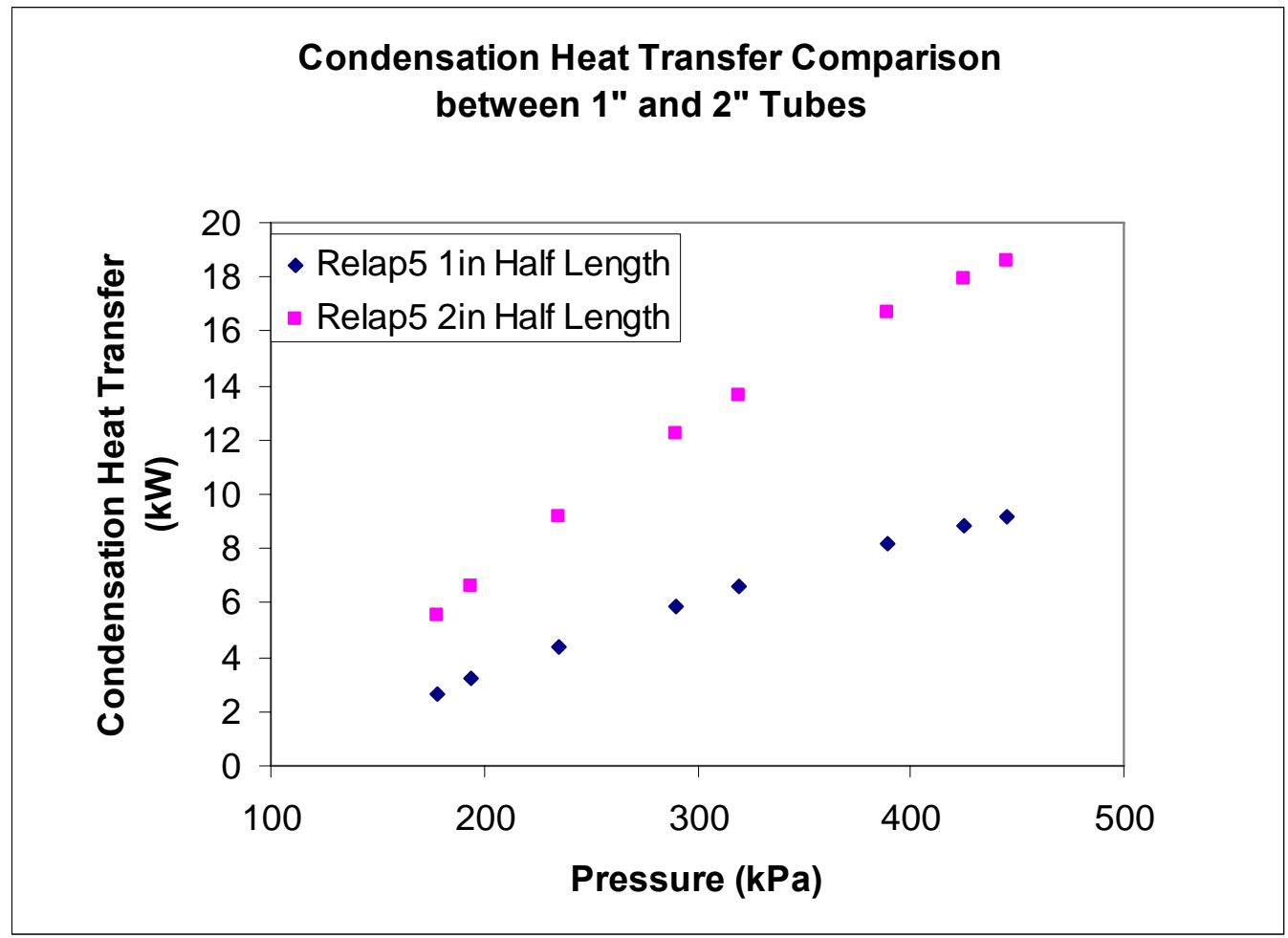

Figure 4.32 Condensation Heat Transfer Comparison between 1" and 2" tubes using Relap5

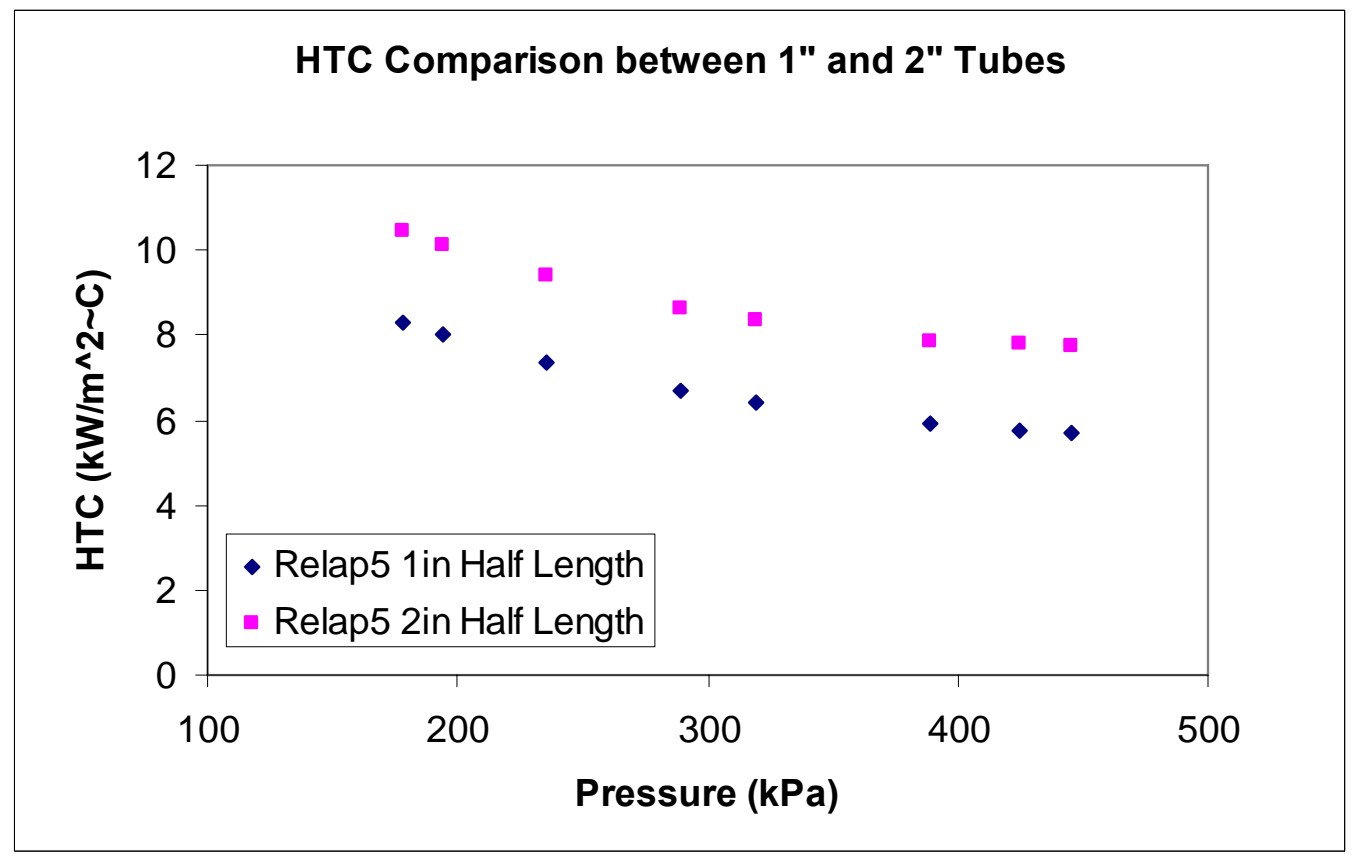

Figure 4.33 HTC Comparison between 1" and 2" tubes using Relap5 


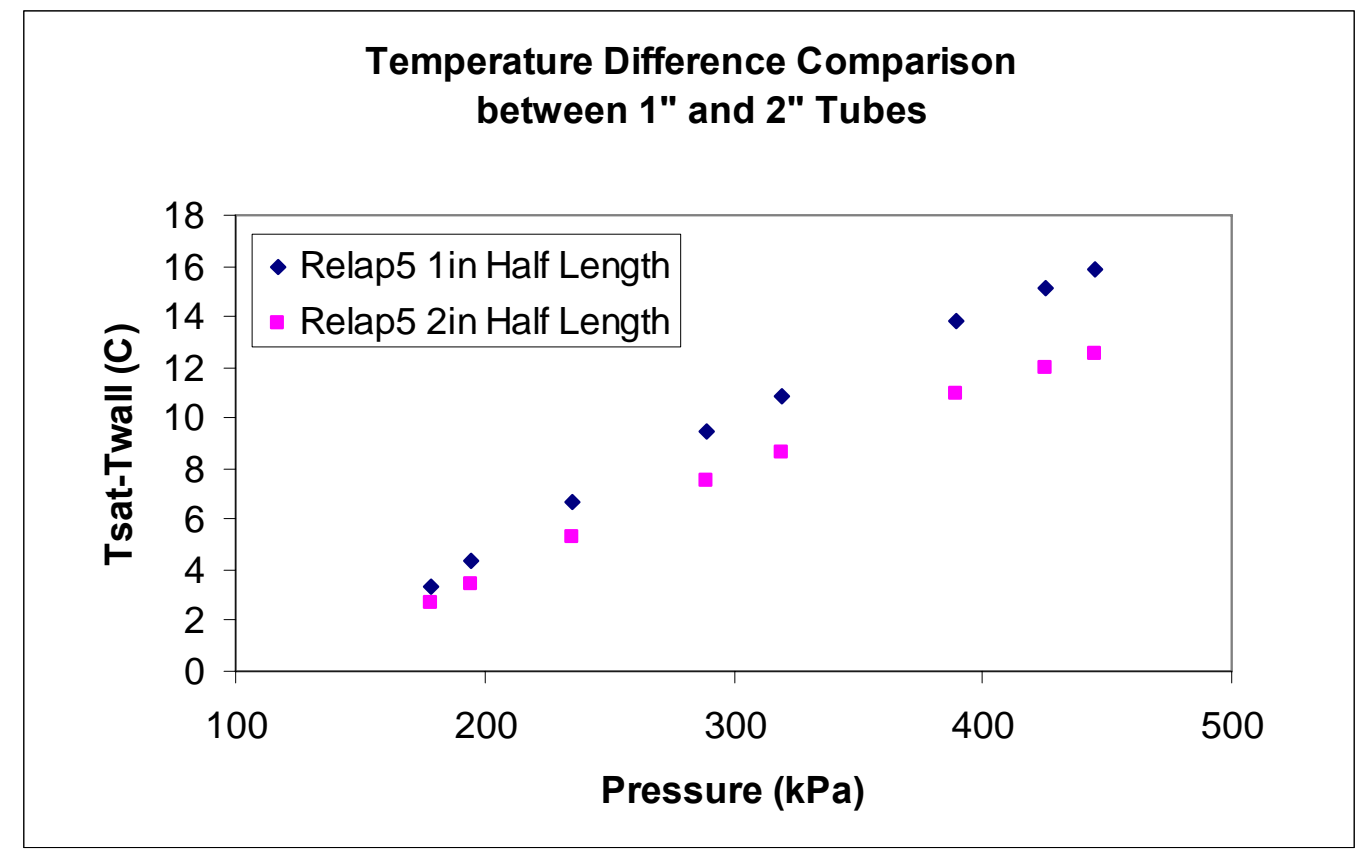

Figure 4.34 Temperature Difference Comparison between 1" and 2" tubes using Re-

$$
\text { lap5 }
$$

\subsection{References}

1. Vierow, K. M. and Schrock, V., Condensation in a Natural Circulation Loop with Noncondensable Gases, Part 1-Heat Transfer, Proc. Int. Conf. Multiphase Flows, Tsukaba, Japan, September (1991).

2. Peterson P. F. Schrock V. E., and Kageyama, Diffusion Layer Theory for Turbulent Vapor Condensation with Non-Condensable gas, J. Heat Transfer, Vol. 115, 998-1003, (1993).

3. Siddique, M., Golay, M. W., Kazimi, M. S., Theoretical Modeling of Forced Convection Condensation of Steam in a Vertical Tube in the Presence of a Noncondensable Gas, Nucl. Tech., Vol. 106, 202-215 (1994).

4. Kuhn, S. Z., Schrock, V. E., Peterson, P. F., An Investigation of Condensation from Steam-Gas Mixture Flow Downward inside a Vertical Tube, Nucl. Eng. Design Vol. 177, 53-69 (1997).

5. Revankar S. T. and Oh S., Analytical And Experimental Study Of The Effects Of Non-Condensable In A Passive Condenser System For The Advanced Boiling Water Reactor, Yearly Progress Report to DOE, PU/NE-02-10, August (2002). 
6. Chen S. L., Ke M. T., Forced Convective Film Condensation Inside Vertical Tubes, Int. J. Multiphase Flow, 19, 1045-1060, (1993).

7. Kinney R.B., Sparrow E. M., Turbulent Flow, Heat Transfer, and Mass Transfer ina Tube with Surface Suction, ASME J. Heat Transfer, Vol. 92, 117-124 (1970).

8. Nusselt, W. A., The Surface Condensation of Water Vapor, Zeit. D. Ver. Deut. Ing., Vol. 60, 541 (1916).

9. Revankar, S. T. , Oh, S, Experimental and theoretical investigation of film condensation with noncondensable gas, International Journal of Heat and Mass Transfer, Volume 49, 2523-2534, 2006.

10. J.G. Collier, Convective boiling and condensation, 2nd ed., McGraw-Hill, New York, 1981.

11. G.A. Hughmark, Film thickness, entrainment, and pressure drop in upward annular and dispersed flow, American Institute of Chemical Engineers Journal 19, 1062-1065, 1973.

12. W.H. McAdams, Heat Transmission, 3rd ed., McGraw-Hill, New York, 1954.

13. F. Blangetti, R. Krebs, E.U. Schlunder, Condensation in vertical tubesexperimental results and modeling, Chemical Engineering Fundamentals 1, 20-63, 1982.

14. W.M. Kays, M.E. Crawford, Convective heat and mass transfer, 3rd ed., McGraw-Hill, New York, 1993.

15. A.H.P. Skelland, Diffusional mass transfer, John Wiley \& Sons, New York, 1974.

16. S. Oh, S.T. Revankar, Boundary layer analysis for steam condensation in a vertical tube with noncondensable gases, Int. J. Heat Exchanger 6, 93-124, 2005.

17. S. Oh, Experimental and analytical study of the effects of noncondensable gas in a passive condenser system, Ph. D. thesis, Purdue University, 2004.

18. B.R. Bird, W.E. Stewart, E.N. Lightfoot, Transport phenomena, 2nd ed. John Wiley \& Sons, INC, New York, 2002.

19. S. Z. Kuhn, Investigation of heat transfer from condensing steam-gas mixtures and turbulent films flowing downward inside a vertical tube, $\mathrm{Ph}$. D. thesis, University of California at Berkeley, 1995.

20. Revankar, S. T. , Oh, S, Analytical and experimental study of the effects of non-condensable in a passive condenser system for the advanced boiling wa- 
ter reactor, DOE/NEER Progress Report, PU/NE-03-06, Purdue University, 2003.

21. M.M. Shah, A general correlation for heat transfer during film condensation inside pipes, Int. J. Heat Mass Transfer 22, 547, 1979.

22. K.M. Vierow and V.E. Schrock, Condensation in a Natural Circulation Loop with Noncondensable Gases: Part I :Heat Transfer, Proc. of the Int. Conf. on Multiphase Flow, Tsukaba, Japan, 183, 1991. 


\section{MULTI-TUBE EXPERIMENT PROGRAM}

\subsection{Tube Bundle Experimental Loop}

One of the most important objectives in the project is to conduct condensation tests with a bundle test section. Thus, an experiment loop with bundle test section was constructed. The schematic of the bundle experiment loop is shown in Fig 3.4. A new $52.5 \mathrm{~mm} 4$ tube bundle test section is applied in the loop.

The test facility components include $100 \mathrm{~kW}$ steam generator, four tube bundle condenser, model suppression pool tank and a steam reservoir tank. The facility has instrumentations to measure temperature, steam and air flow rates, water levels, system pressure, pressure drop in the test section, heat flux, and condensation rates.

Basically, the design of bundle loop follows the same idea of that of single-tube test loop. However, due to change of test section from single tube to bundle, some modifications need to be applied on the new loop:

1. A new test section made of four-tube condenser with inlet and outlet plenums. The dimensions of each condenser tube were set to prototype dimensions i.e., it has full length $(1.80 \mathrm{~m})$ and full diameter $(5.08 \mathrm{~cm})$.

2. Power supply was increased from $10 \mathrm{~kW}$ to $100 \mathrm{~kW}$ in order to guarantee the enough steam flow rate for the bundle test section.

3. A new steam generator has been constructed, which has 120 inch in height and 18 inch in diameter. The volume of the new steam generator is well designed to stably provide superheat steam for 90 minutes;

4. An immersion type sheathed electrical heater of $100 \mathrm{~kW}$ capacity was constructed for the steam generator. 


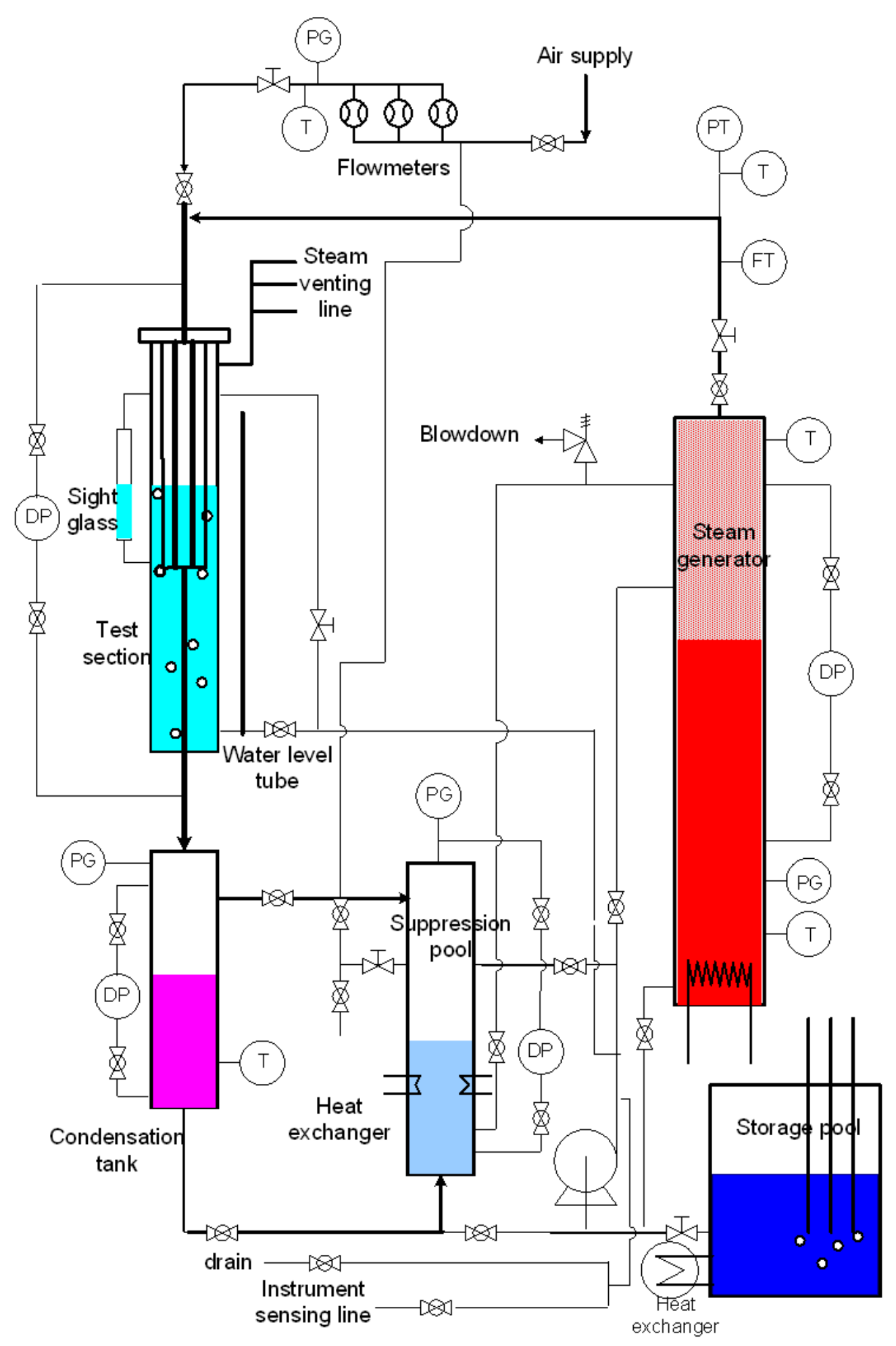

Fig 5.1 Schematic of Bundle PCCS Test Loop 
5. To observe the venting phenomena, a side tank is designed before the entrance of suppression pool. Noncondensable venting line was immersed under the water level in the side tank. A window at the side of the side tank enable camcorder recording of venting phenomenon.

6. Substantial number of instrumentations for the facility.

\section{$\underline{\text { Scaling and Design }}$}

The test facility design was based on using four condenser tubes. The length and size of the condenser tube was used as the prototype sizes i.e., $1.8 \mathrm{~m}$ long and 50.8 $\mathrm{mm}$ in diameter. The scaling analysis was carried out similar to the single tube PCCS condenser design. In Table 5.1 the comparison between the prototype and the experimental loop condenser design is given where the prototype PCCS design was taken as General Electric ESBWR design which is similar to the SBWR design. In Table 5.2 the 4 tube PCCS condenser design parameters are shown.

Table 5.1 PCCS Parameter comparison of experimental PCCS with prototype design

\begin{tabular}{|c|c|c|c|}
\hline \multicolumn{2}{|l|}{ Parameter } & Experiment loop & Prototype \\
\hline \multicolumn{2}{|c|}{ Number of tubes } & 4 & 248 per module \\
\hline \multirow{2}{*}{$\begin{array}{c}\text { Condenser } \\
\text { tubes }\end{array}$} & Length $(\mathrm{mm})$ & 1800 & 1800 \\
\hline & Diameter(mm) & 50.8 & 50.8 \\
\hline \multirow[t]{2}{*}{ Header } & Volume (m3) & 0.0126 & 0.78 \\
\hline & Height $(\mathrm{mm})$ & 660 & 660 \\
\hline \multicolumn{2}{|c|}{$\begin{array}{l}\text { Header center to IC pool bottom } \\
(\mathrm{mm})\end{array}$} & 670 & 670 \\
\hline
\end{tabular}

Table 5.2 Multi-tube PCCS condenser design

\begin{tabular}{|c|c|c|}
\hline \multirow[t]{3}{*}{ Bundle } & Number of tubes & 4 \\
\hline & Condensation tube & Length (mm): 1800, D (mm): 50.8 \\
\hline & Ratio of pitch to diameter & $\mathrm{P} / \mathrm{D}=1.25$ \\
\hline \multirow[t]{3}{*}{ header } & Upper cylinder & Diameter (mm): 66.9, Height $(\mathrm{mm}): 290$ \\
\hline & Lower cylinder & Diameter $(\mathrm{mm}): 152$, Height $(\mathrm{mm}): 370$ \\
\hline & $\begin{array}{l}\text { Header center to secon- } \\
\text { dary pool bottom (mm) }\end{array}$ & 670 \\
\hline \multirow{3}{*}{$\begin{array}{l}\text { Secondary } \\
\text { Pool }\end{array}$} & Diameter $(\mathrm{mm})$ & $160 \mathrm{~mm} \quad(6.3 \mathrm{in})$ \\
\hline & Height (mm) & $3800 \mathrm{~mm}$ \\
\hline & Valid volume $\left(\mathrm{m}^{3}\right)$ & $\begin{array}{l}0.02 \\
\text { current pool) }\end{array}$ \\
\hline
\end{tabular}


The existing steam generator tank could provide only $10 \mathrm{~kW}$ power which was adequate for half length single tube consider tube. A new steam generator capable of supplying $100 \mathrm{~kW}$ steam for four condensers tube was designed. The design parameters for steam generator are shown in Table 5.3. The steam supply line and rest of the piping for the facility were designed based on the maximum of $100 \mathrm{~kW}$ steam flow rate.

Table 5.3 Steam generator design

\begin{tabular}{|c|c|c|}
\hline & Current design & $\begin{array}{l}\text { New design with } 18 " \\
\text { ID }\end{array}$ \\
\hline $\begin{array}{l}\text { Total Vol- } \\
\text { ume }\end{array}$ & $0.293 \mathrm{~m}^{3}$ & $0.501 \mathrm{~m}^{3}$ \\
\hline Height & $2.66 \mathrm{~m} \quad(89 \mathrm{in})$ & $3.05 \mathrm{~m} \quad(120 \mathrm{in})$ \\
\hline Diameter & $0.375 \mathrm{~m}(14.8 \mathrm{in})$ & 0.457 (18 in) \\
\hline $\begin{array}{l}\text { Valid Vol- } \\
\text { ume }\end{array}$ & $0.1409 \mathrm{~m}^{3}$ & $0.2667 \mathrm{~m}^{3}$ \\
\hline \multicolumn{3}{|l|}{ Heater: } \\
\hline Height & $0.71 \mathrm{~m}(28 \mathrm{in})$ & $0.91 \mathrm{~m}$ (36 in) \\
\hline Power & $10 \mathrm{~kW}$ & $100 \mathrm{kw}$ \\
\hline Steam supply & $4.7 \mathrm{~g} / \mathrm{s}$ & $47 \mathrm{~g} / \mathrm{s}$ \\
\hline $\begin{array}{l}\text { Supply pe- } \\
\text { riod }\end{array}$ & $7 \mathrm{hrs} 40 \mathrm{~min}$ & $1 \mathrm{hr} 26 \mathrm{~min}$ \\
\hline
\end{tabular}

\section{$\underline{\text { Steam Generator }}$}

The steam generator (SG) is made of schedule 10, $406 \mathrm{~mm}$ (18 inch) diameter stainless steel pipe. Its total length is $3.05 \mathrm{~m}$ (120 inch). An immersion type sheathed electrical heater of $100 \mathrm{~kW}$ capacity is mounted at the lower flange of this vessel. The vessel is instrumented with thermocouples. The power to the heater is measured with A.C. Voltmeter and Ammeter. The design operation pressure of the steam generator is $150 \mathrm{psig}, 182^{\circ} \mathrm{C}$. The total valid volume is designed to continuously provide superheat steam for 90 minutes. However, the period of one complete test is about 4-5 hrs, so a high head injection pump is needed to feed water into SG during the experiment. The detailed dimensions of the steam generator are shown in Table 5.4 and Fig 5.2.

A new three phase, $240 \mathrm{~V}, 100 \mathrm{~kW}$ power supply is employed for the bundle test. According to the max input power, the steam generator can stably provide superheat steam with the max flow rate of $47 \mathrm{~g} / \mathrm{s}$. 


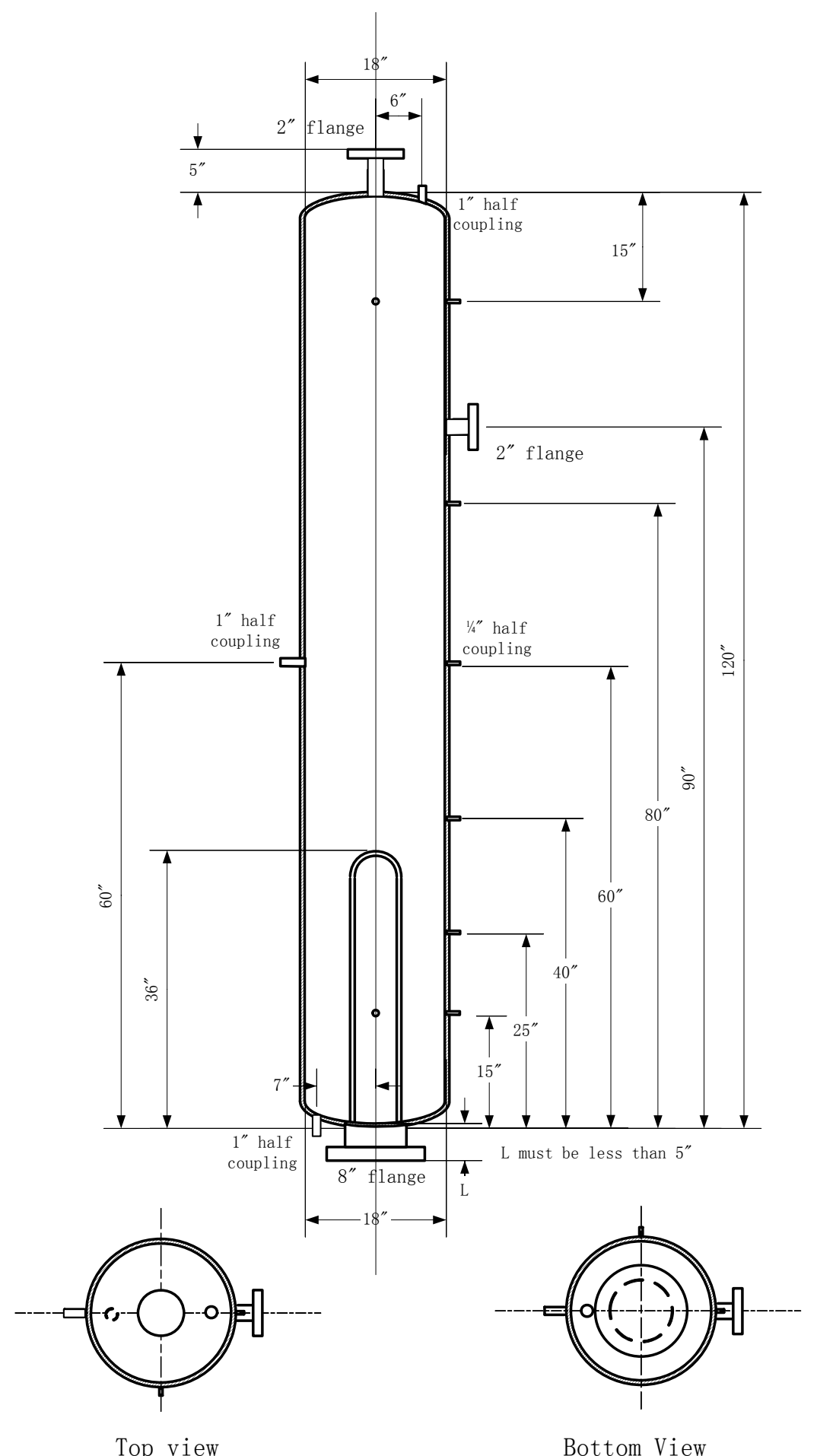

Fig. 5.2 Steam Generator design for bundle loop

(Diameter: 18 inch, Height: 120 inch) 
Table 5.4 Information of Heater and Control Panel for Bundle Loop

\begin{tabular}{|c|c|c|}
\hline Vendor & \multicolumn{2}{|c|}{ ASB Heating Elements Ltd. } \\
\hline \multirow{3}{*}{$\begin{array}{l}\text { Flange Heater } \\
(\mathrm{PF} 125732)\end{array}$} & Power & $100 \mathrm{~kW}$ \\
\hline & Insertion Length & $0.864 \mathrm{~m}$ (34 inch) \\
\hline & Flange & 0.20 (8 inch) $150 \# 316$ S.S \\
\hline \multirow{2}{*}{$\begin{array}{l}\text { Control Panel } \\
\text { (CP25733) }\end{array}$} & Load & $240 \mathrm{~V} 240$ amps 3 phase $100 \mathrm{~kW}$ \\
\hline & Control Type & Temperature Control \\
\hline
\end{tabular}




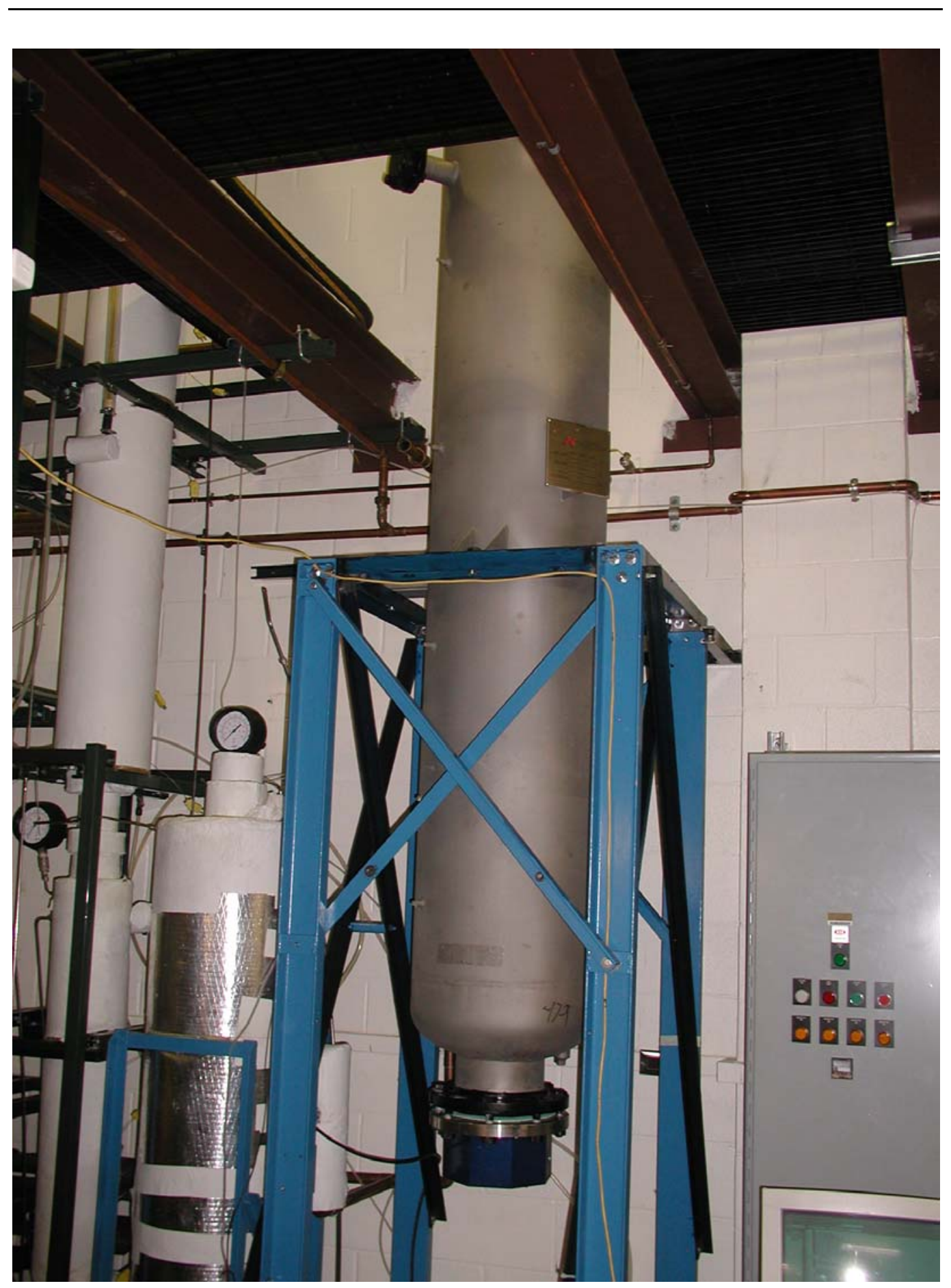

Figure 5.3 Steam generator tank installed. Inset: $100 \mathrm{~kW}$ immersion heater. 


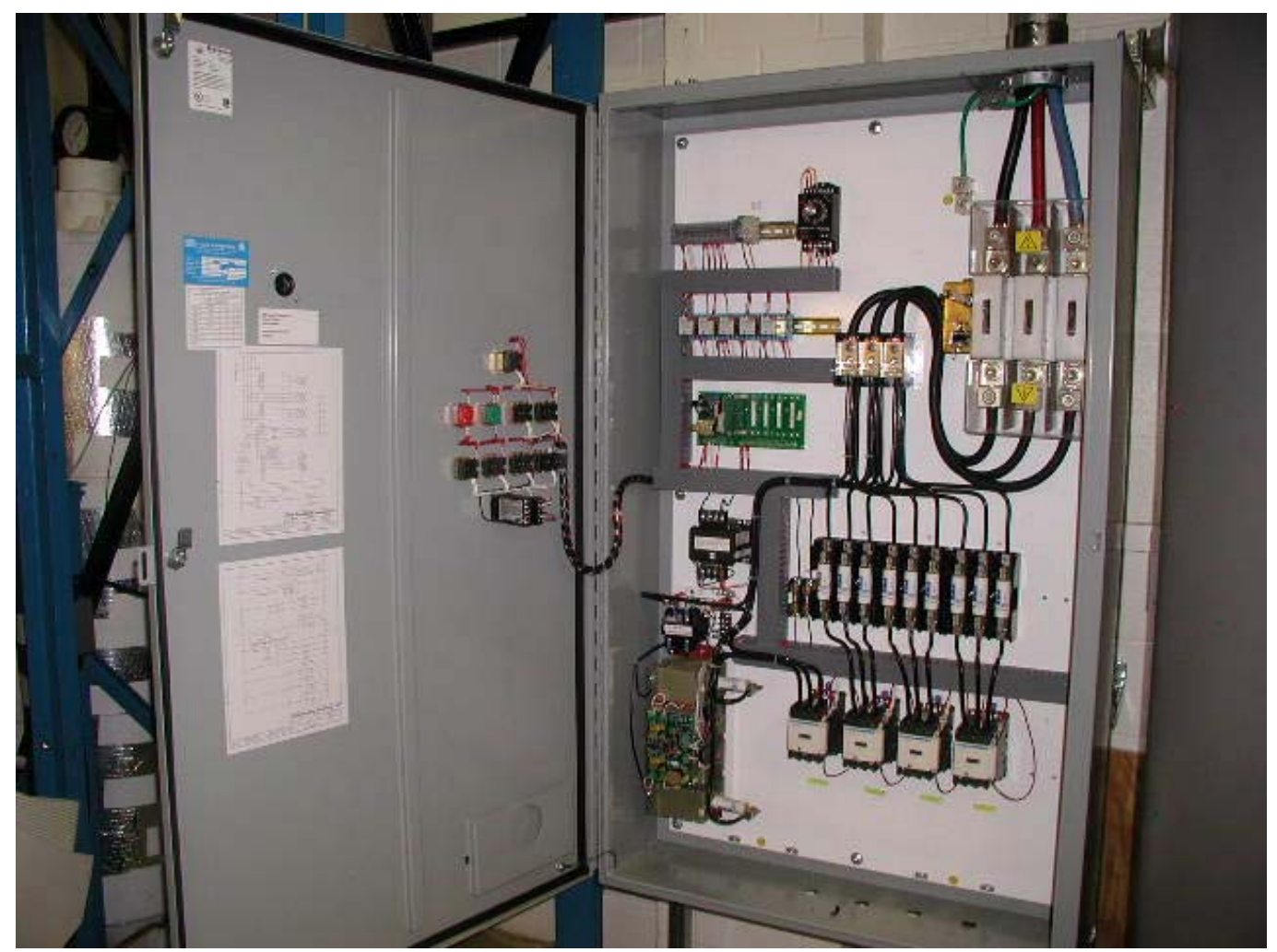

Figure $5.4100 \mathrm{~kW}$ power control panel

\section{$\underline{\text { Test Section }}$}

The specific design of the bundle test section (T/S) was based on the scaling result from the prototype design. The bundle is made of 4 condenser tubes arranged as a square. The tube inner diameter and length are the same as the prototype. The pitch between two tubes was selected according to the standard value of commercial bundle condenser. The whole test section is comprised of two subassemblies. One is the condenser outside tube where the boiling takes place and the other is inside condenser bundle where the condensation takes place.

The outside tube is made of $19.1 \mathrm{~cm}$ (7.5 inch) stainless steel pipe with a top flange and a bottom plate welded to the pipe. Along the outside surface of the $191 \mathrm{~mm}$ (7.5 inch) pipe, various nozzles for thermocouple, sight glass, feed, drain, and steam exit are installed. The total height of the outside tube is $4100 \mathrm{~mm}$. During the experiment, the condensation heat will be transferred into the outside tube from the inside condensation tube, the water outside is going to be heated and start boiling quickly. The steam comes out of the outside tube from the steam venting line locates on the 
top of the outside tube, which leads to the storage tank. To study the natural circulation in the PCCS pool, a bypass line was connected on the outside tube, starting from the height of top header to the height of bottom header.

The inside condenser bundle includes several parts. On the top of condenser, there is a one meter long insulation part, which is used to measure water level change in the outside tube. This part is also used to minimize the inlet effect. After the insulation part, a top header was design to distribute the incoming steam into four condenser tubes. The volume of the header was calculated from the volumetric ratio between test loop and prototype. To keep the volumetric ration as well as the header length which is important to the pressure drop in the condenser, the header is comprised of two parts, the upper cylinder and lower cylinder. The 4-tube condensation bundle is connected right after the top header. Each tube has $5.08 \mathrm{~cm}$ ( 2 inch) in diameter and $180 \mathrm{~cm}$ in length, which is the same as the prototype design. The four tubes were arranged as a square so that the boiling condition in the center of the bundle can be well achieved. The pitch between two tubes is $6.35 \mathrm{~cm}(2.5 \mathrm{inch})$ and $\mathrm{p} / \mathrm{D}=1.25$. The bottom header, which is the last part of the condenser, is connected with the condensation bundle. The structure and dimension of bottom header is exactly the same with top header. The condensation water and non-condensable/steam mixture from four condensation tubes are collected and lead out of the test section. The detailed dimensions of all the parts are show in the Fig. 5.5.

For the experiments with $52.5 \mathrm{~mm} 4$ tube bundle test section, the condensation rate is faster than the previous tests with $26.6 \mathrm{~mm}$ and $52.5 \mathrm{~mm}$ test sections. The condensation tank is much easier to be full and have to be drained. The drain line of condensation tank is connected from the bottom of condensation tank to the storage tank. A 1 inch schedule 40 stainless steel piping is used in the drain line, the same as previous loop.

Maintaining the pool level is very important for the low pool level test, therefore, a $1 / 2$ feed line was connected to the top of secondary pool with 4 water injection nozzles. The new feed line is capable to give a small but enough flow rates, which minimize the effect of cold water to the boiling pool and hold the pool level as well. The new feed line is made of $1 / 2$ copper tubing and corresponding accessories. 
Local heat flux is another main aim for this research. Since condensation heat transfer can be obtained from the condensation rate which is calculated from the water level change in condensation tank, the local temperature differences between effective 


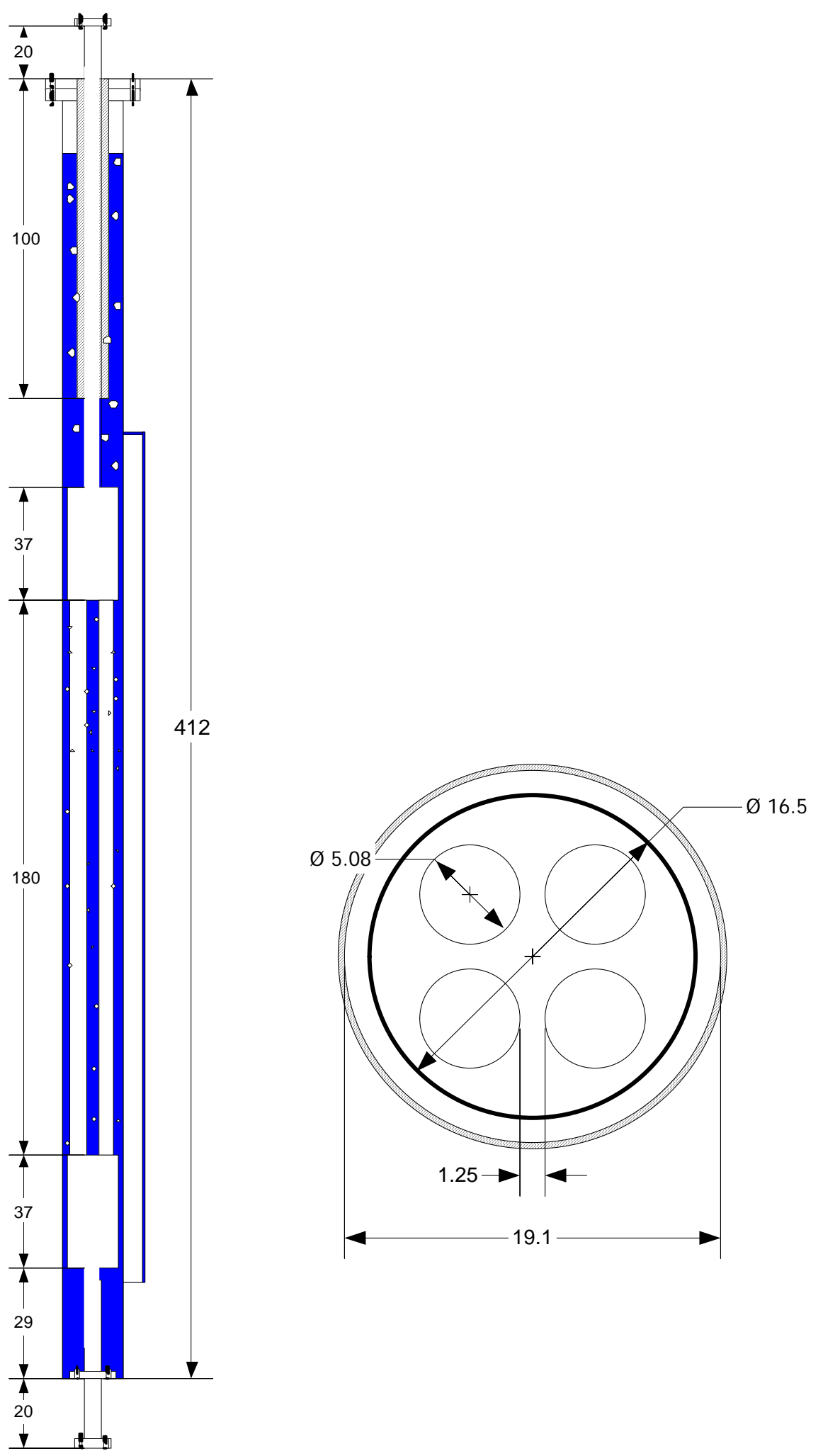

Fig. 5.5 Condenser schematic design and bundle arrangement (unit: $\mathrm{cm}$ ) 
wall thicknesses are the rest of parameters in order to determine the local heat flux. To measure the local temperature along the condensation tube, 140 thermocouples are welded on the condensation tube, 14 T/Cs for each level and 10 levels altogether. 6 heat flux sensors are also mounted along the tube. The detailed layout of the thermocouples and heat flux sensors is shown in Fig 5.6, 5.7 and 5.8.

The secondary boiling pool diagram is shown in Figure 5.9. The figure also shows the assembly of the condenser tube bundle inside the outer boiling pool tank. In Figure 5.10 the picture of secondary pool tank is shown.
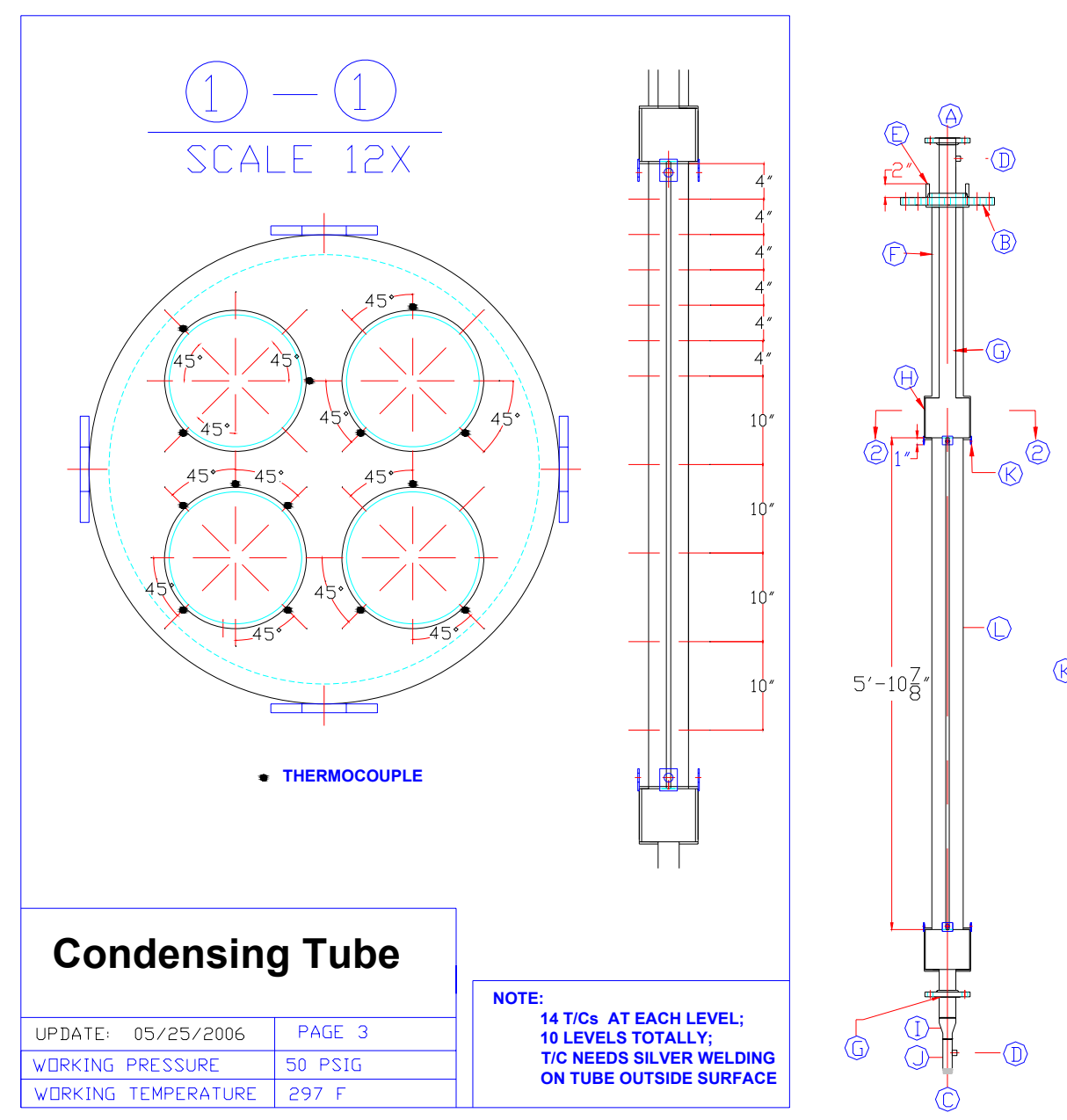

Figure 5.6 Design of four tube bundle condenser and T/C locations 


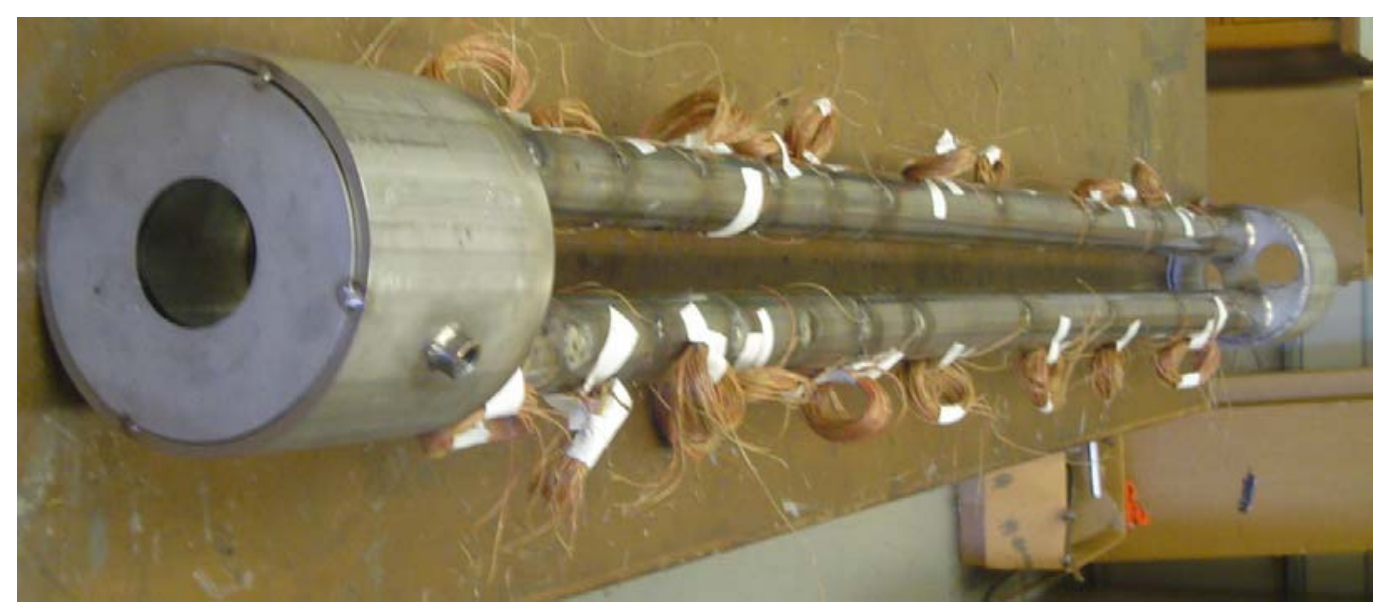

Figure 5.7 Picture of the condenser tube bundle with thermocouples mounted on the tubes.

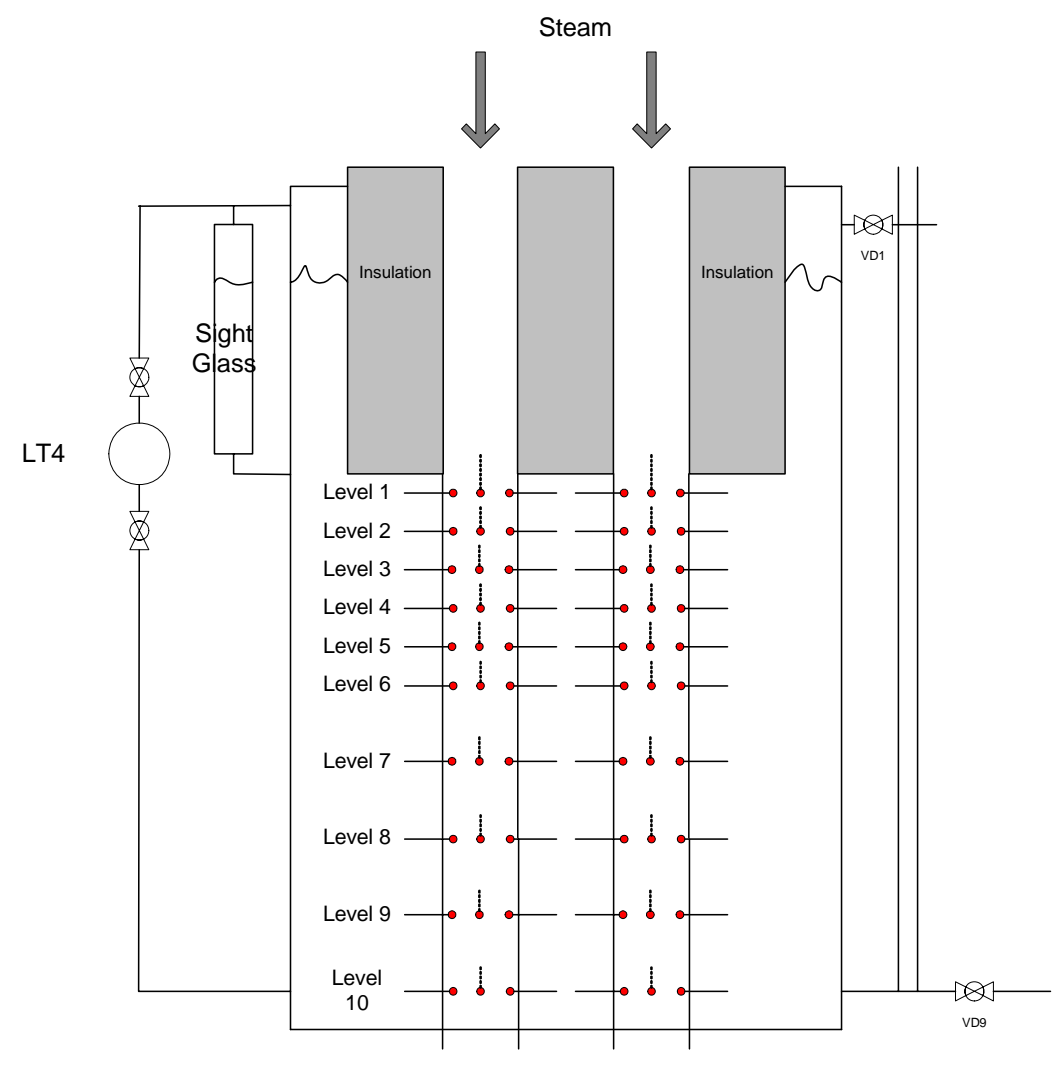

Fig. 5.8 Schematic of $52.5 \mathrm{~mm} 4$ Tube Test Section with Secondary Pool 

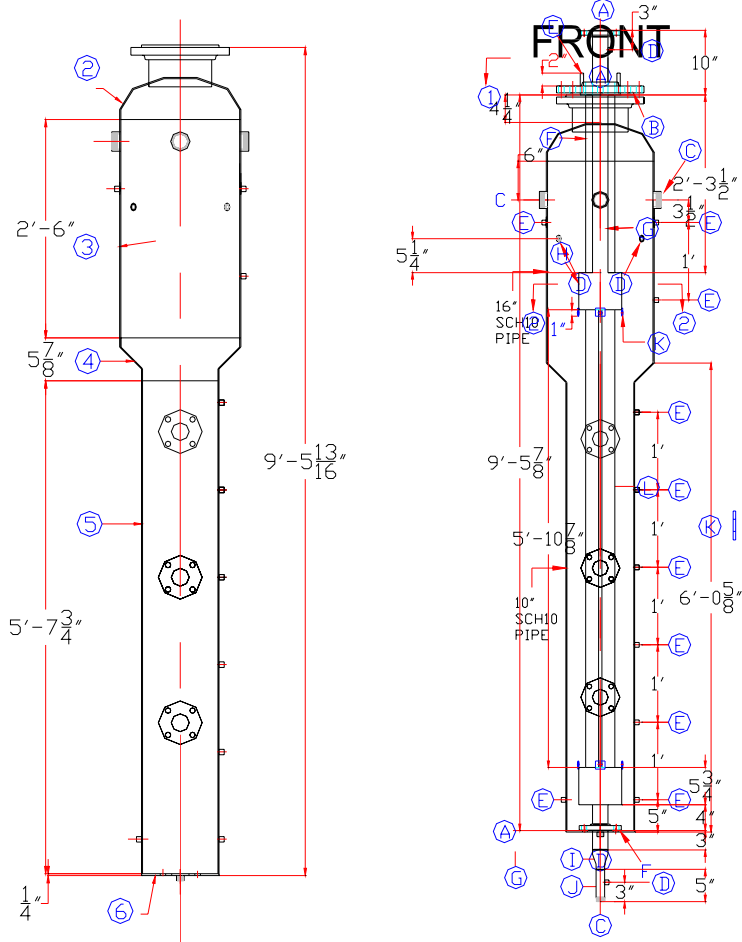

Figure 5.9 Tube bundle condenser secondary boiling pool tank and assembly of the tube bundle inside the boiling pool tank.

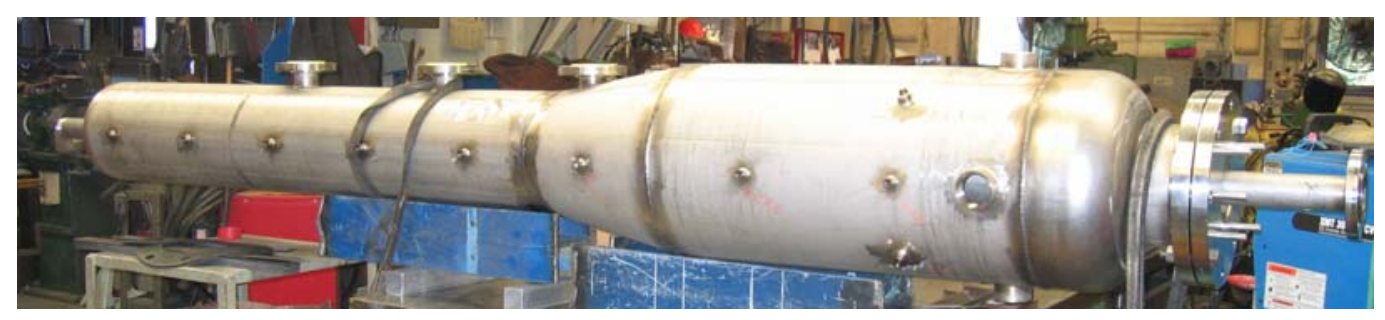

Figure 5.10 Tube bundle condenser secondary pool tank

\section{$\underline{\text { Steam and Air Supply Line }}$}

The steam supply line to the condenser is made of $52.5 \mathrm{~mm}$ ( 2 inch) stainless steel pipe except the upstream and downstream piping of vortex flow meters. Since the diameters of the two vortex flow meters is $38 \mathrm{~mm}$ (1.5inch) and $19 \mathrm{~mm}(3 / 4$ inch), the upstream and downstream piping of vortex flow meter is also $38 \mathrm{~mm}$ (1.5inch) and 19 $\mathrm{mm}(3 / 4$ inch) piping respectively. To minimize the flow disturbance effect on the flow meter, the length of $38 \mathrm{~mm}(1.5 \mathrm{inch})$ and $19 \mathrm{~mm} \mathrm{(3/4} \mathrm{inch})$ upstream piping was selected as greater than the required $\mathrm{L} / \mathrm{D}$ specified in flow meter installation manual. To 
determine the flow condition at vortex flow meter, pressure transducer and thermocouple are installed at the downstream of the vortex flow meter. The sensing line to this pressure transducer is routed upward to drain the condensate in the sensing line.

Air supply line is connected to the steam line and suppression pool. Before the connection to steam line, three rotameters with different flow ranges are installed to measure the wide range of air flow rate. A pressure gauge and a thermocouple are also installed to measure pressure and temperature of air.

Pressure tabs are made at upstream and downstream piping of the test section to measure the test section differential pressure. A pressure gauge is also installed at the downstream piping of the tube. To collect the condensate in the DP sensing line, the sensing lines to DP transducer are routed upward and condensate drain lines are connected to the high and low pressure side of sensing lines. If condensate fills the sensing line, normally closed drain valves are opened to drain the condensate.

\section{$\underline{\text { Condensate Tank }}$}

The condensate tank (CT) collects the condensate. It is made of Schedule 10, $305 \mathrm{~mm}$ (12 inch) pipe and is mounted vertical. The condensate tank is instrumented with thermocouple, pressure gauge and DP cells to measure and monitor temperature, pressure and water level. 

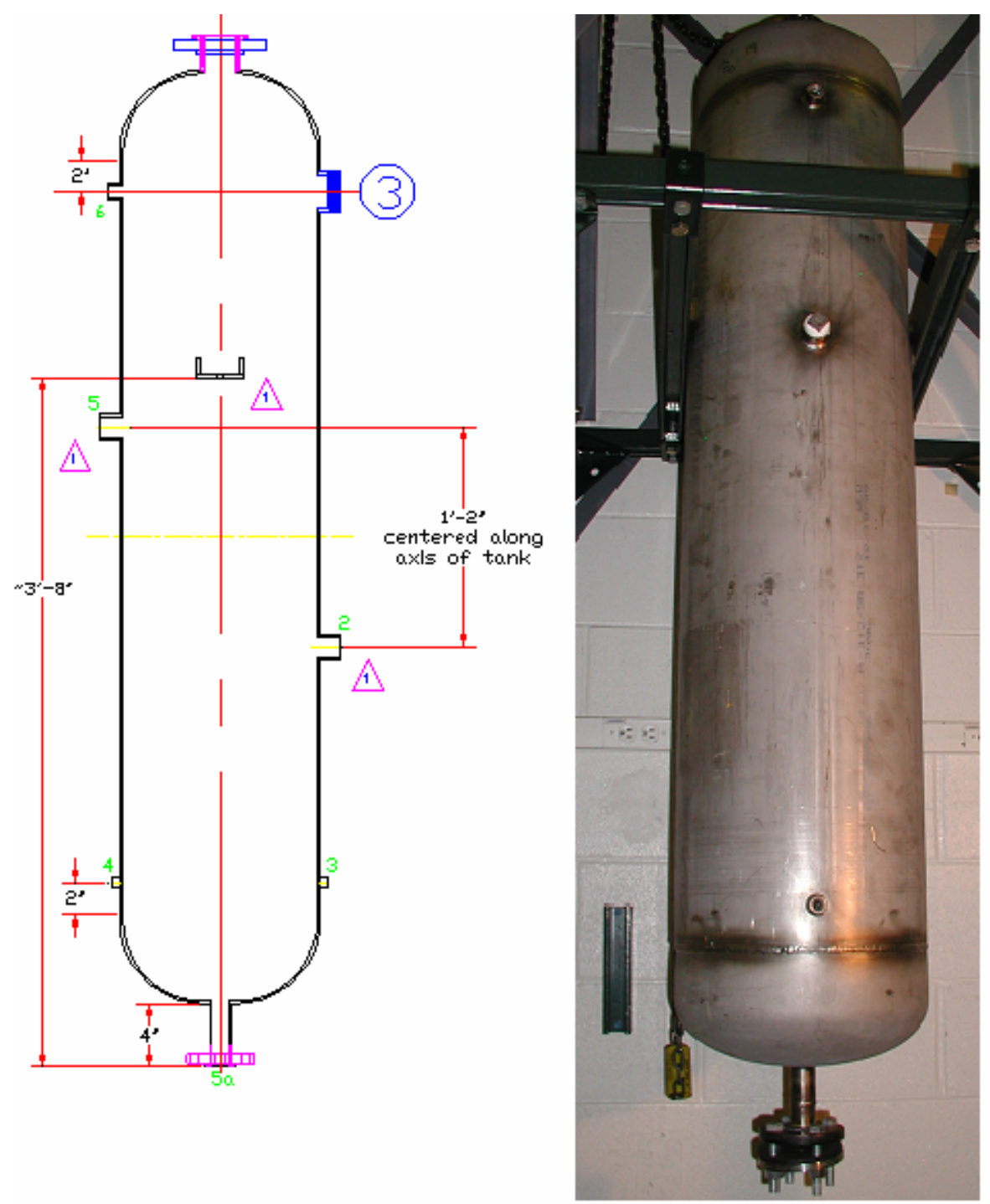

Figure 5.12 Suppression Pool

\section{$\underline{\text { Suppression Pool }}$}

The suppression pool (SP) serves as a collector of the non-condensable gas and the uncondensed steam. During the complete condensation mode, the suppression pool is isolated from the condensing loop. It is made of Schedule $10,40.6 \mathrm{~cm}$ (16 inch) pipe and is mounted vertical. The water level in the suppression pool can be maintained at desired level by continuous bleeding water from the tank. The condenser operating pressure is set by the pressure level in the suppression pool. An airline is connected to the suppression pool 
to set the pressure higher than the atmosphere pressure. A blowdown line is connected to blowdown \& secondary steam dump tank. The suppression pool is instrumented with thermocouple, pressure gauge and DP cells to measure and monitor temperature, pressure and water level. The Suppression pool design and picture is shown in Figure 5.12.
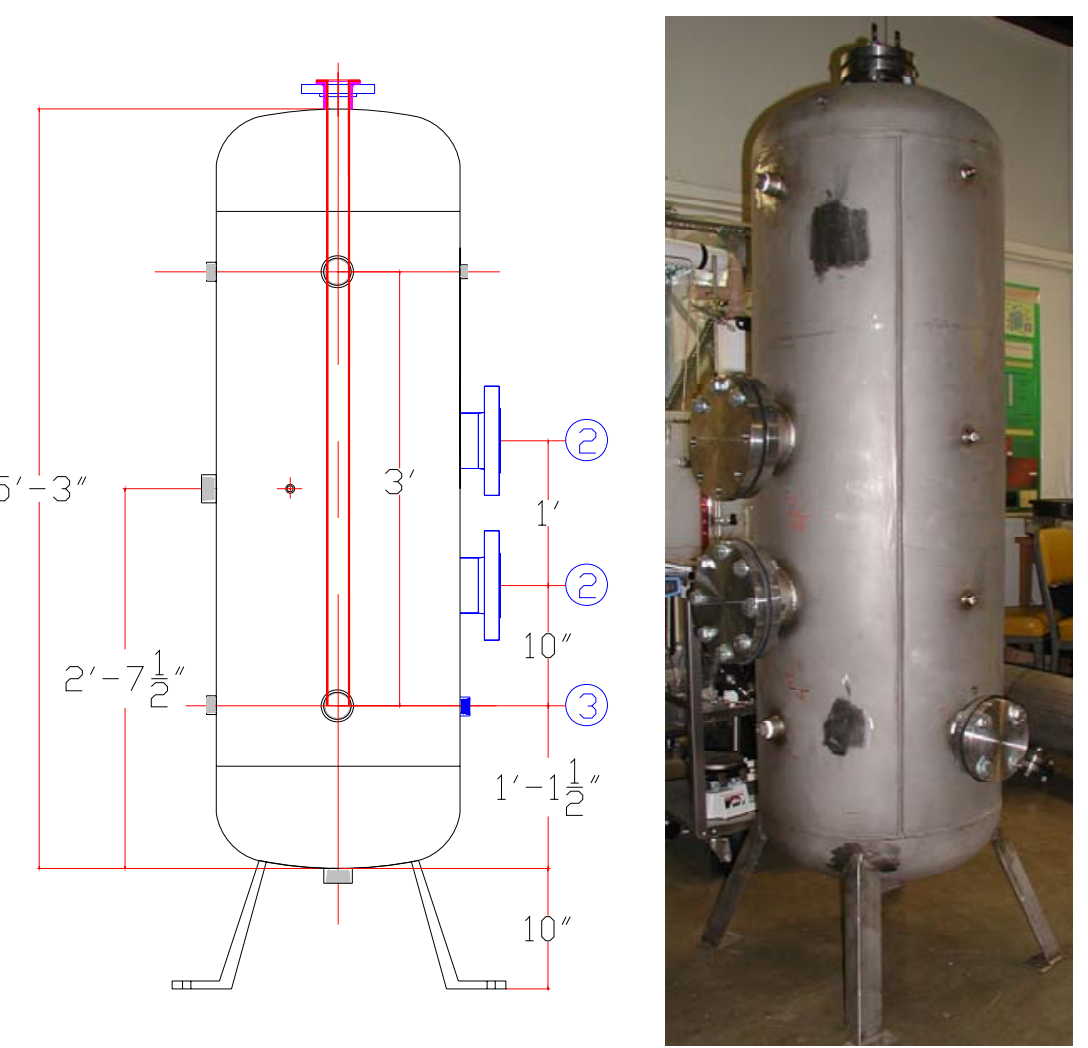

Figure 5.12 Condensate tank

\section{Blowdown \& Secondary Steam Dump Tank}

The blowdown \& secondary steam dump tank (BDT) is an open top cylindrial tank (ROTC275, 275 gallons, 42"dia. x 48"H). It serves as heat \& mass sink and deionized water storage. By use of pump, de-ionized water in this tank is supplied to steam generator, suppression pool, secondary pool, condensate tank and instrument sensing line. Water in SG, SP, CT, and secondary pool can be drained to this tank by 


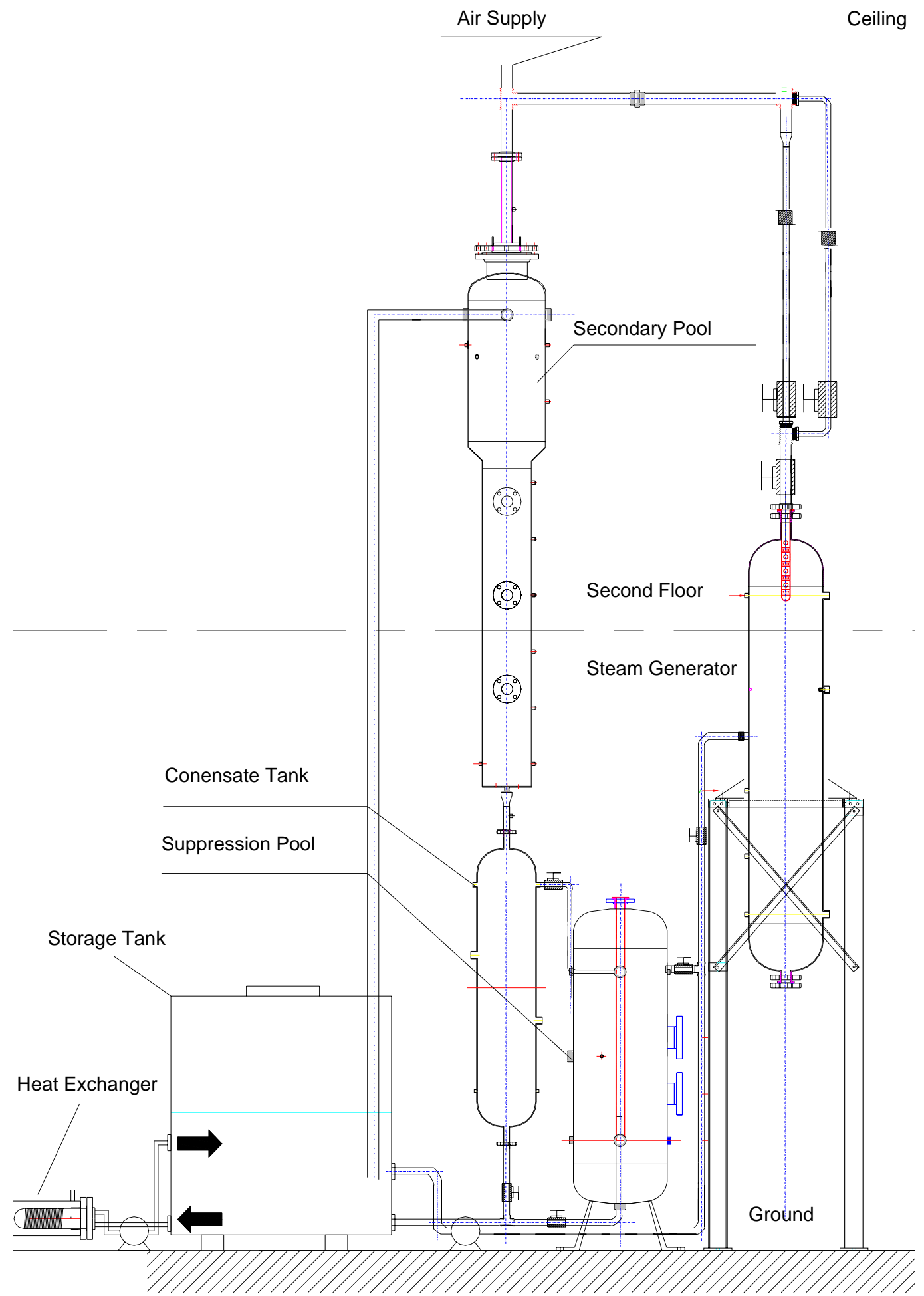

Figure 5.13 Multi-tube PCCS condenser test facility 
gravity. The discharges from relief valve at steam generator and from steam/gas space of suppression pool are routed to this tank for the blowdown purpose. The discharge line is submerged into the water space of blowdown \& secondary steam dump tank. The secondary steam generated in the test section is also discharged to this tank through 4 independent 2 inch copper tubings. To cool the water in BDT, a city water cooling system is employed. The pump circulates the water in the tank, and the city water supply will cool the tank water temperature down.

Instrumentation

Table 5.5 List of Instrumentation for PCCS Loop

\begin{tabular}{|c|c|c|c|}
\hline Instrumentation & Tag Name & Description & Variable \\
\hline \multicolumn{4}{|l|}{ Test Section } \\
\hline Thermocouples & TC-TS-001, 002, .., 140 & $\begin{array}{l}\text { K type, silver wielding, } 14 \\
\text { at each level per tube, } 10 \\
\text { levels }\end{array}$ & Temperature \\
\hline $\begin{array}{l}\text { Heat Flux Sen- } \\
\text { sors }\end{array}$ & $\begin{array}{l}\text { HFS-TS-01, 02, 03, 04, } \\
05,06\end{array}$ & $\begin{array}{l}\text { BF-04, } 1 \text { per level, } 6 \text { lev- } \\
\text { els }\end{array}$ & Heat Flux \\
\hline DP cells & DP-TS-01 & $\begin{array}{l}\Delta \mathrm{P} \text { between inlet and out- } \\
\text { let }\end{array}$ & $\begin{array}{l}\text { Pressure Differ- } \\
\text { ence }\end{array}$ \\
\hline \multicolumn{4}{|c|}{ Secondary Pool } \\
\hline Thermocouple & TC-SEC-01 & K type & Temperature \\
\hline Thermocouple & TC-SEC-02 & K type & Temperature \\
\hline Thermocouple & TC-SEC-03 & K type & Temperature \\
\hline Thermocouple & TC-SEC-04 & K type & Temperature \\
\hline Thermocouple & \begin{tabular}{|l|} 
TC-SEC-05 \\
\end{tabular} & K type & Temperature \\
\hline Thermocouple & TC-SEC-06 & K type & Temperature \\
\hline Thermocouple & TC-SEC-07 & K type & Temperature \\
\hline Thermocouple & \begin{tabular}{|l|} 
TC-SEC-08 \\
\end{tabular} & K type & Temperature \\
\hline DP cells & DP-SEC-01 & $\begin{array}{l}\text { Monitoring the water level } \\
\text { in the Pool }\end{array}$ & Water Level \\
\hline Sight Glass & GW-SEC-01 & $\begin{array}{l}\text { Monitoring the water level } \\
\text { and inspecting, 2" disk }\end{array}$ & Water Level \\
\hline Sight Glass & GW-SEC-02 & Same as above & Water Level \\
\hline Sight Glass & GW-SEC-03 & Same as above & Water Level \\
\hline \multicolumn{4}{|l|}{ Steam Line } \\
\hline Thermocouple & TC-SL-01 & $\begin{array}{l}\mathrm{T} \text { at steam line, on the } \\
\text { cross }\end{array}$ & Temperature \\
\hline Thermocouple & PG-SL-01 & $\begin{array}{l}\text { P at steam line, on the } \\
\text { cross }\end{array}$ & Temperature \\
\hline $\begin{array}{l}\text { Vortex Flow } \\
\text { Meter }\end{array}$ & VM-SL-01 & Foxboro, 1 1/2" & Flow Rate \\
\hline Vortex Flow & VM-SL-02 & Foxboro, 3/4" & Flow Rate \\
\hline
\end{tabular}




\begin{tabular}{|c|c|c|c|}
\hline Meter & & & \\
\hline \multicolumn{4}{|c|}{ Steam Generator } \\
\hline Thermocouple & TC-SG-01 & $\mathrm{T}$ at the top of SG & $\begin{array}{c}\text { Steam Tem- } \\
\text { perature }\end{array}$ \\
\hline Thermocouple & TC-SG-02 & $\mathrm{T}$ at the bottom of SG & $\begin{array}{l}\text { Water Tempera- } \\
\text { ture }\end{array}$ \\
\hline Pressure Gauge & PG-SG-01 & $\mathrm{P}$ inside the vessel & Pressure \\
\hline DP cells & DP-SG-01 & Water level in SG & Water Level \\
\hline \multicolumn{4}{|c|}{ Condensation Tank } \\
\hline Thermocouple & TC-CON-01 & $\mathrm{T}$ inside the vessel & Temperature \\
\hline Thermocouple & TC-CON-02 & $\mathrm{T}$ inside the vessel & Temperature \\
\hline Thermocouple & TC-CON-03 & $\mathrm{T}$ inside the vessel & Temperature \\
\hline Pressure Gauge & PG-CON-01 & $\begin{array}{l}\mathrm{P} \text { at the outlet of condens- } \\
\text { ing tube }\end{array}$ & Pressure \\
\hline DP cells & DP-CON-01 & $\begin{array}{l}\text { Water level inside the ves- } \\
\text { sel }\end{array}$ & Water Level \\
\hline \multicolumn{4}{|c|}{ Suppression Pool } \\
\hline Thermocouple & TC-SP-01 & K type, $\mathrm{T}$ inside the SP & Temperature \\
\hline Thermocouple & TC-SP-02 & K type, $T$ inside the SP & Temperature \\
\hline Thermocouple & TC-SP-03 & K type, $\mathrm{T}$ inside the SP & Temperature \\
\hline Pressure Gauge & PG-SP-01 & $\mathrm{P}$ inside the SP & Pressure \\
\hline DP cells & DP-SP-01 & Water level inside the SP & Water Level \\
\hline \multicolumn{4}{|l|}{ Storage Tank } \\
\hline Thermocouple & TC-ST-01 & K type, $\mathrm{T}$ inside the ST & Temperature \\
\hline Pressure Gauge & PG-ST-01 & $\mathrm{P}$ inside the SP & Pressure \\
\hline \multicolumn{4}{|c|}{ Air Supply Line } \\
\hline Thermocouple & TC-AL-01 & K type, air temperature & $\begin{array}{l}\text { Air Tempera- } \\
\text { ture }\end{array}$ \\
\hline Pressure Gauge & PG-AL-01 & Air pressure & Air Pressure \\
\hline Rotameter & RT-AL-01 & Air flow rate & Air Flow Rate \\
\hline Rotameter & RT-AL-02 & Air flow rate & Air Flow Rate \\
\hline Rotameter & RT-AL-03 & Air flow rate & Air Flow Rate \\
\hline
\end{tabular}

Total:

T/C: 144

DP: 4

PG: 4

PT: 1

Vortex flowmeter: 2

Rotameter: 3

Heat flux sensor: 6

Data Acquisition Systems

We have two data acquisition systems -

1. Measurement Computing 
- Includes PCI-DAS1602/12 and PCI-DAS-TC

- PCI-DAS1602/12, 1 board with 8 channels, measuring the readings (in voltages) of DP cells and vortex flow meters

- using one of them to measure the temperature readings of the $\mathrm{T} / \mathrm{Cs}$ other than test section's T/Cs

- Software - InstaCal \& Labview

2. Keithley Instruments

- $\quad$ Model 2750 with 7708

- 4 model 7708 boards with 160 channels to measure the temperature readings of the test section's $\mathrm{T} / \mathrm{Cs}$

- Software-CEC488 \& ExecLink

\section{$\underline{\text { Safety System }}$}

We have safety system for steam in our experimental loop which includes:

- SG temperature controller;

- SG water level display;

- SG relief valve which can relieve steam to the storage tank; There is also a relief line which can relieve steam inside SP to the storage tank;

- We can bleed air using air bleeding line, and we can open the valve to avoid vacuum after shutdown;

- Heat exchangers to lower temperature for both the storage tank and suppression pool.

\subsection{Experiment procedures}

The test procedures are prepared for the preparatory work, testing and shut down.

\section{Preparatory Work}

The preparatory work is comprised of the following steps: (1) loop study, (2) facility checking, (3) DAS \& Instrumentation, (4) filling steam generator, (5) purging of the instrument line, (6) Power supply checking, (7) filling suppression pool, and (8) filling secondary pool. The tasks in each of the preparatory steps are shown as below. 


\section{1) Loop Study}

Please read carefully this procedure and the documents attached:

- Figure: Test Facility Schematic

- Drawing: Instrumentation of PCCS test loop

- Table 1: Instrumentation List

- Table 2: Description of Valves

- Table 3: Water Filling for Tanks

- Figure: DAS wire terminal distribution

2) Facility checking

- DI water preparation: The total DI water we need for the test is about 260 gallons.

- Site cleaning: Remove unnecessary equipments, materials near the facility.

- Checking equipments (Steam generator, secondary pool, condensate tank, suppression pool and pumps), connecting piping, valves, and fittings.

3) DAS \& Instrumentation

- Instrumentation calibration and Check: DP cells, Vortex Flowmeters, T/Cs, Pressure Gauges

- Check DAS: Turn PC on, operate the programs (Excelink for the top T/Cs board, and Instacal for the bottom T/Cs and voltage measurement board), and see if they're working properly.

4) Power supply checking

- Check SG power supply and its temperature control (Two T/Cs from the SG to the control panel) to see if they are working well.

- Check pump power supply.

- Check DC power supply for DP cells

5) Instrument Line Purging

- Open V10

- Turn on pump

- Fill and vent the air in the instrument sensing lines for each level transducer (DP cells). 

A. Fill the water using the instrument sensing line valves for high pressure side
B. Vent air in sensing line using transmitter venting screw for high pressure side
C. Fill the water using the instrument sensing line valves for low pressure side
D. Vent air in sensing line using transmitter venting screw for low pressure side Note: When filling the condensate tank level instrument, establish the initial CT level by monitoring DP-CON-01 signal.
- Close V2 and V3 which were opened for the initial feed operation

- Close V10

\section{6) Steam Generator Filling}

- Check and verify the normal valve position

- Open V2 and V3 for the initial feed operation (These valves should be opened to bleed the air in the loop for the DI water filling)

- Open V7 and run the pump to fill steam generator

- Fill steam generator monitoring the level using sight glass and DP-SG-01 signal.

The water level L should be: 40 " $<\mathrm{L}<105$ "

\section{- Close V7}

\section{7) Suppression pool Filling}

- Open V8 and run the pump

- Fill suppression pool monitoring the water level using DP-SP-01. The water level should be 31.5 ".

- Close V8

8) Secondary Pool Filling

- Open V9 and run the pump

- Fill secondary pool monitoring the water level using sight glass and DP-SEC-01 signal

Note: Do not fill the full height. Just fill the $3 / 4$ of the full height which is 85 ". Due to the thermal stratification during heating, it is more efficient to heat this level of water first and then fill again the remaining height.

- Close V9

2. Testing 
The procedures for the test operations are given below.

1) SG Heating

- Check the normal valve position

- Close V1

- Set the heater controller setpoint about 240F (about 115.6C).

- Turn on heater

- When SG water temperature, TS1, reach about 100C, and the SG's pressure is about 5-10 psig, open V1 and V21 for several seconds to bleed the air in the SG.

- When the SG's pressure is about 20 psig, open V1 and V21 for several seconds to bleed the air in the SG again.

- Repeat the above steps for the pressure of 40,60, 80 and 100 psig.

- Verify the SG water temperature, TS1, and SG steam temperature, TS2, are almost same.

\section{2) Loop Heating}

- Set the heater controller setpoint about 186C.

- When SG pressure (PG1) reaches about 140 psig (the temperature is about 186C), slightly open V1 to heat up the loop and secondary water pool

- If necessary, close vent valve to SP, V4, to increase the loop system pressure.

Note: At low pressure, the heat transfer rate to secondary side is small. So, it needs to increase the system pressure (recommended pressure - $30 \mathrm{psig}$ ).

- When the secondary water temperatures reach about 90C, regulate the V1 to establish the required steam flow rate.

- When the secondary water temperatures reach about 100C, fill the secondary pool to the full height by turning on the pump and opening V9.

- Close V9

- Turn off the pump

- Open the city water supply valve to cool the storage tank

Note:

D. During the loop heating, vent the air in the loop several times by opening the $\mathrm{V} 4$ to establish the pure steam condition in the loop 
E. During the loop heating, periodically drain the CT water by opening V5 if the condensate tank is full of water.

3) Steady State Condition

- Check the steam flow rate to verify the steady state

- Check the steam temperature at flowmeter to verify the steady state and the superheat condition

- Check the secondary water pool temperature to verify the steady state (TC-SEC01 TC-SEC-08 should be almost same temperature)

- Check the test section pressure (DP-TS-01) to verify the steady state

4) Initial Condition and Test Method for each Operation Mode

\section{A. Complete Condensation Mode}

- Verify that the V4 is closed

- Verify that the air in the loop has been vented during the heating period

- Verify the steady state condition described in 4)

- Do the data log described in 6)

B. Periodic Venting Mode

- Initially establish the Complete Condensation Mode described above

- Open V17

- Regulate F11, V14, V15, V16, and V17 to obtain required small amount of air flow

- Select the base pressure, vent DP (Usually $0.5 \mathrm{psi}$ ) and measurement duration

- Start to log the data

- Open V4 to reduce the test section pressure below the base pressure

- Use stop-watch to log the periodic vent time interval. When the test section pressure reach the base pressure, reset the stop-watch. (start time)

- When the test section pressure reach the base pressure + vent DP, quick open the V4

- When the test section pressure decrease below to the base pressure, quick close the V4 
Note: To maintain the vent DP properly, it needs some undershooting in the pressure before close the V4.

- Count the vent number in mind

- Repeat the periodic venting until the predetermined measurement duration

- Log the number of vent and the measurement duration.

C. Through Flow Mode

- Verify that the V4 is opened

- Open V17for noncondensable gas test and regulate F11, V14, V15, V16, and V17 to obtain required amount of air flow

- Maintain the test section pressure at a desired level by use of the blowdown valves (V19 and V20) or air supply line valve (V18)

- Verify the steady state condition described in 4)

- Do the data log described in 6)

\section{6) Data Log}

- When the initial condition is obtained for each operating mode, start to record the DAS.

- Fill the log sheet

Note:

1) During the test, check the test section DP signal. If the condensate fills the DP sensing line, DP output will not show correct signal. For this condition, open the condensate drain valve to drain condensate in the sensing line.

2) During the test, periodically fill the secondary pool with water by use of V9

3) During the test, periodically drain the condensate tank water by use of V5

\section{Shutdown Operation}

The following are the tasks in shutdown of the facility after the test.

1) Loop Cooling

- Turn off the heater

- Close V17 if necessary

- Wide open V1

- Open V19 if necessary

- Periodically fill the secondary pool with water by use of V9 
- Periodically drain the condensate tank water by use of V5

- When system pressure reach to almost $1 \mathrm{~atm}$, open V20

- When no steam is generated from the system, close the city water supply line valve

\section{2) Drain}

- Drain the secondary pool water when its temperature decreases below $60 \mathrm{C}$

- Drain SG, SP, and CT water into the storage tank if necessary.

\section{Transient Operation}

1) For the complete condensation:

- Close the venting line from the condensation tank.

- Start the test from a steady state at complete condensation mode with full height water level.

- As the decrease of secondary water level, system pressure will keep increasing.

- Continuously recording data until the secondary water level decreases to $20 \%$ of full height.

- Drain the condensation tank when the condensation is full during the data acquisition period.

2) For the test with non-condensable gases:

- Open the venting valve from the condensation tank to get an initial condition at through flow mode.

- In the through flow condition, system pressure will keep the same as the secondary level decreases.

- Continuously recording data until the secondary water level decreases to $20 \%$ of full height.

- Drain the condensation tank when the condensation is full during the data acquisition period.

Table 5.6 Description of Valves

\begin{tabular}{|l|l|}
\hline Name & Description \\
\hline Steam Line & V1: Steam flow control valve (ball, NO) 2" \\
& V2: Steam flow control valve (ball, NO) 1.5" \\
\hline
\end{tabular}




\begin{tabular}{|l|l|}
\hline & V3: Steam flow control valve (ball, NO) 0.75" \\
\hline Water Feed & V10: Water feed line valve from the storage tank (ball, NO) \\
& V7: Water feed line valve to SG (ball, NC) \\
& V8: Water feed line valve to SP (ball, NC) \\
& V9: Water feed line valve to secondary pool (ball, NO) \\
& V12: Water drain line valve from SG (ball, NC) \\
& V6: Water drain line valve from SP (ball, NC) \\
& V5: Water drain line valve from CT (ball, NC) \\
\hline Steam venting & V4: Steam venting line from CT to SP (Ball, NO) \\
\hline line & \\
\hline Air supply line & V11: Air supply line valve(ball, NO) \\
& V14: Air supply line valve downsteam rotameter (ball, NC) \\
& V15: Air supply line valve downsteam rotameter (ball, NC) \\
& V16: Air supply line valve downsteam rotameter (ball, NC) \\
& V17: Air supply line valve just before main steam supply line (ball, \\
& NC) \\
\hline Steam/Air & V18: Air supply line valve to SP (ball, NC) \\
Blowdown & V19: SP blowdown valve to the storage tank (ball, NC) \\
Line & V20: SP blowdown valve to the atomosphere (ball, NC) \\
\hline Air Bleed Line & V21: Air bleed valve (ball, NO) \\
\hline
\end{tabular}

Note: Valve type and normal position (NO-normal open, NC-normal closed) are shown in parenthesis. 


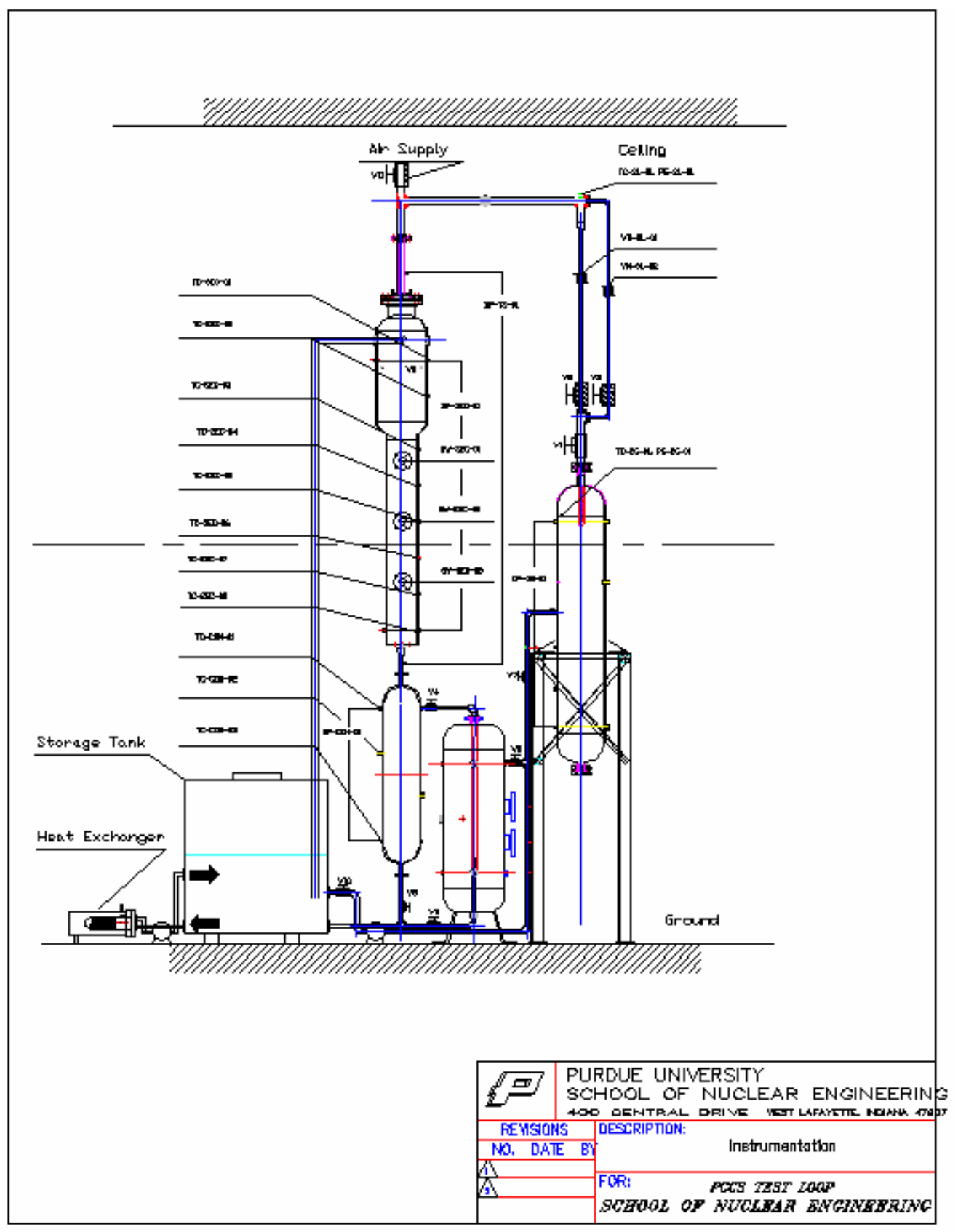

Fig 5.14 Instrumentation

\subsection{Data reduction}

Data reduction process is the same with previous test but the condenser tube geometry was changed into that of $52.5 \mathrm{~mm}$ test section.

The overall heat transfer coefficient in condenser is defined as follows: 


$$
U=\frac{Q_{\text {con }}}{A_{i}\left(T_{S A T}-T_{P}\right)},
$$

where $Q_{c o n}$ is the condensation heat transferred by condenser tube, $A_{i}$ is the heat transfer area of tube inside, $T_{S A T}$ is the saturation temperature at the steam partial pressure $\left(P_{S A T}\right)$ and $T_{P}$ is the secondary pool water temperature.

The condensation heat transferred by condenser tube, $Q_{\text {con }}$ can be calculated as follow:

$$
Q_{c o n}=m_{c o n} h_{f g}\left(P_{S A T}\right) \text {, }
$$

where $m_{e v a}$ is the condensation mass flow rate calculated from the condensate tank water level difference during the test and $h_{f g}\left(P_{S A T}\right)$ is the latent heat of condensation based on the steam partial pressure $P_{S A T}$. The condensation mass flow rate can be checked by the comparison with the supplied steam flow rate during the complete condensation mode.

This condensation heat transfer rate should be equal to the secondary side heat removal rate, $Q_{\text {tot }}$, which is sum of the evaporative heat transfer rate and the heat loss from the secondary tube surface.

$$
\begin{gathered}
Q_{\text {con }}=Q_{\text {tot }} \\
Q_{\text {tot }}=m_{\text {eva }} h_{f g}\left(T_{P}\right)+Q_{h l},
\end{gathered}
$$

where $m_{\text {eva }}$ is the evaporative mass flow rate calculated from the secondary pool water level difference during test, $h_{f g}\left(T_{P}\right)$ is the latent heat of evaporation based on the secondary pool water temperature, and $Q_{h l}$ is the heat loss rate loss from the secondary tube surface obtained from the heat loss measurement test.

The heat transfer area of tube inside, $A_{i}$, can be calculated as follows:

$$
A_{i}=\pi D_{i} H_{\text {tube }} .
$$

The measured steam bulk temperature was slightly higher than the saturation temperature at the system pressure. It means that the state of the steam-air mixture is superheat. However, the amount of sensible heat transfer is much less than that of condensation heat transfer. So, the sensible heat transfer is ignored. 
The overall heat transfer coefficient is given by the following equation derived by the heat balance among the condenser tube inside, tube wall and tube outside.

$$
U=\left[\frac{1}{h_{c}}+\frac{1 n\left(D_{o} / D_{i}\right) D_{i}}{2 k_{w}}+\frac{D_{i}}{h_{\mathrm{sec}} D_{o}}\right]^{-1} .
$$

The first term of the right hand side of above equation corresponds to the tube side condensation heat transfer, the second term corresponds to the tube wall conduction heat transfer, and the third term corresponds to the secondary side pool boiling heat transfer.

Neglecting the heat transfer along condenser tube length, the condensation heat transfer coefficient, $h_{c}$, is defined as follows:

$$
h_{c}=\frac{Q_{\text {con }}}{A_{i}\left(T_{S A T}-T_{W i}\right)}
$$

where $T_{W i}$ is the tube inside wall temperature.

The secondary side pool boiling heat transfer coefficient, $h_{\text {sec }}$, is defined as follows:

$$
h_{\mathrm{sec}}=\frac{Q_{\mathrm{con}}}{A_{o}\left(T_{W o}-T_{P}\right)}
$$

where $T_{W_{0}}$ is the tube outside wall temperature and $A_{o}$ is the heat transfer area of tube outside.

$A_{o}$ is expressed as follows:

$$
A_{o}=\pi D_{o} H_{\text {tube }}=\frac{D_{i}}{D_{o}} A_{i}
$$

From equation (5.6), the condensation heat transfer coefficient can be expressed as follows:

$$
\frac{1}{h_{c}}=\frac{1}{U}-\frac{1 n\left(D_{o} / D_{i}\right) D_{i}}{2 k_{w}}-\frac{D_{i}}{h_{\mathrm{sec}} D_{o}}
$$

Substituting eqs. (5.1), (5.2), (5.3), (5.8) and (5.9) to eq. (5.10), the condensation heat transfer coefficient can be simplified as follows: 


$$
\begin{aligned}
\frac{1}{h_{c}} & =\frac{A_{i}\left(T_{S A T}-T_{P}\right)}{m_{c o n} h_{f g}\left(P_{S A T}\right)}-\frac{1 n\left(D_{o} / D_{i}\right) D_{i}}{2 k_{w}}-\frac{D_{i} A_{o}\left(T_{W o}-T_{P}\right)}{D_{o} m_{c o n} h_{f g}\left(P_{S A T}\right)} \\
& =\frac{A_{i}\left(T_{S A T}-T_{P}\right)}{m_{c o n} h_{f g}\left(P_{S A T}\right)}-\frac{1 n\left(D_{o} / D_{i}\right) D_{i}}{2 k_{w}}-\frac{A_{i}\left(T_{W o}-T_{P}\right)}{m_{c o n} h_{f g}\left(P_{S A T}\right)} \\
& =\frac{A_{i}\left(T_{S A T}-T_{W o}\right)}{m_{c o n} h_{f g}\left(P_{S A T}\right)}-\frac{1 n\left(D_{o} / D_{i}\right) D_{i}}{2 k_{w}} \\
& =\frac{2 k_{w} A_{i}\left(T_{S A T}-T_{W o}\right)-m_{c o n} h_{f g}\left(P_{S A T}\right) \ln \left(D_{o} / D_{i}\right) D_{i}}{2 k_{w} m_{c o n} h_{f g}\left(P_{S A T}\right)}
\end{aligned}
$$

Finally, the condensation heat transfer coefficient can be expressed with the known or experimentally obtainable values as follows:

$$
h_{c}=\frac{2 k_{w} m_{c o n} h_{f g}}{2 k_{w} \pi D_{i} H_{\text {tube }}\left(T_{S A T}-T_{W o}\right)-m_{c o n} h_{f g} \ln \left(D_{o} / D_{i}\right) D_{i}} .
$$

The condensation mass flow rate can be calculated with the following equation.

$$
m_{\text {con }}=\frac{\Delta H_{r e f}}{\Delta t} \rho_{r e f} A_{C T}
$$

where $\Delta H_{\text {ref }}$ is the condensate tank level difference converted to the reference temperature $(4 \mathrm{C})$ condition, $\Delta t$ is the measurement time, $\rho_{\text {ref }}$ is the density at the reference temperature, and $A_{C T}$ is the cross-sectional area of the condensate tank.

Air mass flow can be calculated and then the non-condensable gas mass fraction can be determined.

$$
\begin{gathered}
m_{\text {air }}=\rho_{\text {air }} V_{\text {air }} \\
V_{\text {air }}=F_{\text {air }} \sqrt{\frac{T_{r e f}}{T_{\text {mes }}} \frac{P_{\text {mes }}}{P_{r e f}}} \\
W_{\text {air }}=\frac{m_{\text {air }}}{m_{\text {air }}+m_{\text {steam }}}
\end{gathered}
$$

where $F_{\text {air }}$ is the air flow reading from rotameter, $T_{\text {ref }}$ is the absolute temperature at standard condition ( $294 \mathrm{~K}$ or $530 \mathrm{R}), \quad T_{\text {mes }}$ is the absolute temperature of air, $P_{\text {ref }}$ is pressure at standard condition ( $1 \mathrm{~atm}$ or $14.7 \mathrm{psia}), P_{\text {mes }}$ is the measured pressure of air and $m_{\text {steam }}$ is the steam inlet mass flow rate measured by vortex flow meter.

Vapor partial pressure can be calculated from Gibbs-Dalton ideal gas mixture equation as follow: 


$$
\frac{P_{S A T}}{P_{T O T}}=\frac{1-W_{\text {air }}}{1-W_{\text {air }}\left(1-\frac{M_{v}}{M_{a}}\right)}
$$

where, $P_{\text {ТОT }}$ is the total pressure which is the sum of the vapor partial pressure and air partial pressure, $M_{v}$ and $M_{a}$ are the molecular weight of the vapor and air, respectively.

Inlet steam Reynolds number and average condensation Nusselt number can be calculated with the following equation.

$$
\begin{gathered}
\operatorname{Re}_{\text {steam }}=\frac{\rho_{\text {steam }} V_{\text {steam }} D_{i}}{\mu_{\text {steam }}}=\frac{4 m_{\text {steam }}}{\pi D_{i} \mu_{\text {steam }}} \\
N u_{c}=\frac{h_{c} D_{i}}{k_{\text {condensate }}},
\end{gathered}
$$

where $\mu_{\text {steam }}$ is the viscosity of steam and $k_{\text {condensate }}$ is the thermal conductivity of the condensate film.

\subsection{Test Results}

\subsubsection{Introduction}

The multi-tube test facility was used to perform the same type of experiments as with the single condensation tube. PCCS operation modes that have been simulated include complete condensation and through flow modes. For complete condensation experiments, the test facility uses pure steam without the presence of noncondensable gas. The tube bundle is given a steady supply of pure steam at a steady flow pressure and is allowed to condense by heat transfer from the water in the secondary pool. When the water level in the secondary pool is completely full it is called a full height experiment. Several full height complete condensation experiments were performed for several steam flow rates and flow pressures to develop a trend for the condensation rate. To study the effect of the secondary height on the condensing capabilities of the tube bundle, complete condensation experiments were repeated with different water levels in the secondary pool. Experiments with different water levels for the secondary height were separated into four groups: $1 / 4,1 / 2,3 / 4$, and full height. The 
next group of experiments, called transient tests, allowed the secondary height to change over time as steam condenses and water boils off in the secondary pool. These experiments showed how the change in secondary height effected the steady state pressure, steam flow rate, and condensation rate. The multi-tube test facility has also been used with the presence of noncondensable gas to simulate through flow mode experiments. For through flow mode, steam and noncondensable gas are supplied to the test section at steady state conditions. The valve connecting the condensate tank and suppression pool is left completely open to allow noncondensable gas and uncondensed steam to pass through and keep the system pressure steady. The experimental method for this PCCS mode is to keep a relatively fixed steam flow rate and flow pressure for several experiments with varying noncondensable gas mass fractions. These results show how the addition of noncondensable gas degrades the condensate rate.

\subsubsection{Multi-Tube Full Height Complete Condensation Results}

In the case of complete condensation PCCS experiments, pure steam is used in the test facility and the valve connecting the condensate tank to the suppression pool remains close to isolate uncondensed steam. The steam flow rate is changed for each experiment to study the correlation between condensation mass flow rate with steam flow and system pressure. With the tube bundle test facility, complete condensation experiments were performed at absolute pressures in the range of 100 to $300 \mathrm{kPa}$. The condensation mass flow rate increased at almost a linear rate to the system pressure, shown in Fig. 5.15, as expected. 


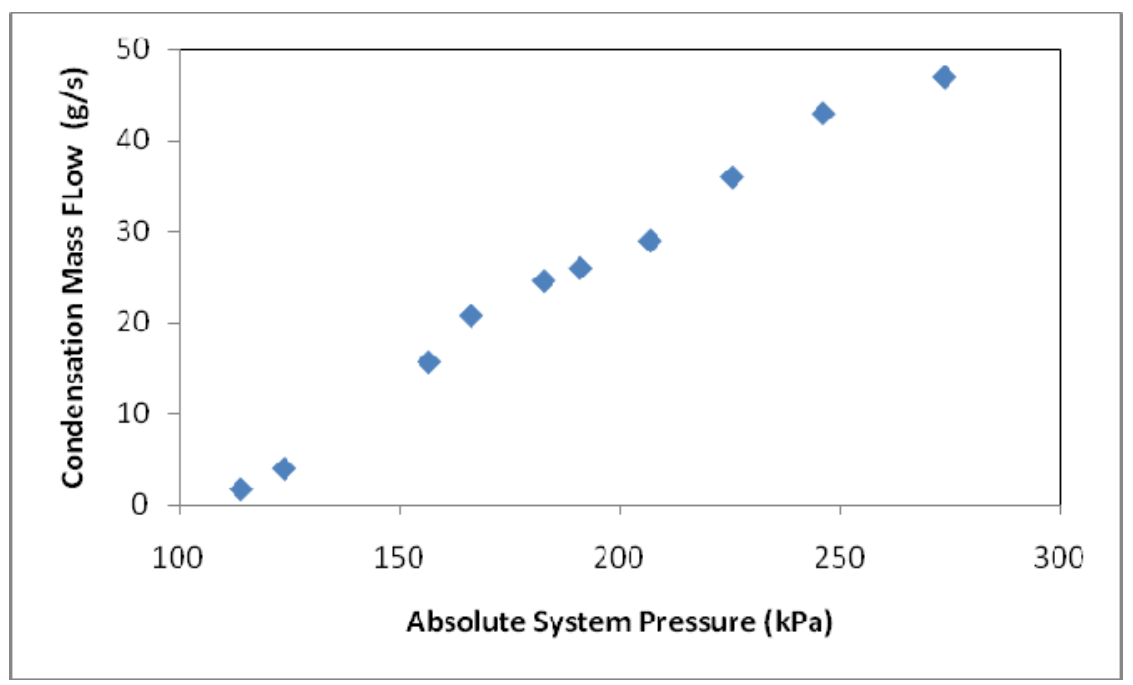

Figure 5.15 Condensation rate as a function of system pressure for multi-tube full height complete condensation experiments

Comparison of the multi-tube complete condensation data to the previous single tube data shows similar trends. Each set of data comes from experiments with different condensing tube dimensions. To compare the different cases, each data set was normalized to that of one full length condensing tube (2" diameter, $1.8 \mathrm{~m}$ height). The single tube data was factored up to normalize to a full diameter and full height condensing tube. The multi-tube data was factored down by about four times to normalize to one condensing tube. When the normalized data sets are plotted together, they produce similar increasing trends in condensation mass flow rate with the system pressure. The multi-tube condensation rates showed to be slightly higher than the data from the single tube test sections. This effect could be a result of turbulent mixing in the secondary pool from multiple condensing tubes, causing a better heat removal capability. 


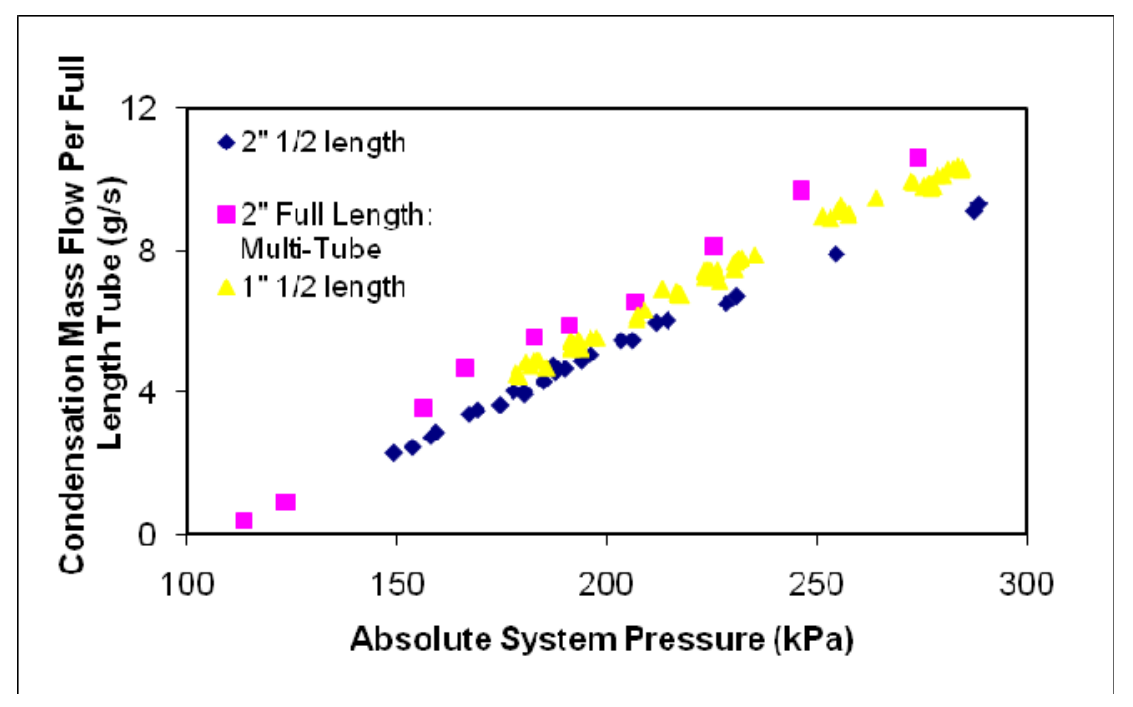

Figure 5.16 Multi-tube condensation rates compared to single tube results. All condensation rates were normalized to the condensation flow rate per full length condensing tube.

\subsubsection{Multi-Tube Varying Secondary Height Complete Condensation Results}

Complete condensation experiments were also performed with different levels on water in the secondary pool to study the effect on the condensation rate. Data for full height complete condensation experiments had already been performed. Experiments were then performed at three other secondary pool water levels: $1 / 4,1 / 2$, and $3 / 4$ heights. The results from these experiments show a decrease in condensation mass flow rate with decreasing secondary water level. However, the decrease in condensate flow is not as big as the decrease in the secondary water height. This is clear in the case of the $3 / 4$ height experiments, where the condensate flow is almost as big as for the full height experiments. The explanation for this result is that the data for the secondary pool water height actually reads the collapsed water level. The secondary pool is continuously boiling off, causing it to have two phases present: water and vapor. A secondary pool void fraction results in the actual water level to be higher than what is recorded. When the collapsed water level in the secondary pool is around $3 / 4$ height, the actual two phase water level is close to the top of the 
condensers. The decrease in condensate flow can be better seen in the cases with $1 / 4$ and $1 / 2$ water height experiments.

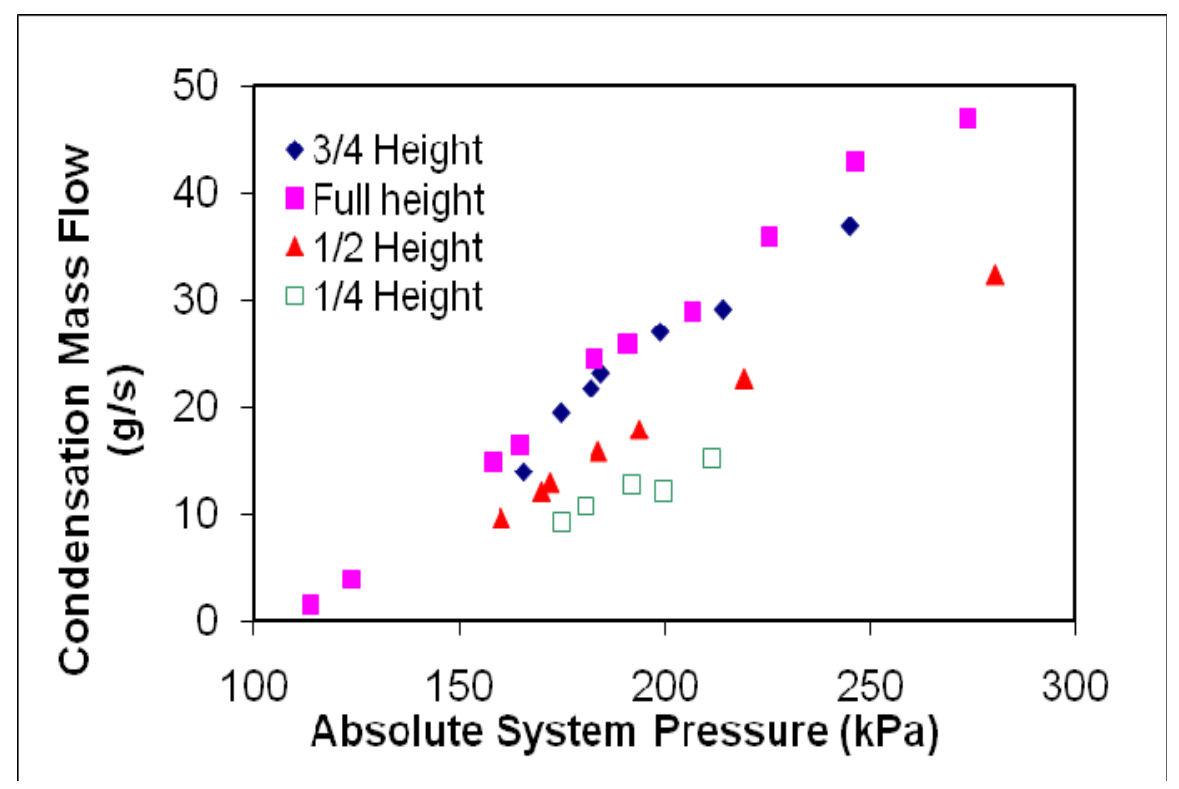

Figure 5.17 Condensation mass flow rates as a function of system pressure from multi-tube tests for four groups of secondary heights: $1 / 4,1 / 2,3 / 4$, and full

Along with steady state complete condensation experiments at different secondary water levels, transient experiments were performed with a varying secondary water level. For this type of experiment, a steam flow rate is supplied to the test section and the water in the secondary pool is allowed to continuously boil off. Three cases were performed, each at a different starting system pressure. To get different starting system pressures, the power supply to the steam generator was set at three different temperatures: $210^{\circ} \mathrm{F}, 215^{\circ} \mathrm{F}$, and $220^{\circ} \mathrm{F}$. Each complete transient case was obtained through three stages of experimental operation. When the condensate tank filled with water, the experiment was shut down and the tank was emptied. The experiment would then be resumed under the same conditions with the secondary pool water level at the same height where it left off. Three stages of experimental operation were necessary to develop a complete data set from full secondary water level to completely empty.

The transient experimental results show that the higher the starting system pressure is the faster the secondary pool will dry out. The change in secondary water 
height over time for each of the three cases is displayed in Fig. 5.18. The secondary water height starts to decrease faster in each case at around $60 \%$ full. This result is due to a decrease in secondary pool diameter at this specific height. The pressure response to the change in secondary water height is displayed in Fig. 5.5 over the same time scale. Overall, the generalized trend is an increase in system pressure as the secondary water height decreases. This is due to a decrease in the condensing capability of the secondary pool leading to an increase in system pressure. The high pressure case shows an initial decrease in system pressure before starting to increase for the remainder of the experiment. The initial decrease in system pressure is most likely a result of the steam flow rate and pressure to not reach a steady state until some of the water in the secondary pool has already been boiled off.

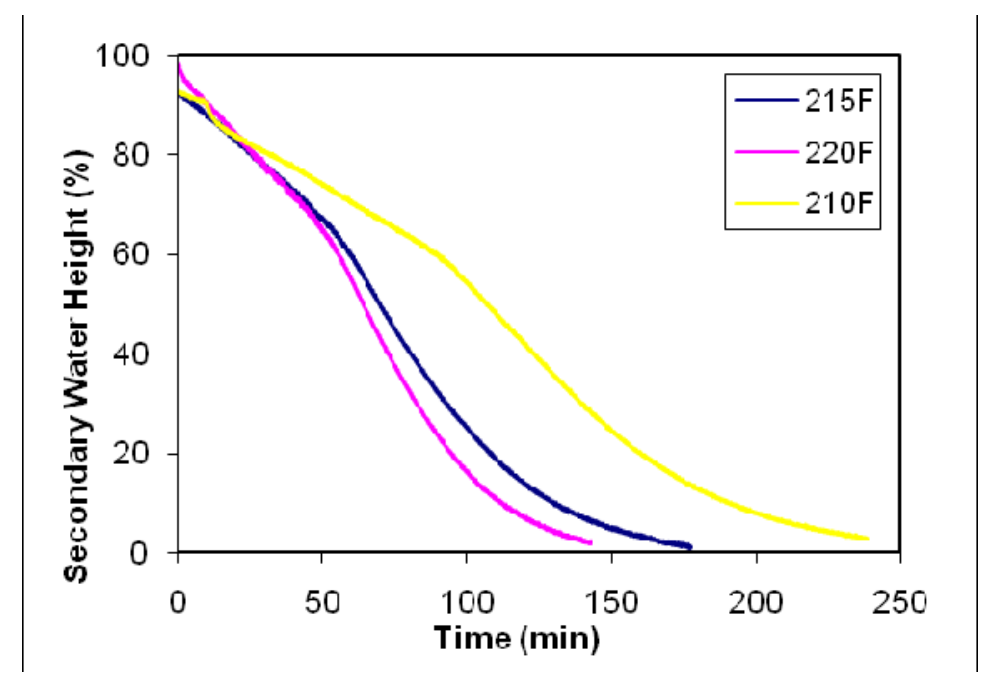

Figure 5.18 Three complete transient cases at different power supply temperatures $\left(210^{\circ} \mathrm{F}, 215^{\circ} \mathrm{F}\right.$, and $\left.220^{\circ} \mathrm{F}\right)$ for multi-tube complete condensation experiments 


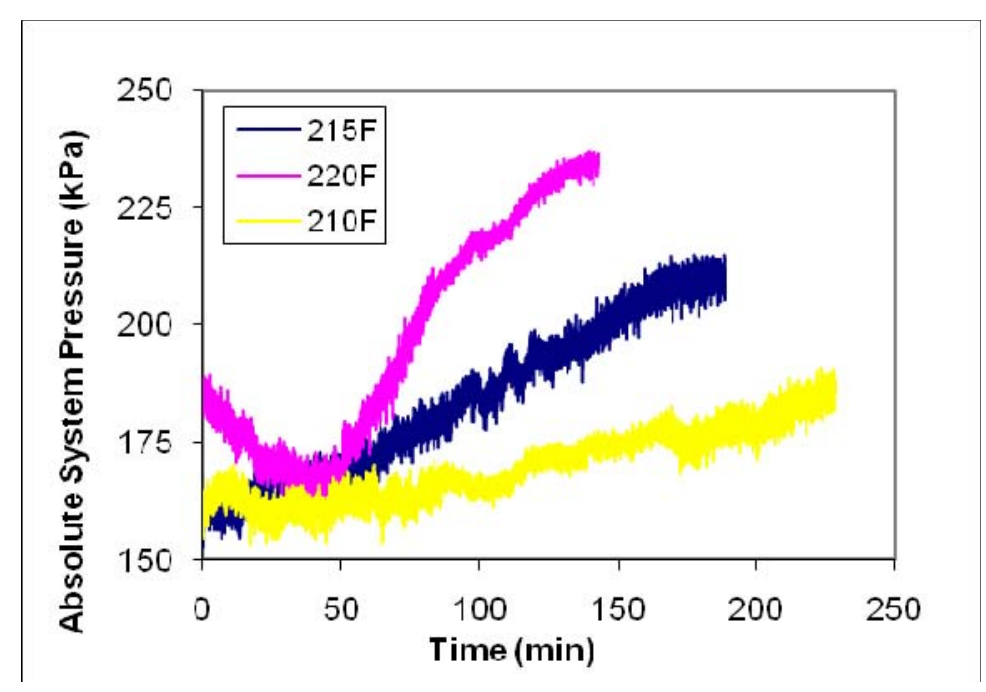

Figure 5.19 System pressure responses to decreasing secondary water level over time for multi-tube complete condensation experiments

Throughout the transient experiments, the condensate mass flow rate continued to change with the secondary water level. For each case, condensate rates were calculated over small time periods during the experiment to compare the condensate mass flow with the time, system pressure, and secondary water height. The condensate mass flow rate shows to stay relatively steady and then start dropping off with time, due to the decreasing secondary water height. The condensate flow rate drops slower in the lower pressure cases because the secondary pool takes longer to boil off. The initial steady state condition is caused by the secondary water level remaining above the active length of the condensing tubes for a time period at the beginning of the experiments. The condensate mass flow rate also decreases with increasing system pressure. The decreasing condensate mass flow rate affects the experiment operating conditions causing an increase in system pressure. An initial increase in condensate flow occurs due to an increase in system pressure reaching an initial full height steady state. The plot of condensate mass flow rate as a function of secondary water height is displayed in Fig. 5.22. This trend shows a region, when the secondary water height is between 0 and $75 \%$, where the condensate flow rate depends strongly on the height of the secondary water level. The higher the level of water in the secondary pool means greater condensing capabilities for the PCCS. 


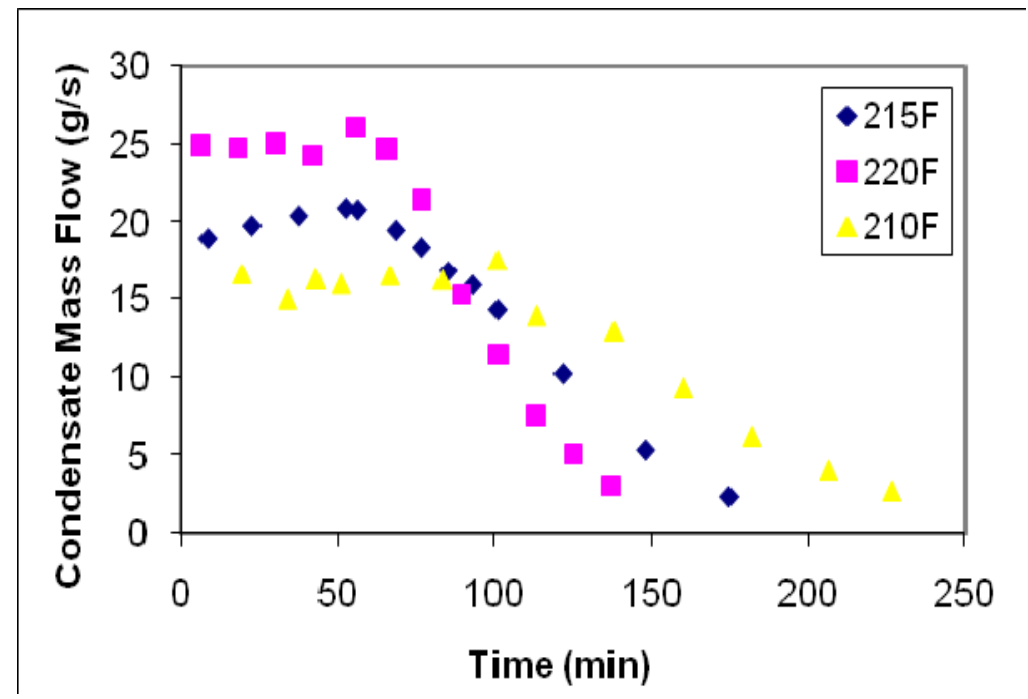

Figure 5.20 Condensation mass flow rate as a function of time, during decreasing secondary water level, for multi-tube complete condensation experiments

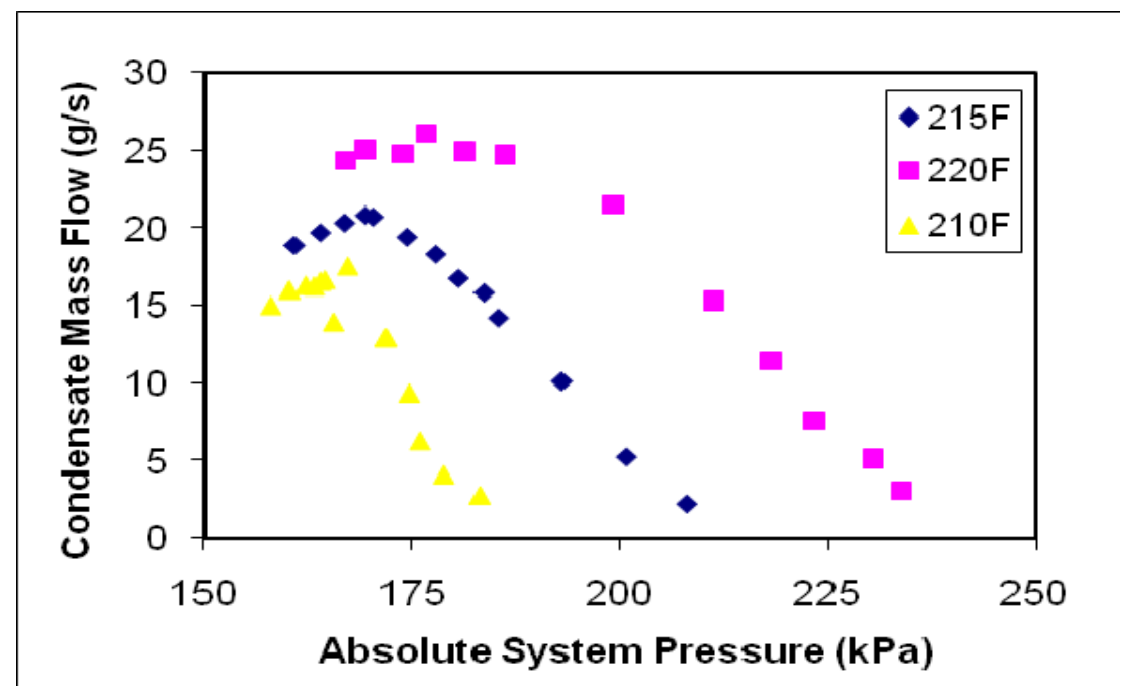

Figure 5.21 Condensation mass flow rate as a function of increasing pressure, during decreasing secondary water level, for multi-tube complete condensation experiments 


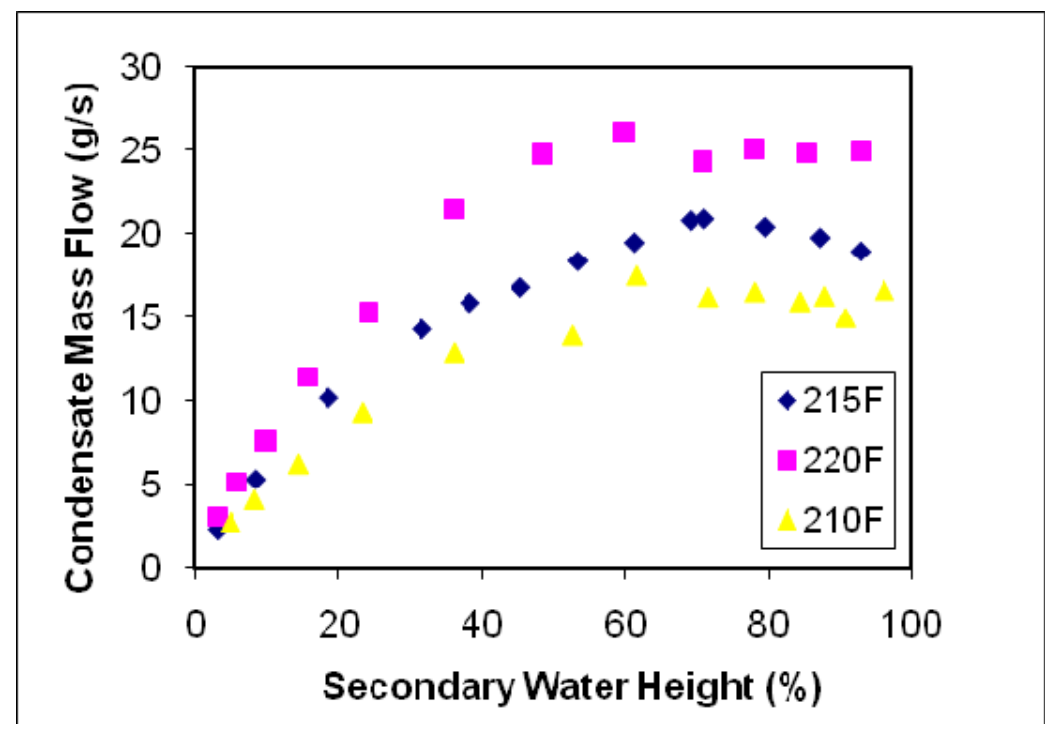

Figure 5.22 Condensation mass flow rate as a function of secondary water level for multi-tube complete condensation experiments

\subsubsection{Multi-Tube Through Flow Mode Results}

\subsubsection{Results}

Table 5.7 Summary of multi-tube through flow mode experimental results

\begin{tabular}{|l|c|c|c|c|c|}
\hline Experiment No. & $\mathbf{1}$ & $\mathbf{2}$ & $\mathbf{3}$ & $\mathbf{4}$ & $\mathbf{5}$ \\
\hline $\begin{array}{l}\text { Flow pressure } \\
\text { (psi) }\end{array}$ & 23.93 & 19 & 33.72 & 22 & 21 \\
\hline $\begin{array}{l}\text { Steam Genera- } \\
\text { tion Rate } \\
\text { (grams/sec) }\end{array}$ & 39.65 & 21.33 & 33.23 & 41.35 & 46.47 \\
\hline $\begin{array}{l}\text { Vortex Flow } \\
\text { Rate (grams/sec) }\end{array}$ & 39.23 & 22.61 & 33.92 & 41.91 & 46.53 \\
\hline $\begin{array}{l}\text { Condensation } \\
\text { Rate (grams/sec) }\end{array}$ & 34.08 & 19.69 & 27.30 & 33.44 & 26.93 \\
\hline $\begin{array}{l}\text { SEC Boil-off } \\
\text { Rate (grams/sec) }\end{array}$ & 17.20 & 20.15 & 21.36 & 33.03 & 26.46 \\
\hline $\begin{array}{l}\text { Air Flow Rate } \\
\text { (grams/sec) }\end{array}$ & 0.177 & 0.182 & 0.284 & .396 & 2.095 \\
\hline Air fraction (\%) & 0.45 & 0.80 & 0.84 & .94 & 4.5 \\
\hline
\end{tabular}




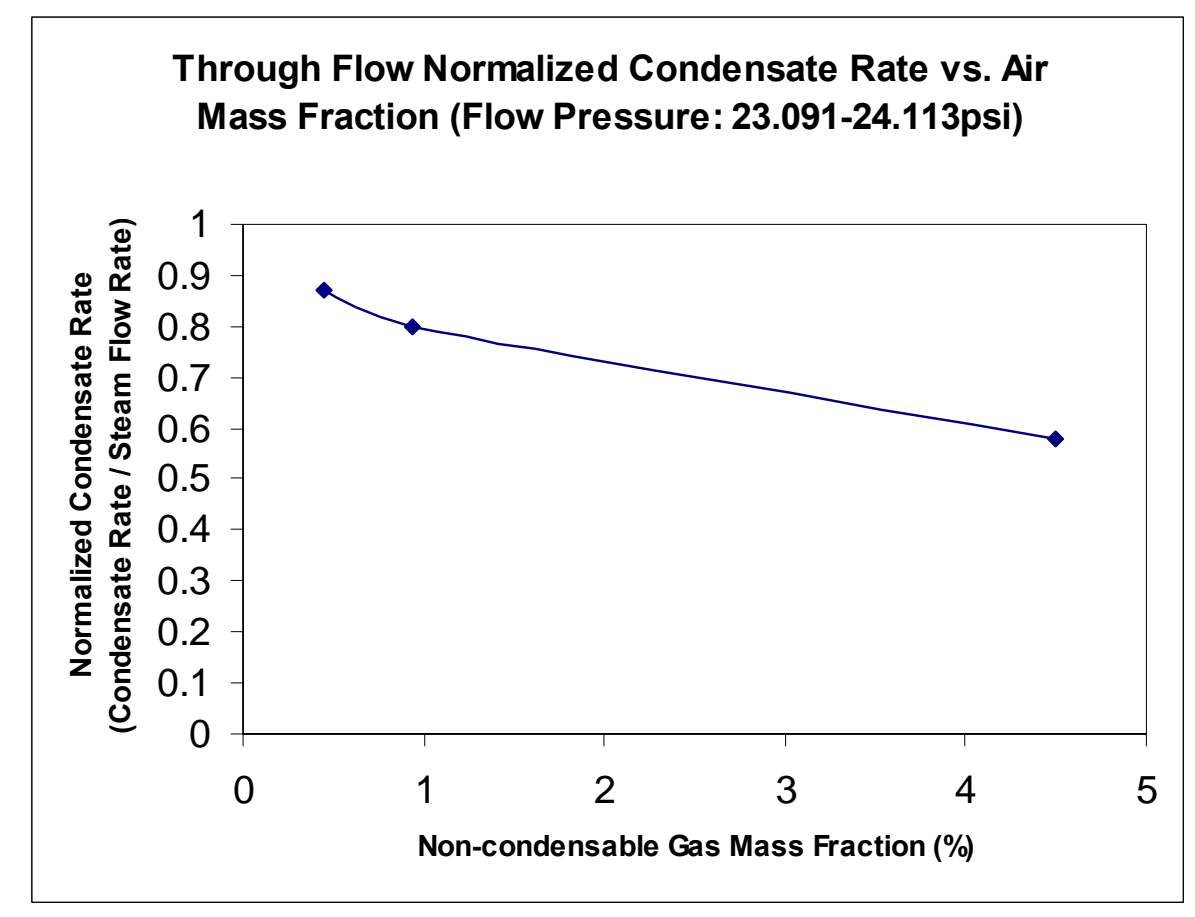

Fig 5.23Through Flow Normalized Condensate Rate vs. Air Mass Fraction (Flow

$$
\text { Pressure: 23.091-24.113psi) }
$$

5.4.4.2 Typical Through Flow Experiment Data and Plots

SG Temperature Setting: $240 \mathrm{~F}$

Parameters recorded:

Data SG pressure 40psi

CT pressure 36psi

Air pressure 22psi

Air flow rate $30.5 \mathrm{CFH}$

Equations for Air Flow Rate Calculation

$\mathrm{ACF}=(\mathrm{SCF}) * \mathrm{P}($ standard $) / \mathrm{P}($ actual $) * \mathrm{~T}($ actual $) / \mathrm{T}($ standard $)$

Density $1 /$ density $2=\mathrm{P} 1 / \mathrm{P} 2 * \mathrm{~T} 2 / \mathrm{T} 1$

\section{Results:}

Steady State Period: 2920-3630

Flow pressure: $33.72 \mathrm{psi}$

Steam Generation Rate: $0.5069 \mathrm{in} / \mathrm{min} * 240 \mathrm{in} 2 \times 1 \mathrm{gram} / \mathrm{cm} 3=33.226 \mathrm{grams} / \mathrm{sec}$

Vortex Flow Rate: $1.1258 \mathrm{~m} 3 / \mathrm{min} / 0.553155 \mathrm{~m} 3 / \mathrm{kg}=33.92 \mathrm{grams} / \mathrm{sec}$

Condensation Rate: $0.8329 \mathrm{in} / \mathrm{min} * 120 \mathrm{in} 2 \times 1 \mathrm{gram} / \mathrm{cm} 3=27.30 \mathrm{grams} / \mathrm{sec}$

SEC Boil-off Rate: $21.36 \mathrm{grams} / \mathrm{sec}$

Air Supply: 
$\mathrm{SCF}=30.5 \mathrm{CFH}$

Mass Flow Rate $=0.863663 \mathrm{~m} 3 / 3600 \mathrm{sec} * 1.184 \mathrm{~kg} / \mathrm{m} 3=0.284 \mathrm{grams} / \mathrm{sec}$

Air fraction: $0.84 \%$ using Vortex Flow Rate

\section{Plots}

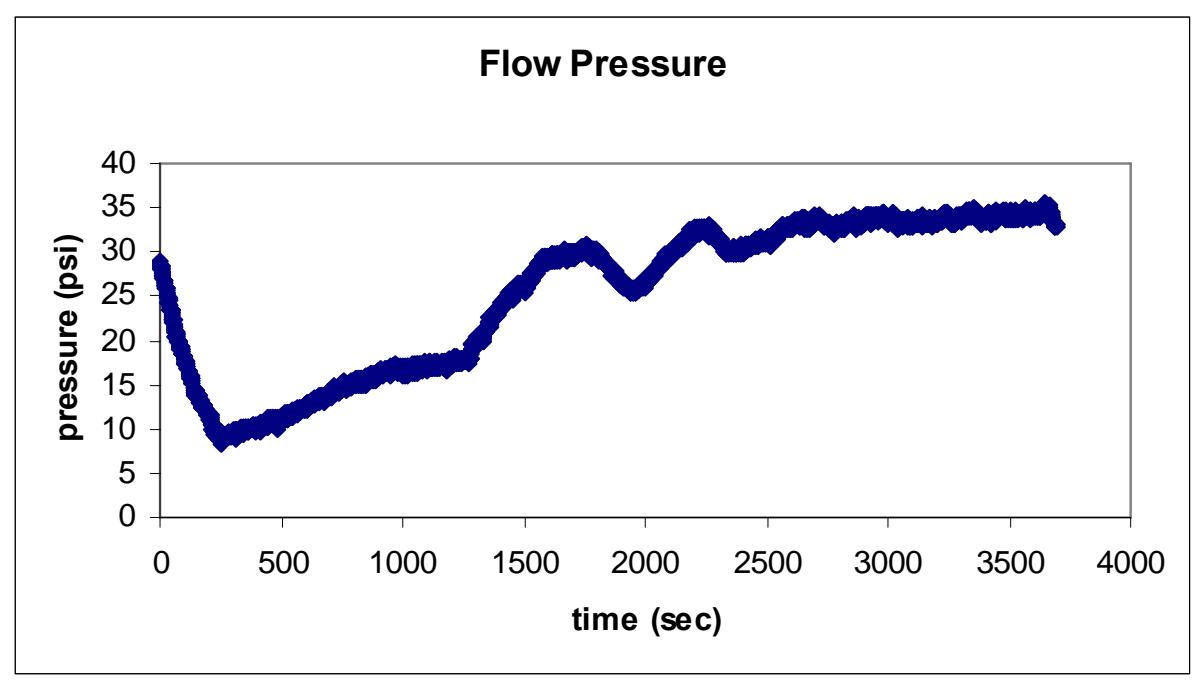

Fig 5.24 Flow Pressure Change during a Through Flow Experiment 

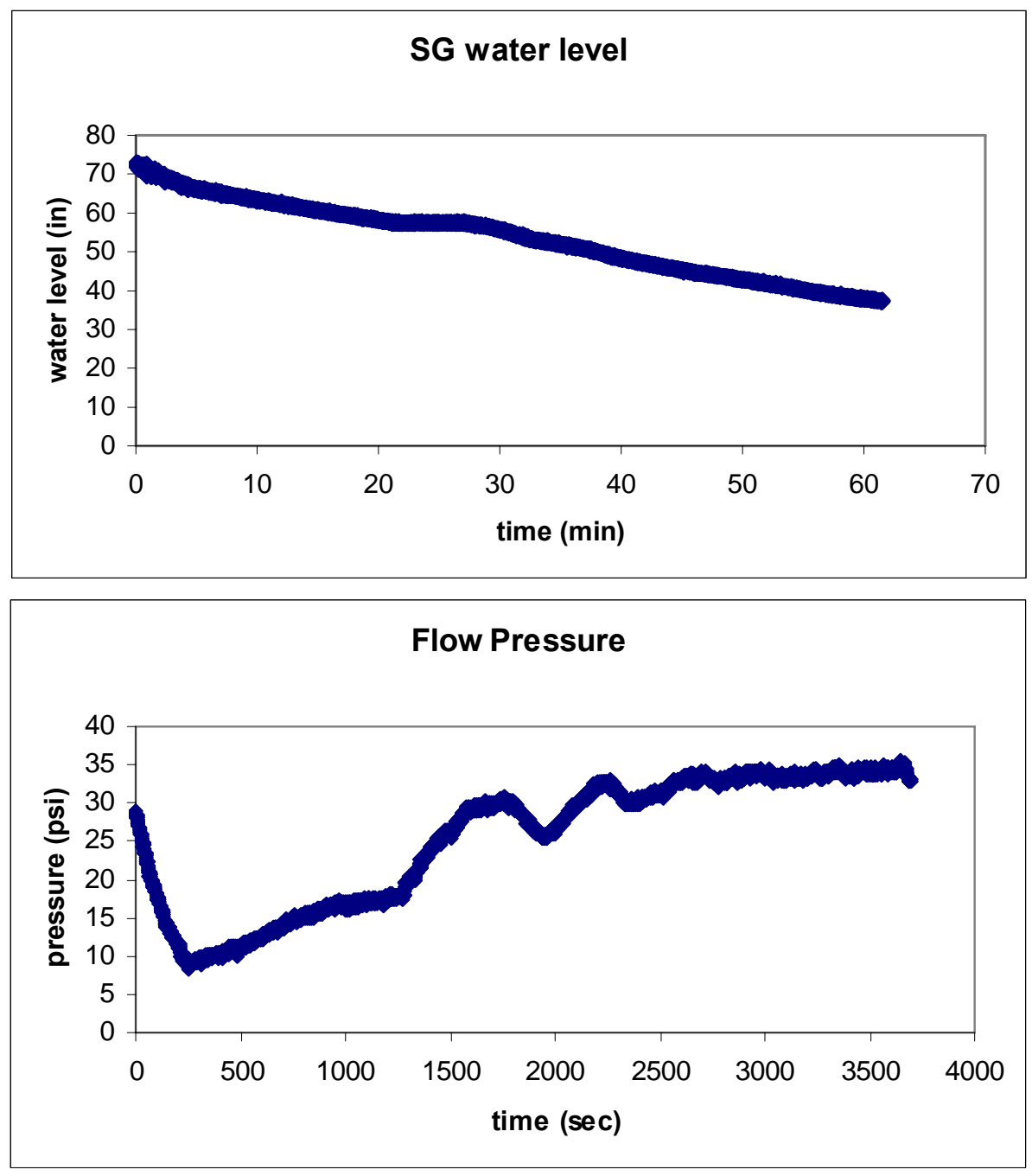

Fig 5.25 SG Water Level Change during a Through Flow Experiment

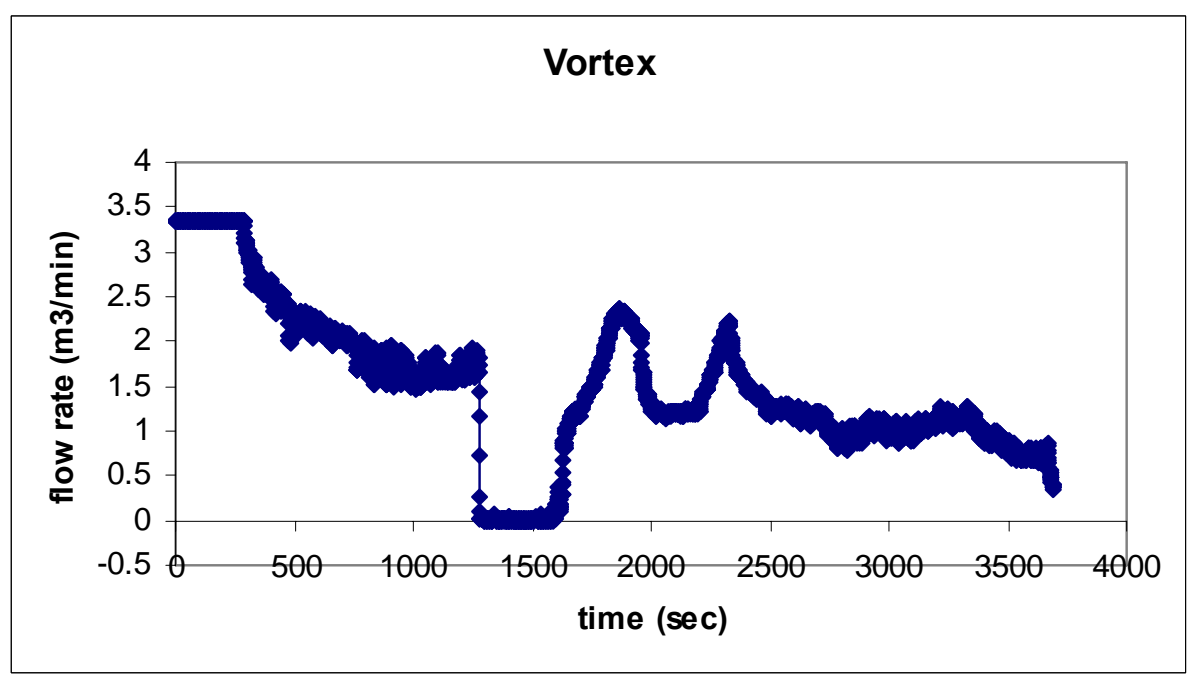

Fig 5.26 Steam Flow Rate Change during a Through Flow Experiment 


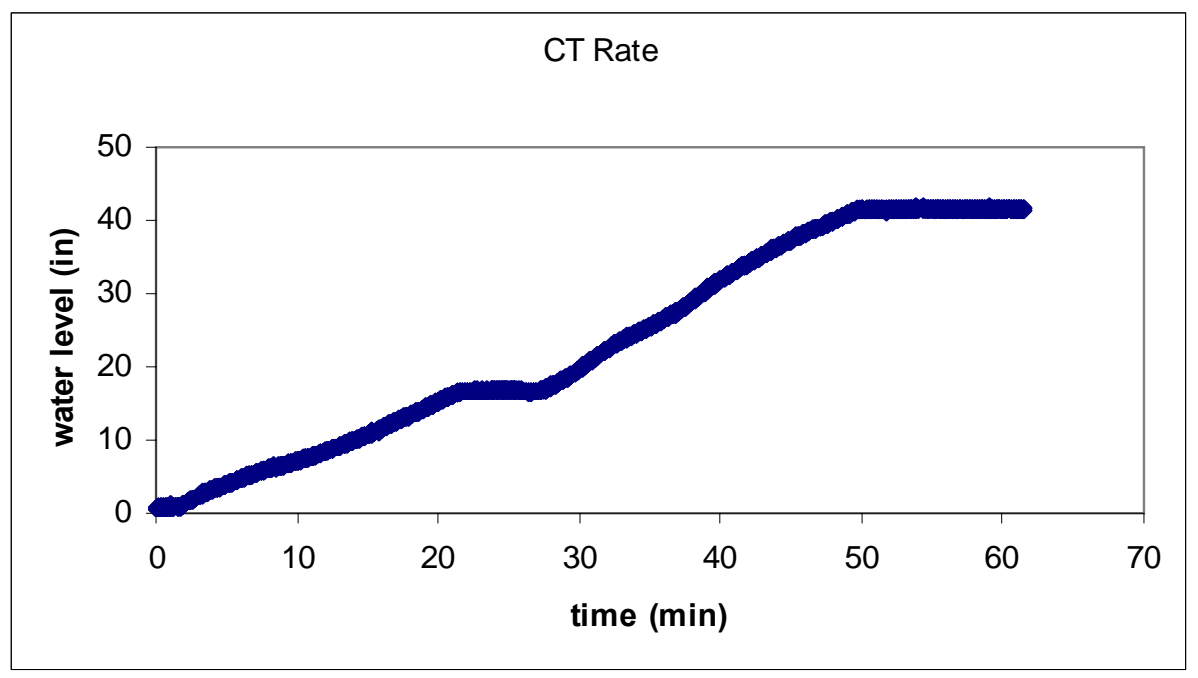

Fig 5.27 CT Water Level Change during a Through Flow Experiment

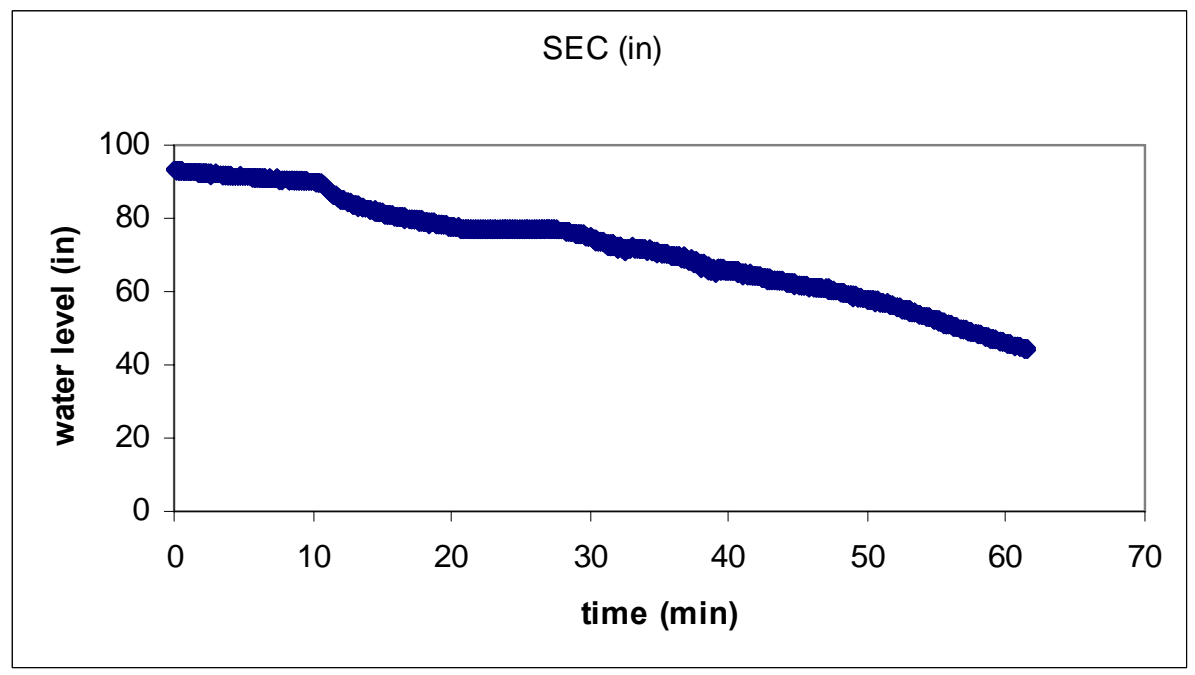

Fig 5.28 SEC Water Level Change during a Through Flow Experiment

From the above data and plots, we can see the condensate rate reduction in the presence of non-condensable gases is very large even though the NC fraction is very small.

\subsection{References}

1. Revankar S. T. and Ishii M., Scaling of condensation and vent phenomena in the passive containment cooling system (PCCS) of the Simplified Boiling Water Reactor (SBWR), Third International Conference on Multiphase Flow, ICMF'98, Lyon, France, June 8-12, Proceedings (CD-ROM), pp1-8, 1998. 
2. S. T. Revankar and D. Pollock, Analytical And Experimental Study Of The Effects Of Non-Condensable In A Passive Condenser System For The Advanced Boiling Water Reactor, Yearly Report (May, 2000 to April, 2001), Purdue University, School of Nuclear Engineering Report, PU/NE-01-3, May 2001

3. GE Nuclear Energy, "SBWR Standard Safety Analysis Report," Report No. 25A5113 Rev. A, August, (1992). 


\section{ACCOMPLISHMENTS}

Here the accomplishments of this project are summarized.

- A primary scaling analysis for the single and multi-tube PCCS condenser was performed. The scaling parameters were identified to scale down the prototype condenser design.

- An experimental loop was constructed with $5.04 \mathrm{~cm}$ inch diameter condenser. The design of the condenser tube was based on the scaling analysis.

- The design and construction for an experiment loop with four tube condenser was completed. A new steam generator capable of $100 \mathrm{~kW}$ steam supply, new suppression pool tank and loop components with instrumentations were installed.

- Condensation experiments were conducted on the test facility with a single (5.04 $\mathrm{cm})$ tube. Experimental database was obtained for three PCCS flow conditions: through flow; complete condensation; and cyclic venting at different secondary pool water level. Single tube transient tests with continuous secondary water level change in forced flow and complete condensation modes was also conducted and data sets were acquired. Data were obtained with or without the presence of noncondensable gas.

- Condensation experiments were conducted on the test facility with four tube condenser. Experimental database was obtained for three PCCS flow conditions: through flow; complete condensation; and cyclic venting at different secondary pool water level. Four tube bundle transient tests with continuous secondary water level change in complete condensation mode were also conducted and data sets were acquired. Data was obtained with and without the presence of noncondensable gas.

- A boundary layer model developed by previous researcher was employed to calculate various parameters in the tests with $2.54 \mathrm{~cm}$ and $5.04 \mathrm{~cm}$ test sections. Calculation results from different test sections were compared each other, also com- 
pared with experiment data. The conclusions from model analysis were consistent and verified by experiment data.

- A heat and mass analogy model was developed to predict the film wise condensation with noncondensable gas. The analysis results of the model were compared with the experimental average condensation heat transfer coefficient data for $26.6 \mathrm{~mm}$ ID and $52.5 \mathrm{~mm}$ ID tube and with the local condensation heat transfer coefficient data from literature. The agreement was satisfactory except for high heat transfer coefficient cases such as very low pressure or small NC gas mass fraction conditions.

- PCCS tube condensation was modeled with RELAP5 thermalhydraulics code. Experimental data was compared with the RELAP5 code predictions for complete condensation mode of operation. Two condensation models in the RELAP5 code were assessed. 